\title{
"Studies on Ramularia Leaf Spots on Barley - Resistance Phenotyping, Epidemiology and Pathogenicity"
}

\author{
Dissertation \\ to obtain the Ph. D. degree \\ in the Faculty of Agricultural Sciences, \\ Georg-August-University Göttingen, Germany
}

\author{
Presented by \\ Nazanin Zamani-Noor \\ born in Shiraz-Iran
}

Göttingen, November 2011 
1. Name of referee:

2. Name of co-referee:

Date of dissertation:
Prof. Dr. Andreas von Tiedemann

Prof. Dr. Petr Karlovsky

18 November 2011 
"The knowledge of anything, since all things have causes, is not acquired or complete unless it is known by its causes."

Avicenna (Iran 1602-1659) 


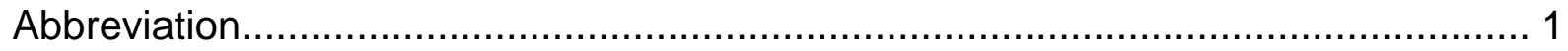

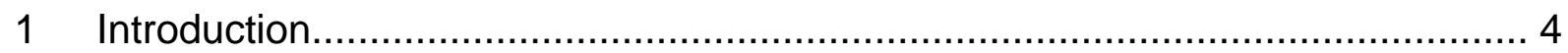

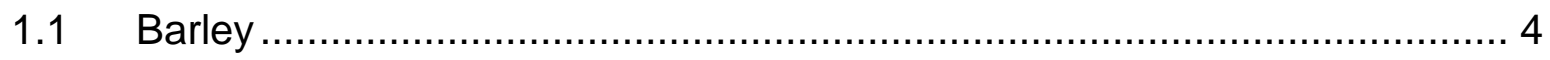

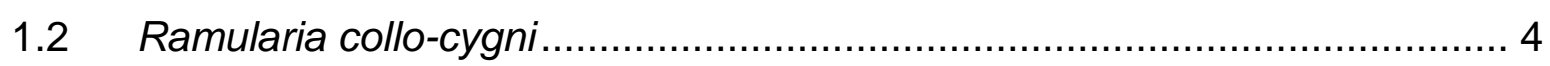

1.3 Life cycle of $R$. collo-cygni............................................................... 5

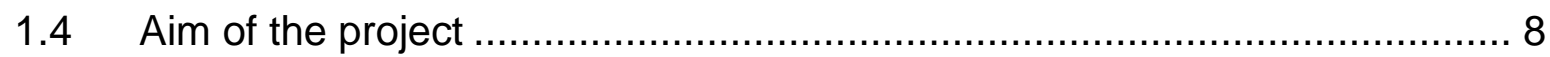

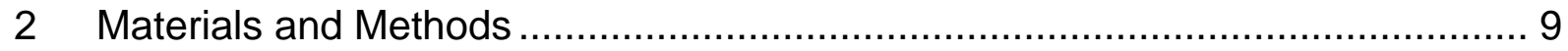

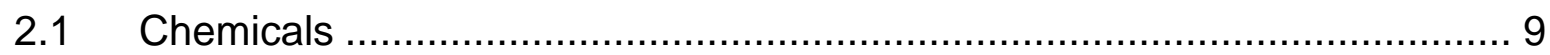

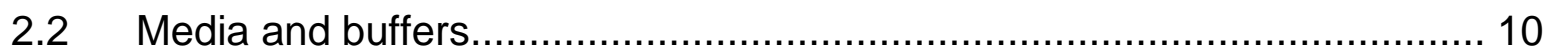

2.3 In vitro cultivation of Ramularia collo-cygni ......................................... 11

2.3.1 Isolation of the pathogen ...............................................................

2.3.2 Cultivation and propagation ......................................................12

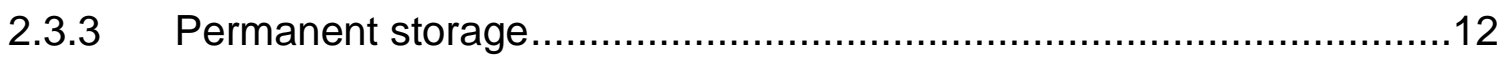

2.3.4 Sporulation intensity of Rcc isolates............................................12

2.3.5 Sporulation intensity of the isolates after cultivation at $-80^{\circ} \mathrm{C} \ldots \ldots \ldots \ldots . . .13$

2.4 Disease assessment methods .......................................................... 13

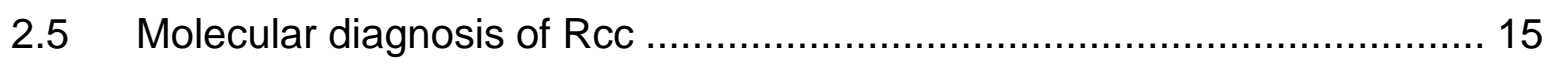

2.5.1 DNA extraction from fungal mycelia .............................................15

2.5.2 DNA extraction from plant material ...............................................15

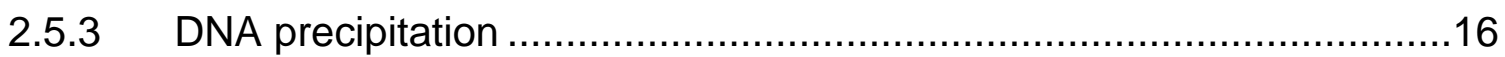

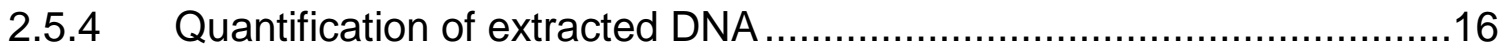

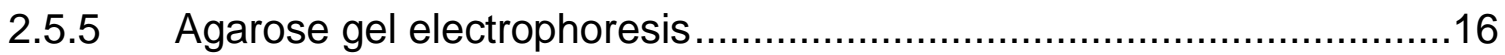

2.5.6 Semiquantitative polymerase chain reaction (PCR) ..........................17

2.5.7 Quantitative real time polymerase chain reaction (qPCR) ..................17

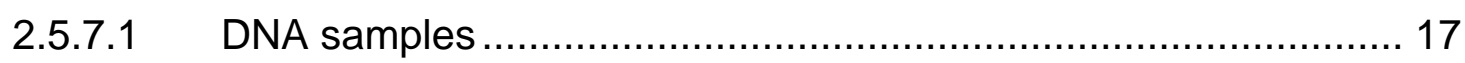

2. 5.7.2 Quantitative Real Time PCR analysis ....................................... 18

2. 5.7.3 Primer specificity and sensitivity .......................................... 19

2.6 Experiments under controlled environmental conditions ........................... 20

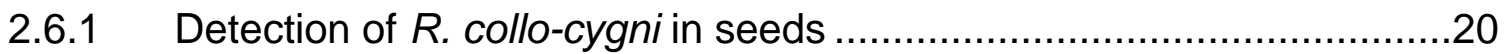

2.6.2 Assessment of the systemic fungal development from seeds to the

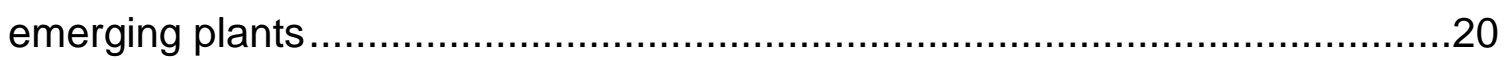

2.6.3 Elimination of fungal infestation of seeds by hot water treatment.........21

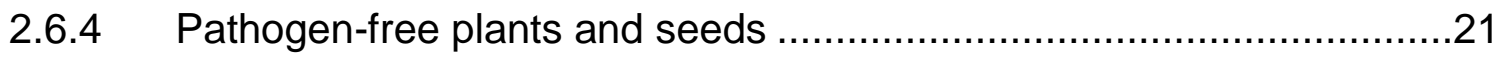




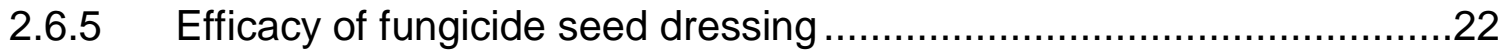

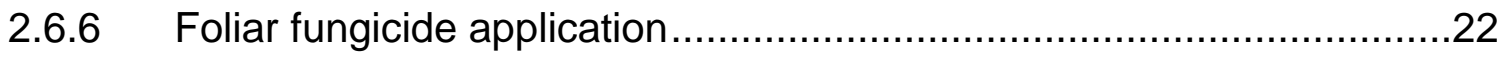

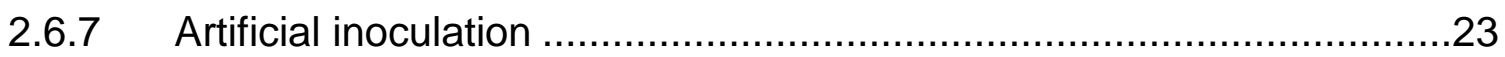

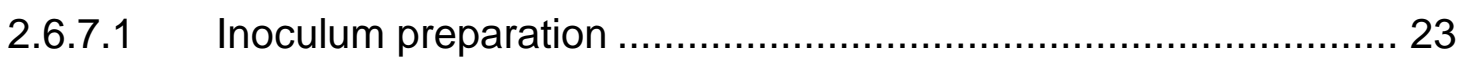

2.6.7.2 Evaluation of resistance at different plant growth stages ............ 23

2.6.7.3 In vitro inoculation system..................................................... 24

2.6.8 Resistance evaluation under controlled conditions ...........................25

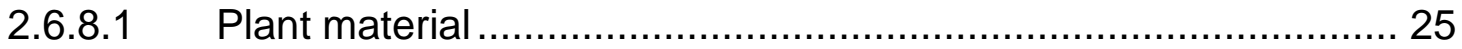

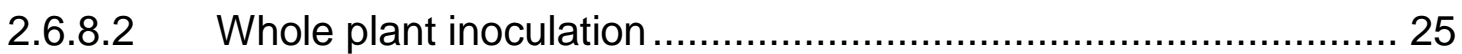

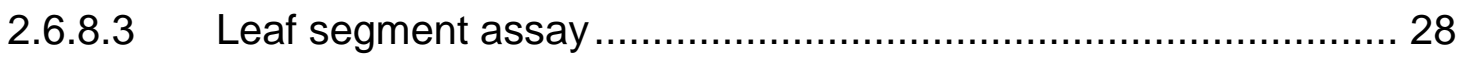

2.6.9 Effect of stressors on symptom development..................................28

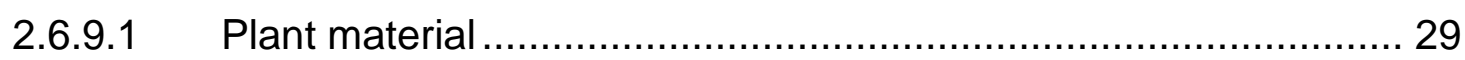

2.6.9.2 Inducing senescence with chemical stressors …....................... 29

2.6.9.3 Senescence induction by physical stressors.............................. 29

2.6.10 Fungal development inside the plant after artificial inoculation ............30

2.6.11 Morphology and chemical composition of the leaf cuticular wax layer during plant development .........................................................................

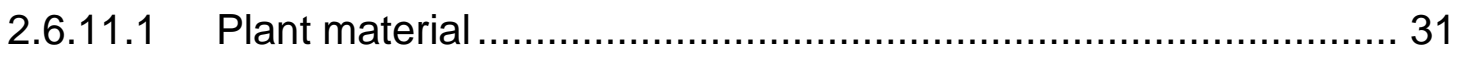

2.6.11.2 Extraction and analysis of the cuticular wax layer ...................... 31

2.6.11.3 Environmental scanning electron microscopy (ESEM) ............... 31

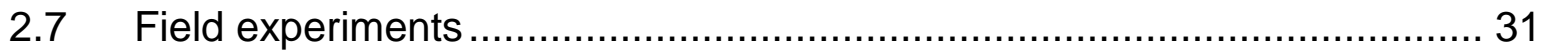

2.7.1 Monitoring spore dispersal by wind ...............................................

2.7.2 Monitoring spore dispersal in rain and snowfall.................................32

2.7.3 Resistance screening under field conditions ....................................32

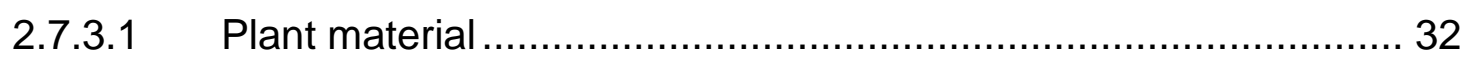

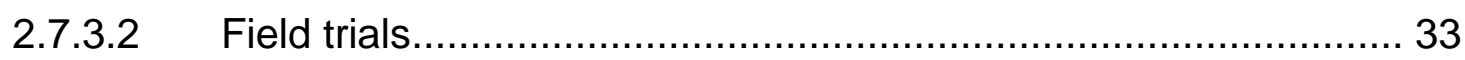

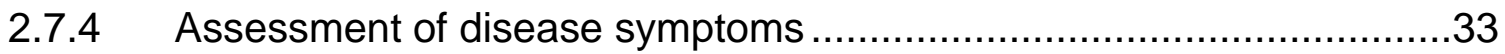

2.7.5 Assessment of fungal development under field conditions...................33

2.7.6 Determination of rubellin in naturally infected leaves from fields ...........34

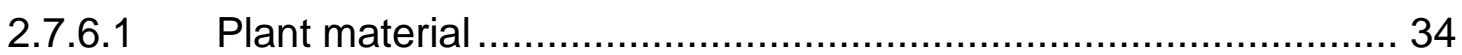

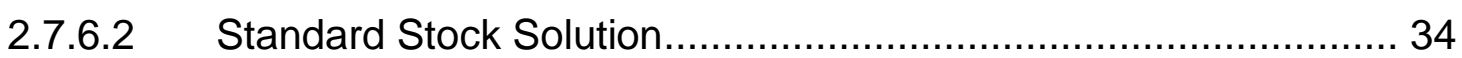

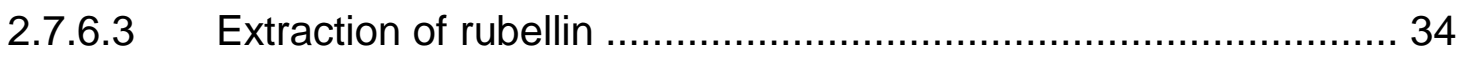

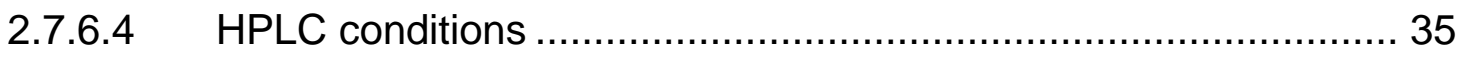




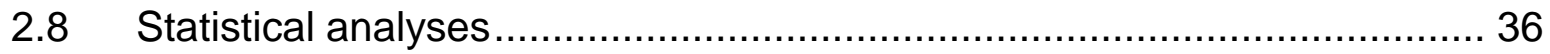

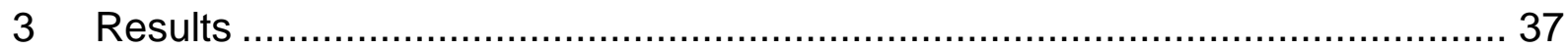

3.1 In vitro cultivation of Ramularia collo-cygni .......................................... 37

3.1.1 Isolation of Rcc from infected barley leaves .........................................

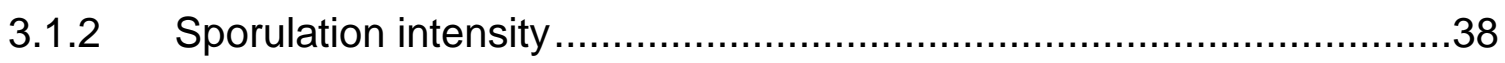

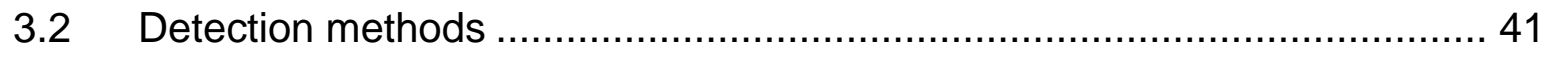

3.2.1 Disease phenotyping on spring barley lines under field conditions ......41

3.2.2 Analysis of extracted DNA and PCR amplification ............................43

3.3 Quantitative molecular diagnosis of Rcc ............................................ 43

3.3.1 Specificity and sensitivity of primers...............................................

3.3.2 Optimising quantitative real-time PCR ……...................................4

3.4 Experiments under controlled conditions............................................... 46

3.4.1 Rcc development from seed to emerging plant .................................46

3.4.2 Seed disinfestations by hot water treatment...................................47

3.4.3 Elimination of fungal development from infested seeds by hot water...48

3.4.4 Efficacy of seed dressing and foliar fungicide application ...................49

3.4.5 Resistance evaluation at different plant growth stages ......................52

3.4.6 Development of an in vitro inoculation system .................................55

3.4.7 Resistance screening under controlled environmental conditions ........57

3.4.8 Symptom development in younger stages of the plant........................63

3.4.9 Fungal systemic development inside the plant ....................................64

3.4.10 Morphology and chemical composition of leaf wax layer .....................65

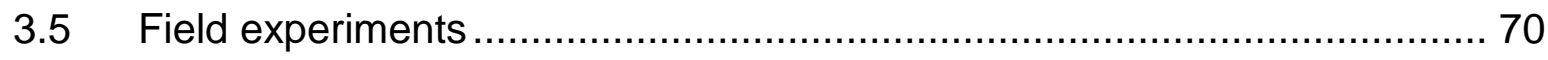

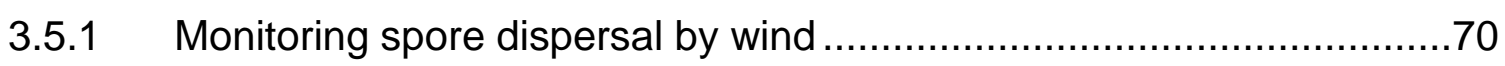

3.5.2 Monitoring spore dispersal by rain and snowfalls ..............................72

3.5.3 Resistance screening under field conditions .......................................73

3.5.4 Quantification of fungal DNA during symptom development ................83

3.5.5 Quantification of fungal toxin during symptom development ................85

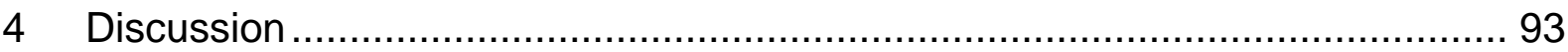

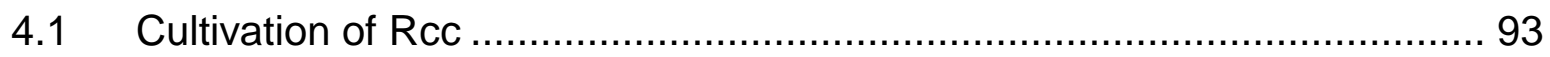

4.2 Ramularia leaf spot disease phenotyping................................................ 94

4.3 Rcc spore dispersal by wind and precipitation ...................................... 94

4.4 Rcc systemic development inside the plant............................................... 96 


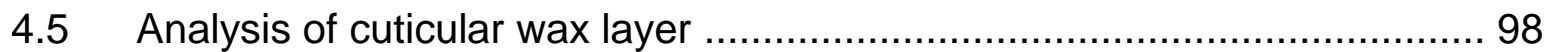

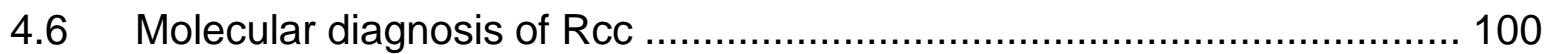

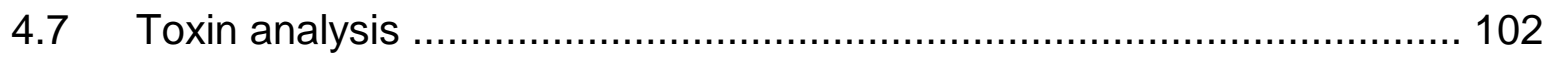

4.8 Evaluation of resistance screening methods for RLS ........................... 104

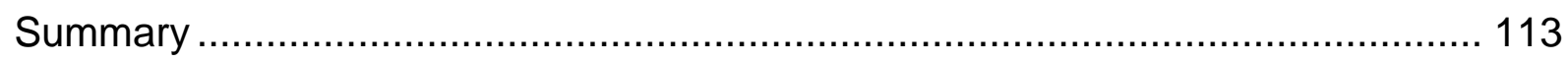

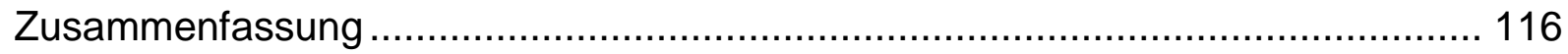

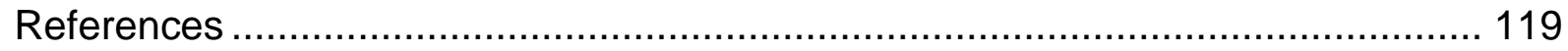

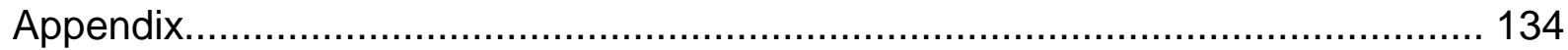

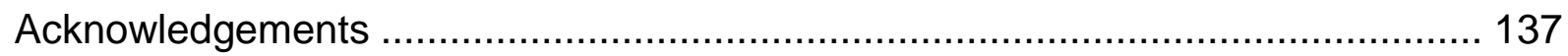

Curriculum Vitae .................................................. Fehler! Textmarke nicht definiert. 


\section{Abbreviation}

bp

${ }^{\circ} \mathrm{C}$

$\mathrm{cm}$

CTAB

$\mathrm{C}_{\mathrm{t}}$

cv.

DNA

dNTP

dpi

dt

EDTA

ESEM

et al.

\section{$\mathrm{EtOH}$}

$\mathrm{F}$

F-1

F-2

FE

$g$

$\mathrm{GH}$

GS

$\mathrm{h}$

ha

$\mathrm{HCl}$

$\mathrm{H}_{2} \mathrm{O}$

HPLC

L

LSA

$M$

$\mathrm{m}$

$\mathrm{m}^{2}$ base pairs

degree Celsius

centimeter

hexadecyltrimethylammoniumbromid

threshold cycle

cultivar

deoxyribonucleic acid

deoxnucleotide-5'-triptophate

days post inoculation

deciton

ethylenediaminetetraacetic acid

environmental scanning electron microscopy

et alii (and others)

ethanol

flag leaf

second leaf from top

third leaf from top

field experiment

gram

greenhouse

growth stage

hour

hectare

hydrochloric acid

water

high performance liquid chromatography

litre

leaf segment assay

mol per litre

milli

square meter 


\begin{tabular}{|c|c|}
\hline $\mathrm{mg}$ & milligram \\
\hline $\mathrm{ml}$ & millilitre \\
\hline $\mathrm{N}$ & nitrogen \\
\hline$\mu$ & micro \\
\hline$\mu l$ & microlitre \\
\hline umol & micromole \\
\hline $\mathrm{mM}$ & millimolar \\
\hline $\mathrm{mm}$ & millimetre \\
\hline $\min$ & minute \\
\hline $\mathrm{n}$ & number of samples \\
\hline $\mathrm{n}$ & nano \\
\hline $\mathrm{ng}$ & nanogram \\
\hline n.s. & not significant \\
\hline NUV & near ultraviolet light \\
\hline OD & optical density \\
\hline PCR & polymerase chain reaction \\
\hline$p$ & pico \\
\hline $\mathrm{pg}$ & picogram \\
\hline $\mathrm{pH}$ & $\begin{array}{l}\text { a measure of the acidity or basicity of an } \\
\text { aqueous solution }\end{array}$ \\
\hline PLS & physiological leaf spot \\
\hline Ppb & part per billion \\
\hline ppm & part per million \\
\hline qPCR & quantitative real-time PCR \\
\hline r & correlation coefficient \\
\hline Rcc & Ramularia collo-cygni \\
\hline $\mathrm{RH}$ & relative humidity \\
\hline ROS & reactive oxygen species \\
\hline RNA & ribonucleic acid \\
\hline RNAse & ribonuclease \\
\hline rpm & revolutions per minute \\
\hline$r_{\mathrm{s}}$ & spearman correlation coefficient \\
\hline S & second \\
\hline
\end{tabular}


SD

SOD

RLS

RT

Taq

TBE

TE

Tris

$\mathrm{U}$

UV

$\mathrm{V}$

V8A

vs.

$\mathrm{v} / \mathrm{v}$

$\mathrm{w} / \mathrm{v}$

WA

$\%$ standard deviation

superoxide dismutase

ramularia leaf spot

room temperature

Thermus aquaticus

tris-Borate-EDTA buffer

tris-EDTA

trishydroxymethylaminomethane

unit

ultraviolet

volt

vegetable juice agar

versus

volume by volume

weight by volume

water agar

percent 


\section{Introduction}

\section{$1.1 \quad$ Barley}

Barley (Hordeum vulgare L.) is one of the oldest cultivated cereals in the history of agriculture as domesticated about 8000 B.C. barley cultivation currently ranks four in hectare and crop production in all over the world. The wild relative of the plant is known as Hordeum spontaneum C. Koch. According to the revised taxonomy, $H$. vulgare L. and H. spontaneum C. Koch, as well as Hordeum agriocrithon Aberg, are considered to be subspecies of $H$. vulgare.

Many diseases affect the quality, yield and therefore profitability of barley and need to be controlled effectively. Apart from different barley foliar diseases caused by pathogens like Rhynchosporium secalis (barley scald), Pyrenophora teres (barley net blotch), Puccinia striiformis f. sp. hordei (yellow rust) and Blumeria graminis f. sp. hordei (powdery mildew), Ramularia collo-cygni (Ramularia leaf spot) is known to be an important pathogen of winter and spring barley.

\subsection{Ramularia collo-cygni}

The deuteromycete Ramularia collo-cygni (Syn.: Ophiocladium hordei Cavara 1893, Ovularia hordei (Cavara) Spraque 1946, Ramularia hordeicola Braun 1988) is a perthotrophic fungus and has gained increasing importance as the causal agent of a novel leaf spot disease on barley, Ramularia leaf spot (RLS). At present, this novel disease has been reported from different barley growing regions in Europe, New Zealand and Canada (Huss et al., 1987; Sutton \& Waller, 1988; Sheridan, 1996; Sachs et al., 1998; Sachs, 2002; Minarikova et al., 2002; Harvey 2002; Pinnschmidt \& Hovmøller, 2003; Oxley \& Havis, 2004; Leistrumaite \& Liatukas, 2006). The disease also has been recognised on oat (Avena sativa), wheat (Triticum aestivum), rye (Secale cereale), maize corn (Zea mays) and also different grasses (Poaceae) (Sachs, 2002, 2006; Huss, 2008, 2011). Although RLS was first reported more than 100 years ago (Cavara 1893), it was only in the early 1980s that RLS began to get serious scientific attention. However, it was often confused with physiological leaf 
spots caused by abiotic factors (Wu \& von Tiedemann, 2004) and other pathogens such as Pyrenophora teres (Sachs, 2002).

The fact that Rcc has been recognized as a major pathogen of barley only quite recently is mainly due to difficulties in isolating and identifying the fungus (Sutton \& Waller, 1988; Sachs, 2004). Ramularia collo-cygni was not considered to be a 'typical' Ramularia species because of its curled conidiophore (like a swan's neck) and conidia with eccentrically positioned scars. The name of the species collo-cygni derives from the special swan neck shape of the conidiophores (Collum=neck, Cygnus=swan). Crous et al. (2000) studied the phylogenetic analysis on ITS-1, ITS-2 and 5.8S DNA sequence data from 46 species of Mycosphaerella, including three species with Ramularia anamorphs. They showed that not only Rcc clusters with other typical Ramularia species, but also the teleomorph of Rcc, if it exists, is likely to be a species of Mycosphaerella.

\subsection{Life cycle of $R$. collo-cygni}

Ramularia leaf spot disease occurs conspicuously late in the growing season. While no or a few symptoms are visible during stem elongation stages, the disease severity in the field may increase dramatically within a few days and become the dominant disease after the crop has passed the flowering stage. Symptoms are characterized by small brown to blackish brown necrotic lesions, delimited by leaf veins and usually with a yellow halo.

Symptoms of RLS first become visible on the older senescing (lower) leaves after ear emergence. Once visible, they spread rapidly to the younger (upper) leaves with further maturation of the plant. The rapid leaf senescence induced by RLS results in premature loss of green leaf area in crops and can lead to substantial yield losses.

During stem extension in barley, Rcc can survive as a saprophyte on the dead lower leaves (Huss, 2004). It has not yet been conclusively studied how far the pathogen is also seed-borne or soil-borne, but infested grains and heavily infested straw have been found (Havis et al., 2004). However, there is also evidence that Rcc grows systemically and asymptomatically in the plant (Havis et al., 2006; Salamati \& Reitan, 2006), which was confirmed by PCR-based detection methods (Havis et al., 2006). Investigating the life cycle of Rcc using a PCR based diagnostic method indicated 
that the fungus can be detected before the appearance of visible symptoms but the earliest detection date varies between seasons and variety (Frei et al., 2007). In addition, at the end of the growing season the pathogen was found widespread in harvested grain samples and can thus be transmitted to developing plants from infected seed stocks (Havis et al., 2006). Under these circumstances, symptom development and fungal sporulation appear to be triggered by the transition of the plant from vegetative to reproductive growth (Reitan \& Salamati, 2006; Schützendübel et al., 2008). In favourable weather conditions the main fungal structures, conidiophores, emerge mainly from stomata on the abaxial side of the leaf. Conidia of Rcc are very small, solitary, ellipsoid in shape, averaging size $8.0 \mu \mathrm{m}$ $\mathrm{x} 4.4 \mu \mathrm{m}$, ranging from $6.2 \mu \mathrm{m}-10.6 \mu \mathrm{m}$ in length and $3.2 \mu \mathrm{m}-6.0 \mu \mathrm{m}$ in width.

Further studies showed that Rcc induces necrotic cell death in leaves by secreting a class of photodynamic toxins (rubellins) after invading the apoplast (Heiser et al., 2003). Miethbauer et al. (2003) showed that Rcc produces a number of metabolites, including an anthraquinoid identified as rubellin D (Fig. I).

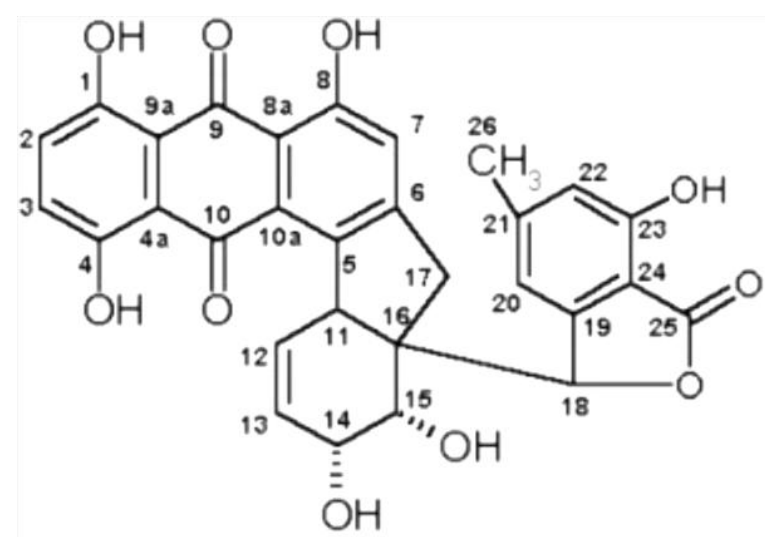

Figure I. Chemical structure of rubellin D (Heiser et al., 2004).

The toxin induced light- and concentration-dependent necrosis in barley leaves, and in a model system was shown to exhibit photodynamic activity, triggering the lightdependent production of reactive oxygen species (ROS) such as hydrogen peroxide, superoxide anion radical and its more toxic derivative hydroxyl radical, leading to the peroxidation of $\alpha$-linolenic acid, thus breaking down plant membrane fatty acids and bleaching pigments (Heiser et al., 2003). It was shown that damage to the plant caused by ROS formation is prevented in plants by the activity of several 
antioxidative enzymes scavenging oxygen radicals (Scandalios, 1993). Subsequent works demonstrated that rubellin $\mathrm{D}$ also induced the peroxidation of $\alpha$-linolenic acid in tobacco leaves, suggesting that it is a host non-specific toxin (Heiser et al., 2004). It was shown that in addition to rubellin $D, R c c$ also produces rubellin $A, B, C$ and $E$ (Miethbauer et al., 2003). Heiser et al. (2004) showed that rubellin B, which is not soluble in the plant, is produced first and is then converted to the more polar rubellin $D$, which possesses greater solubility in the plant. She suggested that rubellin production by the fungus results in oxidative stress, which in turn is involved in the formation of leaf spots. The fungus is then able to colonize the necrotic host tissue, while the continued production of rubellins accelerates leaf necrosis. The early loss of green leaf area, coupled with reduced rates of photosynthesis, is likely to result in the premature ripening observed under field conditions (Heiser et al., 2004).

Further experiments showed that most barley genotypes appear to be susceptible to the pathogen, although there is moderate resistance to Rcc in some varieties of both spring and winter barley (Pinnschmidt \& Sindberg, 2006). Observations of Burke et al. (2001), Cromey et al. (2004), Greif (2004), Pinnschmidt \& Hovmøller (2003) suggest that genetic variability in RLS resistance exists and can be used in resistance breeding and disease management. Pinnschmidt and Sindberg (2006) have suggested that efficient cultivar resistance against RLS exists and, if enhanced by resistance breeding efforts, could play a vital role in achieving RLS control. Chemical controls strategies are also tools to keep leaves green and in turn prevent yield losses.

For the control of RLS it might be important to apply fungicides before symptoms develop, which is still difficult to forecast. In contrast to control through resistant varieties, fungicides have been found to provide a useful control strategy against Rcc (Oxley et al., 2006). Current control methods rely on foliar fungicides applied at booting growth stage, before leaf spots appear. Not all fungicides are effective, and some, including fenpropimorph can be detrimental, leading to rapid loss in green leaf (Oxley et al., 2002). It was investigated that fungicides which achieved effective control of Rcc include chlorothalonil and prothioconazole. Epoxiconazole provides moderate levels of control, whilst the co-formulated fungicide epoxiconazole and boscalid achieved better control of Rcc than epoxiconazole alone (Oxley et al., 
2006). Christiansen et al. (2009) have shown that the fungicides Opera and Bell with the active ingredient epoxiconazole were greatly responsible for disease control.

\subsection{Aim of the project}

The aim of this project was to identify resistance sources in spring barley to Ramularia and develop molecular markers which can be used as selection tools and speed up the selection process for Ramularia resistant genotypes. To fulfil these tasks, reliable inoculation systems and disease ratings are prerequisite. The development and improvement of greenhouse inoculation methods were important aspects of the project, so that Ramularia resistance of barley genotypes could be assessed on the basis of these tests. The greenhouse data were to be evaluated under field conditions. Due to sometimes complex and confusing leaf symptoms, tools for precise disease assessment (quantitative PCR) have been developed and used for specific detection of Ramularia biomass in leaves of field samples. Based on these generated phenotypic data molecular marker development has been done. The objectives of the project are summarized below:

$>\quad$ Optimization of an artificial inoculation system

$>\quad$ Development of an in vitro inoculation system

$>\quad$ Development of a disease assessment scale

$>\quad$ Phenotyping of susceptible and resistant genotypes under controlled conditions

$>\quad$ Diagnosis of Rcc by means of quantitative PCR as an alternative method to ELISA

$>\quad$ Phenotyping of susceptible and resistant genotypes under field conditions

$>\quad$ Furthering of knowledge on the epidemic spread and interaction of Rcc with its host plant 


\section{Materials and Methods}

\subsection{Chemicals}

Agar Agar

Agarose

Albi Vegetable juice

Ammonium acetate

Benzimidazole

Calcium carbonate $\left(\mathrm{CaCO}_{3}\right)$

Casein

Chloroform

dNTPs-Mix (10mM)

Dream Taq-buffer (10x)

EDTA

Ethanol (100\%)

Ethidium bromide

Ethephon

Fluorescein

Glycerine

Lambda DNA Standard

Loading Dye

Magnesium chloride

Paraquat

PCR-Puffer

Quant-iT-PicoGreen dsDNA reagent

RNAse

Silwet gold

Sodium chloride

Streptomycin sulphate

Sybrgreen

Taq DNA polymerase $(5 \mathrm{U} / \mu \mathrm{l})$

TE buffer

Tris $\mathrm{pH} 8$
Merk, Darmstadt

Applichem, Darmstadt

Albi, Bühlenhausen

Applichem, Darmstadt

Merk, Hohenbrunn

Roth, Karlsruhe

Roth, Karlsruhe

Applichem, Darmstadt

Fermentas, St. Leon-Rot

Fermentas, St. Leon-Rot

Roth, Karlsruhe

Sigma, Taufkirchen

Applichem, Darmstadt

Bayer crop Science

BioRad, Hercules, CA, USA

Roth, Karlsruhe

BMG Labtech, Offenburg

Fermentas, St. Leon-Rot

Fermentas, St. Leon-Rot

Syngenta, Maintal

Fermentas, St. Leon-Rot

BMG Labtech, Offenburg

Applichem, Darmstadt

Spiess-Urania

Applichem, Darmstadt

Duchefa Biochemi

Invitrogen, Karlsruhe, Haarlem

Fermentas, St. Leon-Rot

Applichem, Darmstadt

Fermentas, St.Leon-Rot 
Tween20

100bp Ladder Plus
Scarlau Chemie S.A.

Fermentas, St. Leon-Rot

\subsection{Media and buffers}

All following media were autoclaved at $121^{\circ} \mathrm{C}, 103.4 \mathrm{kPa}$ presure for $20 \mathrm{~min}$ to prevent any contamination with bacteria and other fungi.

Normal V8-Agar recipe

V8 juice

$100 \mathrm{ml}$

$\mathrm{CaCO}_{3}$

$2 \mathrm{~g}$

Agar

$15 \mathrm{~g}$

Distilled water

$900 \mathrm{ml}$

Modified V8-Agar recipe

V8 juice

$200 \mathrm{ml}$

$\mathrm{CaCO}_{3}$

$2 \mathrm{~g}$

Agar

$15 \mathrm{~g}$

Distilled water

$800 \mathrm{ml}$

Czapek- Dox liquid

$\mathrm{NaNO}_{3}$

$3 \mathrm{~g}$

$\mathrm{K}_{2} \mathrm{HPO}_{4}$

$1 \mathrm{~g}$

$\mathrm{MgSO}_{4} \times 7 \mathrm{H}_{2} \mathrm{O}$

$0.5 \mathrm{~g}$

$\mathrm{KCl}$

$0.5 \mathrm{~g}$

$\mathrm{FeSO}_{4} \times 7 \mathrm{H}_{2} \mathrm{O}$

$0.01 \mathrm{~g}$

Saccharose

$30 \mathrm{~g}$

Distilled water up to 1 I

Water agar $(0.75 \%)$

Agar

$7.5 \mathrm{~g}$

Distilled water $1000 \mathrm{ml}$ 
$\underline{\text { CTAB extraction buffer }}$

CTAB

$\mathrm{NaCl}$

Tris pH 8.0

EDTA

Distilled water

2-Mercaptoethanol

TE-buffer

Tris pH 8.0

EDTA
$1 \%$

$0.7 \mathrm{M}$

$50 \mathrm{mM}$

$10 \mathrm{mM}$

up to $100 \mathrm{ml}$

$1 \%$ (was added directly before use)

$10 \mathrm{mM}$

$1 \mathrm{mM}$

\subsection{In vitro cultivation of Ramularia collo-cygni}

\subsubsection{Isolation of the pathogen}

For Isolation of the pathogen from leaf, infected leaves from naturally infected barley fields were harvested. The abaxial part of the leaf was examined under a binocular microscope for sporulating fungal structures. Pale clusters of conidiophores bearing conidia emerging from stomata indicated Ramularia infestation.

A single conidium was picked off from the end of a conidiophore with a sterile thin needle and transferred to a vegetable juice agar growth medium containing $25 \mathrm{ppm}$ Acanto (250 g/L picoxystrobin, Syngenta, Crop Protection, Maintal, Germany) and $100 \mathrm{ppm}$ streptomycin sulphate. Rcc has been shown to be insensitive to strobilurin fungicides, so other fungi than Rcc can be eliminated. Streptomycin sulphate was added to avoid bacterial contaminations. All plates were incubated in a growth chamber at $20^{\circ} \mathrm{C}$ under permanent NUV light. After 7-10 days individual colonies derived from single spores were transferred to a new V8A medium. Transferring to new plates was continued until the pure pathogen free of any contaminants was obtained. 


\subsubsection{Cultivation and propagation}

The cultivation of Rcc isolates was carried out, using V8A medium, which was cultured by one Rcc isolate and placed approximately $25 \mathrm{~cm}$ from permanent NUV light. Mycelial fragments and spores of 12 days culture were scraped from the surface of the medium using a sterile spatula by adding $2 \mathrm{ml}$ sterile tab water. One hundred microlitre of spore-mycelia suspension were transferred to a new V8A medium and distributed on the surface of the agar plate. The new Petri dishes were incubated in a growth chamber at $20^{\circ} \mathrm{C}$ under permanent NUV light for at least 10 days.

\subsubsection{Permanent storage}

For short term storage, pure-culture isolates of Rcc strains were inoculated onto a thick layer of $\mathrm{V} 8 \mathrm{~A}$ medium and incubated in a growth chamber at $20^{\circ} \mathrm{C}$ under permanent NUV light. After 10 days all Petri dishes were sealed completely with parafilm (Parafilm ${ }^{\circledR} \mathrm{M}$ and dispenser) and stored at $4^{\circ} \mathrm{C}$ in the dark cold chamber. For long term storage of Rcc isolates, glycerol freezing medium was used. CzapekDox liquid medium and glycerol were separately autoclaved and cooled down to room temperature. Previously, pure-culture isolates of the fungal strains were inoculated onto V8A medium and incubated in a growth chamber at $20^{\circ} \mathrm{C}$ and placed approximately $25 \mathrm{~cm}$ from permanent NUV light. After 10 days, $1.5 \mathrm{ml}$ of CzapekDox-Medium was added to the fine growth plate and all fungal materials were scraped from the surface of the medium using a sterile spatula. $750 \mu$ of spores and mycelial suspension were taken with a sterile pipette and poured in a sterile $1.5 \mathrm{ml}$ Eppendorf tube. $250 \mu$ sterile glycerol was added to each Eppendorf tube, vortexed to mix the solution and then kept at $-80^{\circ} \mathrm{C}$ in the freezer. For further experiments, cultures were reactivated on modified V8A medium.

\subsubsection{Sporulation intensity of Rcc isolates}

For each Rcc isolate, maximal potential sporulation intensity was evaluated by inoculating each isolate onto a new V8A medium. Three replicates were prepared for each isolate. All plates were incubated in a growth chamber at $20^{\circ} \mathrm{C}$ and placed at approximately $25 \mathrm{~cm}$ distance from permanent NUV light. Spores were harvested by 
scraping from the surface of medium using a sterile spatula at 3, 6, 9, 12, 15 and 18 days post cultivation and the number of spores was counted with a Thoma haemocytometer (Hecht-Assistent, Sondheim, Germany).

\subsubsection{Sporulation intensity of the isolates after cultivation at $-80^{\circ} \mathrm{C}$}

For this experiment, the isolates nRcc 01, nRcc 03, nRcc 08, nRcc 12, nRcc 19, and nRcc 21 were used, which in previous studies had shown higher sporulation intensity. One hundred microlitres of spore suspension of each isolate, which had been stored at $-80^{\circ} \mathrm{C}$ in the freezer, were spread on the surface of V8A medium containing $25 \mathrm{ppm}$ Acanto (250 g/L picoxystrobin, Syngenta, Crop Protection, Maintal, Germany) and 200 ppm streptomycin sulphate. All plates were incubated in a growth chamber at $20^{\circ} \mathrm{C}$ and placed approximately $25 \mathrm{~cm}$ from permanent NUV light. After 12 days spores were harvested by scraping off the surface of medium using a sterile spatula. First the number of spores per millilitre was counted, then cultivated again on a new V8A medium and incubated in a growth chamber at the same conditions as before. After 12 days spores were harvested again from the second set of the media, the number of spores was counted and again re-cultivated onto a new medium. Spores were harvested from the third set of the media and the number of spores per millilitre was counted with a Thoma haemocytometer slide (Hecht-Assistent, Sondheim, Germany).

\subsection{Disease assessment methods}

Visual scoring: Ramularia leaf spots are characterized by abundant small brown speckles usually with a yellow halo. Symptoms of RLS first become visible on the older senescing (lower) leaves after ear emergence. Once visible, they spread rapidly on the younger (upper) leaves with further maturation of the plant. Under binocular microscope observation, conidiophores are seen as bunches of white spots bearing conidia in parallel rows on the lower side of leaves.

Disease assessment (percentage of necrotic leaf area) was carried out according to the assessment key for Blumeria graminis (Bartels et al., 2000). 

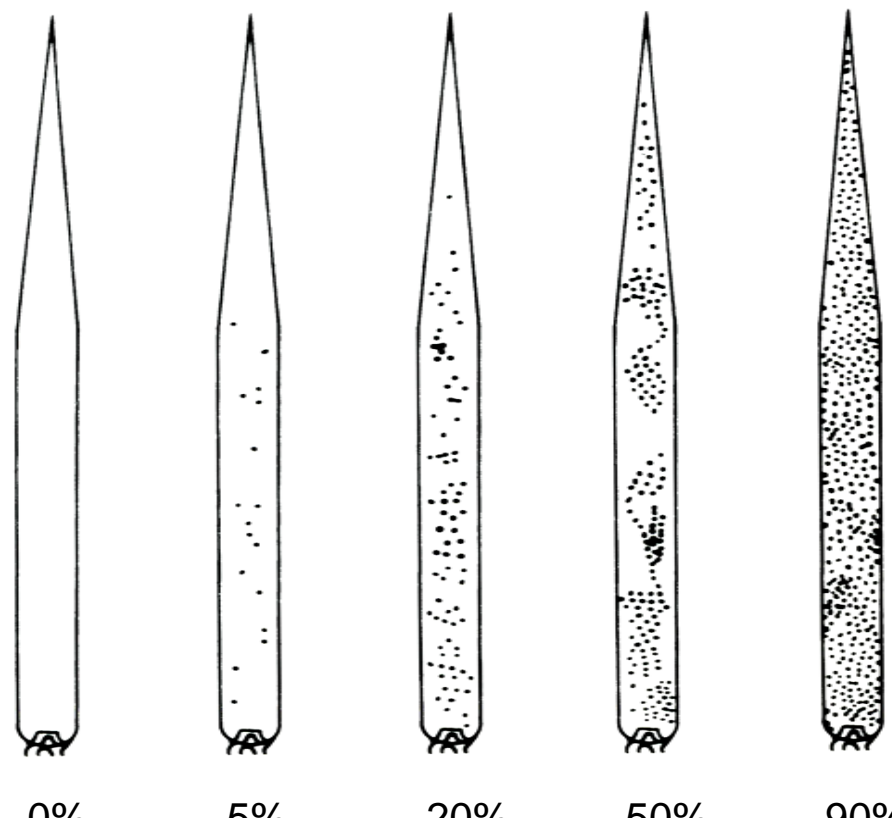

$0 \%$

$5 \%$

$20 \%$

$50 \%$

$90 \%$

Figure 1. Disease assessment key for evaluating the percentage necrotic leaf area caused by Ramularia collo-cygni (Bartels et al., 2000)

In this study, plant phenological growth stage assessment was done according to Tottman and Broad 1987(Table 1).

Table 1. A decimal code for the growth stages of spring barley

\begin{tabular}{lc}
\hline Development phase & Decimal growth stage code \\
\hline Germination & $00-09$ \\
Seedling growth & $10-19$ \\
Tillering & $20-29$ \\
Stem elongation & $30-39$ \\
Booting & $40-49$ \\
Ear emergence & $50-59$ \\
Flowering (Anthesis) & $60-69$ \\
Milk development & $70-79$ \\
Dough development & $80-89$ \\
Ripening & $90-99$ \\
\hline
\end{tabular}


Detecting Rcc by molecular methods: Traditional detection of Rcc is based on visual observation of disease symptoms on plants. Under field conditions, Rcc symptoms are often confused with necrotic spotting caused by abiotic factors or other barley pathogens such as Pyrenophora teres. Therefore, alternative polymerase chain reaction (PCR) based methods for detection of Rcc was developed (Havis et al., 2006; Frei et al., 2007).

\subsection{Molecular diagnosis of Rcc}

\subsubsection{DNA extraction from fungal mycelia}

Different Rcc isolates were grown for 10 days at $20^{\circ} \mathrm{C}$ on autoclaved sterile cellophane sheets, which were laid on V8A medium. About $100 \mathrm{mg}$ of mycelia were harvested from the cellophane sheet by scraping the surface with a sterile spatula. The harvested mycelia were stored in a $2 \mathrm{ml}$ sterile Eppendorf tube. A small volume (100 $\mu$ l, measured in the tube) of sterile sea sand was added to the tube, which was then vigorously mixed for 20 seconds. The mycelium was ground twice ( 2 min each time) on ice with a Laboratory stirrer $\left(\mathrm{IKA}^{\circledR}, \mathrm{RW} 16\right.$ basic, Germany) holding a stainless steel bit that fit the vial exactly. Total genomic DNA was extracted from fine ground material with DNeasy Plant Mini Kits (Qiagen GmbH, Hilden, Germany) according to the manual of the kit. The purified DNA was diluted in $150 \mu$ l of dilution buffer.

\subsubsection{DNA extraction from plant material}

Leaf samples were ground using sterile mortar and pestle under liquid nitrogen. One hundred milligram of fine ground material was used for DNA extraction. DNA was extracted with DNeasy Plant Mini Kits (Qiagen $\mathrm{GmbH}$, Hilden, Germany). Extraction was performed according to the manufacturer's protocol. The purified DNA was diluted in $150 \mu$ l of dilution buffer. To check the purity and concentration of DNA, 10 $\mu$ l of each sample was run on a $1 \%$ agarose gel at $60 \mathrm{~V}$ for 1 hour. All DNA samples were diluted to $25 \mathrm{ng} / \mu \mathrm{l}$ in preparation for quantitative and qualitative PCR and stored at $-20^{\circ} \mathrm{C}$. 


\subsubsection{DNA precipitation}

To increase sensitivity of amplification during PCR, DNA purification is needed to remove the inhibitors. In the present study, to precipitate DNA, 1:10 volume of 3M sodium acetate $(\mathrm{pH} 5.2)$ and 2 volumes of cold $100 \%$ ethanol were added to the extracted DNA (One volume is the volume of the solution containing the DNA). The solution was centrifuged at $14,000 \mathrm{rpm}$ for 15 minutes at $4^{\circ} \mathrm{C}$. The supernatant was removed carefully and the pellet was rinsed twice with $70 \%$ cold ethanol. The washed pellet was centrifuged again for 5 minutes at $14,000 \mathrm{rpm}$ at $4^{\circ} \mathrm{C}$. The remaining ethanol was removed and the pellet was air-dried under the Laminar Flow clean bench. Finally the pellet was re-suspended in $100 \mu \mathrm{l}$ sterile distilled water and stored at $-20^{\circ} \mathrm{C}$ for further studies.

\subsubsection{Quantification of extracted DNA}

Two different methods were used to quantify the extracted DNA. In the first method, DNA concentration was determined according to its optical density at $260 \mathrm{~nm}$, assuming the absorbance of 1 unit corresponds to a concentration of $50 \mu \mathrm{g}$ DNA per millilitre. The purity of DNA was measured from the ratio of the absorbance at 260 $\mathrm{nm}$ and $280 \mathrm{~nm}$, assuming that pure DNA has a ratio of 1.8-2.0 nm (Sambrook et al., 1989).

To quantify unknown DNA concentrations in the second method, DNA concentrations of $10 \mu \mathrm{l}$ were adjusted by densitometry with ethidium bromide $(0.0001 \%(\mathrm{v} / \mathrm{v}))$ stained agarose gels (1\% (w/v) in TE buffer) using Lambda Phage DNA as standards with different amounts ranging from 100, 75, 50, 25 and $10 \mathrm{ng}$. Gel documentation and analysis were performed with the Multi-Analyst software (Version 1.1, Bio-Rad Laboratories, Hercules, USA).

\subsubsection{Agarose gel electrophoresis}

To check the quality of extracted DNA, $10 \mu \mathrm{l}$ of DNA aliquot was loaded in $1 \%$ agarose gel. Agarose (Applichem, Darmstadt) was dissolved in 0.5xTBE buffer (Boric acid $55.03 \mathrm{~g} / \mathrm{L}$ (0.89 M); EDTA-Na $2.2 \mathrm{H}_{2} \mathrm{O} 7.44 \mathrm{~g} / \mathrm{L}$ (0.02 M); Tris $107.81 \mathrm{~g} / \mathrm{L}(0.89 \mathrm{M})$ ) in a microwave oven. Melted agarose was cooled to $60^{\circ} \mathrm{C}$, and then $0.0001 \% \mathrm{v} / \mathrm{v}$ 
ethidium bromide was added to the solution and poured on a gel support and remained for 30 minutes. The gel was put in a $0.5 x T E$ buffer tank and DNA was run at 1-3 volts per $\mathrm{cm}$. Gel documentation and analysis were performed with the MultiAnalyst software (Version 1.1, Bio-Rad Laboratories, Hercules, USA).

\subsubsection{Semi quantitative polymerase chain reaction (PCR)}

Semi quantitative PCR was carried out in a final volume of $25 \mu \mathrm{l}$ with $25 \mathrm{ng}$ of unknown DNA and contained one unit of Dream Taq DNA Polymerase (Fermentas, St. Leon-Rot), $0.5 \mu \mathrm{M}$ forward primer (Rcc 1: 5'-ACTGAGTGAGGGAGCAATCC-3'), $0.5 \mu \mathrm{M}$ reverse primer (Rcc 5b: 5'-GCGACGACTCGAACTCCTCTGC-3') (primers were taken from Havis et al., 2006), $500 \mu \mathrm{M}$ dNTPs, $0.5 \mathrm{mM}$ of $\mathrm{MgCl}_{2}$ and 10X Dream Taq PCR buffer (containing Tris- $\mathrm{HCl}, \mathrm{KCl},(\mathrm{NH} 4)_{2} \mathrm{SO}_{4}$ and $15 \mathrm{mM} \mathrm{MgCl}_{2}$, pH 8.7; Qiagen). The following cycling conditions were used on a Primus 96 Plus thermocycler (Eppendorf Mastercycler ${ }^{\circledR}$ Thermal Cyclers, Germany): An initial denaturation step at $95^{\circ} \mathrm{C}$ for 2 minutes was followed by 36 cycles of denaturation for $1 \mathrm{~min}$ at $95^{\circ} \mathrm{C}$, annealing for $20 \mathrm{~s}$ at $68^{\circ} \mathrm{C}$ and elongation for $1 \mathrm{~min}$ at $72^{\circ} \mathrm{C}$, followed by a final elongation step at $72^{\circ} \mathrm{C}$ for 10 minutes. As a negative control pre-mix solution without any DNA and as a positive control, 10 pg of pure Rcc DNA was used. PCR products (426 bp amplification) were separated on 1.5-2\% an Ethidium bromide stained agarose gel at $60 \mathrm{~V}$ for 1.5-2 hours and visualized under UV-light on a gel documentation system (Quantity One, Version 4.5.0 Bio-Rad Laboratories, Hercules, USA).

\subsubsection{Quantitative real time polymerase chain reaction (qPCR)}

To quantify the exact amount of pathogen which is responsible for disease symptoms, quantitative polymerase chain reaction ( $\mathrm{PPCR}$ ) can be used. This method was used for the plants which were infected under field conditions.

\subsubsection{DNA samples}

Pure Rcc isolate (nRcc 20) was used to obtain Rcc genomic DNA. Fungal DNA was extracted according to 2.5.1. Total plant genomic DNA without any contamination 
with Rcc was extracted from spring barley cv. Barke according to 2.5.2. The quantification of extracted DNA was measured according to 2.5.4.

\section{5.7.2 Quantitative Real Time PCR analysis}

Quantitative real-time PCR was carried out in Karlovsky lab (University of Göttingen, Department of Molecular Phytopathology and Mycotoxin Research) in a total volume of $25 \mu \mathrm{l}$ (Table 2). Three simultaneous replicates were used for each sample to confirm the reproducibility and reliability of the results. Sterile distilled water was used instead of DNA sample as a negative control.

The real time PCR was carried out in an iCycler iQ (iCycler system, BioRad, Hercules, CA, USA) according to the following program: the PCR-program has an initial denaturation step of $15 \mathrm{~min}$, followed by 36 cycles with a denaturation step for $1 \mathrm{~min}$ at $95^{\circ} \mathrm{C}$, annealing for $20 \mathrm{~s}$ at $68^{\circ} \mathrm{C}$ and elongation for $1 \mathrm{~min}$ at $72^{\circ} \mathrm{C}$. Fluorescence was detected after each elongation step and the program was completed with a final elongation step of $10 \mathrm{~min}$ at $72^{\circ} \mathrm{C}$. The melt curve analysis was performed at $95^{\circ} \mathrm{C}$ for $1 \mathrm{~min}$, followed by a $55^{\circ} \mathrm{C}$ step for $1 \mathrm{~min}$ and subsequent measurements within a range of $55^{\circ} \mathrm{C}$ to $95^{\circ} \mathrm{C}$ (every $10 \mathrm{~s}$ in $0.5^{\circ} \mathrm{C}$ temperature increments).

In the real-time PCR application, the accumulation of the amplicon is monitored by each cycle based on the emission of fluorescence.

Table 2. Real-Time PCR reaction mixture in total volume of $25 \mu \mathrm{l}$

\begin{tabular}{|c|c|c|c|}
\hline Chemicals & Concentration & Final concentration & $\mu \mathrm{l}$ per reaction \\
\hline $\mathrm{H}_{2} \mathrm{O}$ bidest. & & & Up to $25 \mu \mathrm{l}$ \\
\hline $10 \times$ Buffer & $10 x$ & $1 x$ & 2.5 \\
\hline $\mathrm{MgCl}_{2}$ & $25 \mathrm{mM}$ & $0.5 \mathrm{mM}$ & 0.5 \\
\hline dNTP & $10 \mathrm{mM}$ & $500 \mu \mathrm{M}$ & 0.5 \\
\hline F-Primer (Rcc1) & $10 \mu \mathrm{M}$ & $0.5 \mu \mathrm{M}$ & 1.25 \\
\hline R-Primer (Rcc 5b) & $10 \mu \mathrm{M}$ & $0.5 \mu \mathrm{M}$ & 1.25 \\
\hline DreamTaq Polymerase & $5 \mathrm{U} / \mu \mathrm{l}$ & $1 U$ & 0.2 \\
\hline SybrGreen & $1: 1000$ & $1: 100000$ & 0.25 \\
\hline Fluorescein & $1 \mu \mathrm{M}$ & $10 \mathrm{nM}$ & 0.25 \\
\hline DNA sample & $\sim 25 \mathrm{ng} / \mu \mathrm{l}$ & & 2 \\
\hline
\end{tabular}




\section{5.7.3 Primer specificity and sensitivity}

In the present study, forward primer Rcc1 (5'-ACTGAGTGAGGGAGCAATCC-3') and reverse primer Rcc 5b (5'-GCGACGACTCGAACTCCTCTGC-3') were used as described in Havis et al. (2006). The specificity of the primer was evaluated again by applying PCR on a collection of DNA from different plants (without any fungal contaminations) and different DNA from fungal pathogens (Table 3 ).

Table 3. Source of different genomic DNA from different plants and fungal plant pathogens which was used to test the specificity of the primers

\begin{tabular}{lcll}
\hline Organism & Number of Isolates & Isolated from & Origin \\
\hline Ramularia collo-cygni & 32 & Barley & Germany \\
Ramularia collo-cygni & 18 & Barley & Sweden \\
Drechslera teres & 1 & Barley & Germany \\
D. tritici-repentis & 1 & Wheat & Germany \\
Fusarium culmorum & 1 & Barley & Finland \\
F. graminearum & 1 & Barley & New South Wales \\
F. avenaceum & 1 & Wheat & United Kingdom \\
F. verticillioides & 1 & Maize & Germany \\
Phoma lingam & 1 & Oilseed rape & Germany \\
Septoria tritici & 1 & Wheat & Germany \\
Verticillium longisporum & 1 & Oilseed rape & Germany \\
Sclerotinia sclerotiorum & 1 & Oilseed rape & Germany \\
Barley cv. Barke & 2 & ---------- & Germany \\
Barley cv. Hatifa & 2 & -------- & Germany \\
Barley cv. Lisanne & 2 & --------- & Germany \\
Wheat cv. Centrum & 2 & --------- & Germany \\
Wheat cv. Ritmo & 2 & -------- & Germany \\
Maize & 2 & --------- & Germany \\
\hline
\end{tabular}

The sensitivity of the primers was evaluated by plotting the logarithm of ten fold dilution series of known concentrations of pure Rcc DNA (1ng, 100 pg, 10 pg, 1pg, $0.1 \mathrm{pg}, 0.01 \mathrm{pg}$ and $0.001 \mathrm{pg}$ ) against the threshold cycle $\left(\mathrm{C}_{\mathrm{t}}\right)$ values. For each concentration, three technical replicates were used. The mean threshold cycle $\left(C_{t}\right)$ 
values of the three replicates were fit by linear regression to derive the template DNA concentration.

Additionally, the sensitivity of Rcc primers was evaluated by amplifying specific concentration of target DNA (pure Rcc DNA) inside high concentration of non-target DNA (barley plant DNA). For this reason, three different amounts of Rcc DNA (100, $10,1 \mathrm{pg}$ ) were mixed artificially in a specific amount (20 ng) of plant DNA (spring barley cv. Barke) and used as templates in the real-time PCR. The relationship between the $C_{t}$ values and the different concentrations of fungal DNA were determined and compared with the result of standard curves of fungal DNA.

\subsection{Experiments under controlled environmental conditions}

\subsubsection{Detection of $R$. collo-cygni in seeds}

For this experiment, barley seeds (cv. Franziska) were harvested from a severely infected barley field near Eschwege, Germany in July 2008. Ten samples, of three seeds each, were taken randomly as ten replicates. The seeds were ground to a fine powder for 1.5 min using a mixer mill grinder (Retsch MM 200, Retsch GmbH, Haan, Germany). Twenty milligram of each ground seed sample was used for DNA extraction. Total DNA was extracted with DNeasy Plant Mini Kits (Qiagen $\mathrm{GmbH}$, Hilden, Germany). The PCR reaction was carried out as described in 2.5.6.

\subsubsection{Assessment of the systemic fungal development from seeds to the emerging plants}

Heavily naturally infected seeds (cv. Franziska) were sown and grown in $9 \mathrm{~cm} \times 9 \mathrm{~cm}$ plastic pots, containing a mix of potting soil and sand (3:1). All plants were grown in climate chambers under day/night temperature of $20 / 16^{\circ} \mathrm{C}$, with a 16 hours photoperiod and a light intensity of $100 \mu \mathrm{mol} \mathrm{m} \mathrm{m}^{-2} \mathrm{~s}^{-1}$ at the height of pots and 300 $\mu \mathrm{mol} \mathrm{m} \mathrm{m}^{-2} \mathrm{~s}^{-1}$ at the height of ears provided by Halide lamps (PHILIPS MASTER TL5 HO 54W/840/Germany). Plants were well watered and fertilized regularly (Hakaphos $15 \% \mathrm{~N}, 15 \% \mathrm{~K} 2 \mathrm{O}, 11 \% \mathrm{P} 2 \mathrm{O}, 1 \% \mathrm{MgO})$. During plant development, at growth stages 13-15 and 30-33 the fully expanded leaf from top, at growth stage 51-55 the flag leaf, 
F-1 and F-2 and at growth stage 87-91 the first generation seeds were harvested. Leaf samples were frozen directly in liquid nitrogen and kept at $-20^{\circ} \mathrm{C}$ for further experiments. DNA was extracted from the different plant materials according to 2.5.2. PCR reaction carried out as described in 2.5.6.

\subsubsection{Elimination of fungal infestation of seeds by hot water treatment}

To find the appropriate temperature and optimal duration of treatment, an extra experiment was carried out for checking the effect of hot water treatment on barley seeds viability and germination in the absence of pathogen. For this reason, barley seeds were treated with three different temperatures $\left(48,50\right.$ and $\left.52^{\circ} \mathrm{C}\right)$ and duration of 0 (control), 5, 10, 15, 20, 25 and 30 minutes. For each treatment 5 replicates and in each replicate 10 seeds were used. After each treatment, the seeds were immediately put into water at $15^{\circ} \mathrm{C}$ for five minutes for rapid cooling then placed on filter paper which had been moistened with sterile distilled water in a $9 \mathrm{~cm}$ Petri dish and incubated at room temperature $\left(\sim 25 \pm 2^{\circ} \mathrm{C}\right)$. After five days, the number of seedlings was counted separately in each group and the percentage of germinated seeds was determined.

In the following experiments, barley seeds cv. Franziska, which were infected strongly with Rcc under field conditions, were used and divided into two parts. One part after hot water treatment and one part as a control without any treatment were sown and grown under the same conditions as described in 2.5.2. During plant development, at growth stages 13-15 and 30-33 the completely expanded leaf from the top, at growth stage 51-55 the flag leaf, F-1 and F-2 and at growth stage 87-91 the first generation seeds were harvested. DNA was extracted from the harvested plant materials according to 2.5.2 and PCR was carried out as described in 2.5.6.

\subsubsection{Pathogen-free plants and seeds}

Results from previous PCR studies gave clear evidence for a systemic symptomless growth of the fungus from contaminated seeds into emerging plants. In order to evaluate the importance of latent seed-borne infection vs. leaf infection with airborne conidia, we used seed dressings and consecutive applications of foliar fungicides during plant development to produce pathogen-free plants and seeds. 


\subsubsection{Efficacy of fungicide seed dressing}

This experiment was carried out with barley seeds cv. Barke, which were strongly infected with Rcc under field conditions. Seeds were dressed with fungicides at the dosage recommended by the company (Table 4). Seeds were then air dried, placed on filter paper which had been moistened with sterile distilled water in a $9 \mathrm{~cm}$ Petri dish, and incubated at room temperature $\left(\sim 25 \pm 2^{\circ} \mathrm{C}\right)$. After 5 days the germinated seeds were sown in $9 \mathrm{~cm} \times 9 \mathrm{~cm}$ plastic pots, containing a mix of potting soil and sand (3:1). All plants were grown at the same conditions as explained in 2.5.2. During plant development, at growth stages 13-15 and 30-33 the completely expanded leaf from the top, at growth stage 51-55 the flag leaf, F-1 and F-2 and at growth stage 8791 the first generation of seeds were harvested. Leaf samples were frozen directly in liquid nitrogen and kept at $-20^{\circ} \mathrm{C}$ for further experiments.

Table 4. Active ingredients used in commercial chemicals and timing of treatments

\begin{tabular}{|c|c|c|c|c|}
\hline Fungicide Trade Name & \multicolumn{2}{|c|}{ Active ingredient $(\mathrm{g} / \mathrm{L})$} & $\begin{array}{l}\text { Rate of use in } \\
\text { Spring barley }\end{array}$ & $\begin{array}{l}\text { Plant growth stage } \\
\text { at the time of } \\
\text { application }\end{array}$ \\
\hline $\begin{array}{l}\text { EFA }^{\circledR} \\
\text { Bayer Crop Science, } \\
\text { Germany }\end{array}$ & $\begin{array}{l}\text { Fluoxastrobin, } \\
\text { Tebuconazole, } \\
\text { Prothioconazole, } \\
\text { Triazoxide }\end{array}$ & $\begin{array}{l}37.5 \\
3.75 \\
25 \\
10\end{array}$ & $160 \mathrm{ml} / \mathrm{dt}$ & $\begin{array}{c}\text { GS } 0 \\
\text { (seed dressing) }\end{array}$ \\
\hline $\begin{array}{l}\text { Solitaer }{ }^{(\circledast)} \\
\text { Syngenta Agro, } \\
\text { Germany }\end{array}$ & $\begin{array}{l}\text { Cyprodinil } \\
\text { Fludioxonil } \\
\text { Tebuconazole }\end{array}$ & $\begin{array}{l}25 \\
25 \\
10\end{array}$ & $200 \mathrm{ml} / \mathrm{dt}$ & $\begin{array}{c}\text { GS } 0 \\
\text { (seed dressing) }\end{array}$ \\
\hline $\begin{array}{l}\text { Zardex } \mathrm{G}^{(\circledR)} \\
\text { Syngenta Agro, } \\
\text { Germany }\end{array}$ & $\begin{array}{l}\text { Cyproconazol } \\
\text { Imazalil }\end{array}$ & $\begin{array}{l}5 \\
20\end{array}$ & $300 \mathrm{ml} / \mathrm{dt}$ & $\begin{array}{c}\text { GS } 0 \\
\text { (seed dressing) }\end{array}$ \\
\hline $\begin{array}{l}\left.\text { Proline }^{(}\right) \\
\text {Bayer Crop Science, } \\
\text { Germany }\end{array}$ & Prothioconazole & 250 & $0,8 \mathrm{l} / \mathrm{ha}$ & $\begin{array}{l}\text { GS } 39-41 \\
\text { GS } 65-69\end{array}$ \\
\hline
\end{tabular}

\subsubsection{Foliar fungicide application}

Barley seeds cv. Barke which were harvested from a barley field strongly infected with Rcc, and divided into two groups. One group of seeds was treated with Zardex $G$ (which showed the best efficacy in the previous study) and the other group of seeds remained untreated and were sown and grown at the same conditions as 
explained in 2.5.2. At growth stage 39-41, a systemic foliar fungicide, Proline, was sprayed with a hand sprayer onto the upper surface of each plant in the dosage, which is recommended by the company (Table 3). One week after foliar treatment, F-1 leaves were harvested and frozen directly in liquid nitrogen. Total DNA was extracted and kept at $-20^{\circ} \mathrm{C}$ for further experiments. At growth stage $65-69$, plants which had not been treated with foliar fungicide at growth stage 39-41, were evenly sprayed with Proline. In following at growth stage 87-91, the first generation seeds from treated and non treated plants were harvested. Total DNA was extracted from seeds. All DNA samples were checked via qPCR for existence of Rcc.

\subsubsection{Artificial inoculation}

\subsubsection{Inoculum preparation}

Since no work has been done concerning virulence of Rcc isolates, a mixture of different isolates, which had shown the highest sporulation intensity in previous studies were used to maximise the chance of successful inoculation. Before each inoculation, the inoculum was prepared by transferring each isolate from $-80^{\circ} \mathrm{C}$ to V8A medium and re-cultured again on new V8A mediums. Ten days after the second cultivation, the inoculum, which was a combination of spores and mycelia, was harvested from Petri dishes and suspended in $50 \mathrm{ml}$ distilled tab water. The mycelial fragments and spores were sieved through fine cloth and adjusted to a density of $1 \times 10^{5}$ spores per millilitre. Before inoculation, $0.01 \%$ Silwet gold was added to the suspension. A control set of plants was mock-inoculated with water and Silwet gold.

\subsubsection{Evaluation of resistance at different plant growth stages}

To evaluate resistance in different barley cultivars against Rcc, it is necessary to find reliable and practical methods for producing symptoms by artificial inoculation under controlled conditions. Seeds of four different cultivars of spring barley (Barke, Hatifa, IPZ 24727, and Lisanne) were sown and grown as described in 2.6.2. To detect any seed contamination with Rcc, DNA was extracted from fully expanded leaves by DNeasy Plant Mini Kits (Qiagen GmbH, Hilden, Germany) at growth stage 13. The 
extracted DNA was used as a template for the specific fungal detection by using specific primers for Rcc (Havis et al., 2006). At different growth stages (15, 25-28, 33-35, 41-45 and 49-51), the plants were evenly sprayed with a fine mist of sporemycelia suspension as described in 2.6.7.1, until the inoculum suspension began to run off the leaves. After inoculation, all plants were incubated at $20^{\circ} \mathrm{C}$, a high relative humidity of $>95 \%$, a $16 / 8$ hours light/darkness cycle and a light intensity of $120 \mu \mathrm{mol} . \mathrm{m}^{-2} \cdot \mathrm{s}^{-1}$ at the height of the pots and $350 \mu \mathrm{mol} . \mathrm{m}^{-2} \cdot \mathrm{s}^{-1}$ at the height of ears using Halide lamps (EYE Clean Arc ${ }^{\mathrm{TM}}$ MT 400DL/BH). Fifteen days post inoculation, the percentage of necrotic leaf area caused by RLS on leaf F-1 was scored.

\subsubsection{In vitro inoculation system}

For in vitro testing of barley lines for resistance to Rcc, a leaf segment assay was developed, using the same cultivars of spring barley as in the previous experiment. Five centimetre leaf segments were cut from leaves of barley plants at different growth stages $(15,25 / 28,33 / 35,41 / 45$ and 49/51), and laid upside down onto the surface of $0.75 \%$ water agar containing $40 \mathrm{ppm}$ benzimidazole in a $10 \mathrm{~cm} \times 10 \mathrm{~cm}$ Petri dish (5 leaflets per dish). To keep the leaf segments green as long as possible, two pieces of water agar blocks were placed on the both cutting edges. Leaf segments were sprayed with the same inoculum which was used for the whole plant inoculation using an atomizer. After inoculation all Petri dishes were incubated in a growth chamber at $20^{\circ} \mathrm{C}$, first for 48 hours in darkness then 16 hours daylight and a light intensity of $30 \mu \mathrm{mol} \mathrm{m} \mathrm{m}^{-2} \mathrm{~s}^{-1}$ using Halide lamps (OSRAML 18W/30-Warm White/Germany). The number of necrotic spots on individual leaf segments was counted after 15 days post inoculation. 


\subsubsection{Resistance evaluation under controlled conditions}

\subsubsection{Plant material}

Forty spring barley genotypes with known and unknown resistance to Rcc were used in this study (Table 5).

Table 5. Description of spring barley genotypes which were evaluated for resistance to Ramularia collo-cygni under field and controlled environmental conditions (FE: Field experiment; GH: Greenhouse; LSA: Leaf segment assay).

\begin{tabular}{|c|c|c|c|c|}
\hline Genotype & Origin & Breeder & mlo & Used in \\
\hline Audrey & $\begin{array}{l}\text { (Xanadu x Simba) x } \\
\text { Marnie }\end{array}$ & Nordsaat & ----- & FE 2009/FE 2010 \\
\hline Barke & Libelle $\times$ Alexis & Saatzucht J. Breun & mlo9 & $\begin{array}{l}\text { FE 2009/FE } 2010 \\
\text { GH and LSA }\end{array}$ \\
\hline Braemar & NF C5563 x NFC 94-20 & Cebeco & mlo11 & $\begin{array}{l}\text { FE 2009/FE } 2010 \\
\mathrm{GH} \text { and LSA }\end{array}$ \\
\hline Conchita & Viskosa/LP 629.1.95 & KWS Lochow GmbH & mlo11 & $\begin{array}{l}\text { FE 2009/FE } 2010 \\
\text { GH and LSA }\end{array}$ \\
\hline Fairytale & $\begin{array}{l}\text { Colston x (Recept x } \\
\text { Power) }\end{array}$ & Sejet & ----- & $\begin{array}{l}\text { FE 2009/FE } 2010 \\
\mathrm{GH} \text { and LSA }\end{array}$ \\
\hline Gaute & $\begin{array}{l}\text { (Xanadu x Simba) x } \\
\text { Marnie }\end{array}$ & Nordsaat & ----- & $\begin{array}{l}\text { FE } 2009 \\
\mathrm{GH} \text { and LSA }\end{array}$ \\
\hline GS 2298 & $\begin{array}{l}\text { (Xanadu x Simba) x } \\
\text { Marnie }\end{array}$ & $\begin{array}{l}\text { Ackermann Saatzucht } \\
\text { GmbH \& Co.KG }\end{array}$ & ---- & $\begin{array}{l}\text { FE 2009/FE } 2010 \\
\mathrm{GH} \text { and LSA }\end{array}$ \\
\hline GS 2300 & $\begin{array}{l}\text { (Xanadu x Simba) x } \\
\text { Marnie }\end{array}$ & Nordsaat & ----- & $\begin{array}{l}\text { FE 2009/FE } 2010 \\
\text { GH and LSA }\end{array}$ \\
\hline GS 2301 & $=$ Audrey & Ackermann & ---- & $\begin{array}{l}\text { FE 2009/FE } 2010 \\
\text { GH and LSA }\end{array}$ \\
\hline Gustav & Meltan x Baronesse & SW Seed & ---- & $\begin{array}{l}\text { FE 2009/FE } 2010 \\
\text { GH and LSA }\end{array}$ \\
\hline Hatifa & $\begin{array}{l}\text { Viskosa x Pasadena } \\
\text { (Dubled Haploid) }\end{array}$ & Nordic Seed & ----- & $\begin{array}{l}\text { FE 2009/FE } 2010 \\
\text { GH and LSA }\end{array}$ \\
\hline
\end{tabular}


Continuing from previous page (Table 5)

\begin{tabular}{|c|c|c|c|c|}
\hline Henrike & Marnie/Bolina & $\begin{array}{l}\text { Nordsaat Saatzucht } \\
\text { GmbH }\end{array}$ & ---- & $\begin{array}{l}\text { FE 2009/FE } 2010 \\
\text { GH and LSA }\end{array}$ \\
\hline IPZ 24727 & $\begin{array}{l}\text { Br. } 3546 \text { - Omega } \\
15122 \text { x Maresi }\end{array}$ & LfL & ----- & $\begin{array}{l}\text { FE 2009/FE } 2010 \\
\text { GH and LSA }\end{array}$ \\
\hline Isabella & Power x Recept & Sejet & ----- & $\begin{array}{l}\text { FE 2009/FE } 2010 \\
\mathrm{GH} \text { and LSA }\end{array}$ \\
\hline JB Flavour & $\begin{array}{l}\text { (W27515/14622/Ack } \\
\text { 1846)/Annabell }\end{array}$ & $\begin{array}{l}\text { Saatzucht Josef Breun } \\
\text { GdbR }\end{array}$ & ----- & $\begin{array}{l}\text { FE 2009/FE } 2010 \\
\text { GH and LSA }\end{array}$ \\
\hline Jennifer & $\begin{array}{l}\text { (Zenobia/Celebra)/ } \\
\text { Marnie }\end{array}$ & $\begin{array}{l}\text { Ackermann Saatzucht } \\
\text { GmbH \& Co.KG }\end{array}$ & ---- & $\begin{array}{l}\text { FE 2009/FE } 2010 \\
\text { GH and LSA }\end{array}$ \\
\hline Justina & Henni x Krona & Toft Plant Breeding & ----- & $\begin{array}{l}\text { FE } 2009 \\
\text { GH and LSA }\end{array}$ \\
\hline Kangoo & Braemar/Roxana & Limagrain Nederland B.V. & ----- & $\begin{array}{l}\text { FE 2009/FE } 2010 \\
\text { GH and LSA }\end{array}$ \\
\hline Kia & Henni x Krona & Toft Plant Breeding & & FE 2010 \\
\hline Lanfeust & Astoria $\times$ Aspen & Secobra & ----- & FE 2009 \\
\hline Lisanne & Bellevue/Pasadena & LIMAGRAIN GmbH & ---- & $\begin{array}{l}\text { FE 2009/FE } 2010 \\
\mathrm{GH} \text { and LSA }\end{array}$ \\
\hline Macaw & Dray x Fractal & Serasem & ----- & FE 2009 \\
\hline Marthe & Neruda x Recept & $\begin{array}{l}\text { Nordsaat Saatzucht } \\
\text { GmbH }\end{array}$ & mlo11 & $\begin{array}{l}\text { FE 2009/FE } 2010 \\
\text { GH and LSA }\end{array}$ \\
\hline Mercada & $\begin{array}{l}\text { (Orthega x LP4261.92) } \\
\text { x LP } 6900.92\end{array}$ & Ackermann & ---- & $\begin{array}{l}\text { FE 2009/FE } 2010 \\
\text { GH and LSA }\end{array}$ \\
\hline Mimer & Pss 7020-3 x A 8932 & Nordic seed & ----- & $\begin{array}{l}\text { FE 2009/FE } 2010 \\
\text { GH and LSA }\end{array}$ \\
\hline Nymfe & $\begin{array}{l}\text { Power x (Prestige } x \\
\text { Recept) }\end{array}$ & Sejet & ---- & $\begin{array}{l}\text { FE 2009/FE } 2010 \\
\text { GH and LSA }\end{array}$ \\
\hline Pasadena & Marina x Krona & Lochow-Petkus GmbH & ----- & $\begin{array}{l}\text { FE 2009/FE } 2010 \\
\text { GH and LSA }\end{array}$ \\
\hline
\end{tabular}


Continuing from previous page (Table 5)

\begin{tabular}{|c|c|c|c|c|}
\hline Power & $\begin{array}{l}\text { Saloon x (Colada x (Lux } \\
\text { x Annabell)) }\end{array}$ & $\begin{array}{l}\text { Saatzucht Streng GmbH } \\
\& \text { Co.KG }\end{array}$ & ----- & $\begin{array}{l}\text { FE 2009/FE } 2010 \\
\text { GH and LSA }\end{array}$ \\
\hline Primadonna & Viskosa/Ria & $\begin{array}{l}\text { Saatzucht Firlbeck GmbH } \\
\& \text { Co. KG }\end{array}$ & ----- & FE 2009 \\
\hline Publican & Drum/Sebastian & Syngenta Seeds GmbH & ----- & FE 2009 \\
\hline Quench & Sebastian/Drum & Syngenta Seeds GmbH & mlo11 & $\begin{array}{l}\text { FE 2009/FE } 2010 \\
\text { GH and LSA }\end{array}$ \\
\hline Ria & Hadm/96677-87 & Saatzucht Hadmersleben & ----- & $\begin{array}{l}\text { FE 2009/FE } 2010 \\
\text { GH and LSA }\end{array}$ \\
\hline Scandium & Roxana x Delibes & Nordic Seed & ----- & $\begin{array}{l}\text { FE 2009/FE } 2010 \\
\text { GH and LSA }\end{array}$ \\
\hline Scarlett & $\begin{array}{l}\text { Amazone } \times \text { Br. } \\
\text { St.2730e } \times \text { Kym }\end{array}$ & $\begin{array}{l}\text { Saatzucht Josef Breun } \\
\text { GdbR }\end{array}$ & ----- & $\begin{array}{l}\text { FE 2009/FE } 2010 \\
\text { GH and LSA }\end{array}$ \\
\hline Sebastian & Lux/Viskosa & $\begin{array}{l}\text { Sejet/Saatzucht Streng } \\
\text { GmbH \& Co.KG }\end{array}$ & ----- & $\begin{array}{l}\text { FE 2009/FE } 2010 \\
\text { GH and LSA }\end{array}$ \\
\hline Signora & Prestige xTavern & Serasem & mlo & $\begin{array}{l}\text { FE 2009/FE } 2010 \\
\text { GH and LSA }\end{array}$ \\
\hline Styx & $\begin{array}{l}\text { Viskosa } \mathrm{x} \text { Landlord } \mathrm{x} \\
\text { Pasadena }\end{array}$ & $\begin{array}{l}\text { Saatzucht Streng GmbH } \\
\& \text { Co.KG }\end{array}$ & ----- & FE 2009 \\
\hline Thule & $\begin{array}{l}\text { Power } x \text { (Prestige } x \\
\text { Recept) }\end{array}$ & Sejet & ----- & FE 2010 \\
\hline Umbrella & $\begin{array}{l}\text { Annabell x Breun St. } \\
6163 a 17\end{array}$ & $\begin{array}{l}\text { Saatzucht Josef Breun } \\
\text { GdbR }\end{array}$ & ----- & $\begin{array}{l}\text { FE 2009/FE } 2010 \\
\text { GH and LSA }\end{array}$ \\
\hline Varberg & $\begin{array}{l}\text { Orthega x LP 4261.92) } \\
\text { x LP } 6800.92\end{array}$ & KWS Lochow GmbH & ----- & $\begin{array}{l}\text { FE 2009/FE } 2010 \\
\text { GH and LSA }\end{array}$ \\
\hline Victoriana & (LP/5191)/Saloon & KWS Lochow GmbH & mlo11 & $\begin{array}{l}\text { FE 2009/FE } 2010 \\
\text { GH and LSA }\end{array}$ \\
\hline Waldemar & Gustav x Simba & SW Seed & ----- & $\begin{array}{l}\text { FE 2009/FE } 2010 \\
\text { GH and LSA }\end{array}$ \\
\hline
\end{tabular}




\subsubsection{Whole plant inoculation}

Plants of different spring barley genotypes were sown and grown in $9 \mathrm{~cm} \times 9 \mathrm{~cm}$ plastic pots, containing a mix of potting soil and sand (3:1). All plants were grown in the climate chamber as described in 2.6.2. To detect any seed contamination with Rcc, DNA was extracted from fully expanded leaves by DNeasy Plant Mini Kits (Qiagen $\mathrm{GmbH}$, Hilden, Germany) at growth stage 13. The extracted DNA was used as a template for specific fungal detection by using specific primers for Rcc (Havis et al., 2006). In whole plant inoculation, plants at GS 55-59 were evenly sprayed with a fine mist of inoculum as described in 2.6.7.1 until start of run off. A control set of plants were mock-inoculated with water and Silwet gold. After inoculation, all plants were incubated at $20^{\circ} \mathrm{C}$ at a relative humidity of $>95 \%$ and a $16 / 8$ hours light/darkness cycle and a light intensity of $120 \mu \mathrm{mol} \mathrm{m}^{-2} \mathrm{~s}^{-1}$ at the height of pots and $350 \mu \mathrm{mol} \mathrm{m}{ }^{-2} \mathrm{~s}^{-1}$ at the height of ears using Halide lamps (EYE Clean Arc ${ }^{\mathrm{TM}}$ MT $400 \mathrm{DL} / \mathrm{BH}$ ). Disease symptom development (\% necrotic leaf area) was scored from 3 to 15 days after inoculation according to the assessment key (see 2.4) for Blumeria graminis (Bartels et al., 2000).

\subsubsection{Leaf segment assay}

In this experiment, $5 \mathrm{~cm}$ leaf segments were cut from F-1 leaves at Gs 55-59 and laid upside down onto the surface of $0.75 \%$ water agar containing $40 \mathrm{ppm}$ benzimidazole in a $10 \mathrm{~cm} \times 10 \mathrm{~cm}$ Petri dish (5 leaflets per dish). Both cut ends of the segments were pushed under the surface of the agar. Leaflets were sprayed with the same inoculum which was used in the whole plant inoculation using an atomizer. After inoculation all Petri dishes were incubated in a growth chamber at $20^{\circ} \mathrm{C}$, the first 48 hours in darkness followed by 16 hours daylight with a light intensity of $30 \mu \mathrm{mol} \mathrm{m} \mathrm{m}^{-2} \mathrm{~s}^{-1}$ using Halide lamps (OSRAML 18W/30-Warm White/Germany). The number of necrotic spots on the individual leaflets was counted 15 days after inoculation.

\subsubsection{Effect of stressors on symptom development}

This experiment was carried out to develop an inoculation method to enable resistance evaluation for Rcc in different barley genotypes at younger growth stages. 
In the present study, we tried to increase oxidative stress by different stressors to disturb plant defence systems in barley seedlings during incubation.

\subsubsection{Plant material}

This experiment was carried out with the spring barley cultivars Barke and Hatifa. According to the previous studies under field and greenhouse conditions, these cultivars had shown the strongest susceptibility to Rcc. Seeds were sown and plants were grown as described in 2.6.2.

\subsubsection{Inducing senescence with chemical stressors}

Ethephon (Camposan-Extra): At growth stage 13 (3 ${ }^{\text {rd }}$ leaf fully expanded and $4^{\text {th }}$ leaf starting to emerge), 10 plants of each cultivar were pre-treated by spraying $0.1,0.2$, 0.45 and $0.9 \mathrm{l} / \mathrm{ha}$ of Ethephon with a hand sprayer. For each treatment also ten plants were sprayed with water as a mock-inoculation. Three days after stress treatment, plants were evenly sprayed with a fine mist of inoculum as described in 2.6.7.1 until just before the inoculum began to run off the leaves. After inoculation all plants were transferred to the climate chamber under controlled conditions as described in 2.6.2. Disease symptom development (\% necrotic leaf area) was scored from 3 to 15 days after inoculation.

Paraquat (Methyl Viologen): At GS 13, 10 plants of each cultivar were pre-treated by spraying $5,10,25,50,100 \mu \mathrm{M} / \mathrm{I}$ of paraquat with a hand sprayer. For each treatment also ten plants were sprayed with water as a mock inoculation. Following experiments were done similarly to 2.6.9.2.

\subsubsection{Senescence induction by physical stressors}

High temperature: At growth stage 13, 10 plants of each cultivar were exposed to high temperature $\left(40^{\circ} \mathrm{C}\right)$ by putting them in a growth chamber for $1,2,4,6,12$, and 24 hours. After each treatment plants were directly inoculated with a fine mist of inoculum and then transferred to the chamber under controlled conditions as 
explained in 2.6.2. Disease symptom development (\% necrotic leaf area) was scored from three to 15 days after inoculation.

Low temperature: Ten barley plants of each cultivar at GS 13 were directly chilled at $4^{\circ} \mathrm{C}$ in a growth chamber for 1, 2, 4, 6, 12, and 24 hours. After each treatment the plants were directly inoculated with a fine mist of inoculum and then transferred to the chamber under controlled conditions as explained at 2.6.2. Disease symptom development (\% necrotic leaf area) was scored from 3 to 15 days after inoculation.

UV-light: A set of plants at GS 13 was exposed to NUV radiation at $0.30 \mu \mathrm{mol} \mathrm{m} \mathrm{m}^{-2} \mathrm{~s}^{-1}$ (obtained from lamps; PHILIPS: TDL 36W/08-Germany) for 1, 2, 4, 6, 12, and 24 hours. After each treatment the plants were directly inoculated with a fine mist of inoculum and then transferred to the growth chamber under controlled conditions as described at 2.6.2. Disease symptom development (\% necrotic leaf area) was scored from 3 to 15 days after inoculation.

\subsubsection{Fungal development inside the plant after artificial inoculation}

The experiment was carried out with spring barley cultivars Barke and Hatifa, which were shown the highest susceptibility to Rcc in previous studies. Seeds were sown and plants were grown similarly to 2.6.2. At growth stage 13, the fully expanded leaf from top was harvested and examined by PCR to check any seed contamination with Rcc. Only non infected plants, which showed no contamination, were used for further experiments. At GS 23-25, the youngest fully expanded leaf was inoculated carefully by spraying fine mist of inoculum (2.6.7.1) with an atomizer. After inoculation, each leaf was covered with plastic bag to keep the humidity. At GS 55-59, the flag leaf, $\mathrm{F}-1$, and F-2 leaves were harvested separately, directly frozen in liquid nitrogen and DNA was extracted from fine ground plant material by DNeasy Plant Mini Kits (Qiagen $\mathrm{GmbH}$, Hilden, Germany). The extracted DNA was used as a template for specific fungal detection by using specific primers for Rcc (Havis et al., 2006). 


\subsubsection{Morphology and chemical composition of the leaf cuticular wax layer during plant development}

\subsubsection{Plant material}

The experiment was carried out using the susceptible spring barley cv. Barke. Plants were sown and grown according to 2.6.2. During plant development, at growth stages 13 and 33 the first fully expanded leaf from the top and at growth stage 45-49 and 59-61 the leaves F-1 and F-2 were harvested. Afterwards, the leaf surface area was measured and leaves were used for further experiments.

\subsubsection{Extraction and analysis of the cuticular wax layer}

Plant waxes were extracted by dipping each leaf in hexane for 30 s at room temperature. The hexane extracts were filtered into a vial where the hexane was evaporated using nitrogen gas, leaving only a wax residue for injecting into the gas chromatograph. Analysis of the cuticular wax layer was conducted by Dirk Jessen, University of Göttingen, Department of Plant Biochemistry.

\subsubsection{Environmental scanning electron microscopy (ESEM)}

ESEM was carried out to examine the fine leaf surface structure and to detect any changes in the wax morphology during plant development. Leaf discs of one centimetre diameter were taken with a cork borer. Segments were stuck on SEM stubs with double-sided carbon tape and viewed under the microscope. ESEM was carried out by Dr. Kirsten Techmer; University of Göttingen, Geosciences Department, Crystallography Division.

\subsection{Field experiments}

\subsubsection{Monitoring spore dispersal by wind}

Since the airborne Rcc spores play an important role in the disease cycle, semi selective medium (Vegetable juice $200 \mathrm{ml}, \mathrm{CaCO}_{3} 2 \mathrm{~g}$, Agar $15 \mathrm{~g}$ and distilled water 
800ml, containing 25ppm Acanto (250 g/L picoxystrobin, Syngenta, Crop Protection, Maintal, Germany) and 200ppm streptomycin sulphate) was used as a spore trap in the colder months (October and November) in three consecutive years (2008-2010) and in the field trail 2010 to determine the timing of spore dispersal and spore concentration. Spore traps were installed one metre above ground in the colder season and $0.5 \mathrm{~m}$ above barley plants in the field trial. Twice a week, 8 Petri dishes were placed vertically against four wind directions. After 24 hours Petri dishes were collected and incubated under NUV light (30 cm distances from the light source) at $20^{\circ} \mathrm{C}$. After 10 days the number of newly germinated Rcc colonies was counted.

\subsubsection{Monitoring spore dispersal in rain and snowfall}

In this study, the mobility and spread of Rcc inoculum through the air and over large distances was investigated. Rain samples were collected on the roof of a building at several kilometres distance from barley fields and about $30 \mathrm{~m}$ above the ground within 1 day after a rain event. Rain and snow samples were first filtered through $0.05 \mu \mathrm{m}$ filter membranes (Sartorius-Membrane filter GMBH) then membranes were transferred into $15 \mathrm{ml}$ falcon tubes containing $10 \mathrm{ml}$ of sterile TE buffer (10 mM Tris$\mathrm{Cl}, 1 \mathrm{mM}$ EDTA, $\mathrm{pH}$ 7.5). The tubes were vortexed vigorously twice for 10 minutes to detach the spores from the membranes and then centrifuged at 10,000 rpm for 30 min at $4^{\circ} \mathrm{C}$. The supernatant was discarded, and the pellet was re-suspended in 100 $\mu \mathrm{l}$ of sterile distilled water. DNA was extracted with DNeasy Plant Mini Kits (Qiagen $\mathrm{GmbH}$, Hilden, Germany). The extracted DNA was dissolved in $30 \mu$ dilution buffers and $15 \mu$ of that was used directly as a template for specific fungal detection by using specific primers for Rcc (Havis et al., 2006).

\subsubsection{Resistance screening under field conditions}

\subsubsection{Plant material}

Forty spring barley genotypes with known and unknown resistance to Rcc were evaluated against Ramularia leaf spot disease under field conditions (Table 5). 


\subsubsection{Field trials}

Field experiments were conducted under natural field conditions in two consecutive years (2009 and 2010) in Lenglern, Lower Saxony, Germany. In each year seeds were sown in a randomized complete block design and each trial had three replicates (1.5m $\times 2 \mathrm{~m}$ for each replicate). In both experiments no artificial inoculation was done and the barley cultivars only received natural inoculum. The field trial was specifically chosen for its optimal conditions for disease development. At growth stage 35-37, the fungicide Acanto (250 g/L picoxystrobin; $0.5 \mathrm{Lha}^{-1}$ ) was applied to protect the plants from the other barley pathogens.

\subsubsection{Assessment of disease symptoms}

In the year 2009, the severity of disease symptoms was evaluated on three different leaves (flag leaf, F-1, F-2) in all cultivars twice, once at early growth stage (61-65) and once at a late growth stage (73-75). At each time point, 50 plants per each replicate, were randomly harvested and screened for percentage of necrotic leaf area caused by Rcc according to Bartels et al. (2000). In the year 2010, the disease symptoms were visually assessed on the leaf $\mathrm{F}-1$ for all cultivars at growth stage 61 65 and continued weekly until the plants reached to growth stage 73-75 ( $n=150$ $\left(3^{\star} 50\right)$ for each time point).

\subsubsection{Assessment of fungal development under field conditions}

In the year 2010, in ten cultivars (Barke, IPZ 24727, Lisanne, Marthe, Nymfe, Power, Quench, Signiora, Thule, and Victoriana) with known and unknown resistance to Rcc, the amount of fungal DNA was determined at different growth stages under field conditions. For each cultivar, 50 leaves ( $F-1)$ from each replicate were collected from the field, dried in the oven at $38^{\circ} \mathrm{C}$, ground to fine powder and DNA was extracted from $1 \mathrm{~g}$ pooled material by modified CTAB protocol (Brandfass and Karlovsky 2008). Following the CTAB treatment, $400 \mu \mathrm{l}$ supernatant were transferred to a $1.5 \mathrm{ml}$ Eppendorf tube and $4 \mu \mathrm{l}$ of RNAse A of the DNeasy Plant Mini Kit (Qiagen GmbH, Hilden, Germany) was added to each tube. The DNA extraction was conducted with 
the kit according to the manual instructions. The extracted DNA was used as a template for specific fungal detection by qPCR.

\subsubsection{Determination of rubellin in naturally infected leaves from fields}

The toxin analysis was made with the help of Dr. Philip Kössler (University of Göttingen, Department of Molecular Phytopathology and Mycotoxin Research).

\subsubsection{Plant material}

In 2010, ten spring barley cultivars (Barke, IPZ 24727, Lisanne, Marthe, Nymfe, Power, Quench, Signiora, Thule, and Victoriana) were chosen to evaluate the amount of fungal toxin at different growth stages under field conditions. For each cultivar, 50 leaves $(\mathrm{F}-1)$ were collected from the field at each time point, dried in the oven at $38^{\circ} \mathrm{C}$ and ground to the fine powder. Rubellin $\mathrm{D}$ was extracted from $1 \mathrm{~g}$ pooled material.

\subsubsection{Standard Stock Solution}

The toxin (rubellin D) stock solution was prepared by Dr. Sebastian Miethbauer (Friedrich Schiller University of Jena, Germany). The solid toxin was dissolved in methanol: water $(9: 1 \mathrm{v} / \mathrm{v})$ resulting in a concentration of $1 \mathrm{mg} / \mathrm{ml}$. This mixture was further diluted in a 1:10 folds series in water: methanol $(9: 1 \mathrm{v} / \mathrm{v})$ and used as the standard solution for the optimization and calibration studies. Standard curves were calculated by linear regression.

\subsubsection{Extraction of rubellin D}

A new extraction method was used to recover rubellin $D$. The sample extraction and preparation was performed by adding $20 \mathrm{ml}$ of solvent (acetone: methanol: water; 60: 20: $20 \mathrm{v} / \mathrm{v} / \mathrm{v}$ ) to each sample. The samples were extracted by shaking for 12 hours in a lab-shaker (ADOLF KÜHNER AG, Basel, Switzerland) at $100 \mathrm{rpm}$ at room temperature. The mixture was first centrifuged for 10 minutes at $5000 \mathrm{rpm}$ then the supernatant was filtered through a filter (Apti Flow-PTFE $0.2 \mu \mathrm{l}$ ) into a new $15 \mathrm{ml}$ 
falcon tube. Two millilitre of each sample were evaporated to dryness under vacuum and resolved in $1 \mathrm{ml}$ demineralised water. Liquid-Liquid-Extraction was done by adding 1.5 volumes equivalent of ethyl acetate. One millilitre of the supernatant was transferred into a new vial and concentrated to dryness under vacuum.

A Spike calibration test was carried out by adding appropriate rubellin D stock solutions to $500 \mathrm{mg}$ non infected, freeze dried and ground barley leaves. The rubellin extraction was continued as described before.

\subsubsection{HPLC conditions}

The HPLC system consisted of a JASCO PU-2080 plus ternary pump, JASCO AS2059-SF auto sampler and a JASCO FP-2020 plus intelligent fluorescence detector. JASCO ChromPass chromatography data system (version 1.8.6.1) was used for controlling equipment and data processing. Chromatographic separation was conducted at $21^{\circ} \mathrm{C}$ on a Kinetex ${ }^{\mathrm{TM}} \mathrm{C} 18$ column, $50 \times 4,6 \mathrm{~mm}$ i.d. $2.6 \mu \mathrm{m}$ particle size (Phenomenex, Torrance, CA, USA), equipped with a C18, 4x3 mm i.d. security guard cartridge (PHENOMENEX, Torrance, CA, USA).

Both eluents (eluent $A$ : water: acetonitrile, 95:5, v/v; eluent $B$ : acetonitrile) were staggered of $7 \mathrm{mM}$ acetic acid. After an initial time of $0.25 \mathrm{~min}$ at $70 \% \mathrm{~A}$, proportions of $B$ increased linearly to $45 \%$ within $8 \mathrm{~min}$. Followed by a hold time of $4 \mathrm{~min}$ at $98 \%$ $\mathrm{B}$, the system was re-equilibrated at $70 \% \mathrm{~A}$ for $5 \mathrm{~min}$.

The constant flow rate was at $0.2 \mathrm{ml} \mathrm{min}^{-1}$. The fluorescence detector was set up at excitation and emission wavelength of 500 and $547 \mathrm{~nm}$. An injection volume of $20 \mu \mathrm{L}$ samples was chosen throughout the study. Quantification was performed by calculating peak areas. Calibration curves of rubellin in matrix (solved in $\mathrm{MeOH}$ : Water $1: 1 \mathrm{v} / \mathrm{v}$ ) were constructed in the range of $10 \mathrm{ppb}-10 \mathrm{ppm}$. 


\subsection{Statistical analyses}

Comparisons between different genotypes and mean disease scores were performed by analysis of variance (ANOVA) using Fisher's least significant difference (LSD) and considered significant at $p \leq 0.05$ in Statistica version 9.1 (Stat Soft, Inc., Tulsa, Oklahoma, USA). Different letters in the graphs indicate significant differences at a significance level of $5 \%$. Correlation coefficients (Spearman rank) were used to analyse the relationship between different genotypes and disease responses. 


\section{Results}

\subsection{In vitro cultivation of Ramularia collo-cygni}

\subsubsection{Isolation of Rcc from infected barley leaves}

Isolation of $R$. collo-cygni from the infected plants by conventional isolation methods is a challenging task due to its sensitivity to chlorine and ethanol, which are chemicals usually used for surface sterilization. Collecting young leaves at early spotting stages resulted in the successful isolation of Rcc since these are less contaminated by fast growing saprophytes. In total, 21 new Rcc isolates (nRcc 01 to nRcc 21) were isolated in 2009 from a spring barley field, which located in Lenglern, Lower Saxony, Germany (Table 6.). All new Rcc isolates were used in further experiments. Since no work has been done concerning virulence of different isolates of Rcc, a mix of isolates was used to improve the chance of a successful inoculation.

Table 6. Overview of new Ramularia collo-cygni isolates

\begin{tabular}{llcl}
\hline Isolates & Isolated from & Year of Isolation & Field Location \\
\hline nRcc1 & Spring barley cv. Barke & 2009 & Lenglern \\
nRcc2 & Spring barley cv. Barke & 2009 & Lenglern \\
nRcc3 & Spring barley cv. Barke & 2009 & Lenglern \\
nRcc4 & Spring barley cv. Barke & 2009 & Lenglern \\
nRcc5 & Spring barley cv. Barke & 2009 & Lenglern \\
nRcc6 & Spring barley cv. Barke & 2009 & Lenglern \\
nRcc7 & Spring barley cv. Barke & 2009 & Lenglern \\
nRcc8 & Spring barley cv. Barke & 2009 & Lenglern \\
nRcc9 & Spring barley cv. Hatifa & 2009 & Lenglern \\
nRcc10 & Spring barley cv. Hatifa & 2009 & Lenglern \\
nRcc11 & Spring barley cv. Hatifa & 2009 & Lenglern \\
nRcc12 & Spring barley cv. Hatifa & 2009 & Lenglern \\
nRcc13 & Spring barley cv. Hatifa & 2009 & Lenglern \\
nRcc14 & Spring barley cv. Hatifa & 2009 & Lenglern \\
nRcc15 & Spring barley cv. Hatifa & 2009 & Lenglern \\
nRcc16 & Spring barley cv. Scarlett & 2009 & Lenglern \\
\hline
\end{tabular}




\begin{tabular}{llll}
\hline nRcc17 & Spring barley cv. Scarlett & 2009 & Lenglern \\
nRcc18 & Spring barley cv. Scarlett & 2009 & Lenglern \\
nRcc19 & Spring barley cv. Scarlett & 2009 & Lenglern \\
nRcc20 & Spring barley cv. Scarlett & 2009 & Lenglern \\
nRcc21 & Spring barley cv. Scarlett & 2009 & Lenglern \\
\hline
\end{tabular}

\subsubsection{Sporulation intensity}

It is often not easy to produce enough spores for artificial inoculation from fungal isolates. Fungal species but also isolates of the same species may significantly differ in their ability to produce spores. According to the work on the other fungal pathogens, it was expected that successful infections would depend on the presence of suitable amounts of spores as inoculum. There were significant differences $(p \leq 0.05)$ among sporulation intensity of different isolates at different time points (Table 7). While isolates nRcc 02, nRcc 13 and nRcc 15 showed the lowest sporulation intensity, $\mathrm{nRcc} 18, \mathrm{nRcc} 20$ and $\mathrm{nRcc} 21$ had the highest. In the most isolates, the sporulation intensity increased from 3 days to 12 days, then dropped down until it reached the lowest amount at 18 days.

Table 7. Sporulation intensity of different $R$. collo-cygni isolates at different time points

\begin{tabular}{|c|c|c|c|c|c|c|c|c|c|}
\hline \multirow{3}{*}{$\begin{array}{l}\text { Isolate } \\
\text { nRcc } 01\end{array}$} & \multicolumn{8}{|c|}{${\text { Spores/ml }( \pm S D)^{1}}^{1}$} & \\
\hline & \multicolumn{3}{|l|}{3 dpi } & \multicolumn{3}{|l|}{$6 \mathrm{dpi}$} & \multicolumn{3}{|l|}{9 dpi } \\
\hline & 136667 & $( \pm 55275)$ & gh & 146667 & $( \pm 15275)$ & ef & 176667 & $( \pm 05774)$ & gh \\
\hline nRcc 02 & 30000 & $( \pm 10000)$ & $a b$ & 32340 & $( \pm 05652)$ & $a$ & 43333 & $( \pm 05584)$ & $\mathrm{ab}$ \\
\hline nRcc 03 & 120000 & $( \pm 11546)$ & efg & 126667 & $( \pm 05774)$ & $d$ & 143333 & $( \pm 11547)$ & ef \\
\hline nRcc 04 & 110000 & $( \pm 11000)$ & ef & 136667 & $( \pm 15275)$ & de & 160000 & $( \pm 20000)$ & $\mathrm{fg}$ \\
\hline nRcc 05 & 40000 & $( \pm 13247)$ & $a b c$ & 50000 & $( \pm 10000)$ & $\mathrm{ab}$ & 60000 & $( \pm 10000)$ & bcd \\
\hline nRcc 06 & 36667 & $( \pm 05774)$ & $a b c$ & 53333 & $( \pm 14535)$ & $a b$ & 56667 & $( \pm 05674)$ & bcd \\
\hline nRcc 07 & 60000 & $( \pm 10000)$ & $d$ & 56667 & $( \pm 05786)$ & b & 63333 & $( \pm 11547)$ & bcd \\
\hline nRcc 08 & 106667 & $( \pm 41545)$ & e & 106667 & $( \pm 05774)$ & c & 130000 & $( \pm 10000)$ & e \\
\hline nRcc 09 & 50000 & $( \pm 45000)$ & cd & 56667 & $( \pm 06702)$ & b & 73333 & $( \pm 05364)$ & $d$ \\
\hline
\end{tabular}


Continuing from previous page (Table 7)

\begin{tabular}{|c|c|c|c|c|c|c|c|c|c|}
\hline nRcc 10 & 46667 & $( \pm 15275)$ & bcd & 50000 & $( \pm 10000)$ & $\overline{a b}$ & 70000 & $( \pm 10000)$ & cd \\
\hline nRcc 11 & 140000 & $( \pm 10000)$ & hi & 156667 & $( \pm 20817)$ & $\mathrm{fg}$ & 173333 & $( \pm 15275)$ & hi \\
\hline nRcc 12 & 133333 & $( \pm 16047)$ & gh & 160000 & $( \pm 10000)$ & $\mathrm{fg}$ & 203333 & $( \pm 11547)$ & hi \\
\hline nRcc 13 & 26667 & $( \pm 45000)$ & a & 33333 & $( \pm 15275)$ & a & 33333 & $( \pm 05774)$ & $a$ \\
\hline nRcc 14 & 40000 & $( \pm 19000)$ & $a b c$ & 40000 & $( \pm 60000)$ & $a b$ & 53333 & $( \pm 05865)$ & $\mathrm{abcd}$ \\
\hline nRcc 15 & 36667 & $( \pm 15275)$ & $a b c$ & 43333 & $( \pm 16241)$ & $a b$ & 50000 & $( \pm 10000)$ & $a b c$ \\
\hline nRcc 16 & 126667 & $( \pm 13647)$ & fgh & 136667 & $( \pm 25275)$ & de & 170000 & $( \pm 26458)$ & gh \\
\hline nRcc 17 & 130000 & $( \pm 20000)$ & gh & 163333 & $( \pm 15275)$ & $\mathrm{fg}$ & 200000 & $( \pm 45000)$ & i \\
\hline nRcc 18 & 193333 & $( \pm 15865)$ & j & 200000 & $( \pm 50000)$ & h & 250000 & $( \pm 10000)$ & k \\
\hline nRcc 19 & 156667 & $( \pm 05774)$ & $\mathrm{i}$ & 170000 & $( \pm 10000)$ & g & 200000 & $( \pm 10000)$ & j \\
\hline nRcc 20 & 183333 & $( \pm 06073)$ & j & 200000 & $( \pm 45000)$ & $\mathrm{h}$ & 256667 & $( \pm 15275)$ & k \\
\hline nRcc 21 & 220000 & $( \pm 12000)$ & k & 240000 & $( \pm 11000)$ & i & 283333 & $( \pm 20817)$ & 1 \\
\hline
\end{tabular}

${ }^{1}$ Number of spores per millilitre in different Rcc isolates from 3 to 9 days after transferring to V8A medium ( $n=3)$; Values with different letters within the same column indicate significant differences $(p \leq 0.05)$ between the isolates in one point time, calculated by the LSD-Fisher test 
Continue of table 7. Sporulation intensity of different $R$. collo-cygni isolates at different time points

\begin{tabular}{|c|c|c|c|c|c|c|c|c|c|}
\hline \multirow{3}{*}{$\begin{array}{l}\text { Isolate } \\
\text { nRcc } 01\end{array}$} & \multicolumn{7}{|c|}{ 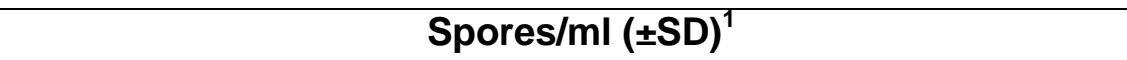 } & & \\
\hline & \multicolumn{3}{|l|}{$12 \mathrm{dpi}$} & \multicolumn{2}{|l|}{$15 \mathrm{dpi}$} & \multicolumn{3}{|c|}{$18 \mathrm{dpi}$} & \\
\hline & 250000 & $( \pm 10000)$ & de & 216667 & $( \pm 25166)$ & def & 56667 & $( \pm 05774)$ & def \\
\hline nRcc 02 & 60000 & $( \pm 20000)$ & $a$ & 46667 & $( \pm 11547)$ & $a$ & 3333 & $( \pm 03571)$ & $a$ \\
\hline $\mathrm{nRcc} 03$ & 190000 & $( \pm 26458)$ & bc & 186667 & $( \pm 53651)$ & $\mathrm{cd}$ & 46667 & $( \pm 04236)$ & $c d$ \\
\hline nRcc 04 & 206667 & $( \pm 25166)$ & bcd & 203333 & $( \pm 20817)$ & de & 50000 & $( \pm 10000)$ & cde \\
\hline nRcc 05 & 76667 & $( \pm 05897)$ & a & 73333 & $( \pm 15275)$ & $\mathrm{ab}$ & 13333 & $( \pm 22913)$ & $a b$ \\
\hline nRcc 06 & 63333 & $( \pm 05774)$ & $a$ & 65000 & $( \pm 22913)$ & $a b$ & 10000 & $( \pm 10000)$ & $a b$ \\
\hline nRcc 07 & 90000 & $( \pm 10000)$ & a & 83333 & $( \pm 11547)$ & b & 20000 & $( \pm 25166)$ & b \\
\hline nRcc 08 & 176667 & $( \pm 06524)$ & $\mathrm{b}$ & 156667 & $( \pm 63240)$ & c & 40000 & $( \pm 02365)$ & c \\
\hline nRcc 09 & 80000 & $( \pm 10000)$ & $a$ & 83333 & $( \pm 11568)$ & b & 6667 & $( \pm 11547)$ & $a$ \\
\hline nRcc 10 & 96667 & $( \pm 15275)$ & a & 73333 & $( \pm 15125)$ & $\mathrm{ab}$ & 10000 & $( \pm 10000)$ & $a b$ \\
\hline nRcc 11 & 253333 & $( \pm 16324)$ & de & 213333 & $( \pm 32146)$ & efg & 82667 & $( \pm 08327)$ & ef \\
\hline nRcc 12 & 343333 & $( \pm 18975)$ & $\mathrm{fg}$ & 236667 & $( \pm 15275)$ & fg & 62667 & $( \pm 04619)$ & ef \\
\hline nRcc 13 & 53333 & $( \pm 06746)$ & a & 46667 & $( \pm 20817)$ & a & 10000 & $( \pm 10000)$ & $\mathrm{ab}$ \\
\hline nRcc 14 & 60000 & $( \pm 20000)$ & $a$ & 56663 & $( \pm 17852)$ & $\mathrm{ab}$ & 10000 & $( \pm 10000)$ & $\mathrm{ab}$ \\
\hline nRcc 15 & 60000 & $( \pm 17321)$ & $a$ & 43333 & $( \pm 25166)$ & $a b$ & 2333 & $( \pm 45000)$ & $a$ \\
\hline nRcc 16 & 240000 & $( \pm 43589)$ & cde & 203333 & $( \pm 20817)$ & de & 50000 & $( \pm 10000)$ & cde \\
\hline nRcc 17 & 280000 & $( \pm 75498)$ & ef & 243333 & $( \pm 25166)$ & $\mathrm{fg}$ & 63333 & $( \pm 06521)$ & $f$ \\
\hline nRcc 18 & 356667 & $( \pm 45092)$ & gh & 296667 & $( \pm 11536)$ & $\mathrm{h}$ & 76667 & $( \pm 06954)$ & g \\
\hline nRcc 19 & 366667 & $( \pm 20817)$ & gh & 253333 & $( \pm 17625)$ & $g$ & 66000 & $( \pm 05292)$ & fg \\
\hline nRcc 20 & 406667 & $( \pm 51316)$ & $\mathrm{h}$ & 296667 & $( \pm 19651)$ & $\mathrm{h}$ & 83333 & $( \pm 06354)$ & $\mathrm{g}$ \\
\hline nRcc 21 & 383333 & $( \pm 87369)$ & gh & 356667 & $( \pm 18635)$ & i & 93333 & $( \pm 45000)$ & $\mathrm{h}$ \\
\hline
\end{tabular}

${ }^{1}$ Number of spores per millilitre in Rcc isolates from 12 to 18 days after transferring to V8A medium $(n=3)$; Values with different letters within the same column indicate significant differences $(p \leq 0.05)$ between the isolates in one time point, calculated by the LSD-Fisher test 
In a parallel study, the sporulation of different Rcc isolates was studied after transferring them from long storage media at $-80^{\circ} \mathrm{C}$ to the new medium. The sporulation intensity varied among the isolates after the first transfer but the sporulation behaviour was also different between different isolates (Table 8). Great significant differences were observed after the second transfer onto new V8-A media. In most isolates no significant differences were found from second to the third transfer.

Table 8. Sporulation of different $R$. collo-cygni isolates after transferring them from long storage medium at $-80^{\circ} \mathrm{C}$ to the new medium and afterwards sub culturing them twice to the new media

\begin{tabular}{|c|c|c|c|c|c|c|c|c|c|}
\hline \multirow{3}{*}{$\begin{array}{l}\text { Isolate } \\
\text { nRcc } 01\end{array}$} & \multicolumn{8}{|c|}{ Spores/ml ( $( \pm S D)^{1}$} & \\
\hline & \multicolumn{2}{|c|}{$1^{\text {st }}$ transfer } & \multirow[b]{2}{*}{$\mathrm{abc} B$} & \multicolumn{2}{|c|}{$2^{\text {nd }}$ transfer } & \multicolumn{4}{|c|}{$3^{d}$ transfer } \\
\hline & 106667 & $( \pm 20817)$ & & 250000 & $( \pm 10000)$ & $\mathrm{ab} A$ & 263333 & $( \pm 37859)$ & a A \\
\hline nRcc 03 & 73333 & $( \pm 16355)$ & a B & 190000 & $( \pm 26458)$ & a A & 193333 & $( \pm 38671)$ & a A \\
\hline nRcc 08 & 83333 & $( \pm 15275)$ & $\mathrm{ab} A$ & 156667 & $( \pm 30551)$ & $c B$ & 223333 & $( \pm 33549)$ & a C \\
\hline $\mathrm{nRcc} 12$ & 113333 & $( \pm 25166)$ & $\mathrm{bc} B$ & 253333 & $( \pm 40415)$ & $\mathrm{ab} A$ & 286667 & $( \pm 49329)$ & a A \\
\hline nRcc 19 & 180000 & $( \pm 10000)$ & $d A$ & 290000 & $( \pm 55678)$ & $\mathrm{bd} A \mathrm{AB}$ & 383333 & $( \pm 80208)$ & bB \\
\hline $\mathrm{nRcc} 21$ & 203333 & $( \pm 45092)$ & $\mathrm{cd} \mathrm{B}$ & 350000 & $( \pm 36056)$ & $d A$ & 343333 & $( \pm 40415)$ & b A \\
\hline
\end{tabular}

${ }^{1}$ Number of spores per millilitre in Rcc isolates after transferring them first from $-80^{\circ} \mathrm{C}$ to new V8A medium and afterwards sub culturing them twice to the new media $(n=3)$; Values with different small letters within the same column indicate significant differences $(p \leq 0.05)$ between the isolates in one time point, values with different capital letter within the same row indicate significant differences $(p \leq 0.05)$ between the isolates after $1^{\text {st }}, 2^{\text {nd }}$ and $3^{\text {d }}$ transfer; calculated by the LSD-Fisher test

\subsection{Detection methods}

\subsubsection{Disease phenotyping on spring barley lines under field conditions}

In this project different spring barley cultivars were screened under field conditions for percentage of necrotic leaf area caused by Rcc according to the rating scale of 
Bartels et al. (2000). In June 2009, barley cultivars were screened for the first time on the field in Lenglern, Lower Saxony, Germany. At GS 61-65, the first symptoms were hardly visible in older leaves. After two weeks, the symptoms (necrotic spots with yellow hallo) were visible on the whole plant and one week later the plants were completely covered with necrotic spots and the leaves were getting dry (Fig. 2).
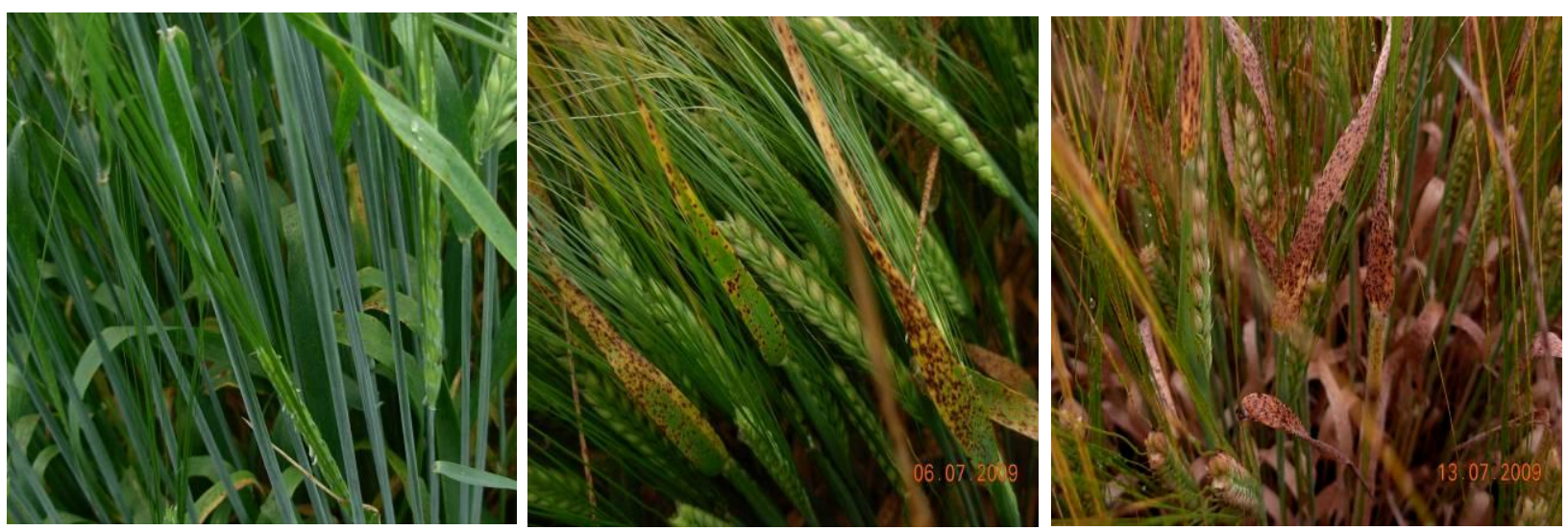

Figure 2. Ramularia leaf spot symptoms in the field (Lenglern, Lower Saxony, Germany) cv. Barke. The first symptoms were visible on 25 June 2009 (left). Two weeks later, on 6 July 2009, plants were covered with necrotic spots which were surrounded by yellow halos (centre). Finally, on 13 July 2009, high disease severity was observed in the field and leaves were getting completely necrotic (right).

Under field conditions, on the abaxial surface of the dead leaf, bunches of bright and white conidiophores carrying conidia emerging from stomata parallel to the leaf veins were observed (Fig. 3).

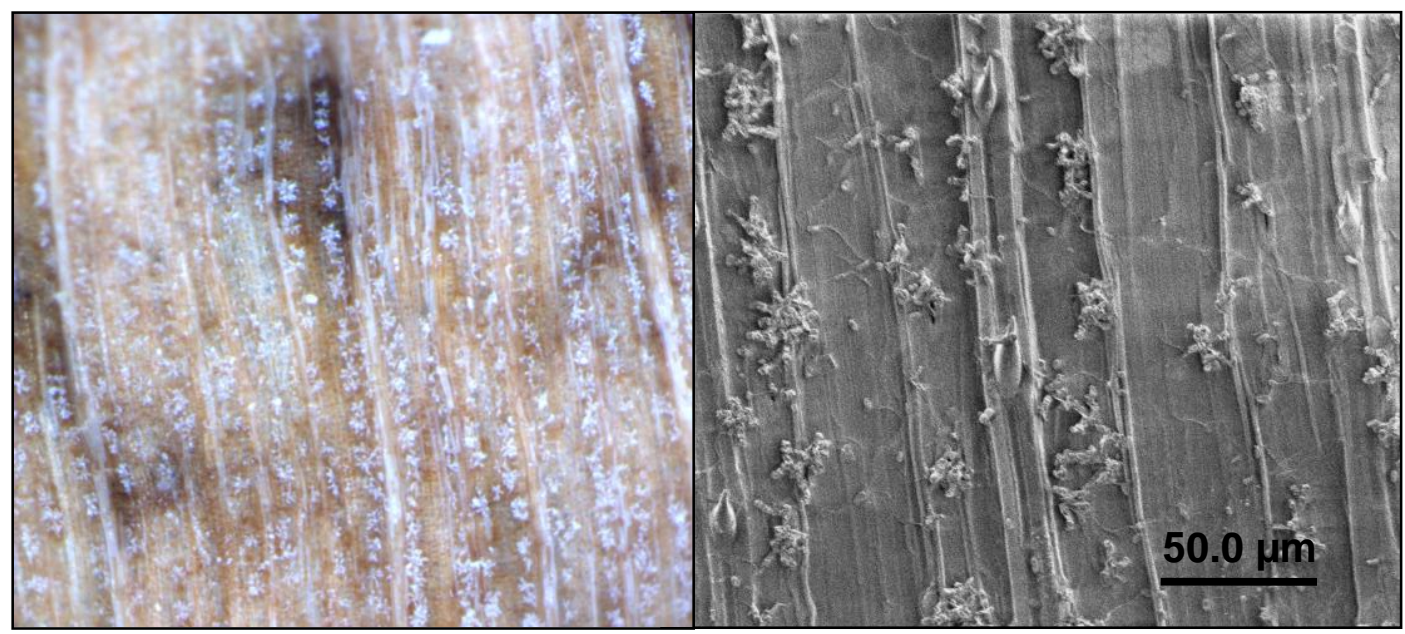

Figure 3. Fungal structure on the abaxial surface of a barley leaf (left: optical microscope; right: environmental scanning electron microscope) 


\subsubsection{Analysis of extracted DNA and PCR amplification}

Extraction of DNA from pure fungal isolates and plant materials was carried out by using the Qiagen DNeasy Plant Mini Kit, which gave the most reliable and reproducible results, in terms of a good quality and quantity of DNA yield. Optimised PCR reaction results in a 426 bp fragment which was amplified by Rcc1 and Rcc5b primers. PCR products, which generated by amplifying different amounts of pure Rcc DNA, was observed on ethidium bromide stained agarose gel until $0.1 \mathrm{pg}$ of DNA (Fig. 4).

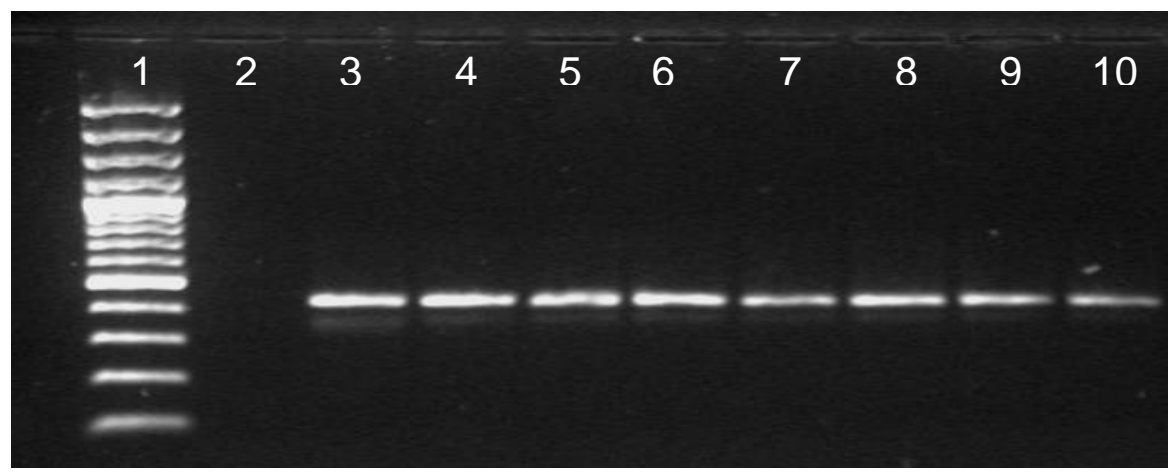

Figure 4. Specificity of the primer pair Rcc1 and Rcc5b for the amplification of a $426 \mathrm{bp}$ fragment of Ramularia collo-cygni. An ethidium bromide-stained agarose gel of PCR products amplified from different dilution series of pure Rcc DNA. Lanes: 1) 100-bp DNA ladder Plus (Fermentas) ; 2) negative control; 3) 1 ng; 4) 100 pg; 5) 50 pg; 6) 25 pg; 7) 10 pg; 8) $5 \mathrm{pg}$; 9) $1 \mathrm{pg}$; 10) $0.1 \mathrm{pg}$

\subsection{Quantitative molecular diagnosis of Rcc}

\subsubsection{Specificity and sensitivity of primers}

Rcc1 and Rcc 5b were previously described by Havis et al. (2006) as specific primers for Rcc. These primers again were evaluated against Rcc isolates from different regions and other fungal and host and non host plant DNAs, using identical amplification conditions as described in 2.5.7. No other products than Rcc were detected from any of the other pathogens or the plant samples.

The spike test was carried out to check the matrix effects and influence of plant genomic DNA on amplification of Rcc DNA. By using a specific concentration of non infected plant genomic DNA (20 ng) which was 200, 2000 and 20000 times more 
than the target DNA (100,10 and $1 \mathrm{pg}$ ) with a regression coefficient of 0.953 , it was greatly confirmed a high degree of sensitivity of the primers in detecting Rcc DNA among other samples (Fig. 5). While plant genomic DNA does not affect PCR reactions targeting fungal DNA, an optimised fungal DNA standard curve was used for the evaluation of the fungal development inside the plants under field conditions.

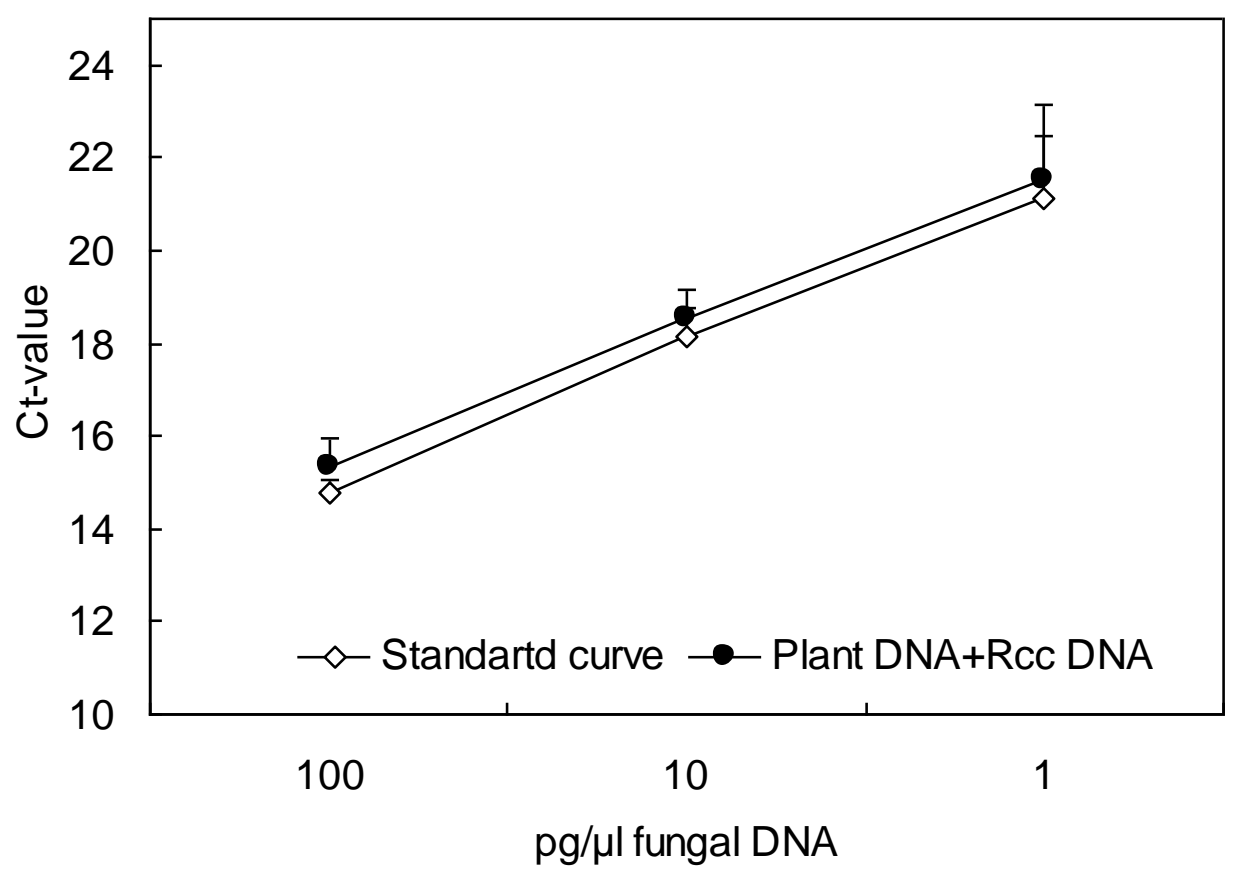

Figure 5. Spike test analysis curves with different amounts of Rcc DNA (100, 10 and $1 \mathrm{pg} / \mu \mathrm{l})$ mixed with $20 \mathrm{ng}$ of non infected barley plant DNA; $y=3.496^{*} x+19.983, R^{2}=0.953$

\subsubsection{Optimising quantitative real-time PCR}

To optimise the protocol of qPCR to detect the maximum amount of fungal DNA in terms of specificity and sensitivity, a temperature gradient qPCR was carried out to determine the optimal annealing temperature for the Rcc primer system. Rcc1 and Rcc5b performed well in speculative evaluation of annealing temperature which was finally set at $68^{\circ} \mathrm{C}$.

The standard curve was made by evaluating the $C_{t}$ values against known serial dilutions of DNA from Rcc pure DNA. The lowest amount of Rcc DNA which was successfully amplified was $0.001 \mathrm{pg}$ at 36 amplification cycles. Additionally, $C_{t}$ values 
were not statistically different between the DNA replicates $(p \leq 0.05)$. The PCR product amplified from $1 \mathrm{ng}$ fungal DNA was already detected at a $C_{t}$ value of 11.2 and continued to 31.7 for $0.001 \mathrm{pg}$ (Table 9).

Table 9. $C_{t}$-values of Rcc standard curves from qPCR amplification

\begin{tabular}{ll}
\hline Pure Rcc DNA concentration $(\mathrm{pg} / \mu \mathrm{l})$ & $\mathrm{C}_{\mathrm{t}}$ value $( \pm \mathrm{SD})^{1}$ \\
\hline 1000 & $11.20( \pm 0.14)$ \\
100 & $14.65( \pm 0.21)$ \\
10 & $18.30( \pm 0.85)$ \\
1 & $23.25( \pm 0.35)$ \\
0.1 & $26.05( \pm 0.21)$ \\
0.01 & $28.40( \pm 0.71)$ \\
0.001 & $31.70( \pm 0.28)$ \\
\hline
\end{tabular}

${ }^{1}$ Threshold cycle \pm Standard deviation $(n=3)$

Accordingly, a strong correlation coefficient was found $\left(R^{2}=0.994\right)$ in standard curves of different serial dilutions, while curve efficiency was about $99.0 \%$ (Fig. 6). The unknown amount of Rcc DNA inside the plants was calculated by equating $C_{t}$ values to standard curves with the exact amount of fungal DNA. The specificity of PCR amplification was measured by analysing the melting curves of double-stranded DNA. The maximum melting temperature was at $91.7^{\circ} \mathrm{C}$. 


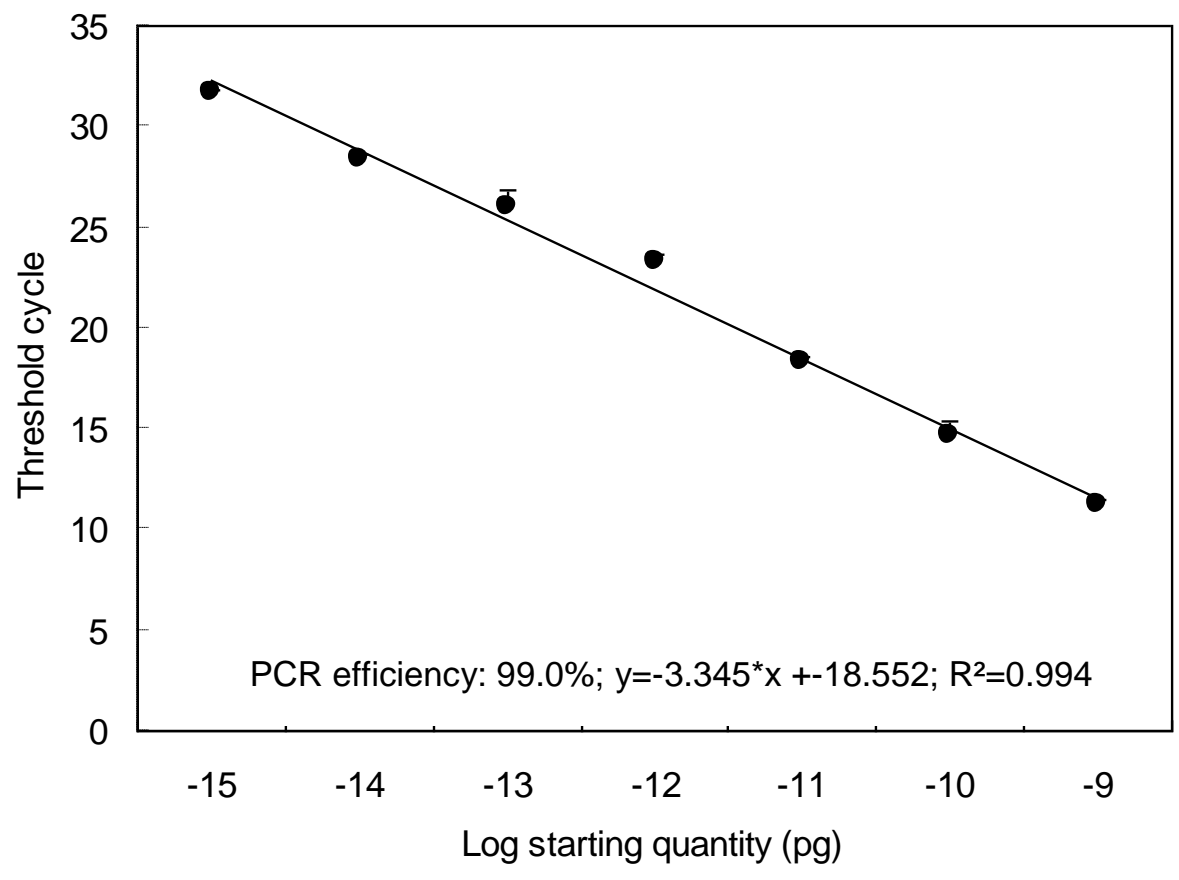

Figure 6. Standard curve of serial dilutions of Rcc genomic DNA amplified with Rcc1 and Rcc $5 b$ primers. Data are means of 3 replicates $( \pm S D)$.

\subsection{Experiments under controlled conditions}

\subsubsection{Rcc development from seed to emerging plant}

The recent development of rapid and reliable methods for detection of Rcc using PCR will make it easier to detect the pathogen in barley crops and should lead to increase information on its epidemiology. This is crucial for the development of reliable systems for disease forecasting and improved disease control.

The present study confirmed the latent occurrence of the fungus during all plant growth stages as well as in seeds. Seeds, which harvested from a severely infected barley field were analysed with PCR and showed high incidence of latent infestation. The seeds were sown in pots and kept under controlled environmental conditions. Plants grown from such seeds were analysed at different growth stages from seedling stage to maturity by qualitative PCR. Analyses revealed the transmission of the fungus from seeds into emerging plants and confirmed the further spread of the fungus in adult plants in a symptomless manner. Under greenhouse conditions, the 
symptomless stage of RLS persisted throughout the first generation of plants emerging from infested seeds until maturity and grain formation (Fig. 7)
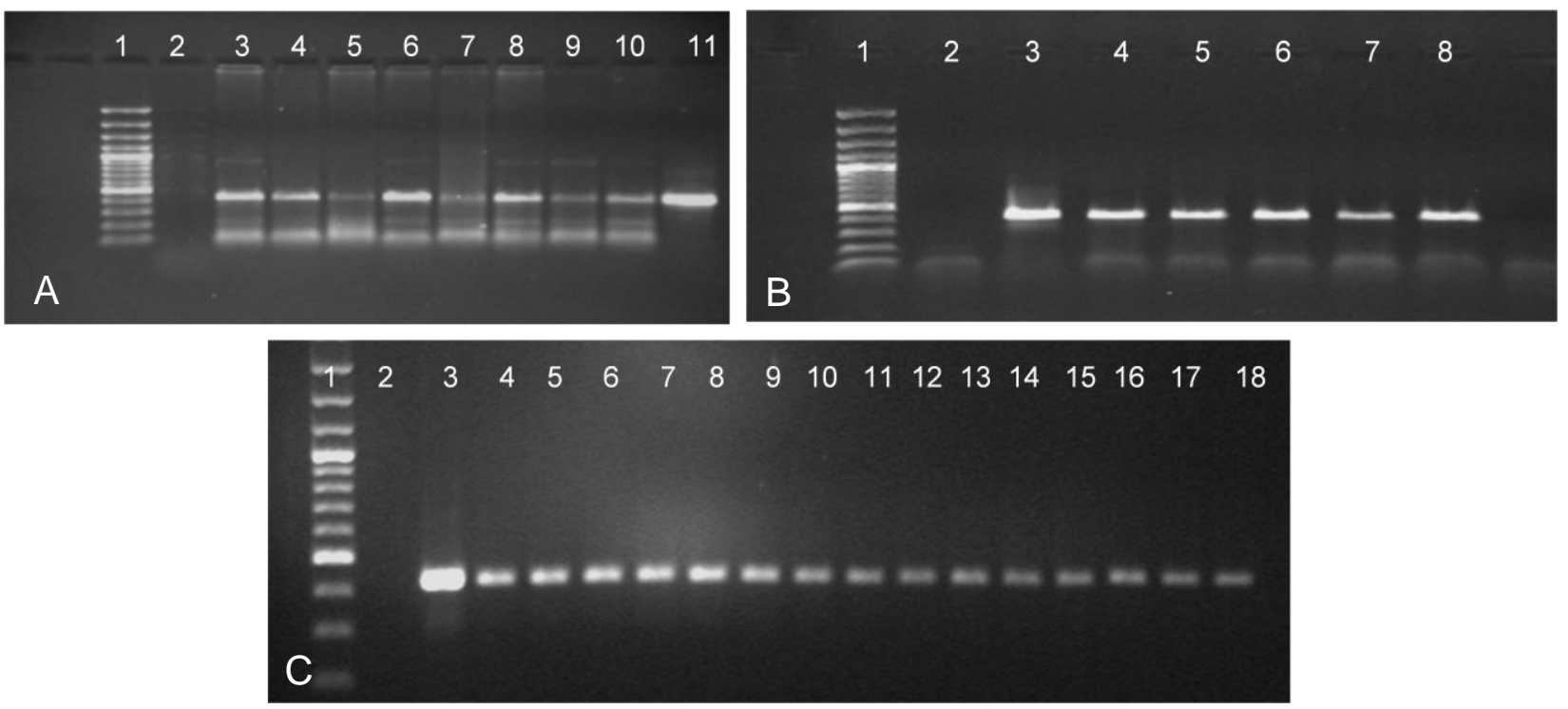

Figure 7. Transmission of the fungus from seeds into emerging plants and first generation seeds. Ethidium bromide-stained agarose gels of Rcc DNA detected by PCR from different plant samples at different growth stages. A: 1) 100-bp DNA ladder Plus (Fermentas); 2) negative control; $3-10$ ) plant samples at GS 11-12; 11) positive control (pure Rcc DNA); $\mathbf{B}: 1$ ) 100-bp DNA ladder Plus (Fermentas); 2) negative control; 3) positive control (pure Rcc DNA); 4-8) plant samples at GS 33-35; C: 1) 100-bp DNA ladder Plus (Fermentas); 2) negative control; 3) positive control (pure Rcc DNA); 4-18) plant samples at GS 69-75; 4-7) F-2 leaves; 8-11) F-1 leaves;12-15) flag leaves; 16-18) first generation seeds.

\subsubsection{Seed disinfestations by hot water treatment}

It was clear that one way for plant pathogens infecting a crop is through the infested seeds. Therefore it is very important to start with "clean" seeds (i.e. those which free of pathogens). During the hot water-treatment of barley seeds, it is critical to follow the instructions exactly, as seeds may be damaged by the treatment and/or the pathogen may not be completely eliminated. Therefore, it is recommended that a small sample be treated and tested for germination prior to treating the entire seed lot. Results indicated that the percentage of seed germination was significantly reduced by increasing the temperature and duration of the treatment (Table 10). The 
strongest damage occurred at $52^{\circ} \mathrm{C}$, when the percentage of seed germination dropped to $53.8 \%$ after $5 \mathrm{~min}$ treatment and decreased to less than $5 \%$ after $30 \mathrm{~min}$. The best results were observed at $48^{\circ} \mathrm{C}$ for $5 \mathrm{~min}$ with $80.4 \%$ seed germination.

Table 10. Effect of treatment temperature and treatment duration on barley seed germination

\begin{tabular}{|c|c|c|c|c|c|c|c|c|c|}
\hline \multirow{3}{*}{$\begin{array}{l}\text { Duration } \\
(\min )\end{array}$} & \multicolumn{8}{|c|}{ Seed germination $\%( \pm S D)^{1}$} & \\
\hline & \multicolumn{2}{|l|}{$48^{\circ} \mathrm{C}$} & & \multicolumn{2}{|c|}{$50^{\circ} \mathrm{C}$} & \multicolumn{4}{|c|}{$52^{\circ} \mathrm{C}$} \\
\hline & 92.8 & $( \pm 2.77)$ & gA & 93.2 & $( \pm 1.78)$ & $\mathrm{fA}$ & 91.6 & $( \pm 02.07)$ & $f A$ \\
\hline 5 & 80.4 & $( \pm 5.22)$ & $f B$ & 61.4 & $( \pm 4.82)$ & eA & 53.8 & $( \pm 08.46)$ & e A \\
\hline 10 & 53.8 & $( \pm 3.70)$ & e C & 46.1 & $( \pm 5.94)$ & $d B$ & 29.4 & $( \pm 4.03)$ & $d A$ \\
\hline 15 & 23.8 & $( \pm 3.11)$ & $d A$ & 25 & $( \pm 3.16)$ & cA & 14.8 & $( \pm 3.34)$ & $c B$ \\
\hline 20 & 14.8 & $( \pm 3.27)$ & $c B$ & 9 & $( \pm 2.23)$ & a A & 5.8 & $( \pm 1.64)$ & b A \\
\hline 25 & 5.4 & $( \pm 3.20)$ & $b B$ & 5 & $( \pm 1.58)$ & a $A B$ & 1.8 & $( \pm 1.92)$ & $\mathrm{ab} A$ \\
\hline 30 & 1 & $( \pm 0.70)$ & a A & 0.6 & $( \pm 0.54)$ & b A & 0.6 & $( \pm 0.54)$ & a A \\
\hline
\end{tabular}

${ }^{1}$ Percentage of barley seed germination after different hot water treatments $(n=50)$; Values with different small letter within the same column indicate significant differences $(p \leq 0.05)$ between different duration treatment at one temperature, values with different capital letter within the same row indicate significant differences $(p \leq 0.05)$ between the different temperature at one duration time; calculated by the LSD-Fisher test

\subsubsection{Elimination of fungal development from infested seeds by hot water}

For this study, infected seeds cv. Barke was divided into two parts. One part receiving hot water treatment at $48^{\circ} \mathrm{C}$ for five minutes and one part as a control without any treatment were sown in pots. Plants grown from these seeds were harvested at different growth stages, i. e. from seedling stage to maturity and checked for presence of the pathogen inside the plant by qualitative PCR. At GS 10, apparently the hot water treatment could successfully eliminate the fungal development inside the plants (Fig. 8). 


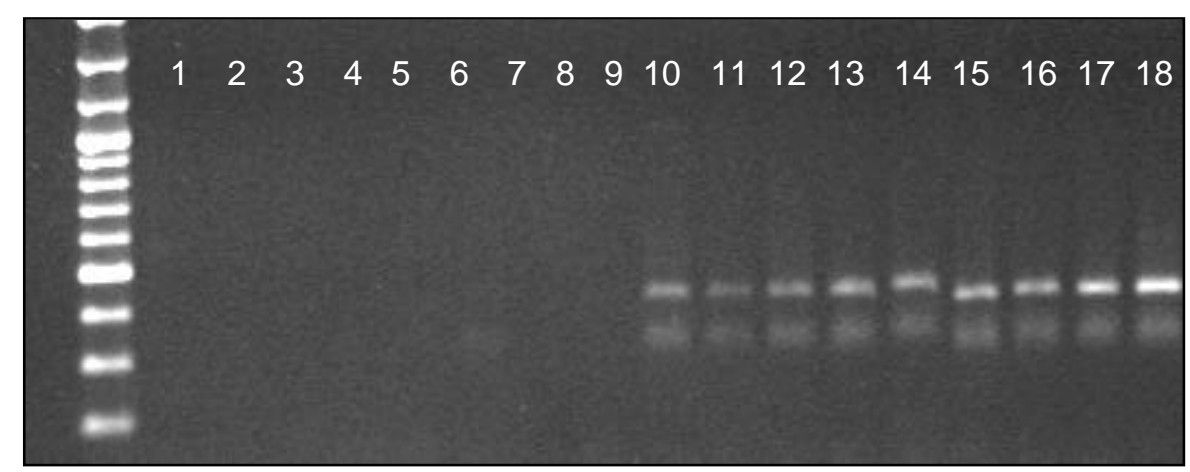

Figure 8. Gel electrophoresis of Rcc DNA detected by PCR from spring barley leaves (cv. Barke) at plant developmental stage GS 10 after hot water treatment. Lanes: 100-bp DNA ladder Plus (Fermentas); 1) negative control; 2-9) plant samples from hot water treatment; 10-17) samples without any treatments; 18) positive control (pure Rcc DNA)

At later growth stages, the application of hot water treatment of seed did not appear to eliminate the presence of Rcc or impair the transfer of the pathogen into the developing plant (Fig.9).

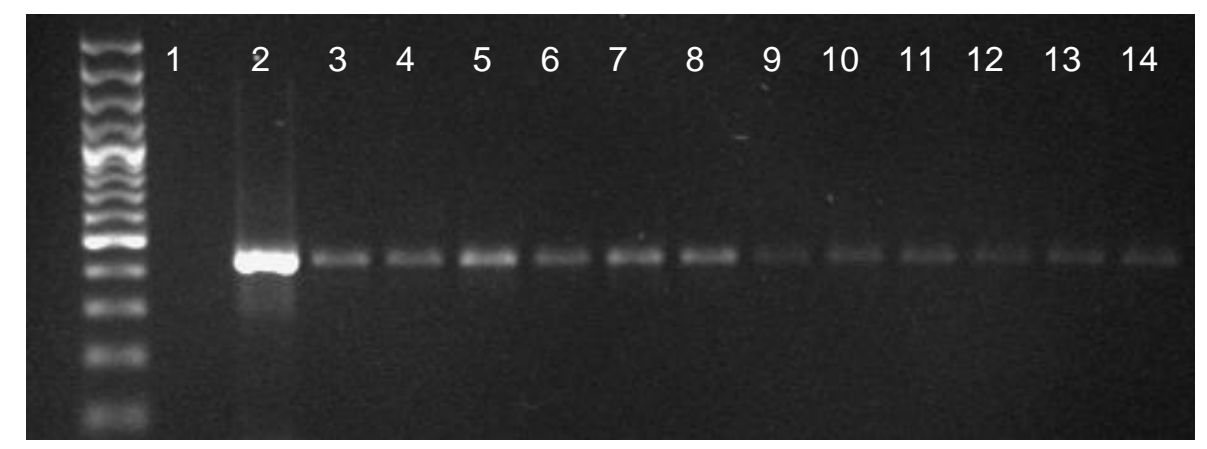

Figure 9. Gel electrophoresis of Rcc DNA detected at GS 61-65 in F-1 leaves of spring barley (cv. Barke) by PCR. Lanes: 100-bp DNA ladder Plus (Fermentas); 1) negative control; 2) positive control (pure Rcc DNA) 3-8) samples without any treatments; 9-14) plant samples from seed hot water treatment

\subsubsection{Efficacy of seed dressing and foliar fungicide application}

Results from our previous studies gave clear evidence for a systemic symptomless growth of the fungus from contaminated seeds into emerging plants. The fungus spread into shoots and leaves and finally into grains in a symptomless manner. Similar results were obtained by other groups suggesting that RLS is a seed-borne 
disease. However, there is no direct proof that seed contamination is a key factor for the outbreak of RLS epidemics in the field. In order to evaluate the importance of latent seed-borne infection vs. leaf infection with airborne conidia, seed dressings and consecutive applications of foliar fungicides was used during plant development to produce pathogen-free plants and seeds. Results of QPCR from plant samples at GS 13 demonstrated that between the three different seed dressing fungicides, Zardex G (cyproconazole and imazalil, 300ml/dt) was the most efficient (Fig. 10).

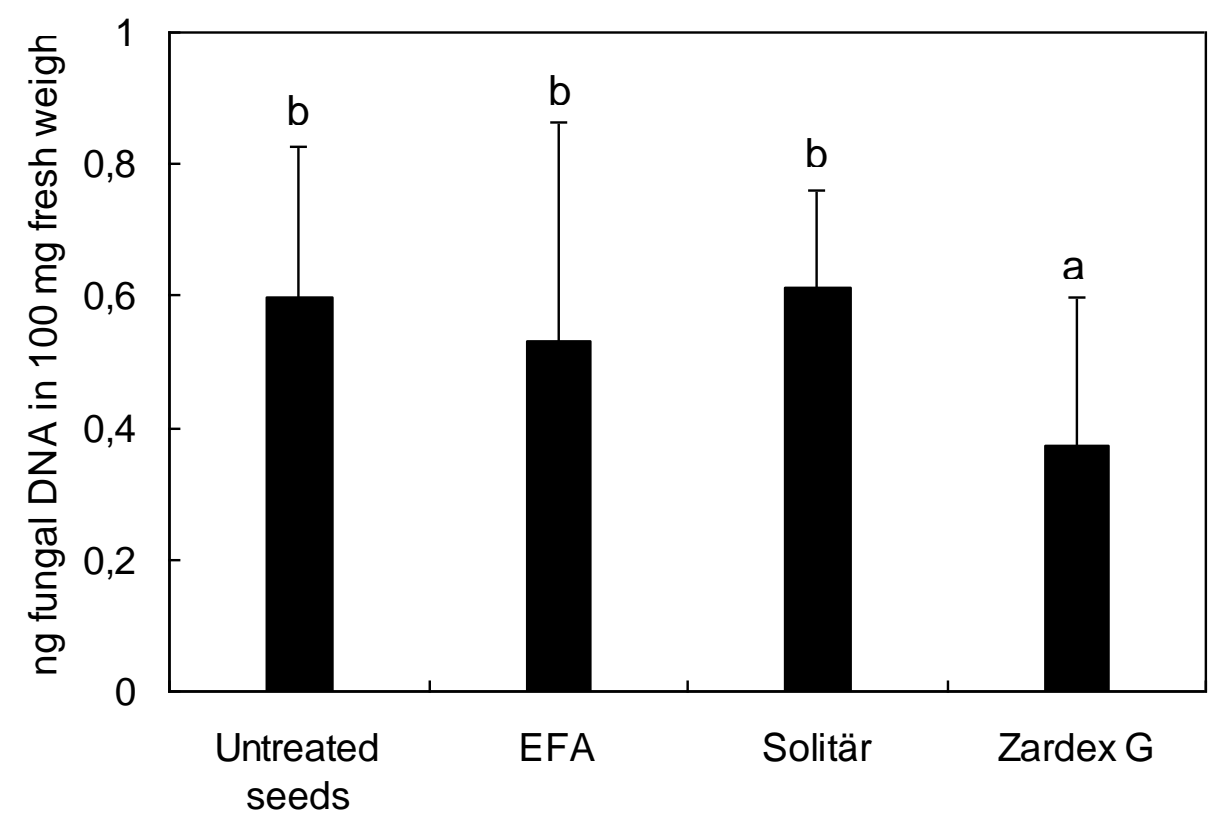

Seed dressing application

Figure 10. Efficacy of different fungicide seed treatments on Rcc development inside the leaves of spring barley (cv. Barke) at plant growth stage GS 13. Mean of ten samples are given with standard deviations. Values with different letter indicate significant differences ( $p \leq$ $0.05)$ between treatments; calculated by the LSD-Fisher test

The systemic foliar fungicide Proline (prothioconazole) controlled fungal systemic spread during different growth stages. Final results have shown that neither seed dressing with fungicide, nor foliar fungicide had a complete effect on fungal development inside the plants when they were used separately (Fig. 11). 


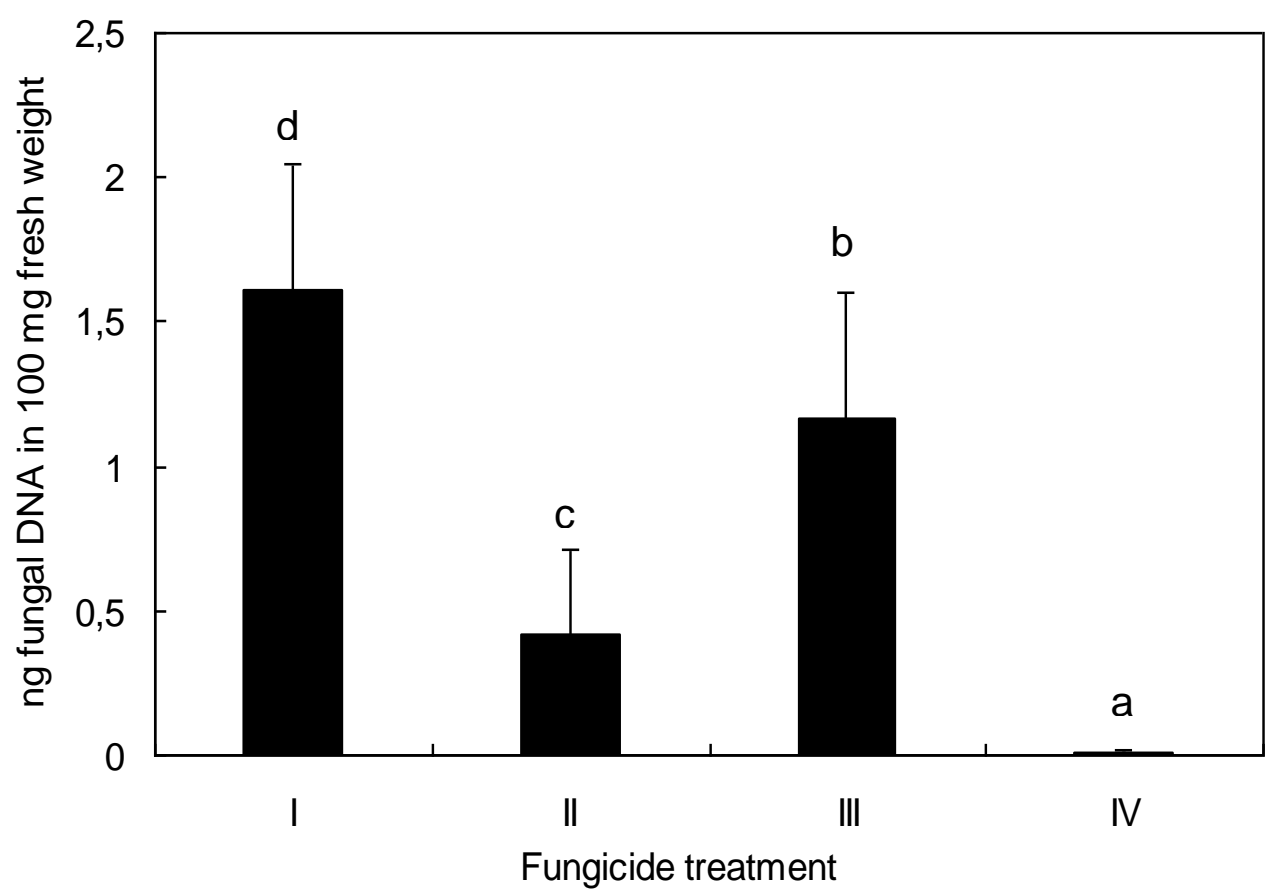

Figure 11. Influence of seed treatment (Zardex G: cyproconazole $5 \mathrm{~g} / \mathrm{L}$ and imazalil $20 \mathrm{~g} / \mathrm{L}$; $300 \mathrm{ml} / \mathrm{dt}$ ) and foliar fungicide application (Proline: prothioconazole $250 \mathrm{~g} / \mathrm{L} ; 0.8 \mathrm{l} / \mathrm{ha}$ ) on Rcc development in barley leaves (cv. Barke) at plant growth stage GS 39-41; Mean of ten individual samples are given with standard deviations. Values with different letter indicate significant differences $(p \leq 0.05)$ between treatments; calculated by the LSD-Fisher test I) Untreated seeds; II) Untreated seeds with foliar application (Proline: prothioconazole 250 g/L; $0.8 \mathrm{I} / \mathrm{ha}$ ) at GS 39-41: III) Treated seeds with Zardex G without foliar application; V) Treated seeds with foliar application (Proline: prothioconazole $250 \mathrm{~g} / \mathrm{L} ; 0.8 \mathrm{l} / \mathrm{ha}$ ) at GS 39-41

Using Zardex $G$ before sowing the seeds and applying Proline at early growth stages (39-41) had the strongest inhibitory effect on fungal development inside the plants. The application of Proline at later growth stages (65-69) gave a lower level of control (Fig. 12). 


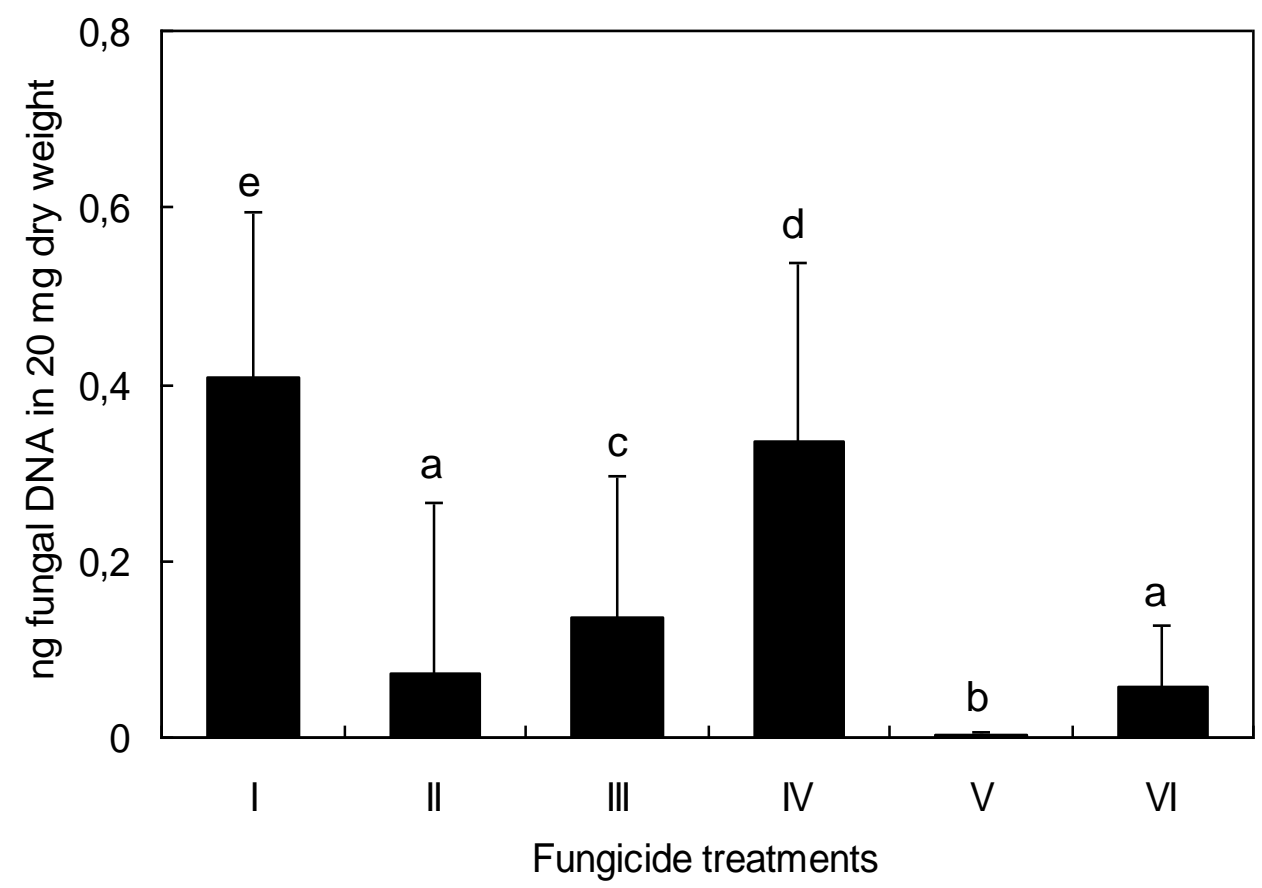

Figure 12. Importance of seed treatment (Zardex G: cyproconazole $5 \mathrm{~g} / \mathrm{L}$ and imazalil 20 $\mathrm{g} / \mathrm{L} ; 300 \mathrm{ml} / \mathrm{dt}$ ) and applying foliar fungicide application (Proline: prothioconazole $250 \mathrm{~g} / \mathrm{L} ; 0.8$ $\mathrm{I} / \mathrm{ha}$ ) at different growth stages on Rcc development into first generation seeds; Mean of ten individual samples are given with standard deviations. Values with different letter indicate significant differences ( $p \leq 0.05$ ) between treatments; calculated by the LSD-Fisher test

I) Untreated seeds; II) Untreated seeds with foliar application (Proline: prothioconazole 250 $\mathrm{g} / \mathrm{L} ; 0.8 \mathrm{l} / \mathrm{ha}$ ) at GS 39-41; III) Untreated seeds with foliar application (Proline: prothioconazole $250 \mathrm{~g} / \mathrm{L} ; 0.8 \mathrm{I} / \mathrm{ha}$ ) at GS 65-69; IV) Treated seeds (Zardex G: cyproconazole $5 \mathrm{~g} / \mathrm{L}$ and imazalil $20 \mathrm{~g} / \mathrm{L} ; 300 \mathrm{ml} / \mathrm{dt}$ ) without any foliar applications; V) Treated seeds (Zardex G: cyproconazole $5 \mathrm{~g} / \mathrm{L}$ and imazalil $20 \mathrm{~g} / \mathrm{L} ; 300 \mathrm{ml} / \mathrm{dt}$ ) with foliar application (Proline: prothioconazole $250 \mathrm{~g} / \mathrm{L} ; 0.8 \mathrm{l} / \mathrm{ha}$ ) at GS 39-41; VI) Treated seeds (Zardex G: cyproconazole $5 \mathrm{~g} / \mathrm{L}$ and imazalil $20 \mathrm{~g} / \mathrm{L} ; 300 \mathrm{ml} / \mathrm{dt}$ ) with foliar application (Proline: prothioconazole $250 \mathrm{~g} / \mathrm{L}$; $0.8 \mathrm{l} / \mathrm{ha}$ ) at GS 65-69

\subsubsection{Resistance evaluation at different plant growth stages}

This experiment was carried out to find authentic and functional methods for producing symptoms by artificial inoculation under controlled environmental conditions to evaluate resistance in different barley cultivars against Rcc. Four different cultivars of spring barley (Barke, Hatifa, IPZ 24727 and Lisanne) were evaluated for RLS. Plants were inoculated at different growth stages kept under 
controlled greenhouse conditions and disease symptoms were scored 18 days post inoculation. Significant differences $(p \leq 0.05)$ among different spring barley genotypes were observed under controlled greenhouse conditions when the plants were inoculated at the older growth stages. The level of necrosis on leaves caused by Rcc significantly depended on the age of the plant at the inoculation time. Leaves which were at the younger growth stages (less than GS 45-49) had significantly lower levels of necrosis than leaves that were at the older growth stages. At earlier growth stages no symptoms were observed. The first symptoms were visible at GS 41-45 and increased at GS 49-51(Fig. 13).

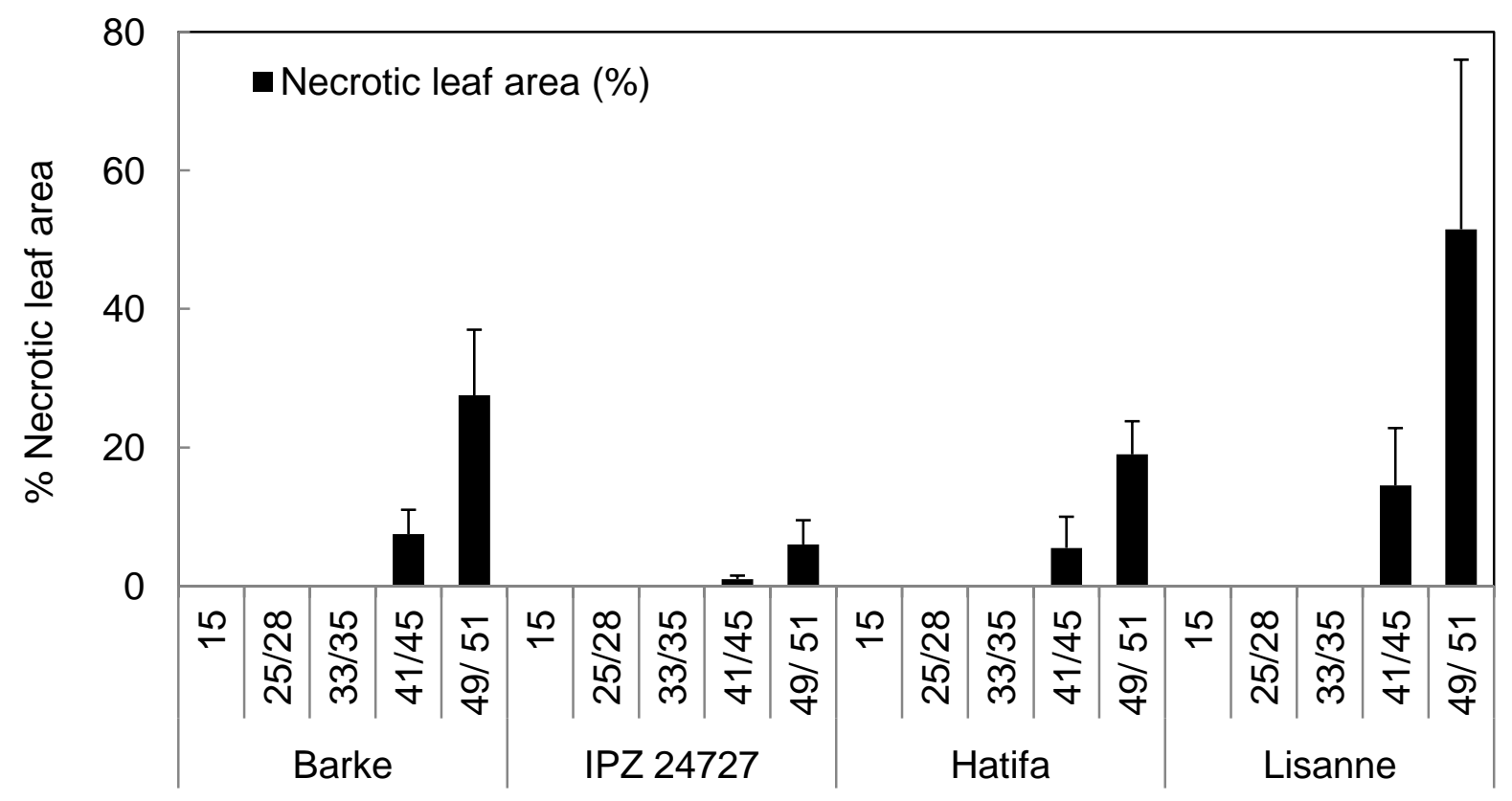

Different growth stages at the time of inoculation

Figure 13. Susceptibility of four different spring barley cultivars to Rcc inoculation at different growth stages. Plants were evenly sprayed with a fine mist of spore-mycelia suspension at different growth stages (15, 25-28, 33-35, 41-45 and 49-51). The percentage of necrotic leaf area caused by RLS on leaf F-1 was scored at 18 dpi. Means of twenty individual leaves (F1) are given with standard deviations.

The increased susceptibility to Rcc in further developed plants was closely studied at growth stage $49-51$ by scoring the percentage of disease development on leaf $\mathrm{F}-1$, from 3 to 18 days after inoculation (Fig. 14). 


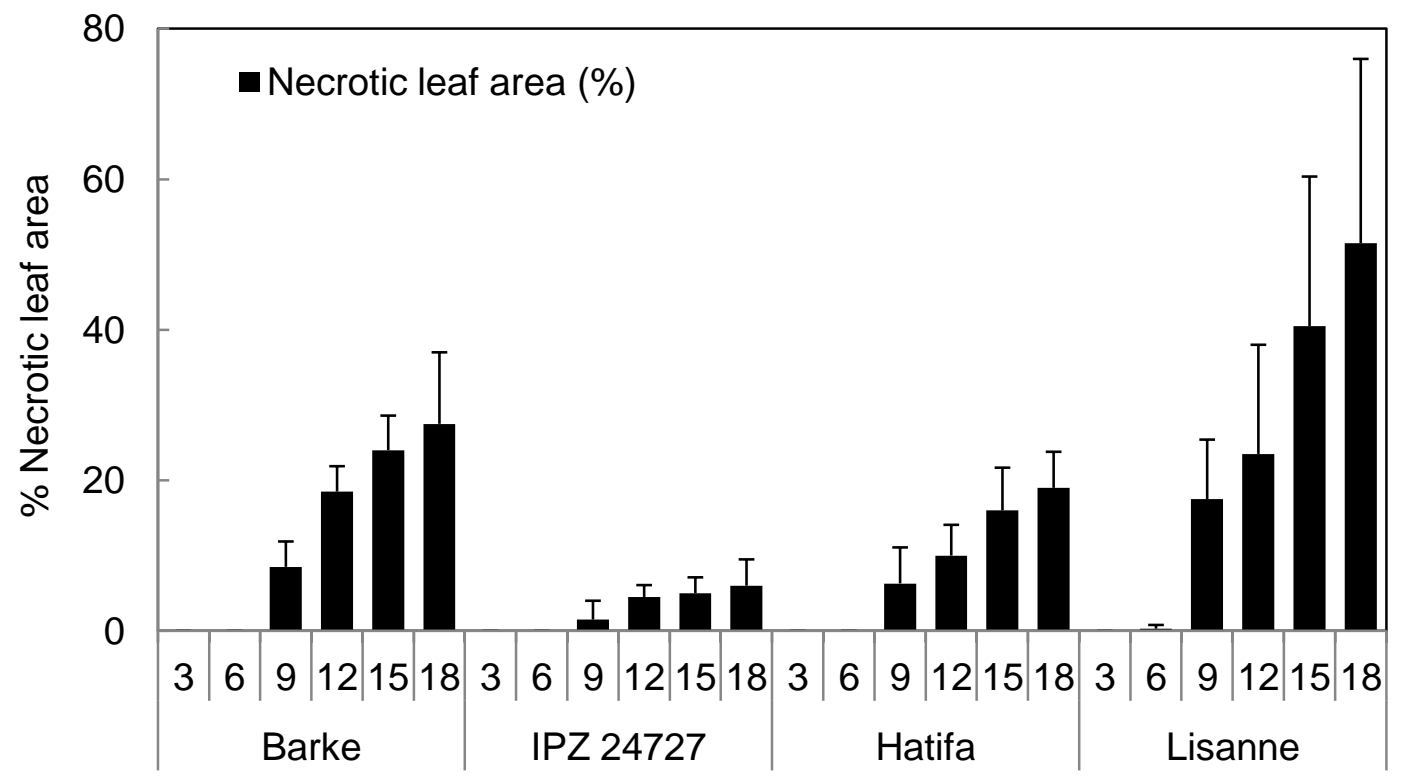

Genotype/ Days post inoculation

Figure 14. Time course of disease development (\% necrotic leaf area) in leaf F-1 of four different spring barley cultivars after inoculation at GS 49-51 in the greenhouse. Mean of twenty individual samples are given with standard deviations.

According to Fig. 13, the first symptoms were visible 9 days after inoculation (necrotic spots on the F-1 leaves) with a subsequent linear increase with time. In contrast to cultivar IPZ 24727 with the highest resistance, cultivar Lisanne showed the highest susceptibility. Symptoms were similar to the symptoms appearing under field conditions (Fig. 15). In this study Barke and Hatifa cultivars were moderately susceptible to Rcc. Further works have focused on the optimisation of the inoculation method to provide favourable conditions for symptom expression. 


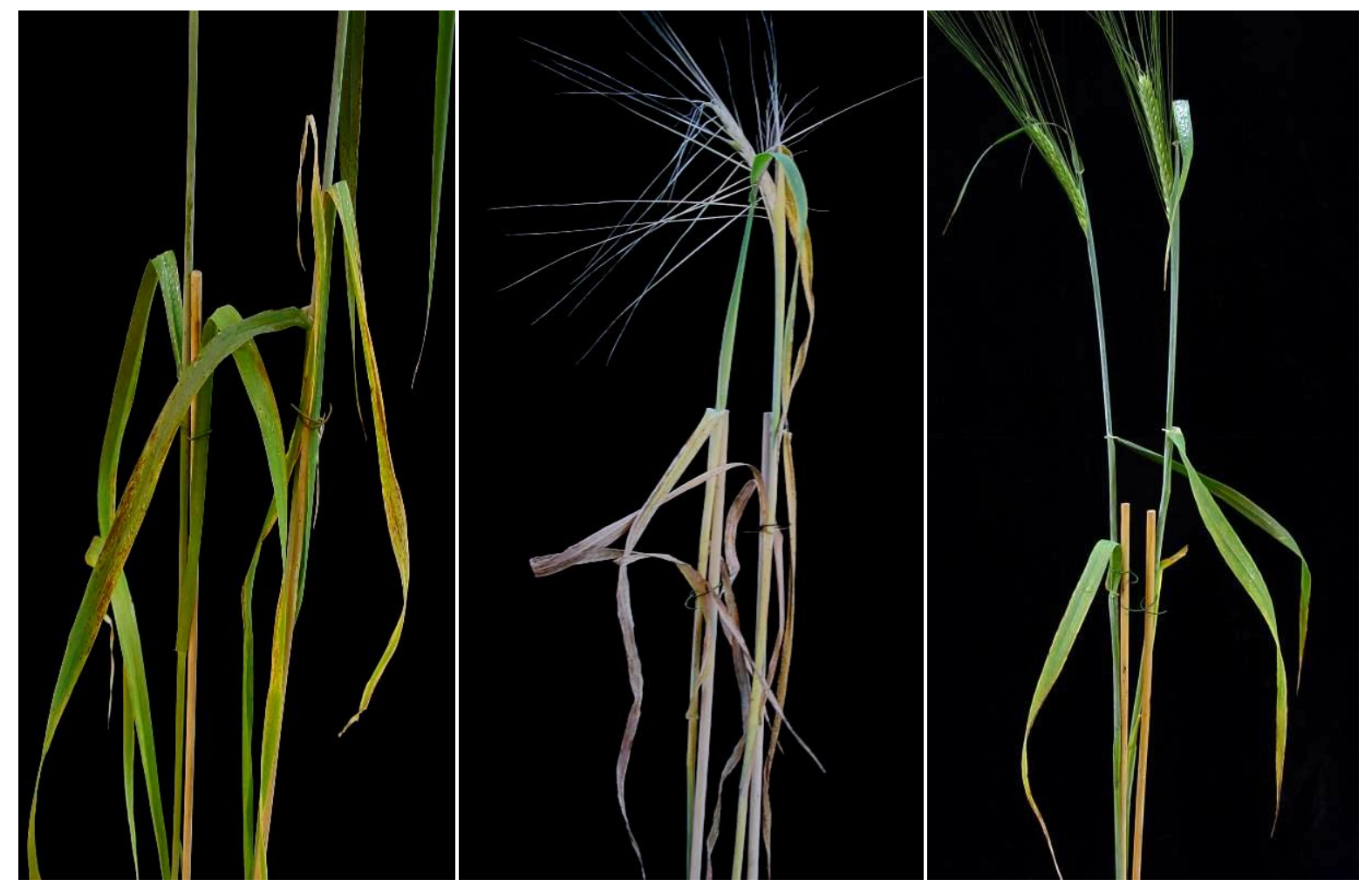

Figure 15. Ramularia collo-cygni symptoms on spring barley leaves (cv. Lisanne) following artificial inoculation under controlled conditions in the greenhouse (left: light necrosis symptoms after $9 \mathrm{dpi}$; centre: high infection and complete necrosis almost in all leaves at 18 dpi; right: mock inoculated plant at $18 \mathrm{dpi}$ )

\subsubsection{Development of an in vitro inoculation system}

For the in vitro testing of barley lines to evaluate resistance to Rcc, a leaf segment assay was developed. The results showed strong differences between the cultivars (Fig. 16). Like in the whole plant inoculation, no symptoms were observed at the younger growth stages such as GS 15 and GS 25-28. In contrast to the whole plants, however, first symptoms on leaf segments were found in GS 33-35. This may be due to the stress induced in leaf segments after cutting from the plants. Results from leaf segments were in agreement with the resistant responses of the whole plants with the highest susceptibility found for cultivar Lisanne and the lowest for cultivar IPZ 24727. In the leaf segment experiment, the best results were obtained 14 days after inoculation at growth stage 55-59 (Fig. 17). 


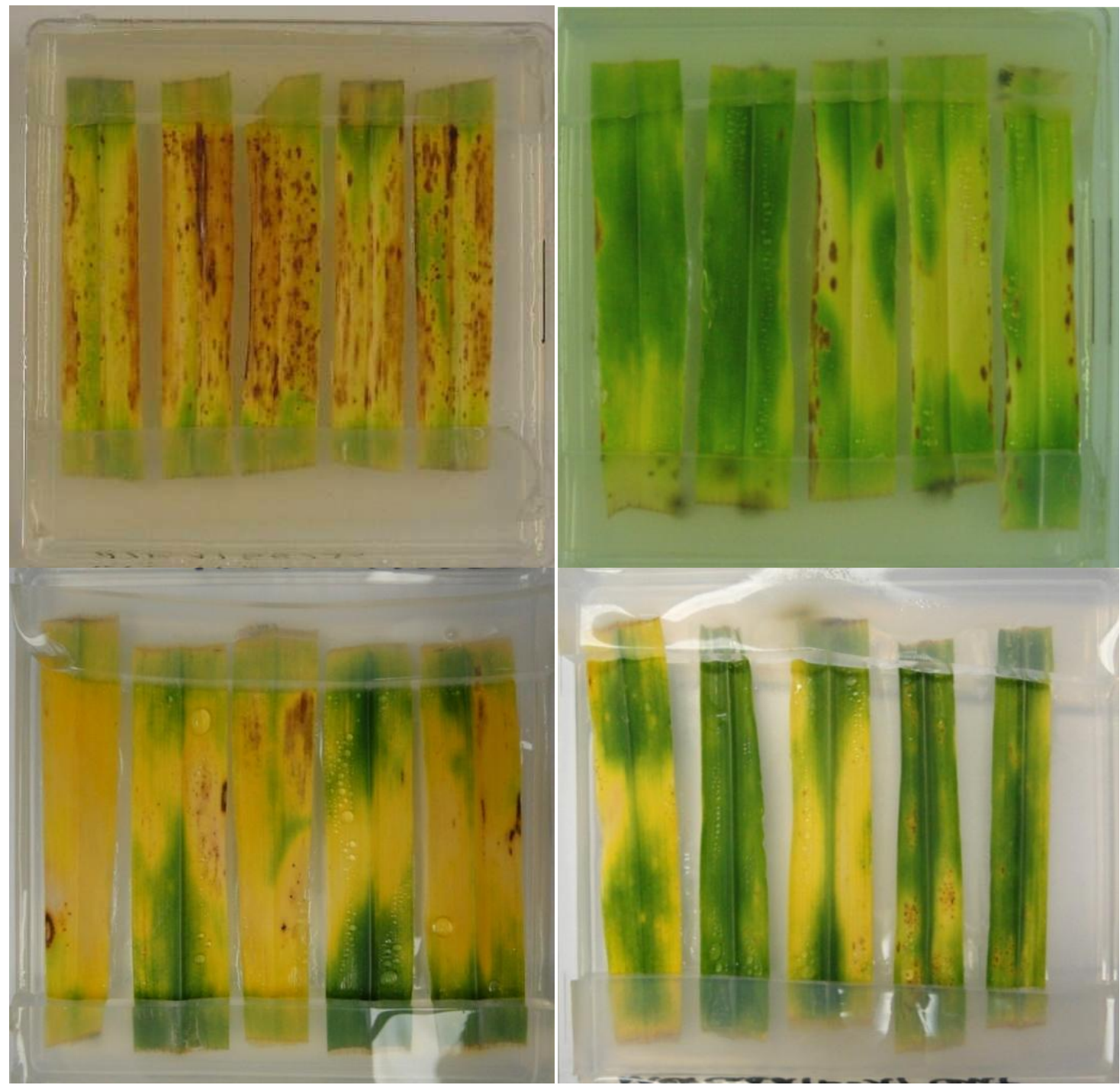

Figure 16. Ramularia collo-cygni infected leaf segments following artificial inoculation at GS 59/51 under controlled environmental conditions; 14 dpi. Cultivar Lisanne was the most susceptible (top left), Lisanne; mock-inoculated (top right), cultivar IPZ 24737 with lowest susceptibility (down left), IPZ 24737; mock-inoculated (down right). 


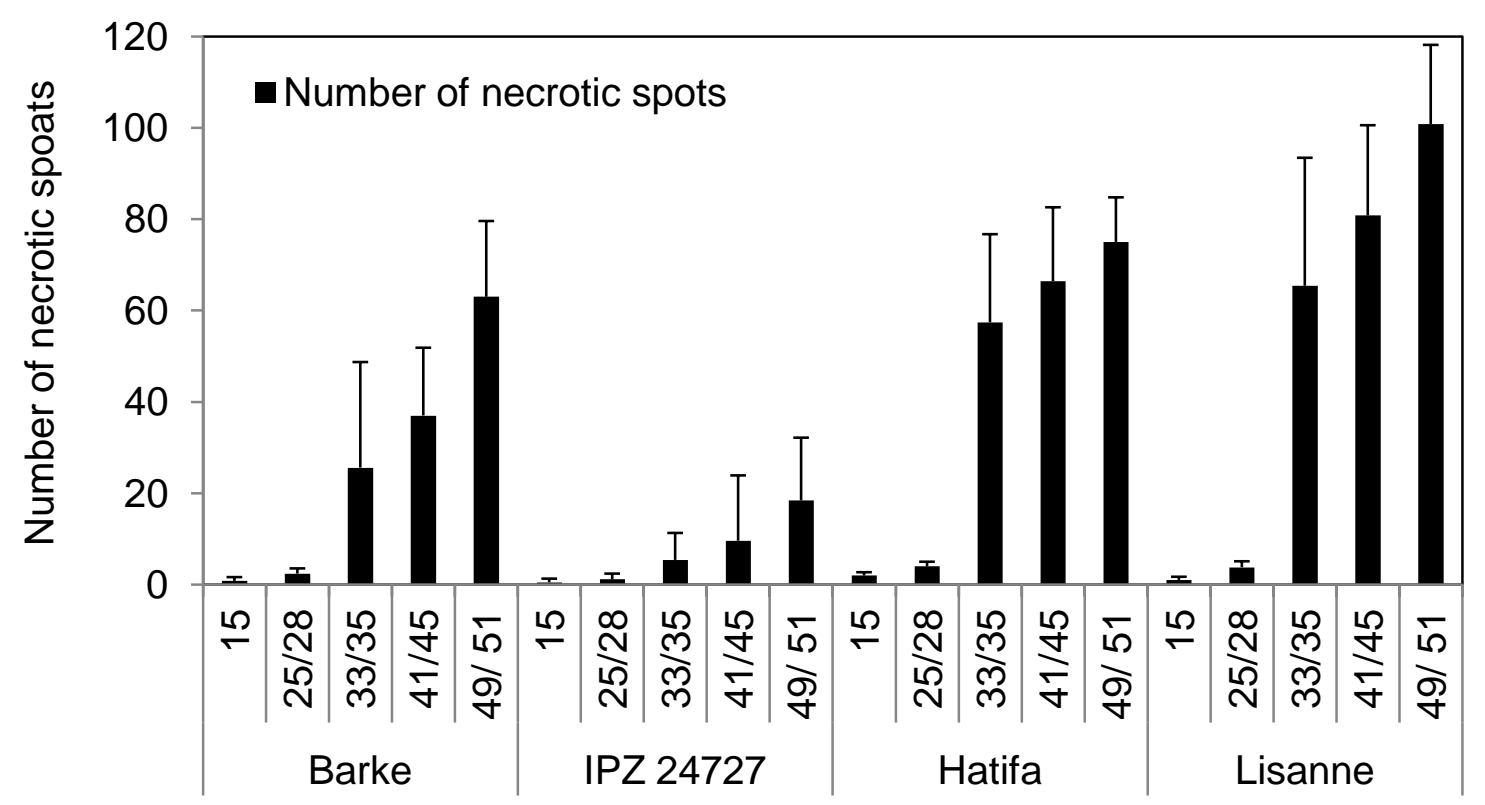

Different growth stages at the time of inoculation

Figure 17. Leaf segment assay for resistance (14 dpi) of four different spring barley cultivars to Rcc at different growth stages at the time of inoculation. Mean of ten individual samples are given with standard deviations.

\subsubsection{Resistance screening under controlled environmental conditions}

Whole plant inoculation: Thirty-eight spring barley genotypes were used for whole plant inoculation and leaf segment assay under controlled environmental conditions. Significant differences ( $p \leq 0.05$ ) were observed among different spring barley genotypes under controlled greenhouse conditions. The final disease development after the whole plant inoculation ranged from $7.33 \%$ for IPZ24727 to $82.23 \%$ for Barke. The results were comparable to the results under field conditions. The analyses of variance for different genotypes in both experiments are presented in Table 11. 
Table 11. Susceptibility of different spring barley cultivars to Ramularia leaf spot disease in whole plant inoculation and leaf segment assay under controlled conditions. Data are means of 20 replicates for whole plant inoculation and 10 replicates for leaf segment assay with standard deviations (in brackets)

\begin{tabular}{|c|c|c|c|c|c|c|}
\hline \multirow[b]{2}{*}{$\begin{array}{l}\text { Spring barley } \\
\text { genotype }\end{array}$} & \multicolumn{3}{|c|}{ Whole plant inoculation } & \multicolumn{3}{|c|}{ Leaf segment assay } \\
\hline & \multicolumn{3}{|c|}{$\begin{array}{c}\text { \% Necrotic leaf area } \\
\qquad( \pm S D)^{1}\end{array}$} & \multicolumn{3}{|c|}{$\begin{array}{l}\text { Number of necrotic spots } \\
\qquad( \pm S D)^{2}\end{array}$} \\
\hline IPZ 24727 & 07.33 & $( \pm 02.74)$ & $\mathrm{a}$ & 13.80 & $( \pm 19.76)$ & $\mathrm{a}$ \\
\hline Gaute & 16.45 & $( \pm 13.52)$ & $\mathrm{b}$ & 18.80 & $( \pm 12.80)$ & a \\
\hline Nymfe & 18.67 & $( \pm 05.16)$ & $\mathrm{b}$ & 36.30 & $( \pm 05.40)$ & bc \\
\hline Varberg & 29.00 & $( \pm 06.06)$ & c & 22.40 & $( \pm 10.11)$ & $a b$ \\
\hline Umberella & 35.00 & $( \pm 13.09)$ & $\mathrm{cd}$ & 41.10 & $( \pm 11.55)$ & cde \\
\hline Scarlett & 37.66 & $( \pm 05.94)$ & de & 38.50 & $( \pm 34.36)$ & bcd \\
\hline Sebastian & 38.65 & $( \pm 06.67)$ & de & 52.60 & $( \pm 15.27)$ & cdefgh \\
\hline GS 2301 & 40.85 & $( \pm 15.36)$ & def & 67.00 & $( \pm 10.17)$ & hijklm \\
\hline Henrike & 43.00 & $( \pm 11.01)$ & efg & 66.60 & $( \pm 14.11)$ & hijkl \\
\hline Scandium & 43.32 & $( \pm 12.06)$ & efg & 58.90 & $( \pm 21.27)$ & fghijk \\
\hline GS 2300 & 44.43 & $( \pm 15.28)$ & efg & 69.80 & $( \pm 14.24)$ & $\mathrm{ijklm}$ \\
\hline Quench & 46.45 & $( \pm 03.99)$ & fgh & 91.70 & $( \pm 22.46)$ & no \\
\hline Kangoo & 48.00 & $( \pm 17.61)$ & ghi & 67.80 & $( \pm 38.32)$ & hijklm \\
\hline Mercada & 48.83 & $( \pm 12.48)$ & ghi & 47.00 & $( \pm 14.47)$ & cdef \\
\hline Mimer & 49.63 & $( \pm 11.97)$ & ghi & 47.30 & $( \pm 18.53)$ & cdefg \\
\hline GS 2298 & 49.25 & $( \pm 09.85)$ & ghi & 59.00 & $( \pm 14.46)$ & fghijk \\
\hline Isabella & 51.39 & $( \pm 14.47)$ & hij & 61.10 & $( \pm 35.19)$ & fghijkl \\
\hline Ria & 52.34 & $( \pm 05.24)$ & hij & 54.50 & $( \pm 12.58)$ & defghi \\
\hline Justina & 52.85 & $( \pm 08.58)$ & hij & 55.60 & $( \pm 32.27)$ & efghi \\
\hline JB Flavour & 53.54 & $( \pm 06.04)$ & hij & 47.40 & $( \pm 10.06)$ & cdefg \\
\hline Signiora & 54.00 & $( \pm 08.84)$ & ij & 79.20 & $( \pm 21.94)$ & $\mathrm{mn}$ \\
\hline Gustav & 54.24 & $( \pm 16.63)$ & ij & 65.60 & $( \pm 15.33)$ & hijklm \\
\hline Jennifer & 54.67 & $( \pm 05.24)$ & ij & 76.30 & $( \pm 26.95)$ & Imn \\
\hline Lisanne & 57.00 & $( \pm 11.32)$ & $\mathrm{jk}$ & 73.20 & $( \pm 28.10)$ & $\mathrm{klm}$ \\
\hline Fairytale & 62.33 & $( \pm 13.76)$ & kl & 62.40 & $( \pm 14.36)$ & fghijkl \\
\hline Conchita & 64.00 & $( \pm 11.16)$ & $\mathrm{klm}$ & 69.30 & $( \pm 10.45)$ & ijklm \\
\hline Victoriana & 65.48 & $( \pm 10.83)$ & Imn & 62.80 & $( \pm 12.35)$ & fghijklm \\
\hline Marthe & 67.59 & $( \pm 10.47)$ & Imn & 61.40 & $( \pm 44.36)$ & fghijkl \\
\hline Power & 71.00 & $( \pm 05.85)$ & mno & 63.70 & $( \pm 26.87)$ & ghijklm \\
\hline
\end{tabular}


Continuing from previous page (Table 11)

\begin{tabular}{lllllll}
\hline Pasadena & 71.37 & $( \pm 06.32)$ & no & 58.80 & $( \pm 20.31)$ & tghijk \\
Braemer & 71.69 & $( \pm 11.60)$ & no & 54.80 & $( \pm 13.27)$ & defghi \\
Waldemar & 75.58 & $( \pm 14.62)$ & op & 71.40 & $( \pm 14.36)$ & jklm \\
Hatifa & 81.66 & $( \pm 09.00)$ & p & 109.8 & $( \pm 23.80)$ & p \\
Barke & 82.23 & $( \pm 10.50)$ & p & 97.20 & $( \pm 28.81)$ & op
\end{tabular}

${ }^{1}$ Percentage of necrotic leaf area due to Rcc on leaf F-1 at $18 \mathrm{dpi}$

${ }^{2}$ Number of necrotic spots on leaf segments due to Rcc on leaf segment from F-1 at 14 dpi Values with different letter within the same column indicate significant differences $(p \leq 0.05)$ between the genotypes; calculated by the LSD-Fisher test

Significant correlations were observed between whole plant inoculation and the percentage of necrotic leaf area achieved under controlled environmental conditions and the disease severity (\%) in the field experiment 2009 and 2010 (Fig. 18 and 19). The Spearman rank correlations between disease severity (\%) in whole plant inoculation under controlled conditions and the field trial in 2009 was relatively higher with correlation coefficient of $r_{s}=0.483$ than with the field trial in 2010 with $r_{s}=0.384$. 


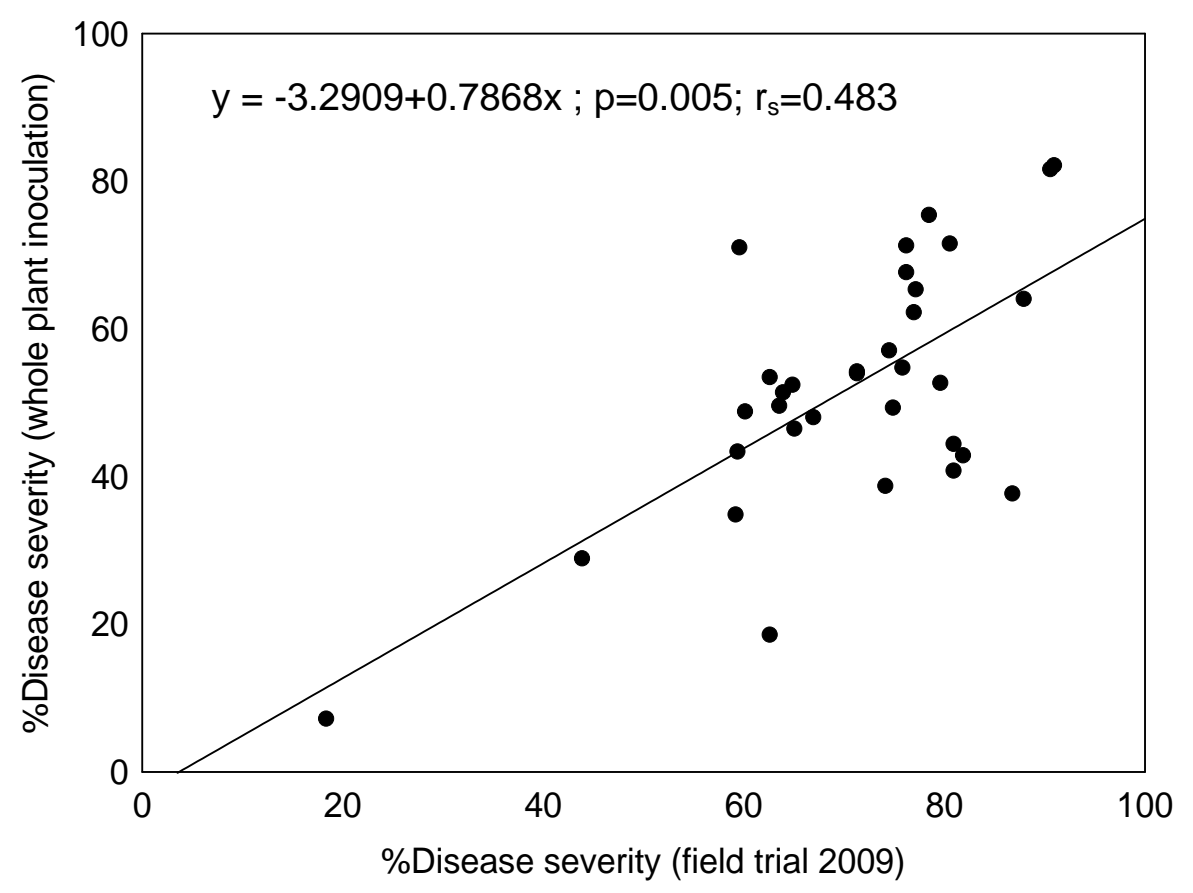

Figure 18. Correlation between the disease severities (\%necrotic leaf area) after whole plant inoculation under controlled environmental conditions and in the field experiment at Lenglern/Germany in 2009. $r_{s}$ : Spearman's rank correlation coefficient, $p$ : $p$-value $\leq 0.05$

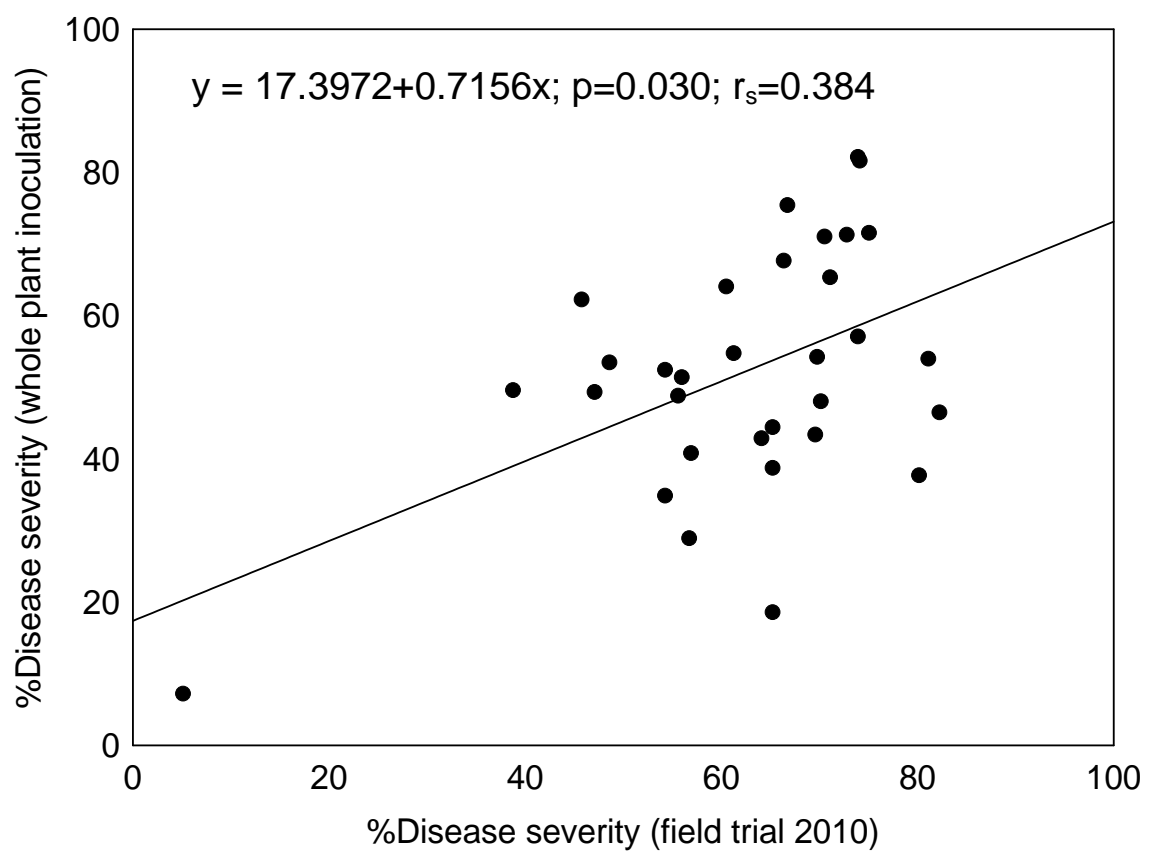

Figure 19. Correlation between disease severity (\%necrotic leaf area) after whole plant inoculation under controlled environmental conditions and in the field experiment at Lenglern/Germany in 2010. $r_{s}$ : Spearman's rank correlation coefficient, $p$ : $p$-value $\leq 0.05$ 
Leaf segment assay: Significant differences ( $p \leq 0.05)$ among different spring barley genotypes were observed in leaf segment experiment. Like the whole plant inoculation, the age of leaves was significantly affecting the number of necrotic spots and disease development. At the older growth stages, the results were comparable with the results of the field experiments and whole plant inoculation under controlled conditions. The average number of necrotic spots ranged from 13.8 for IPZ 24727 to 109.8 for Hatifa. The analyses of variance for different genotypes are given in table 10. There was a significant correlation between the number of necrotic spots caused by Rcc and disease severity (\% necrotic leaf area) in the field experiment 2009 and 2010 (Fig. 20 and 21).

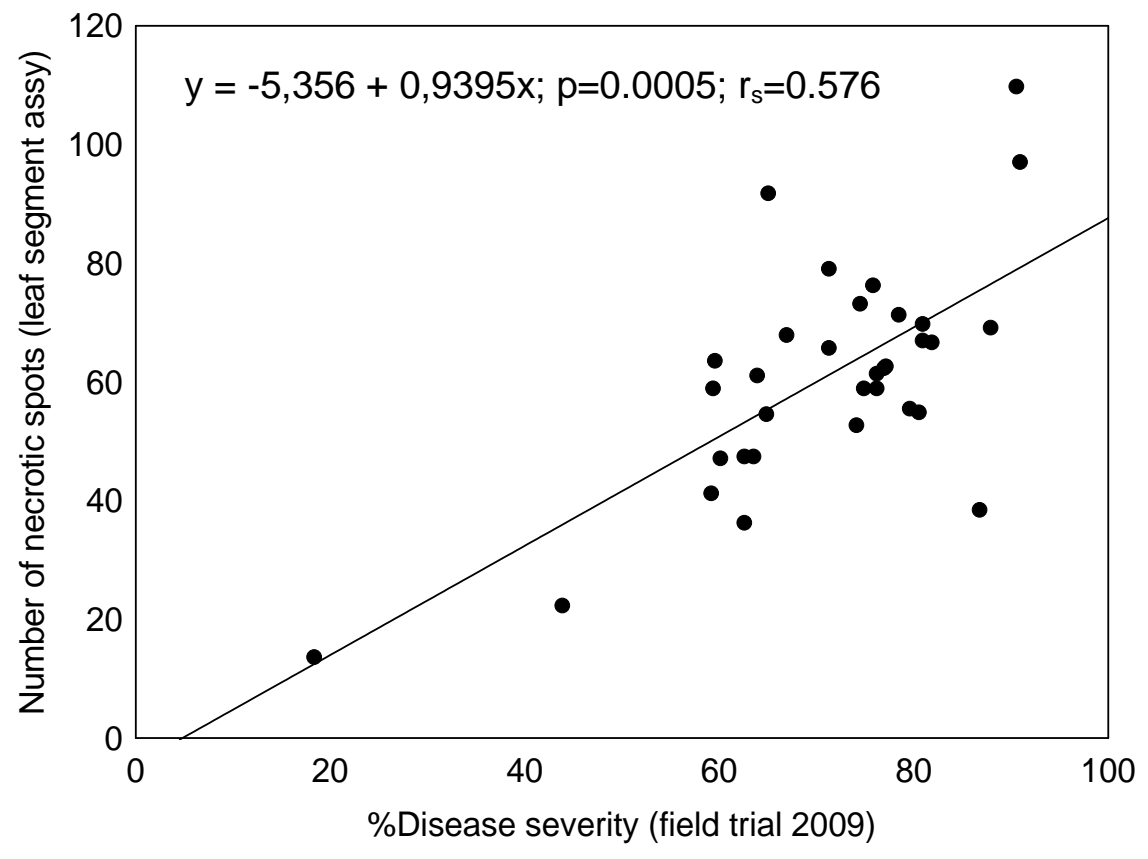

Figure 20. Correlation between number of necrotic spots in the leaf segment assay under controlled conditions and disease severity (\% necrotic leaf area) in the field experiment in Lenglern/Germany in 2009. $r_{s}$ : Spearman's rank correlation coefficient, $p$ : $p$-value $\leq 0.05$ 


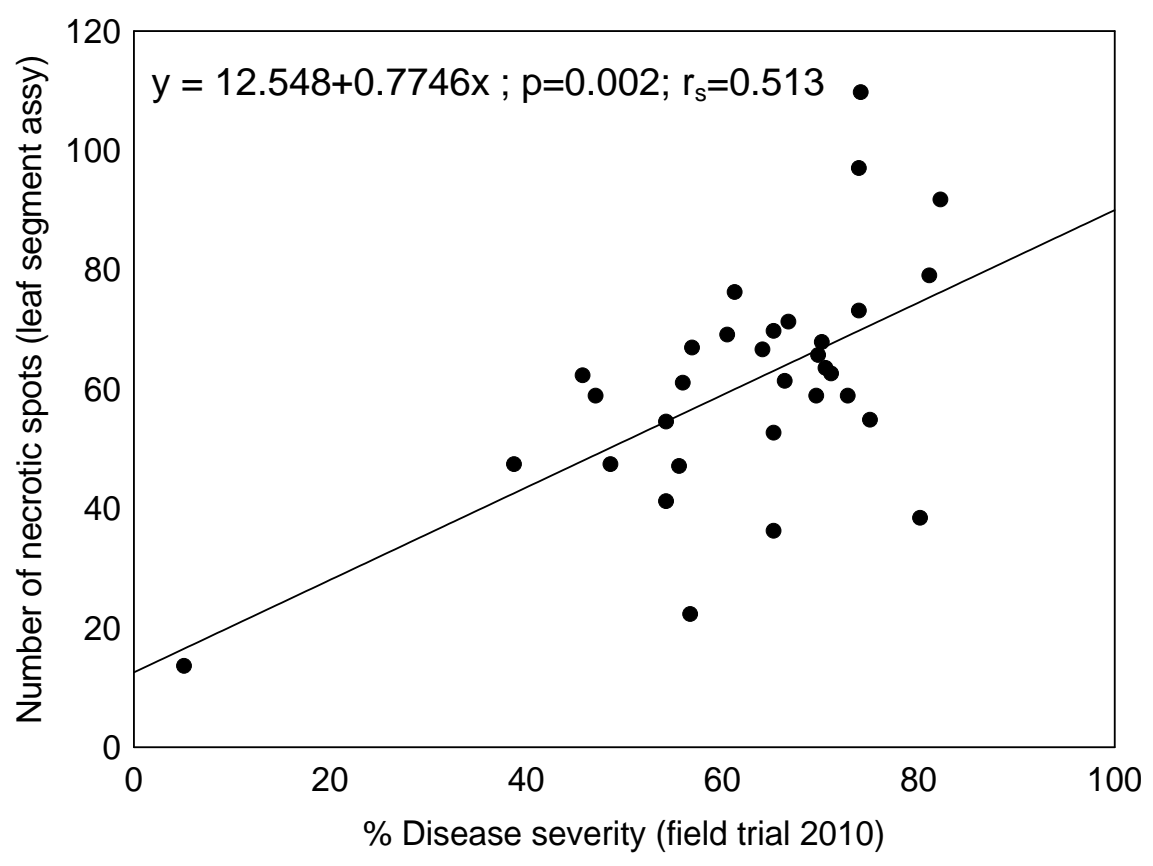

Figure 21. Correlation between number of necrotic spots in leaf segment assay under controlled conditions and disease severity (\%necrotic leaf area) in the field experiment in Lenglern/Germany in 2010. $r_{s}$ : Spearman's rank correlation coefficient, $p$ : $p$-value $\leq 0.05$

The Spearman rank correlation coefficient between the number of necrotic spots in the leaf segment assay and disease severity (\% necrotic leaf area) in the field trial 2009 was approximately similar $\left(r_{s}=0.576\right)$ to the field trial $2010 \quad\left(r_{s}=0.513\right)$. Significant correlations were observed between disease severity (\%) in the greenhouse experiment and the number of necrotic spots derived from leaf segment data with a correlation coefficient of $r_{s}=0.592$ (Fig. 22). 


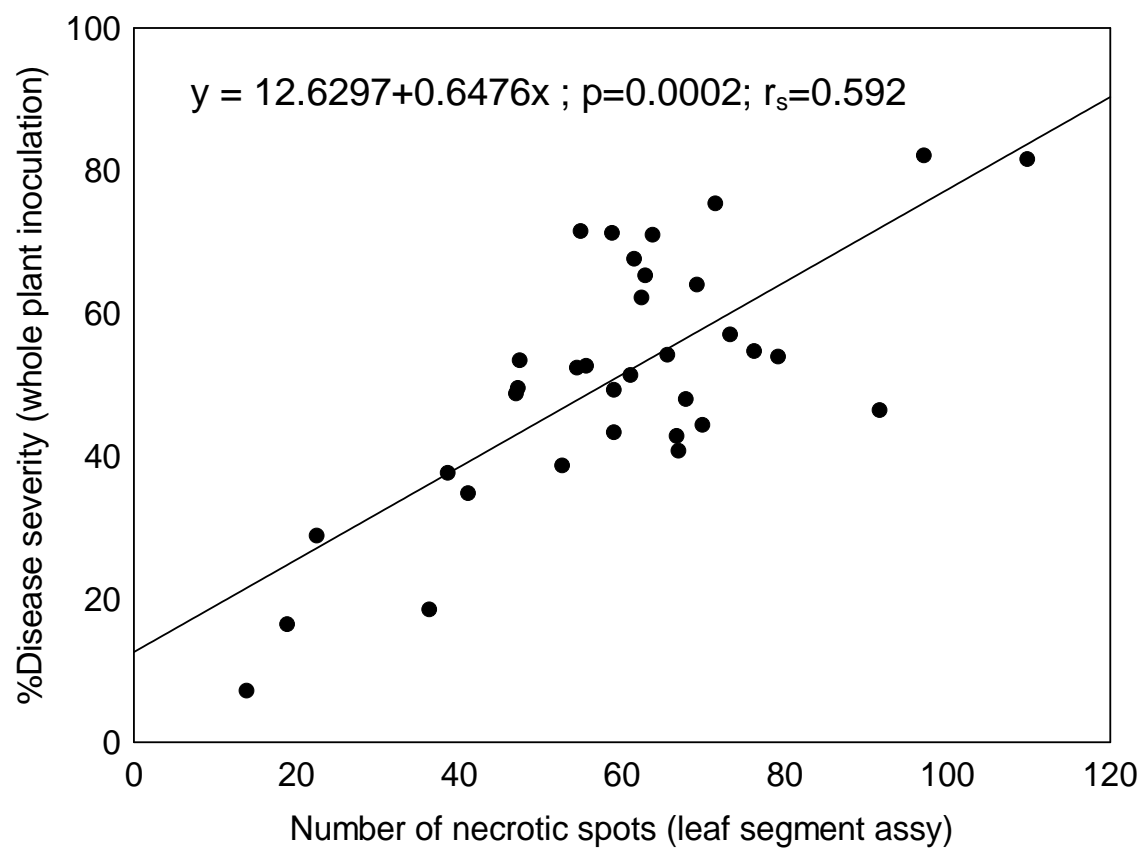

Figure 22. Correlation between disease severity (\%necrotic leaf area) following whole plant inoculation under controlled conditions and the number of necrotic spots in the leaf segment assay. $r_{s}$ : Spearman's rank correlation coefficient, $p$ : $p$-value $\leq 0.05$

\subsubsection{Symptom development in younger stages of the plant}

Under controlled environmental conditions, we could inoculate the plants and produce symptoms at the older growth stages. Applying present methods to inoculate young plants to produce symptoms of RLS was not successful. Development of suitable greenhouse inoculation methods to inoculate barley seedlings in a minimum space and time is crucial for disease assessment in different barley genotypes. In this experiment, we tried to increase oxidative stress by chemical and physical stressors to produce Rcc symptoms in barley seedlings. Visual assessment was carried out on several occasions over two weeks but there was only very little abiotic or physiological spotting. Plants which were exposed to $5,10,25$ and $50 \mu \mathrm{M} / \mathrm{I}$ Paraquat showed no symptoms and they remained completely disease-free until the end of the disease assessment date. Most plants which were exposed to $100 \mu \mathrm{M} / \mathrm{I}$ Paraquat died after few days. Similar results were observed when Ethephon was applied as a stressor. Applying 0.1 and $0.2 \mathrm{l} / \mathrm{ha}$ Ethephon caused no disease symptoms while 0.45 and $0.9 \mathrm{l} / \mathrm{ha}$ resulted in death of the most plants. No symptoms also were observed when plants were exposed to physical stressors (high and low 
temperature, UV-light) for 1, 2 and 4 hours. The results became more notable when plants exposed to the physical stressors more than 12 hours. Yellowish discoloration was observed in the older leaves at eight days after stress application for 12 hours. Exposing plants to the stressors $\left(4^{\circ} \mathrm{C}\right.$ and $\left.40^{\circ} \mathrm{C}\right)$ for 24 hours resulted in limited necrosis spots in the older leaves of the few plants which were comparable to Rcc symptoms (Fig. 23). However, these studies showed promising results but were not enough to consistently produce reliable methods for resistance assessment against Rcc in different barley genotypes.

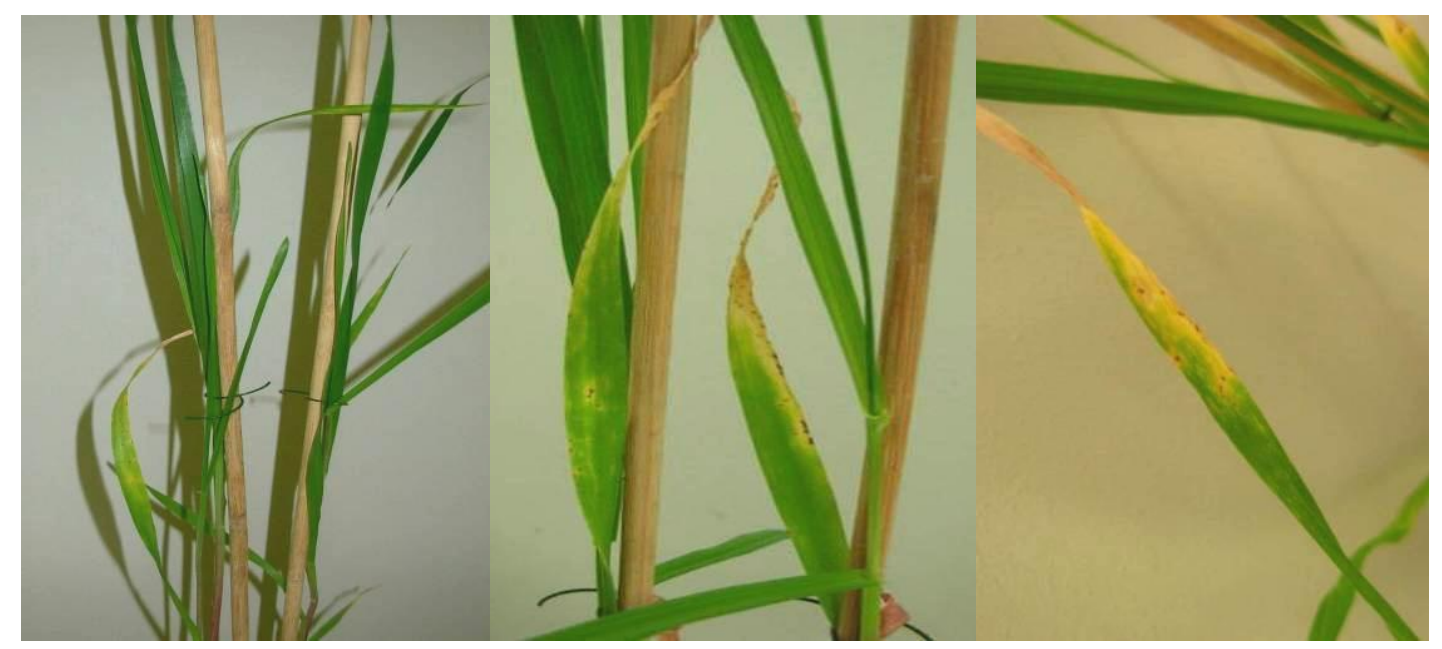

Figure 23. Yellowish discoloration and necrotic spots on lower leaves (older ones) associated with RLS (left: spring barley cv. Hatifa exposed to $4^{\circ} \mathrm{C}$ for $24 \mathrm{~h}$; centre: spring barley cv. Barke exposed to $4^{\circ} \mathrm{C}$ for $24 \mathrm{~h}$; right: spring barley cv. Hatifa exposed to $40^{\circ} \mathrm{C}$ for 24h)

\subsubsection{Fungal systemic development inside the plant}

The experiment was carried out to prove pathogen systemic development inside the plant from the lower parts to the upper part. Three weeks after inoculation, three upper leaves (flag leaf, F-1 and F-2) from each inoculated plant were harvested. Each harvested leaf was analysed separately with PCR. In total, five percent of examined samples showed fungal systemic development inside the plant. Rcc was first detected in F-2 leaves in both barley cultivars (Barke and Hatifa). Just in one case and in cultivar Hatifa the fungus reached to the flag leaf which was detected by PCR. 


\subsubsection{Morphology and chemical composition of leaf wax layer}

The cuticle layer is a hydrophobic barrier that covers the outer surfaces of the leaves. It plays an important role in plant protection against the pathogens invasion. Previous studies by Dörte Wallner (Master study at University of Göttingen, Division of Plant Pathology and Crop Protection, Department of Crop Sciences) showed that Rcc can penetrate not only via natural plant openings like stomata but also via plant tissue directly through the outer surface. These results support the hypothesis that the amount of wax layer at different growth stages has an effect on Rcc penetration and disease development. In this study, we investigated whether the total wax amounts and its composition are being changed during plant development. Total wax layer increased slightly from GS 33 to GS 59-61. It ranged from $17.95 \pm 2.29 \mu \mathrm{g} / \mathrm{cm}^{2}$ in fully expanded leaf from top at GS 33 to $26.72 \pm 4.24 \mu \mathrm{g} / \mathrm{cm}^{2}$ in F-2 at GS 59-61 (Fig. 24).

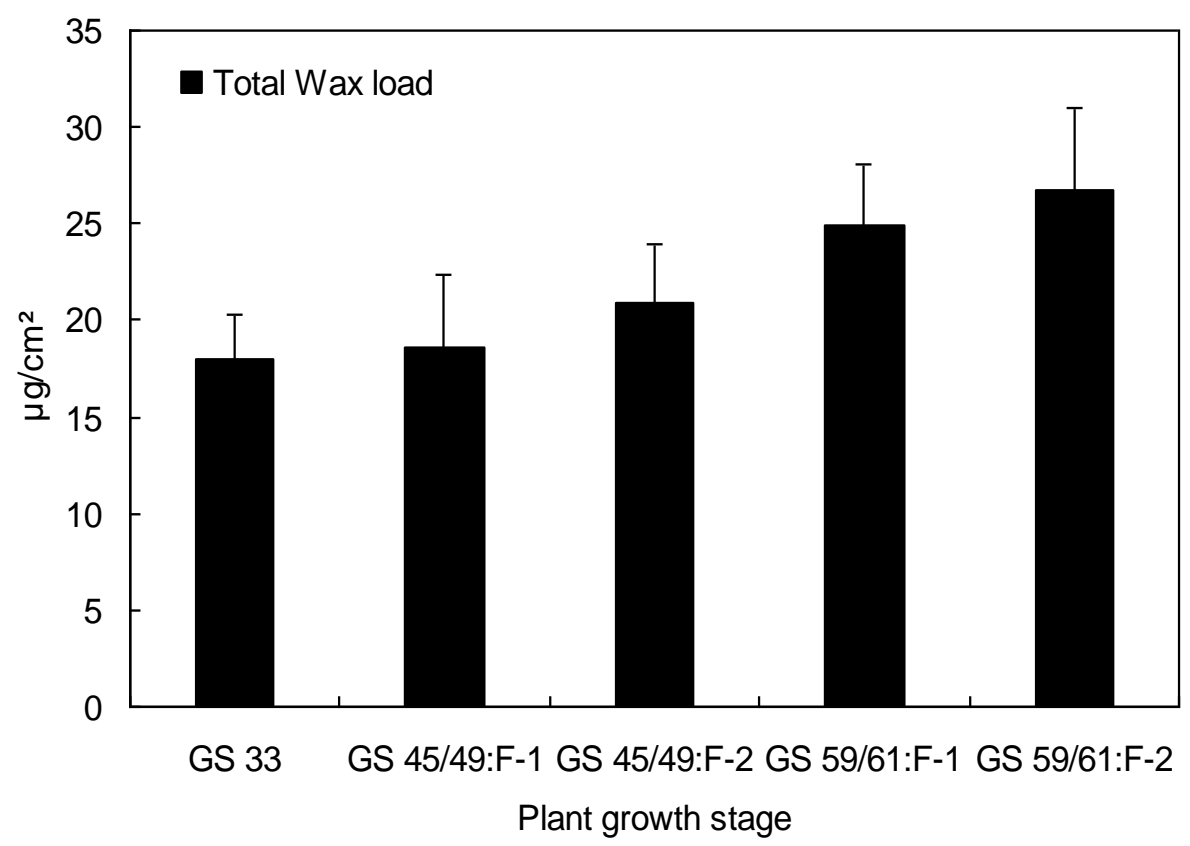

Figure 24. Total wax layer $\left(\mu \mathrm{g} / \mathrm{cm}^{2}\right)$ in different barley leaves (cv. Barke) at different growth stages. Averages of five independent samples are given with standard deviations.

Eight different chemical compounds were determined in the total wax load from leaves at different growth stages. It contains mainly the primary alcohols C20, C22, C24, C26, C28 and the fatty acids C22, C24 and C26. No significant differences were 
observed between the amounts of chemical compounds of the wax layer at different growth stages but in comparison to other compounds, primary alcohol C26 was the major component of the wax layer, which was significantly higher than the other compounds (Fig. 25).

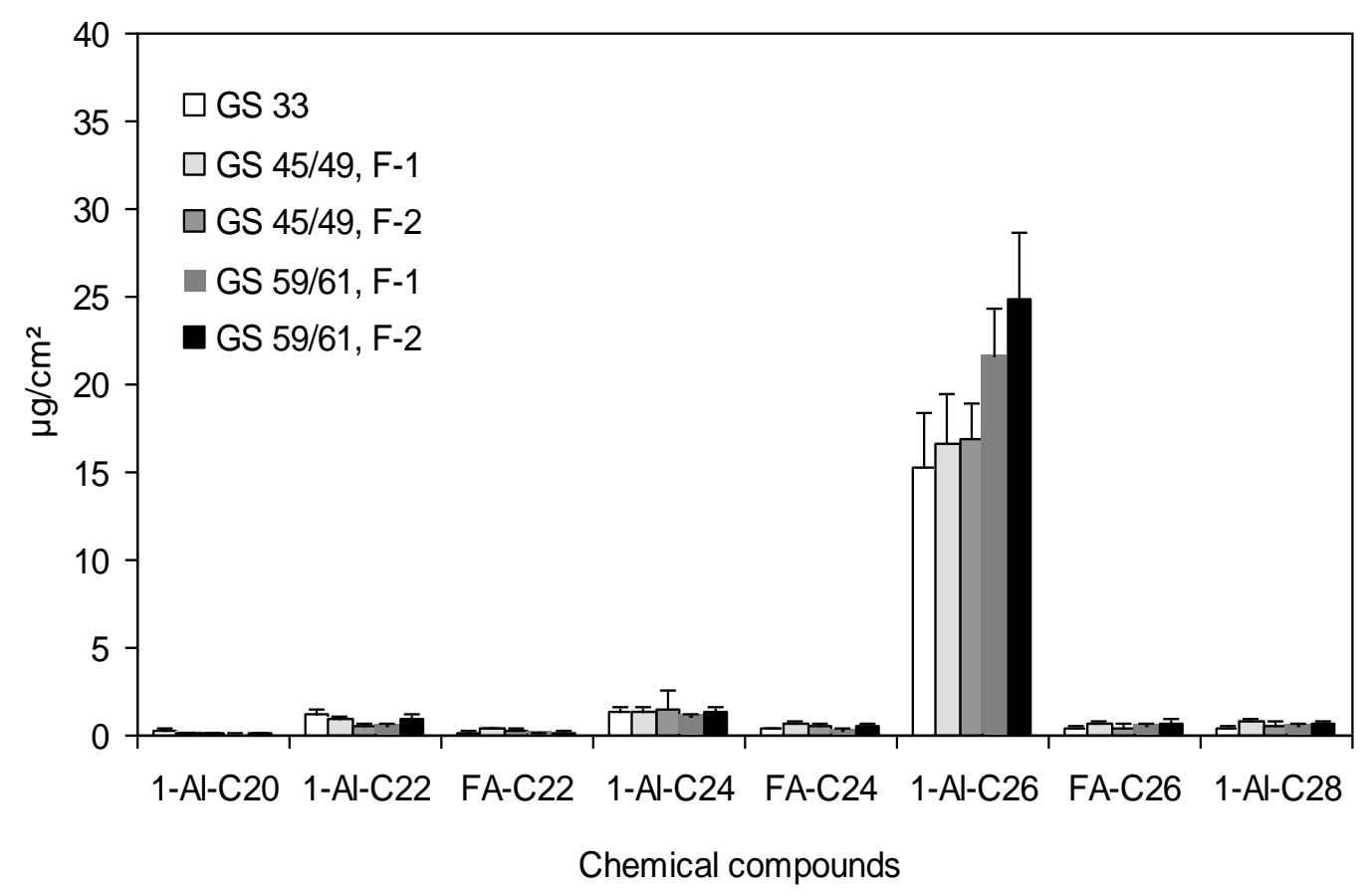

Figure 25. Composition of different chemical compounds $\left(\mu \mathrm{g} / \mathrm{cm}^{2}\right)$ identified in the total wax layer. Averages of five independent samples are given with the standard deviations. (1-Al-C20: primary alcohol C20, 1-Al-C22: primary alcohol C22, FA-C22: fatty acid C22, 1-AlC24: primary alcohol C24, FA-C24: fatty acid C24, 1-Al-C26: primary alcohol C26, 1-FA-C26: fatty acid C 26, 1-Al-C28: primary alcohol C28.

Environmental scanning electron microscopy (ESEM) demonstrated the shape and the position of epicuticular wax crystals. They were plate-shaped and grew from both sides to the centre of the leaf surface. At the early growth stages, the epicuticular wax crystals did not cover the whole surfaces. Some areas were with crystals and some areas without (Fig. 26). However, at the later growth stages wax crystals not only spread regularly on the whole epidermal surface but also the density of wax crystals increased (Fig. 27). At all growth stages, no differences in wax pattern were found between the adaxial and the abaxial epidermis. 


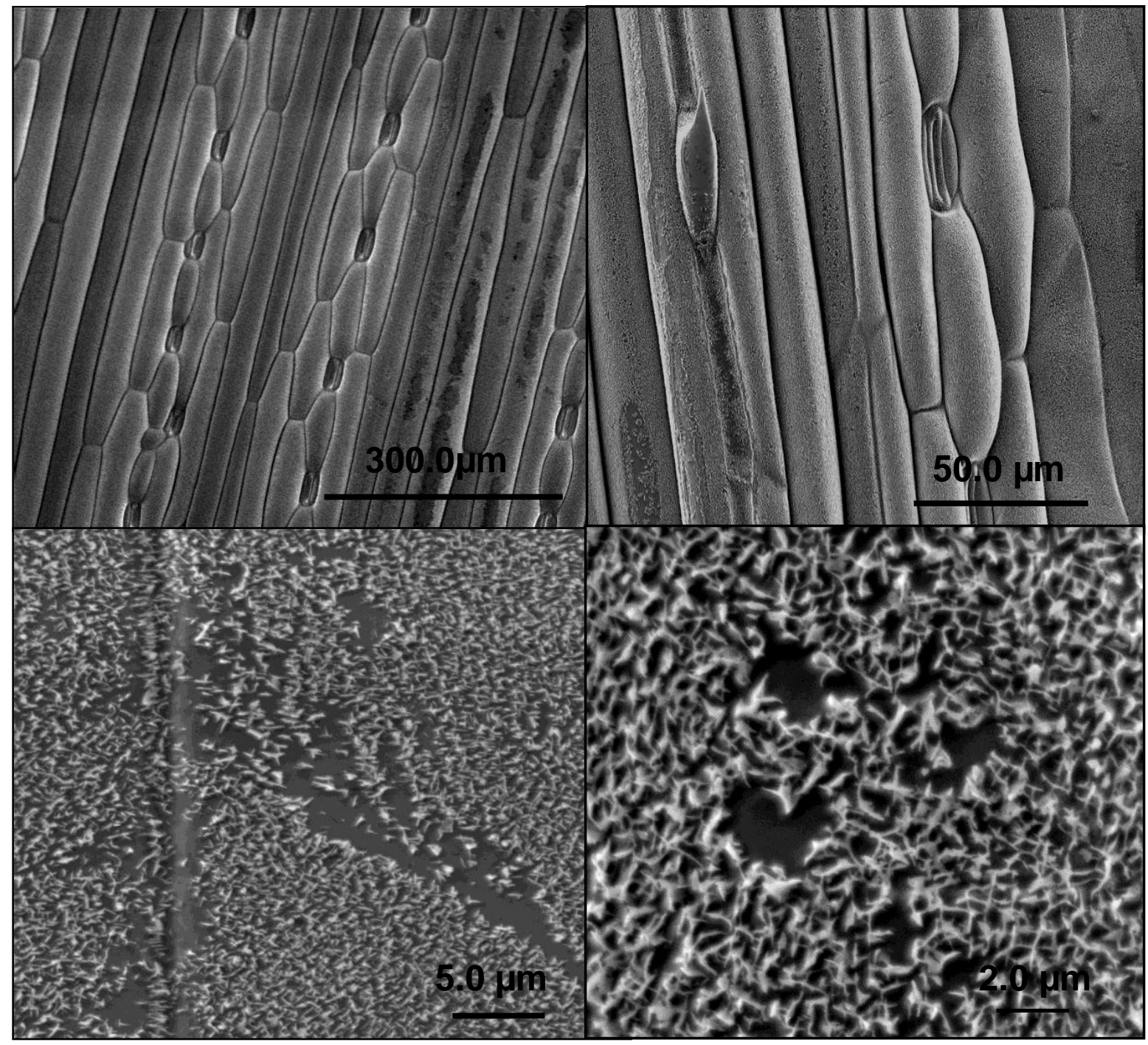

Figure 26: Scanning electron microscope of the leaf surface of the spring barley $\mathrm{cv}$. Barke at GS 13; at this growth stage plate-shaped crystals of the wax layer did not cover the whole surface of the leaf and the density of wax crystals was low but the shape of cells was regular. 


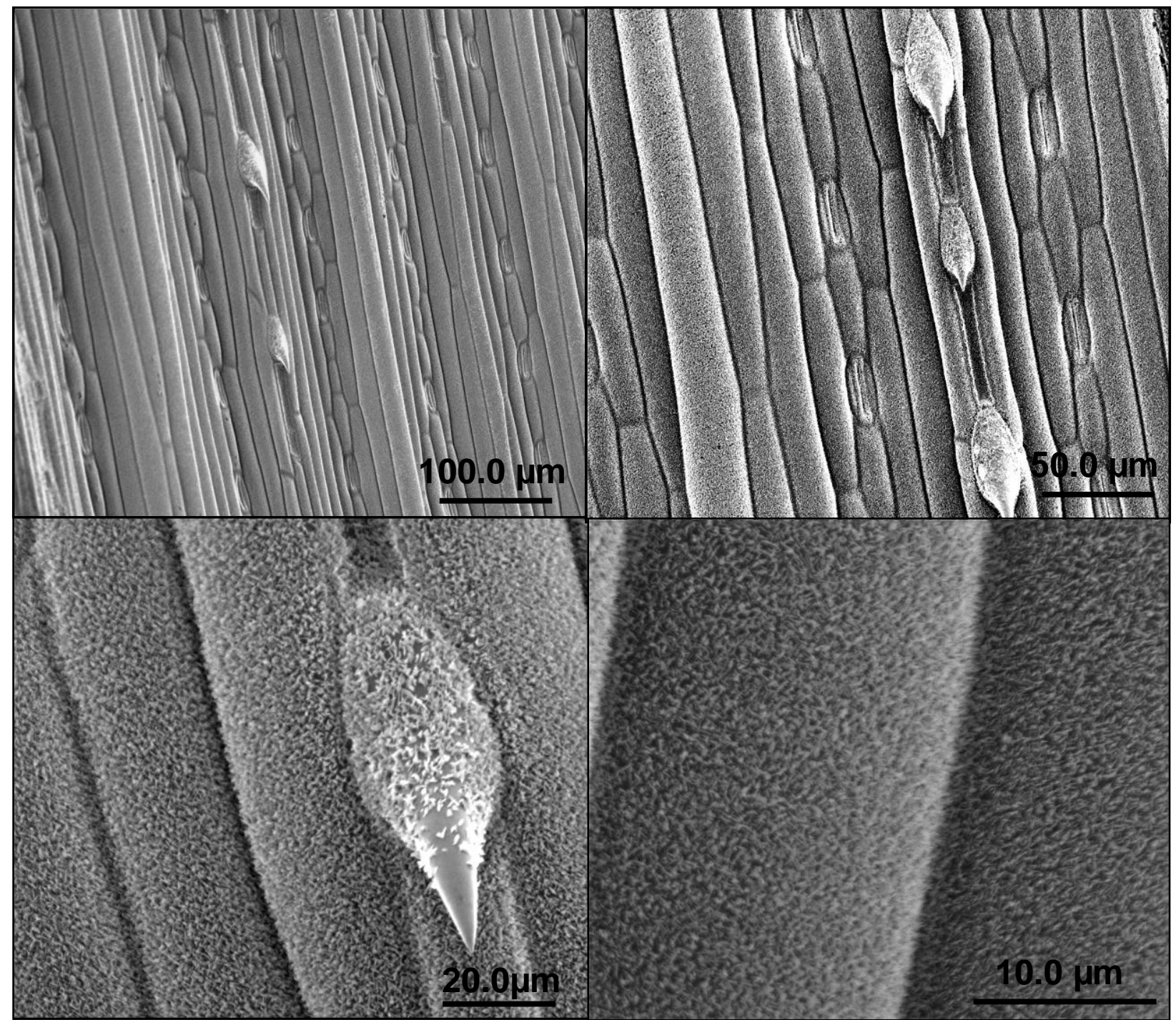

Figure 27. ESEM images of the leaf surfaces of spring barley cv. Barke at GS 33; high density and full covering of the leaf surface with wax crystals was observed in this growth stage.

The photos of ESEM also showed that the surface of the wax layer and the wax cells were regular in shape at the early growth stages (Fig. 26 and 27). Abnormalities in the shape and structures of the cells of cuticle were visible at older stages (Fig. 28). 


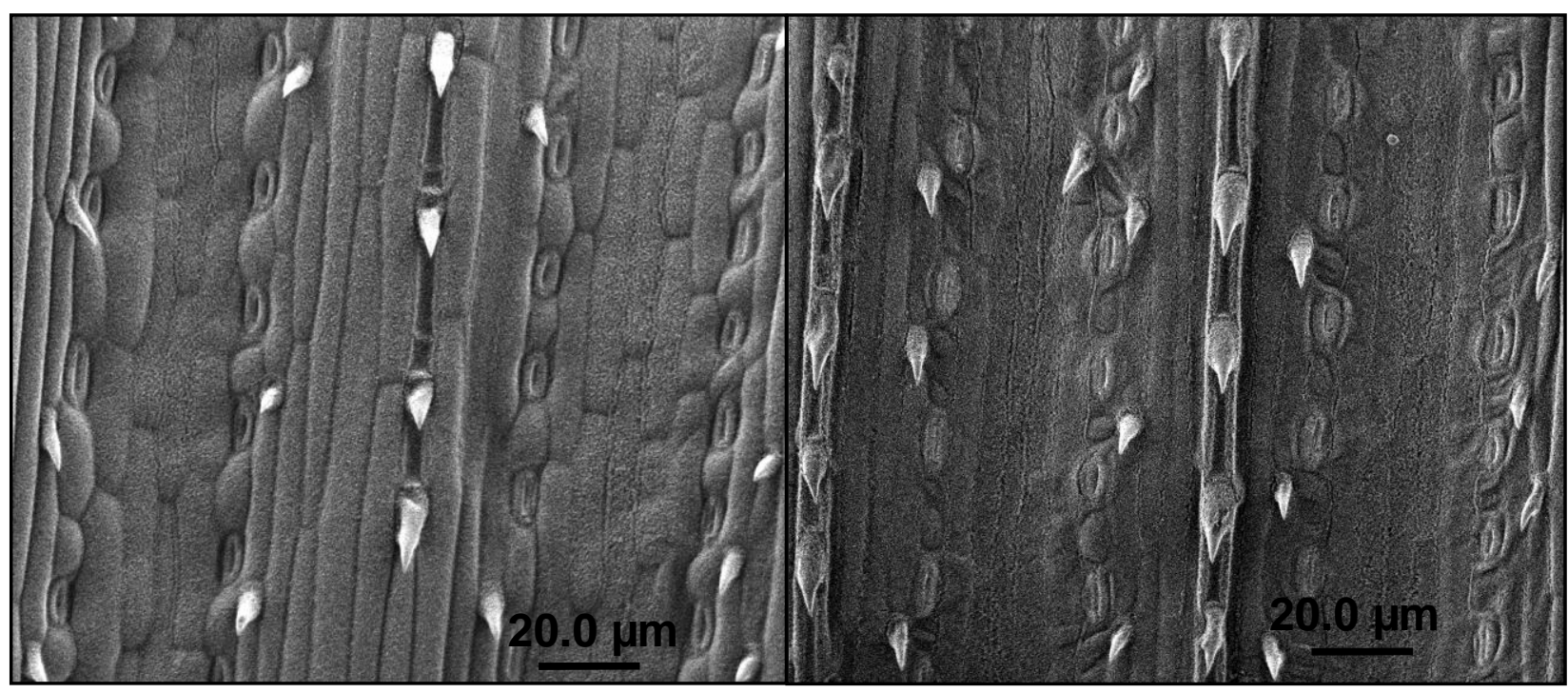

Figure 28. ESEM pictures of F-1 leaf of spring barley cv. Barke at GS 49 (left) and GS 65 (right); abnormalities in cells shape were visible at the later growth stages.

Previous studies by Dörte Wallner 2008 indicated that Rcc mycelium could penetrate via plant tissue directly through the outer cuticular surface. The ESEM photos of the naturally infected barley leaves from field experiments showed that in some cases, the Rcc mycelia may produce special exudates with enzyme activity which removes a part of the outer surface of the leaf cuticle crystals around mycelia (Fig. 29). It may help Rcc to directly penetrate during the infection periods. 

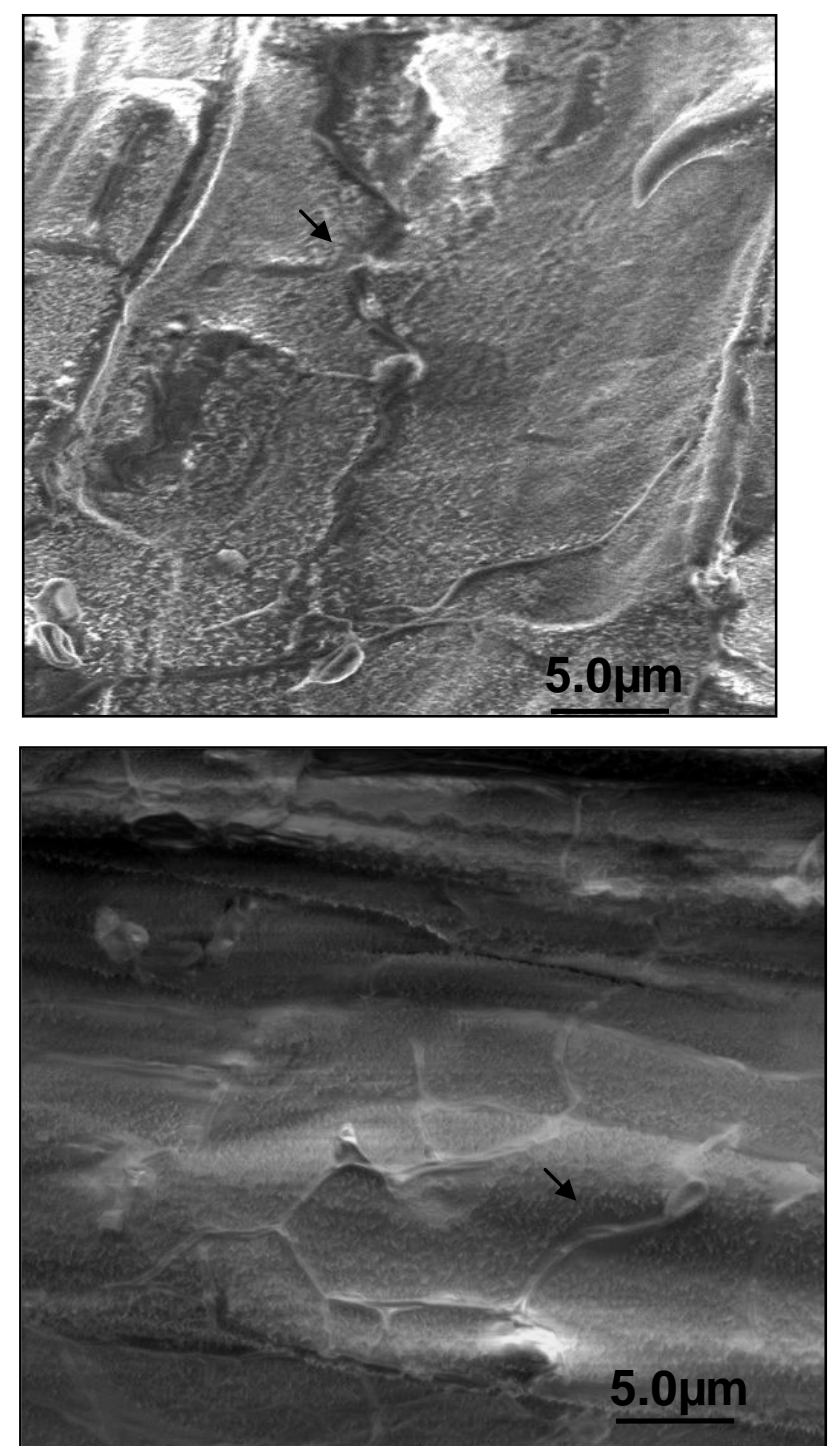

Figure 29. ESEM images of naturally infected leaves from the field; a part of the outer surface of the leaf cuticle crystals around mycelia was removed maybe due to the hyphal enzyme activities.

\subsection{Field experiments}

\subsubsection{Monitoring spore dispersal by wind}

In this study, the presence of Rcc inoculum in the air and its distribution over large distances was investigated. The long-distance transport of spores was first studied using spore traps placed in colder months from October to November in three consecutive years (Fig. 30). 


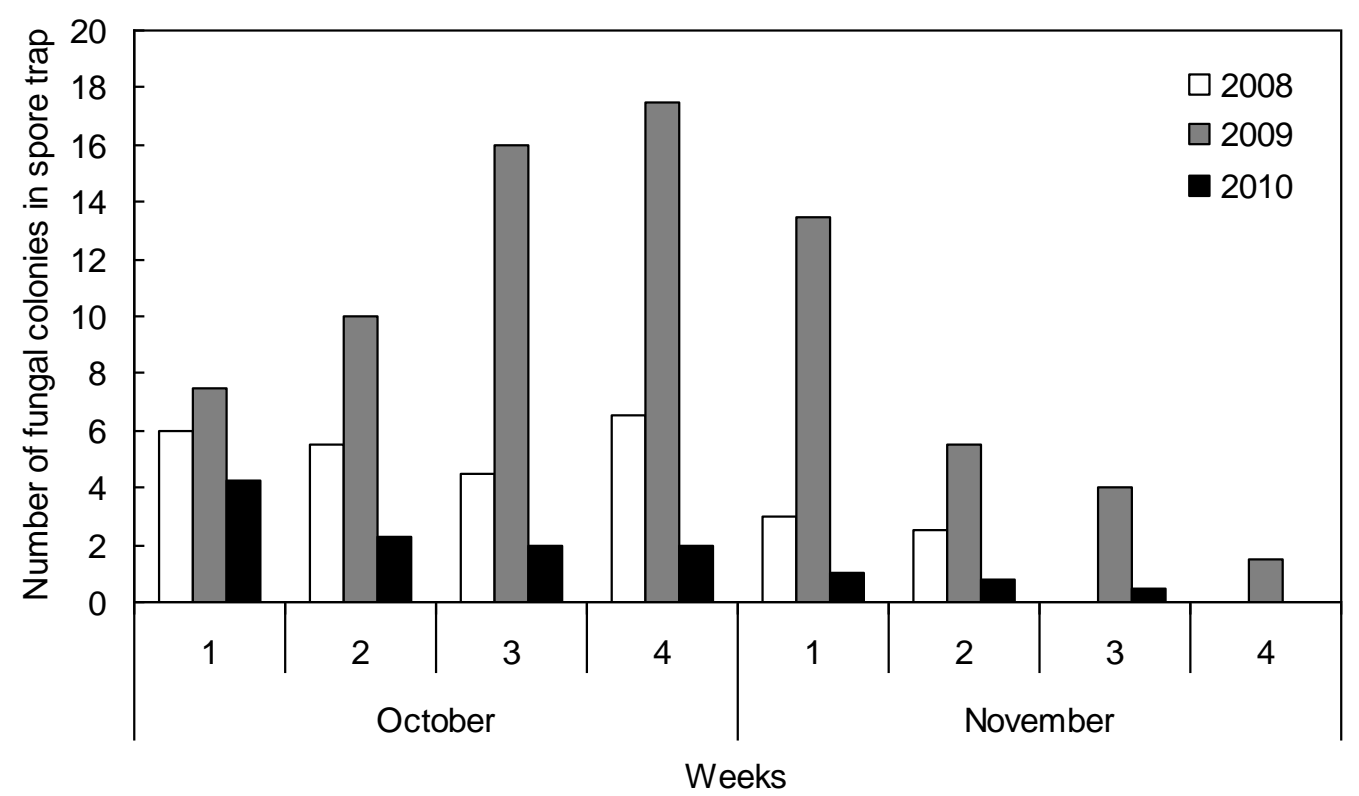

Figure 30. Long-distance dispersal of $R$. collo-cygni spores in colder months in three consecutive years (2008-2010), trapped by semi selective media in Weende, Goettingen.

According to Fig. 30 and compared with numbers of trapped spores during barley growing seasons (Fig. 36), low concentrations of airborne conidia were found during late autumn to early winter. Spore-trapping data showed different patterns in three different years. The total mean concentrations in 2008 were from 6 spores per Petri dishes in the first week of October, fluctuated until the end of the month, and then gently decreased until the end of November. In 2009, a high dispersal of conidia was observed as compared to 2008 and 2010. It started from 7 spores per Petri dish, increased to 16 at the end of October, and then gradually decreased to less than 2 spores at the end of November. Field observation showed that the main source of conidia came from a late sowing spring barley field which was infected by Rcc and located close to our spore traps. Dry conditions in 2010 resulted in a decrease of the number of conidia from 4 spores per Petri dish in the first week of the experiment, then slightly dropped down to zero at the end of the study. In all three years, no spores were detected after November due to the snow and severe weather conditions.

Spore traps with Rcc colonies grown on semi selective V8A medium gave individual presence/absence data in which each colony was responsible for the presence of 
one spore (Fig. 31). On the other hand, using agar media as a spore trap had some disadvantages. When plates were collected after more than one day or in the warm weather conditions, the medium had dried out and fungal colonies were barely visible.

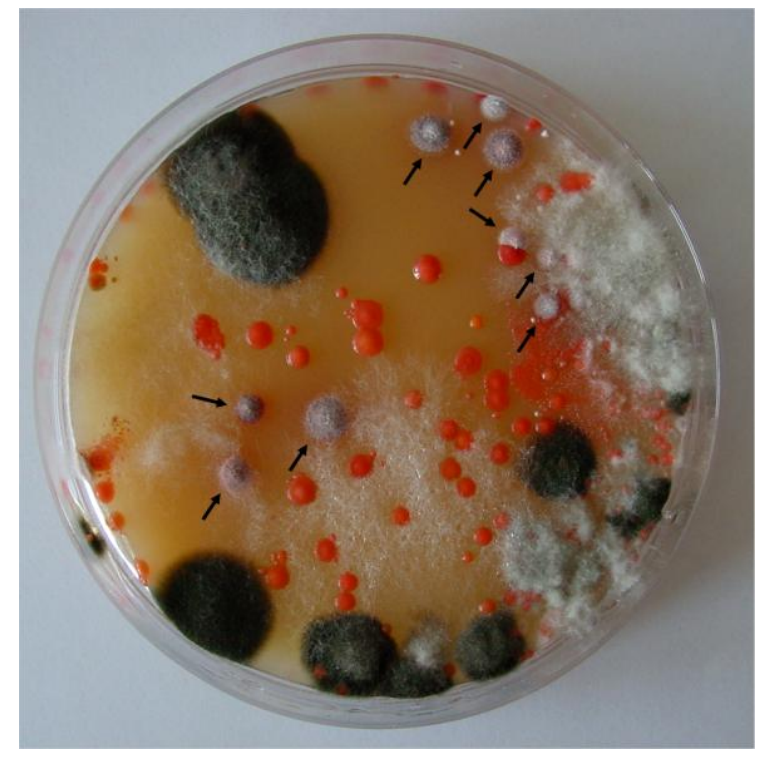

Figure 31. Spore trap containing semi selective V8A medium containing of 25 ppm Acanto (250 $\mathrm{g} / \mathrm{L}$ picoxystrobin) and $200 \mathrm{ppm}$ streptomycin sulphate, which either slow down the growth or inhibit the growth of other fungi or bacteria. Black arrows show the colonies of Rcc.

\subsubsection{Monitoring spore dispersal by rain and snowfalls}

In the present study, rain and snow samples were collected at several kilometres distance from barley fields and about $20 \mathrm{~m}$ above the ground. DNA extractions were performed from rain and snow samples, which were used for qualitative PCR analysis. Among twenty three samples, which were collected during October 2008 to January 2009, 6 (23\%) were found to be positive for Rcc (Fig. 32). These results indicate that Rcc was detectable during late autumn and winter months at larger distances from fields and in higher elevation above ground. We therefore assumed that Rcc inoculum is widespread also in the cooler season and may spread over large distances via the atmosphere and in rain water or snow.

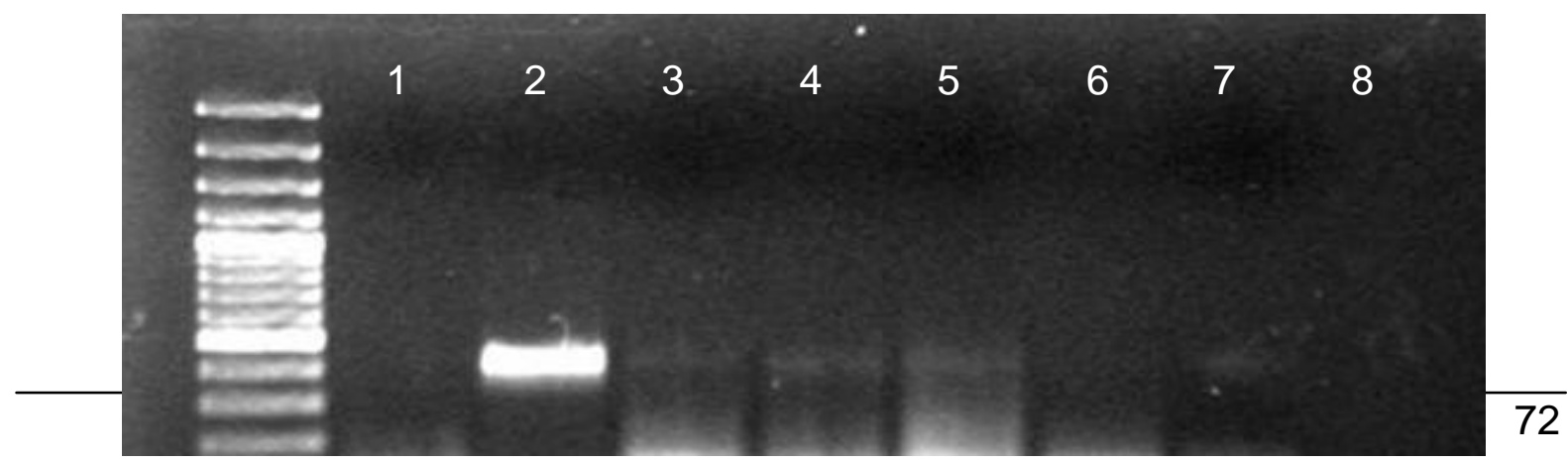


Figure 32. Gel electrophoresis of Rcc DNA in rain and snow samples which were detected by PCR. Lanes: 100-bp DNA ladder Plus (Fermentas); 1) negative control; 2) positive control (pure Rcc DNA) 3, 4, 5, 6 and 8) rain samples which were gathered from 22.10.2008 to 05.01.2009; 7) snow sample which was gathered at 26.11.2008

\subsubsection{Resistance screening under field conditions}

Although temperature, rainfall, and relative humidity were different in July 2009 and July 2010, there was a good agreement among the screening results. There were significant differences ( $\mathrm{p} \leq 0.05$ ) among different spring barley genotypes in different two years under field conditions. Symptom development in the field occurred relatively late in the plant development almost when the plants were at flowering stage. In both years, percentage of disease symptoms for the most genotypes was less than $10 \%$ at early growth stage (61-65). Due to the warm conditions in 2010, the disease level was relatively lower in this year in comparison with 2009 (Fig. 33).

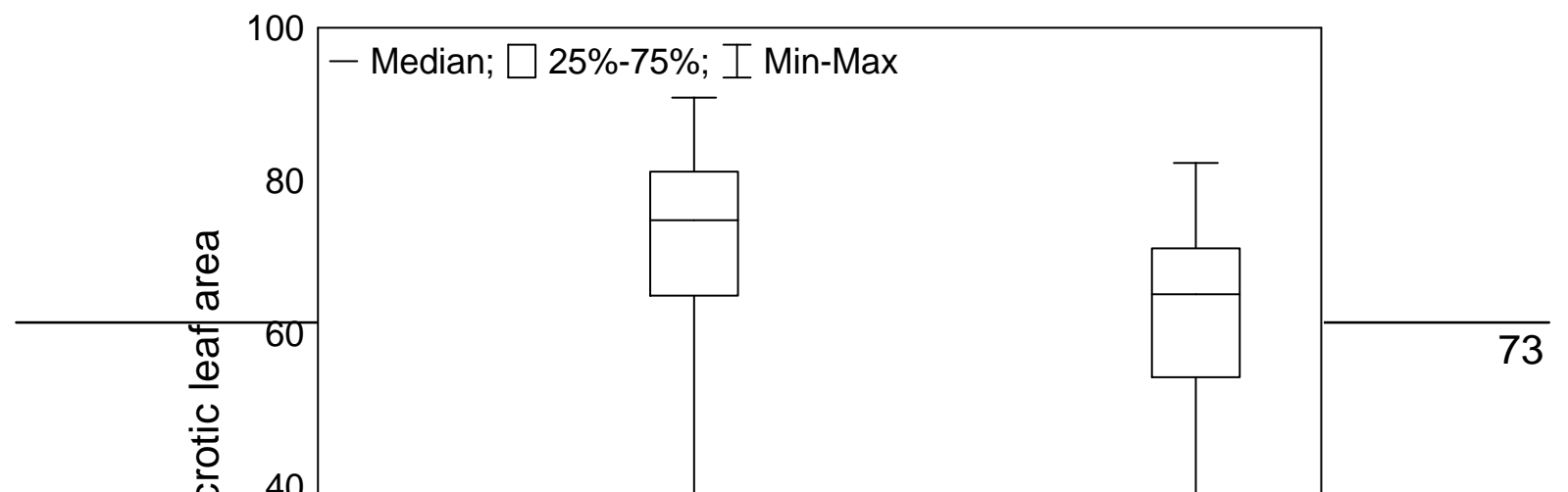


Figure 33. Disease severity (\%) on F-1 leaves of forty different spring barley genotypes at early and late growth stages in two different years (2009 and 2010). Data show Box-WhiskerPlots with median values. Borders of boxes represent $25 \%$ and $75 \%$ quartiles, thus boxes contain $50 \%$ of observed values. Boxes represent $25-75 \%$ of the data and whiskers contain minimum and maximum values.

For field scoring in 2009, first at GS 61-65, 50 plants per each replicate (in total 150 plants) were harvested and three upper leaves (flag leaf, F-1 and F-2) of each plant were scored for RLS by visually estimating the percentage of necrotic leaf area. In all genotypes, symptoms first become visible on leaf $\mathrm{F}-2$ with maximum amount of $23.63 \%( \pm 09.42)$ for Victoriana and $0.0 \%$ for IPZ 24727. Disease symptoms on F-1 ranged from $0.0 \%$ for IPZ 24727 to $15.33 \%( \pm 13.57)$ for Signiora. No visible symptoms were observed on flag leaves. At GS 73-75, scoring of disease symptoms was repeated as like in GS 61-65. Symptoms were clearly visible on all leaves at this time point (Table 12) except for cultivar Gaute which was infected strongly by powdery mildew which made it impossible to score the Rcc disease symptoms.

Table 12. Susceptibility of different spring barley cultivars to RLS in the field trial in 2009 under natural infection conditions. At growth stage 73-75, the three upper leaves were scored by estimating the percentage of necrotic leaf area; data show the mean of $150\left(3^{\star} 50\right)$ replicates with standard deviations (in brackets) 


\begin{tabular}{|c|c|c|c|c|c|c|c|c|c|}
\hline \multirow{2}{*}{$\begin{array}{c}\text { Spring barley } \\
\text { genotype }\end{array}$} & \multicolumn{8}{|c|}{$\%$ Necrotic leaf area (士SD) $^{1}$} & \\
\hline & \multicolumn{3}{|c|}{ Flag Leaf } & \multicolumn{3}{|l|}{$\mathrm{F}-1$} & \multicolumn{3}{|l|}{$\mathrm{F}-2$} \\
\hline Audrey & 24.67 & $( \pm 15.67)$ & mnop & 81.19 & $( \pm 14.74)$ & kImnop & 92.33 & $( \pm 06.11)$ & mnop \\
\hline Barke & 34.33 & $( \pm 15.57)$ & qrst & 90.86 & $( \pm 12.27)$ & $\mathrm{p}$ & 98.33 & $( \pm 05.30)$ & $\mathrm{p}$ \\
\hline Braemer & 38.67 & $( \pm 14.45)$ & rst & 80.53 & $( \pm 19.50)$ & jklmno & 95.00 & $( \pm 09.30)$ & nop \\
\hline Conchita & 30.33 & $( \pm 13.16)$ & opqrs & 87.86 & $( \pm 20.34)$ & nop & 93.33 & $( \pm 03.09)$ & $o p$ \\
\hline Fairytale & 22.67 & $( \pm 12.94)$ & Imno & 76.86 & $( \pm 13.02)$ & ijklmn & 91.20 & $( \pm 04.95)$ & Imnop \\
\hline Gaute & 00.00 & $( \pm 00.00)$ & a & 00.00 & $( \pm 00.00)$ & a & 0.00 & $( \pm 00.00)$ & a \\
\hline GS 2298 & 24.67 & $( \pm 14.82)$ & mnop & 74.86 & $( \pm 18.46)$ & hijkl & 89.67 & $( \pm 03.99)$ & klmnop \\
\hline GS 2301 & 19.40 & $( \pm 13.24)$ & jklmn & 80.86 & $( \pm 11.45)$ & jklmno & 88.33 & $( \pm 04.08)$ & ijklmno \\
\hline GS2300 & 17.67 & $( \pm 17.20)$ & hijklmn & 80.86 & $( \pm 16.09)$ & jklmno & 89.67 & $( \pm 06.67)$ & klmnop \\
\hline Gustav & 9.07 & $( \pm 05.93)$ & abcdefg & 71.19 & $( \pm 14.52)$ & ghijk & 83.00 & $( \pm 05.61)$ & fghij \\
\hline Hatifa & 50.33 & $( \pm 15.86)$ & u & 90.53 & $( \pm 18.63)$ & $\mathrm{p}$ & 96.67 & $( \pm 06.11)$ & op \\
\hline Henrike & 15.00 & $( \pm 13.76)$ & fghijkl & 81.86 & $( \pm 12.65)$ & Imnop & 94.73 & $( \pm 11.26)$ & ghijklm \\
\hline IPZ 24727 & 0.87 & $( \pm 01.25)$ & $a b$ & 18.33 & $( \pm 06.85)$ & a & 24.33 & $( \pm 06.51)$ & b \\
\hline Isabella & 5.07 & $( \pm 05.15)$ & abcd & 63.86 & $( \pm 14.42)$ & cde & 88.33 & $( \pm 08.59)$ & ijklmno \\
\hline JB Flavour & 10.67 & $( \pm 07.76)$ & cdefghij & 62.53 & $( \pm 18.46)$ & $c d$ & 84.00 & $( \pm 06.32)$ & ghijk \\
\hline Jennifer & 11.33 & $( \pm 04.81)$ & cdefghij & 75.86 & $( \pm 13.40)$ & hijkl & 87.67 & $( \pm 10.83)$ & ijklmno \\
\hline Justina & 42.00 & $( \pm 14.37)$ & tu & 79.67 & $( \pm 09.42)$ & mno & 85.87 & $( \pm 21.91)$ & ghijklmn \\
\hline Kangoo & 5.87 & $( \pm 03.40)$ & abcde & 66.86 & $( \pm 12.84)$ & defghi & 87.00 & $( \pm 07.51)$ & hijklmn \\
\hline Lanfeust & 38.67 & $( \pm 29.06)$ & rst & 87.00 & $( \pm 15.90)$ & op & 98.00 & $( \pm 15.21)$ & ijklmno \\
\hline Lisanne & 15.73 & $( \pm 14.05)$ & ghijklm & 74.53 & $( \pm 11.38)$ & ghijk & 84.33 & $( \pm 08.21)$ & ghijk \\
\hline Macaw & 25.67 & $( \pm 12.37)$ & nopq & 76.33 & $( \pm 09.42)$ & hijk & 87.67 & $( \pm 05.94)$ & ijklmno \\
\hline Marthe & 9.40 & $( \pm 10.78)$ & bcdefghi & 76.19 & $( \pm 11.63)$ & hijklm & 84.67 & $( \pm 09.35)$ & ghijkl \\
\hline Mercada & 5.53 & $( \pm 03.72)$ & abcd & 60.19 & $( \pm 12.42)$ & c & 81.00 & $( \pm 05.73)$ & efgh \\
\hline Mimer & 6.53 & $( \pm 04.53)$ & abcdef & 63.53 & $( \pm 09.04)$ & cde & 80.33 & $( \pm 13.29)$ & efg \\
\hline Nymfe & 2.93 & $( \pm 02.74)$ & $a b c$ & 62.53 & $( \pm 11.42)$ & $c d$ & 74.67 & $( \pm 10.77)$ & de \\
\hline Pasadena & 29.67 & $( \pm 18.66)$ & opqr & 76.19 & $( \pm 09.04)$ & $\mathrm{cklm}$ & 87.67 & $( \pm 05.94)$ & ijklmno \\
\hline Power & 10.33 & $( \pm 03.52)$ & cdefghij & 59.53 & $( \pm 20.34)$ & c & 82.67 & $( \pm 07.99)$ & fghij \\
\hline Primadonna & 9.33 & $( \pm 04.58)$ & cdefghij & 69.00 & $( \pm 13.89)$ & efg & 92.00 & $( \pm 03.68)$ & nop \\
\hline Publican & 39.33 & $( \pm 21.45)$ & st & 70.33 & $( \pm 10.93)$ & $\mathrm{fg}$ & 86.33 & $( \pm 13.16)$ & ghijklm \\
\hline Quench & 21.67 & $( \pm 14.47)$ & klmno & 65.00 & $( \pm 11.60)$ & cdefg & 82.33 & $( \pm 05.63)$ & fghi \\
\hline
\end{tabular}

Continuing from previous page (Table 12)

$\begin{array}{lrllllllll}\text { Ria } & 12.67 & ( \pm 11.47) & \text { defghijk } & 64.86 & ( \pm 18.63) & \text { cdef } & 86.67 & ( \pm 10.97) & \text { ghjklmn } \\ \text { Scandium } & 5.07 & ( \pm 04.40) & \text { abcd } & 59.33 & ( \pm 17.27) & \text { c } & 69.67 & ( \pm 14.82) & \text { d } \\ \text { Scarlett } & 23.33 & ( \pm 12.05) & \text { Imno } & 86.86 & ( \pm 06.29) & \text { mnop } & 95.33 & ( \pm 02.97) & \text { mnop }\end{array}$




$\begin{array}{lrllllllll}\text { Sebastian } & 8.00 & ( \pm 03.68) & \text { abcdefg } & 74.19 & ( \pm 06.67) & \text { ghijk } & 86.33 & ( \pm 04.42) & \text { ghijklmn } \\ \text { Signiora } & 33.67 & ( \pm 18.07) & \text { pqrst } & 71.25 & ( \pm 09.35) & \text { ghijk } & 89.00 & ( \pm 04.31) & \text { jklmno } \\ \text { Styx } & 12.47 & ( \pm 14.26) & \text { defghij } & 65.67 & ( \pm 11.78) & \text { cdef } & 88.00 & ( \pm 11.77) & \text { ijklmno } \\ \text { Umberella } & 2.93 & ( \pm 02.74) & \text { abc } & 59.19 & ( \pm 06.21) & \text { c } & 77.00 & ( \pm 08.19) & \text { ef } \\ \text { Varberg } & 5.53 & ( \pm 04.17) & \text { abcd } & 43.86 & ( \pm 13.65) & \text { b } & 61.67 & ( \pm 17.39) & \text { c } \\ \text { Victoriana } & 14.80 & ( \pm 13.41) & \text { efghijkl } & 77.19 & ( \pm 17.90) & \text { ijklmno } & 86.67 & ( \pm 12.49) & \text { ghijklmn } \\ \text { Waldemar } & 18.33 & ( \pm 08.16) & \text { ijklmn } & 78.53 & ( \pm 08.12) & \text { jklmno } & 86.00 & ( \pm 04.71) & \text { ghijklmn }\end{array}$

${ }^{1}$ Percentage of necrotic leaf area due to RLS on three different leaves at GS 73-75. Values with different letter within the same column indicate significant differences $(p \leq 0.05)$ between the genotypes, calculated by the LSD-Fisher test

In 2010, due to strong correlation between the results of disease symptoms on the flag leaf and F-1 $\left(r_{s}=0.7899 ; p=0.0000\right)$ and F-1 to $F-2\left(r_{s}=0.8372 ; p=0.00001\right)$ at GS 73-75 in 2009, the percentage of necrotic leaf area was only estimated on F-1 leaf. At different growth stages (61-65, 65-69, 71-73, and 73-75), fifty F-1 leaves were harvested randomly per each replicate (in total 150 plants) and scored for RLS by visually estimating the percentage of necrotic leaf area (Table 13).

Table 13. Susceptibility of different spring barley cultivars to RLS at field trial in 2010 in Lenglern/Germany under natural infection conditions. Leaf F-1 was scored by estimating the percentage of necrotic leaf area at different growth stages; data are means of $150\left(3^{\star} 50\right)$ replicates with standard deviations (in brackets)

$\%$ Necrotic leaf area ( \pm SD) ${ }^{1}$ 


\begin{tabular}{|c|c|c|c|c|c|c|c|c|}
\hline $\begin{array}{l}\text { Barley } \\
\text { genotypes }\end{array}$ & GS 61-65 & & GS 65-69 & & GS 71-73 & & GS 73-75 & \\
\hline Audery & $0.77( \pm 0.43)$ & abcdef & $2.30( \pm 2.05)$ & cdef & $8.20( \pm 5.38)$ & bcd & $52.80( \pm 08.63)$ & e \\
\hline Barke & $1.07( \pm 1.14)$ & defgh & $4.37( \pm 3.42)$ & ghik & $21.33( \pm 7.76)$ & $\mathrm{jk}$ & $73.83( \pm 08.96)$ & nop \\
\hline Braemar & $1.03( \pm 1.16)$ & cdefgh & $6.63( \pm 3.52)$ & $\mathrm{mn}$ & $45.67( \pm 6.66)$ & $r$ & $75.00( \pm 08.30)$ & $p$ \\
\hline Conchita & $1.03( \pm 1.16)$ & cdefgh & $4.63( \pm 3.78)$ & hijkl & $28.67( \pm 6.15)$ & nop & $60.50( \pm 07.93)$ & $q$ \\
\hline Fairytale & $0.30( \pm 0.47)$ & $\mathrm{ab}$ & $2.00( \pm 1.86)$ & bcd & $6.57( \pm 2.84)$ & bcd & $45.83( \pm 10.09)$ & c \\
\hline GS 2298 & $0.37( \pm 0.49)$ & $a b c$ & $3.90( \pm 3.38)$ & efghij & $19.33( \pm 7.74)$ & ij & $47.00( \pm 08.36)$ & c \\
\hline GS 2300 & $0.83( \pm 0.38)$ & abcdef & $3.90( \pm 3.11)$ & efghij & $13.67( \pm 6.01)$ & $\mathrm{fg}$ & $65.17( \pm 08.24)$ & ij \\
\hline GS 2301 & $0.47( \pm 0.51)$ & abcde & $0.70( \pm 0.95)$ & $a b$ & $5.03( \pm 3.06)$ & $\mathrm{ab}$ & $56.83( \pm 14.11)$ & $\mathrm{fg}$ \\
\hline Gustav & $1.90( \pm 1.75)$ & $\mathrm{klm}$ & $4.50( \pm 3.09)$ & hijkl & $14.83( \pm 8.25)$ & gh & $69.83( \pm 07.37)$ & $\mathrm{klmn}$ \\
\hline Hatifa & $1.13( \pm 1.11)$ & efghij & $6.57( \pm 4.96)$ & $\mathrm{mn}$ & $18.50( \pm 6.04)$ & jk & $74.13( \pm 09.33)$ & $o p$ \\
\hline Henrike & $1.73( \pm 2.29)$ & $\mathrm{ijk} \mathrm{kl}$ & $3.17( \pm 2.84)$ & defgh & $7.53( \pm 5.26)$ & bcd & $64.00( \pm 16.75)$ & hij \\
\hline IPZ 24727 & $0.20( \pm 0.41)$ & a & $0.27( \pm 0.45)$ & a & $2.10( \pm 1.95)$ & a & $5.10( \pm 03.23)$ & a \\
\hline Isabella & $1.80( \pm 1.83)$ & $\mathrm{jklm}$ & $2.60( \pm 1.99)$ & cdef & $10.87( \pm 5.82)$ & ef & $56.00( \pm 10.03)$ & ef \\
\hline JB Flavour & $2.47( \pm 1.96)$ & $\mathrm{m}$ & $4.57( \pm 3.96)$ & cdef & $8.53( \pm 4.12)$ & cde & $48.67( \pm 07.30)$ & $c d$ \\
\hline Jennifer & $2.30( \pm 1.95)$ & Im & $8.37( \pm 3.48)$ & 0 & $26.67( \pm 8.13)$ & $\mathrm{mn}$ & $61.33( \pm 08.70)$ & hi \\
\hline Kangoo & $1.53( \pm 1.61)$ & ghijk & $7.10( \pm 3.67)$ & no & $24.67( \pm 7.18)$ & $\mathrm{Im}$ & $70.17( \pm 06.76)$ & klmno \\
\hline Kia & $1.30( \pm 1.29)$ & fghijk & $3.57( \pm 2.66)$ & defgh & $13.00( \pm 6.51)$ & $\mathrm{fg}$ & $51.17( \pm 05.52)$ & de \\
\hline Lisanne & $0.73( \pm 0.45)$ & abcdef & $6.17( \pm 3.29)$ & Imn & $32.83( \pm 6.11)$ & $p$ & $73.83( \pm 09.97)$ & nop \\
\hline Marthe & $1.13( \pm 1.38)$ & efghij & $3.23( \pm 3.23)$ & defgh & $23.00( \pm 8.26)$ & $\mathrm{kl}$ & $66.33( \pm 07.06)$ & $\mathrm{jk}$ \\
\hline Mercada & $0.60( \pm 0.50)$ & abcd & $4.13( \pm 3.81)$ & fghij & $8.50( \pm 2.98)$ & cde & $55.50( \pm 08.13)$ & ef \\
\hline Mimer & $0.87( \pm 0.90)$ & abcdef & $2.23( \pm 2.01)$ & bcd & $18.33( \pm 4.22)$ & ij & $38.67( \pm 06.01)$ & b \\
\hline Nymfe & $0.60( \pm 0.50)$ & abcde & $2.57( \pm 2.03)$ & cde & $14.17( \pm 4.75)$ & g & $65.17( \pm 07.25)$ & ij \\
\hline Pasadena & $0.70( \pm 0.47)$ & abcdef & $3.93( \pm 3.07)$ & hijk & $31.83( \pm 6.09)$ & op & $72.83( \pm 06.91)$ & mnop \\
\hline Power & $1.90( \pm 1.75)$ & $\mathrm{klm}$ & $4.90( \pm 2.86)$ & ijkl & $17.83( \pm 5.36)$ & hi & $70.50( \pm 07.35)$ & Imno \\
\hline Quench & $0.83( \pm 1.23)$ & bcdef & $5.83( \pm 3.13)$ & $\mathrm{klm}$ & $39.17( \pm 8.00)$ & 0 & $82.33( \pm 05.68)$ & $q$ \\
\hline Ria & $0.63( \pm 0.96)$ & abcdef & $0.77( \pm 1.25)$ & $\mathrm{ab}$ & $9.37( \pm 4.98)$ & de & $54.33( \pm 08.68)$ & ef \\
\hline Scandium & $0.87( \pm 1.22)$ & abcdef & $5.30( \pm 3.79)$ & $\mathrm{jklm}$ & $18.50( \pm 4.38)$ & ij & $69.50( \pm 08.55)$ & $\mathrm{klm}$ \\
\hline Scarlett & $0.60( \pm 0.50)$ & abcdef & $4.93( \pm 3.36)$ & $\mathrm{ijkl}$ & $26.0( \pm 6.62)$ & Imn & $80.07( \pm 09.44)$ & q \\
\hline Sebastian & $2.93( \pm 3.07)$ & $\mathrm{n}$ & $15.2( \pm 7.35)$ & $p$ & $41.50( \pm 7.78)$ & $q$ & $65.17( \pm 07.71)$ & $q$ \\
\hline
\end{tabular}

Continuing from previous page (Table 13)

\begin{tabular}{lllllrllll}
\hline Signiora & $1.67( \pm 1.92)$ & hijkl & $2.20( \pm 2.04)$ & bcd & $13.67( \pm 3.46)$ & fg & $81.17( \pm 07.03)$ & & \\
Thule & $0.43( \pm 0.50)$ & abcd & $1.60( \pm 1.77)$ & abc & $5.57( \pm 3.61)$ & bc & $38.67( \pm 06.81)$ & ef \\
Umbrella & $2.43( \pm 1.99)$ & $\mathrm{m}$ & $2.83( \pm 2.07)$ & cdefg & $6.37( \pm 2.53)$ & bcd & $54.42( \pm 08.42)$ & fg \\
Varberg & $1.97( \pm 1.88)$ & $\mathrm{klm}$ & $3.57( \pm 2.66)$ & defghi & $24.67( \pm 6.56)$ & $\mathrm{lm}$ & $56.67( \pm 08.44)$ & $\mathrm{mno}$
\end{tabular}




$\begin{array}{lllllllll}\text { Victoriana } & 0.73( \pm 0.65) & \text { abcdef } & 2.37( \pm 2.06) & \text { cde } & 26.67( \pm 6.06) & \text { mn } & 71.17( \pm 09.44) & \text { jkl } \\ \text { Waldemar } & 3.93( \pm 3.07) & n & 15.2( \pm 7.35) & \mathrm{p} & 41.50( \pm 7.78) & \mathrm{r} & 66.67( \pm 06.48) & \mathrm{q}\end{array}$

${ }^{1}$ Percentage of necrotic leaf area due to RLS on leaf F-1 at different growth stages. Values with different letter within the same column indicate significant differences $(p \leq 0.05)$ between the genotypes at one time point, calculated by the LSD-Fisher test

According to table 13 the development of disease symptoms in 2010 was low until GS 71-73. In that year, at GS 61-65, the percentage of disease symptoms on F-1 leaves ranged from $0.20( \pm 0.41)$ for IPZ 24727 to $3.93( \pm 3.07)$ for Waldemar. Disease development increased gradually until GS $71-73$ with a minimum amount of $2.10 \%$ $( \pm 1.95)$ for IPZ 24727 and a maximum amount of $45.67 \%( \pm 6.66)$ for Braemar. Favourable conditions for pathogen development between GS 71-73 and GS 73-75 resulted in a dramatic increase in disease symptoms in most barley genotypes, which ranged from 5.10\% ( \pm 03.23$)$ for IPZ 24727 to $82.33 \%$ ( \pm 05.68$)$ for Quench.

Although the cultivar IPZ 24727 showed the strongest resistance reaction to Rcc on F-1 at GS $73-75$ with the disease severity levels of $18.33 \%$ in 2009 and of $5.10 \%$ in 2010, the other cultivars were more or less susceptible. In 2009 the most susceptible cultivars were Barke (90.86\%), Hatifa (90.53\%), and Conchita (87.86\%). Spring barley cultivars Quench (82.33\%), Signiora (81.17\%), and Scarlett (80.07\%) were the most susceptible genotypes in 2010. Dry conditions in 2010 resulted in a limited Rcc epidemic. Rcc is favoured by high humidity conditions and average temperatures of 15 to $20{ }^{\circ} \mathrm{C}$. Meteorological data indicated that temperature was less and relative humidity was much higher during disease development in July 2009 compared to July 2010 (Fig. 34).

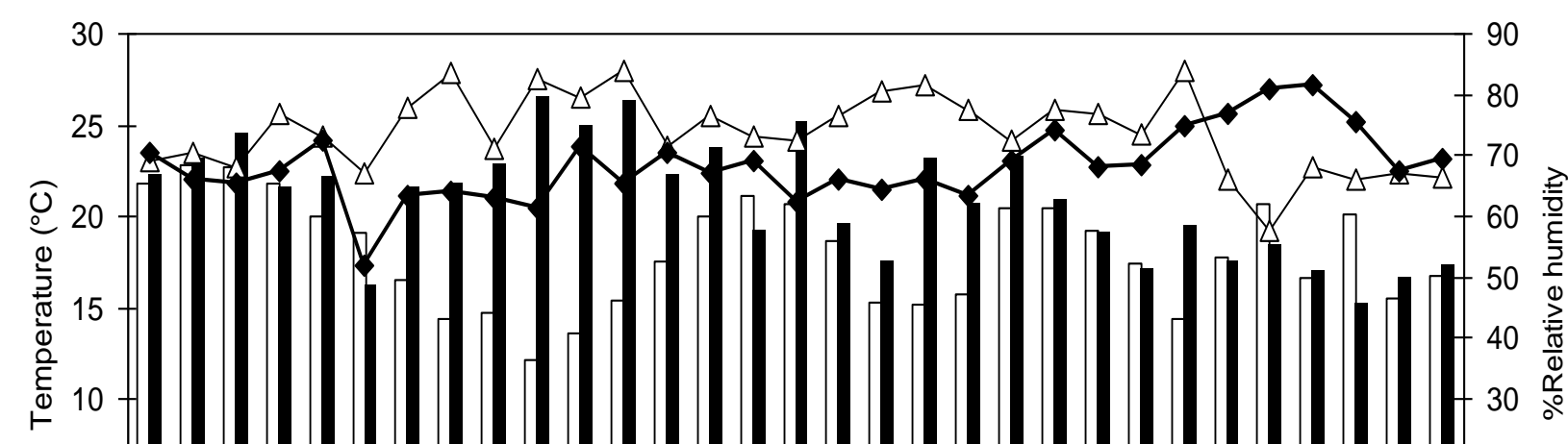


Figure 34. Comparison of average day temperature $\left({ }^{\circ} \mathrm{C}\right)$ and relative humidity (\%) in July 2009 and July 2010 during Rcc infection on the field trial. White columns indicated average day temperature in 2009, which were much lower than black columns (average day temperature in 2010) especially from $1^{\text {st }}$ to $15^{\text {th }}$ of July during major disease development. The white symbols indicate percentage of relative humidity in 2009, which was higher than 2010 (black symbols). Data were recorded by the German Weather Service (DWD), Göttingen station.

The analyses of variance for different genotypes in each year at late growth stage (73-75) and the comparison of each mean value of disease symptoms for each genotype in two years are given in Table 14.

Table 14. Comparison of susceptibility of different spring barley cultivars to RLS in field trials under natural infection conditions in two different years (2009 and 2010) in Lenglern/Germany. Leaf F-1 was scored by estimating the percentage of necrotic leaf area at growth stages $73-75$; data are means of $150\left(3^{*} 50\right)$ replicates with standard deviations (in brackets) 


\begin{tabular}{|c|c|c|c|c|c|c|c|}
\hline \multirow{2}{*}{$\begin{array}{l}\text { Barley } \\
\text { genotypes }\end{array}$} & \multicolumn{6}{|c|}{$\%{\text { Necrotic leaf area }( \pm S D)^{1}}^{1}$} & \multirow[b]{2}{*}{$p$-value } \\
\hline & 2009 & & & 2010 & & & \\
\hline IPZ 24727 & 18.33 & $( \pm 06.85)$ & $\mathrm{a}$ & 05.10 & $( \pm 03.23)$ & $\mathrm{a}$ & $0.000524^{\star}$ \\
\hline Varberg & 43.86 & $( \pm 13.65)$ & b & 56.67 & $( \pm 08.44)$ & fg & 0.020614 \\
\hline Scandium & 59.33 & $( \pm 17.27)$ & c & 69.50 & $( \pm 08.55)$ & $\mathrm{klm}$ & $0.020704^{\star}$ \\
\hline Umberella & 59.19 & $( \pm 06.21)$ & c & 54.42 & $( \pm 08.42)$ & ef & 0.382213 \\
\hline Power & 59.53 & $( \pm 20.34)$ & c & 70.50 & $( \pm 07.35)$ & Imno & 0.057749 \\
\hline Mercada & 60.19 & $( \pm 12.42)$ & c & 55.50 & $( \pm 08.13)$ & ef & 0.082293 \\
\hline Nymfe & 62.53 & $( \pm 11.42)$ & $\mathrm{cd}$ & 65.17 & $( \pm 07.25)$ & ij & 0.058523 \\
\hline JB Flavour & 62.53 & $( \pm 18.46)$ & $\mathrm{cd}$ & 48.67 & $( \pm 07.30)$ & cd & 0.080743 \\
\hline Mimer & 63.53 & $( \pm 09.04)$ & cde & 38.67 & $( \pm 06.01)$ & $\mathrm{b}$ & $0.009890^{\star}$ \\
\hline Isabella & 63.86 & $( \pm 14.42)$ & cde & 56.00 & $( \pm 10.03)$ & ef & 0.237494 \\
\hline Ria & 64.86 & $( \pm 18.63)$ & cdef & 54.33 & $( \pm 08.68)$ & ef & 0.107400 \\
\hline Quench & 65.00 & $( \pm 11.60)$ & cdefg & 82.33 & $( \pm 05.68)$ & $q$ & $0.004359^{\star}$ \\
\hline Kangoo & 66.86 & $( \pm 12.84)$ & defghi & 70.17 & $( \pm 06.76)$ & klmno & $0.032871^{\star}$ \\
\hline Gustav & 71.19 & $( \pm 14.52)$ & ghijk & 69.83 & $( \pm 07.37)$ & klmn & 0.345180 \\
\hline Signiora & 71.25 & $( \pm 09.35)$ & ghijk & 81.17 & $( \pm 07.03)$ & $q$ & 0.077978 \\
\hline Sebastian & 74.19 & $( \pm 06.67)$ & ghijk & 65.17 & $( \pm 07.71)$ & ij & $0.025126^{\star}$ \\
\hline Lisanne & 74.53 & $( \pm 11.38)$ & ghijk & 73.83 & $( \pm 09.97)$ & nop & 0.813320 \\
\hline GS 2298 & 74.86 & $( \pm 18.46)$ & hijkl & 47.00 & $( \pm 08.36)$ & c & $0.011882^{\star}$ \\
\hline Jennifer & 75.86 & $( \pm 13.40)$ & hijkl & 61.33 & $( \pm 08.70)$ & hi & $0.019329^{\star}$ \\
\hline Marthe & 76.19 & $( \pm 11.63)$ & hijklm & 66.33 & $( \pm 07.06)$ & $\mathrm{jk}$ & $0.018869^{\star}$ \\
\hline Pasadena & 76.19 & $( \pm 09.04)$ & $\mathrm{cklm}$ & 72.83 & $( \pm 06.91)$ & mnop & 0.589027 \\
\hline Fairytale & 76.86 & $( \pm 13.02)$ & ijklmn & 45.83 & $( \pm 10.09)$ & c & $0.001713^{\star}$ \\
\hline Victoriana & 77.19 & $( \pm 17.90)$ & ijklmno & 71.17 & $( \pm 09.44)$ & mno & 0.616136 \\
\hline Waldemar & 78.53 & $( \pm 08.12)$ & jklmno & 66.67 & $( \pm 06.48)$ & $\mathrm{jkl}$ & $0.008386^{\star}$ \\
\hline Braemer & 80.53 & $( \pm 19.50)$ & jklmno & 75.00 & $( \pm 08.30)$ & $\mathrm{p}$ & 0.071698 \\
\hline GS 2301 & 80.86 & $( \pm 11.45)$ & jklmno & 56.83 & $( \pm 14.11)$ & $\mathrm{fg}$ & $0.010570^{\star}$ \\
\hline GS2300 & 80.86 & $( \pm 16.09)$ & jklmno & 65.17 & $( \pm 08.24)$ & ij & $0.042881^{\star}$ \\
\hline Audrey & 81.19 & $( \pm 14.74)$ & klmnop & 52.80 & $( \pm 08.63)$ & de & $0.001270^{\star}$ \\
\hline Henrike & 81.86 & $( \pm 12.65)$ & Imnop & 64.00 & $( \pm 16.75)$ & hij & $0.004053^{\star}$ \\
\hline
\end{tabular}

Continuing from previous page (Table 14)

\begin{tabular}{llllllll}
\hline Scarlett & 86.86 & $( \pm 06.29)$ & mnop & 80.07 & $( \pm 09.44)$ & q & 0.335739 \\
Conchita & 87.86 & $( \pm 20.34)$ & nop & 60.50 & $( \pm 07.93)$ & q & $0.0024299^{\star}$ \\
Hatifa & 90.53 & $( \pm 18.63)$ & p & 74.13 & $( \pm 09.33)$ & op & $0.011757^{\star}$
\end{tabular}


Barke $90.86( \pm 12.27)$

$73.83( \pm 08.96)$

0.005769 *

${ }^{1}$ Percentage of necrotic leaf area due to RLS on leaf F-1 in growth stage 73-75. Values with different letter within the same column indicate significant differences $(p \leq 0.05)$ between the genotypes in one year, calculated by the LSD-Fisher test

${ }^{2}$ t-tests between the mean values of each genotype in two different years; ${ }^{\star}$ significant differences at $p \leq 0.05$

Although different results were scored for the field trials in two consecutive years, a significant correlation $\left(r_{s}=0.419\right)$ was observed between field experiments in two different years at growth stage 73-75 (Fig. 35).

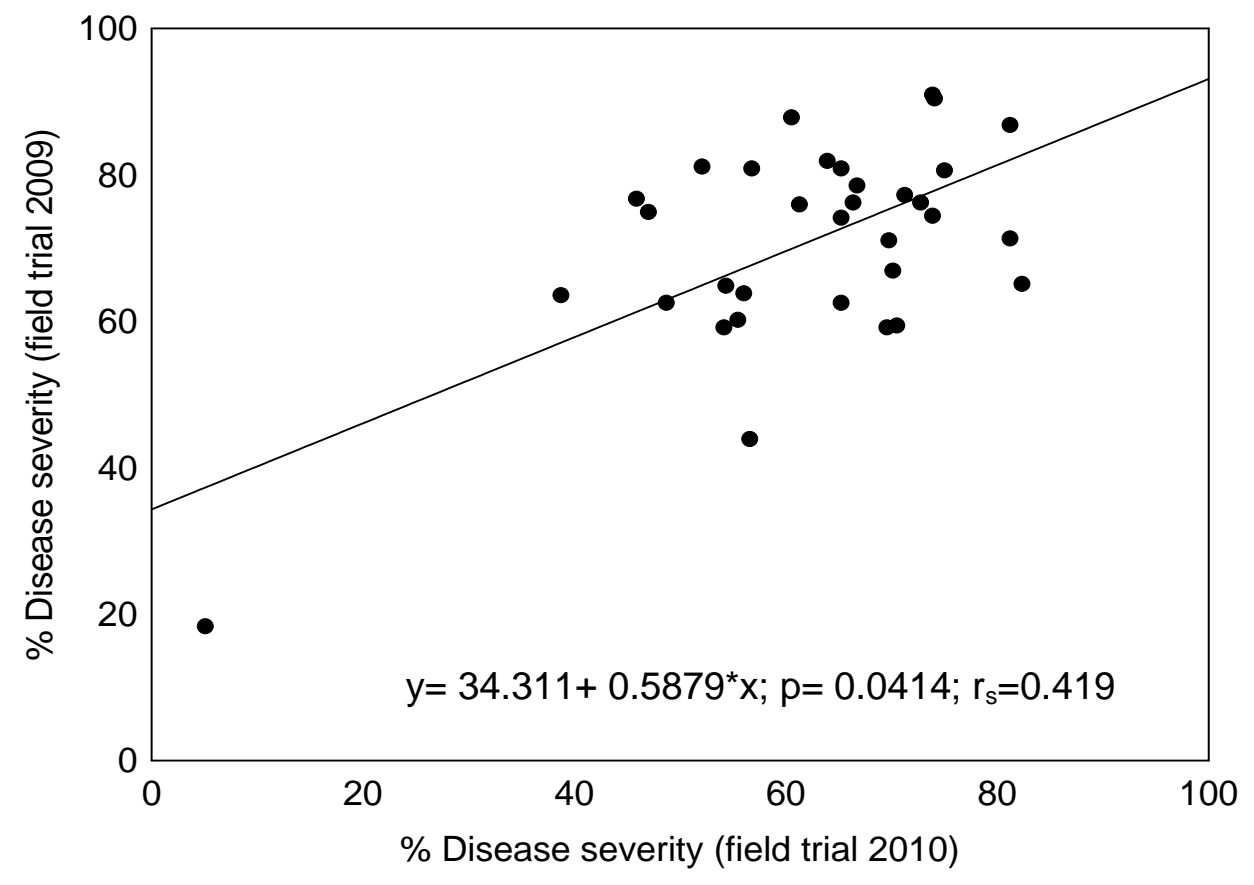

Figure 35. Correlation between disease severity (\% necrotic leaf area) in field experiment 2009 and field experiment 2010, both at Lenglern/Germany. $r_{s}$ : Spearman's rank correlation coefficient, $p$ : $p$-value $\leq 0.05$

Spore trap: In the year 2010, two spore traps, each containing 4 Petri dishes, were installed in both left and right side of the field trial. According to Fig. 36, the mean number of Rcc colonies remained more or less constant from beginning to middle of 
June in both spore traps. Surprisingly, the mean numbers of colonies on spore trap B showed highly significant differences $(p \leq 0.05)$ in comparison to spore trap A during the middle to almost late June. This great peak was detected a week before the first symptoms were visible on the field and plants were at growth stage 55-59. Field observation showed that the main source of this primary inoculum came from a strongly Rcc infected winter barley field which was located close to our field trial and about $30 \mathrm{~m}$ away from spore trap B. The second major peak was observed almost four weeks later when the plants were at growth stage 75/79 and completely were infected by Rcc.

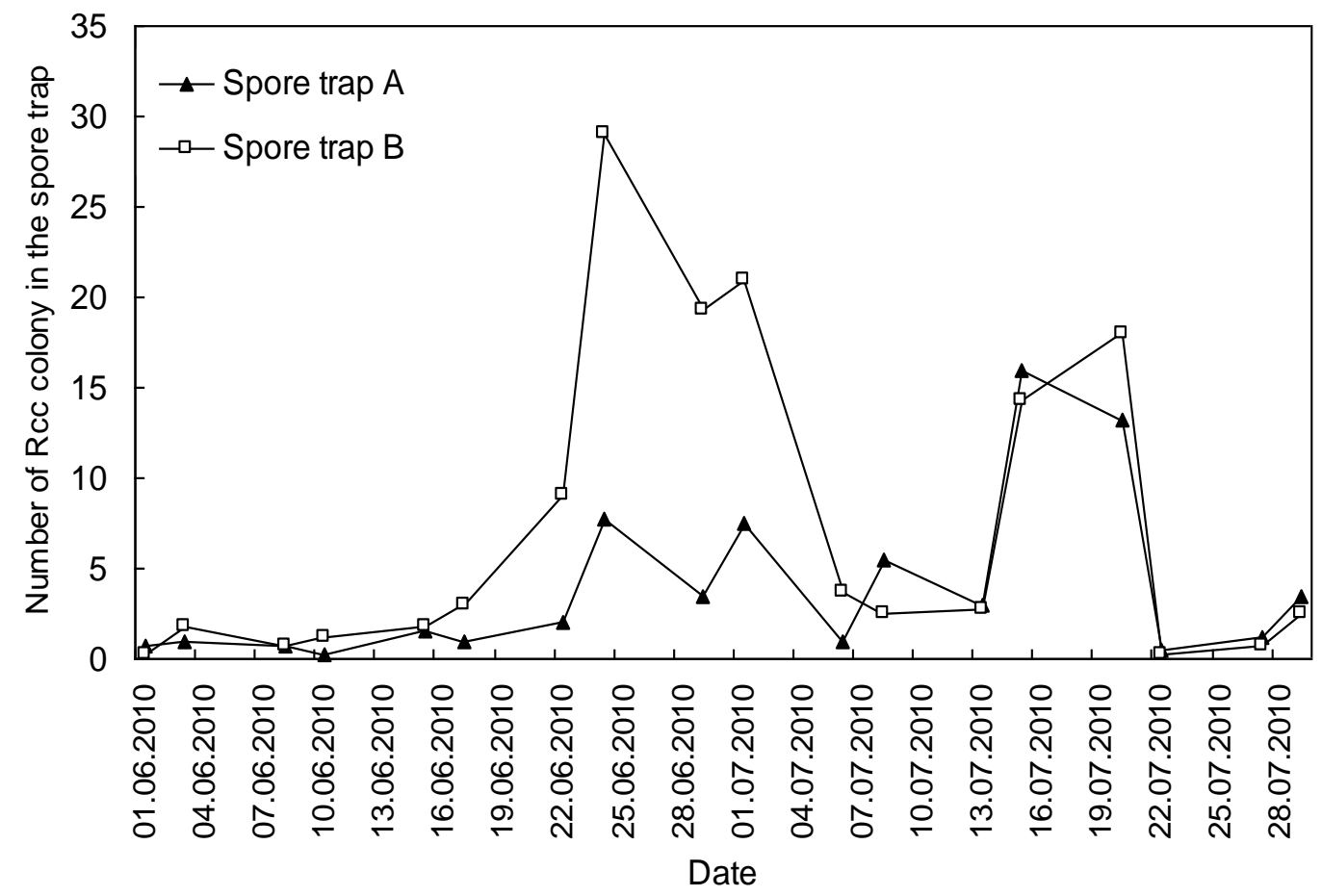

Figure 36. Average density of Rcc spores in spore traps, which were installed on both sides of a field trial from $1^{\text {st }}$ of June until 31st of July 2010; Lenglern, Lower Saxony, Germany.

Weather data during the experiments indicated that environmental conditions did not have strong effect on spore deposition (Fig. 37). 


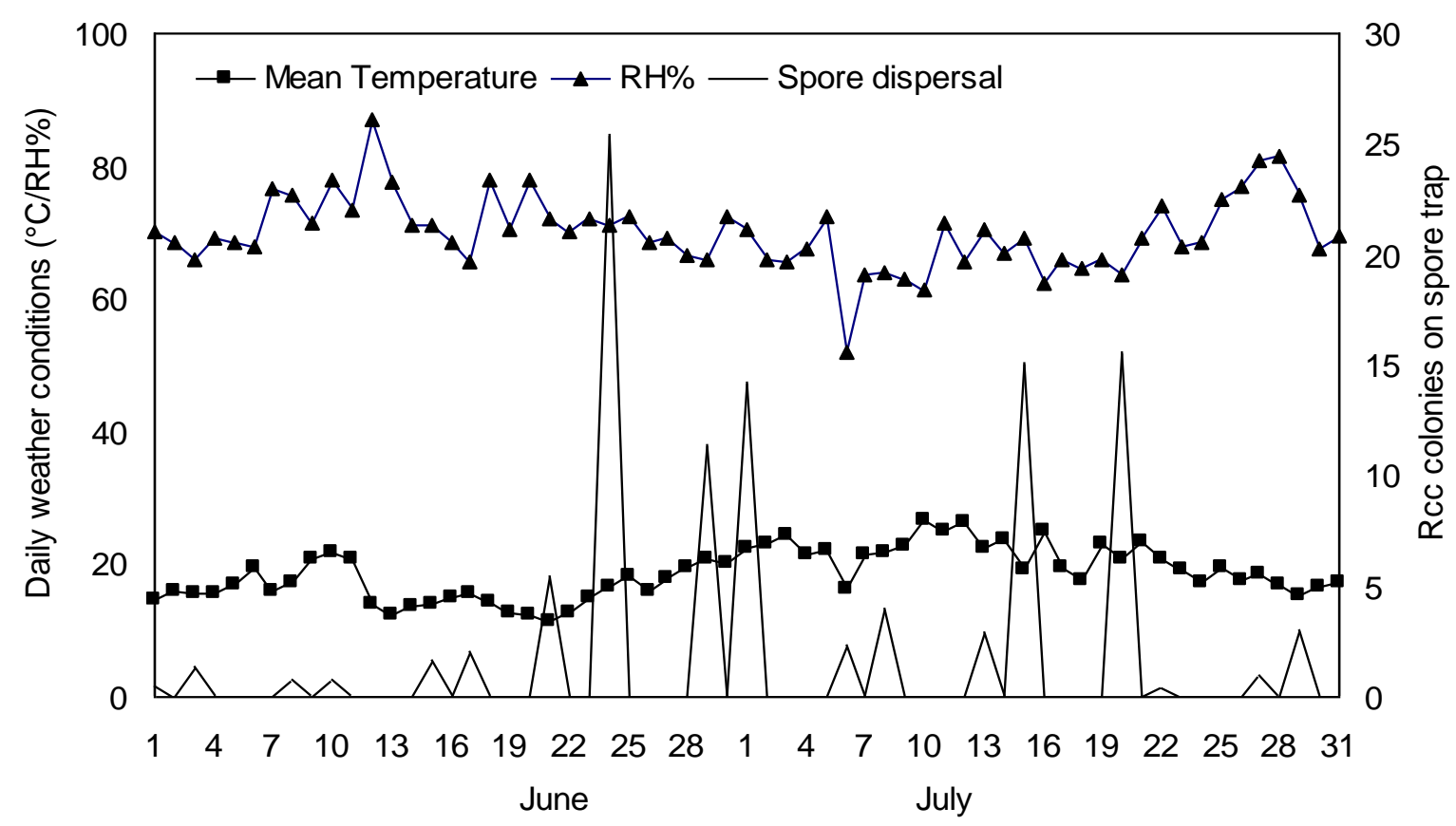

Figure 37. Weather conditions (average day temperature in ${ }^{\circ} \mathrm{C}$ and relative humidity in \%) and Rcc spore dispersal during the time course of the field trial in 2010; Lenglern, Lower Saxony, Germany.

\subsubsection{Quantification of fungal DNA during symptom development}

In previous studies fungal DNA was detected and quantified by qPCR using Rcc1 and Rcc5b primers. According to Fig. 6 , the limit of detection was $0.01 \mathrm{pg} / \mu \mathrm{l}$. In 2010 , development of fungal DNA concentration inside the plant was evaluated in ten different cultivars, starting at GS 61-65 and continuing until GS 73-75. By using specific primers for Rcc, fungal DNA could be detected as early as GS 61-65 in F-1 leaves before symptoms were visible (Fig. 38). At this growth stage, fungal DNA concentrations in most cultivars were calculated roughly to be between $0.01 \mathrm{ng} / \mathrm{g}$ for IPZ 24727 to $0.08 \mathrm{ng} / \mathrm{g}$ for Victoriana. At growth stage 65-69, the amounts of fungal DNA increased slightly in all cultivars to a maximum amount of $0.44 \mathrm{ng} / \mathrm{g}$ dry weight for cultivar Barke. At the next growth stage, DNA concentrations gradually increased from $0.84 \mathrm{ng} / \mathrm{g}$ in cultivar IPZ 24727 (most resistant cultivar), $5.55 \mathrm{ng} / \mathrm{g}$ in cultivar Lisanne (moderate susceptible) to $12.15 \mathrm{ng} / \mathrm{g}$ in cultivar Signiora (susceptible).

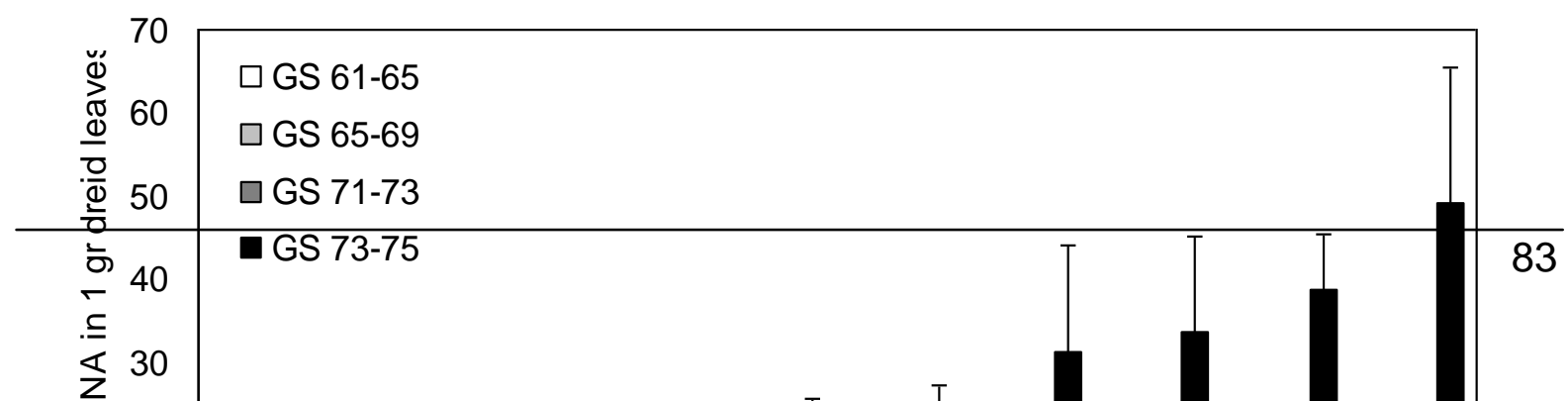


Figure 38. Development of Rcc-DNA detected by qPCR in different spring barley genotypes at different growth stages under field conditions. Sampling time point: $25^{\text {th }}$ June (GS 61-65); $2^{\text {nd }}$ July (GS 65-69); $9^{\text {th }}$ July (GS 71-73) and $16^{\text {th }}$ July (GS 73-75). Columns and whiskers represent the mean and standard deviations of three DNA samples of 50 pooled leaves material; the field experiment was conducted in 2010; Lenglern, Lower Saxony, Germany.

Dry conditions in 2010 resulted in less development of fungal DNA concentration until growth stage 73-75. After this dry period, weather conditions again were favourable for Rcc development. In all cultivars, fungal DNA concentrations increased dramatically. The amount of fungal DNA ranged from $10.44 \mathrm{ng} / \mathrm{g}$ for IPZ 24727, $16.39 \mathrm{ng} / \mathrm{g}$ for Lisanne, $38.78 \mathrm{ng} / \mathrm{g}$ for Barke and $49.25 \mathrm{ng} / \mathrm{g}$ for Quench. At this growth stage plants were infected strongly and the pathogen had already formed conidiophores and conidia on the abaxial part of leaves. These results were comparable to the results of symptom assessment under field conditions, which is suggesting that this time point is convenient for a reliable grouping of the different barley cultivars. Initially, the qPCR data indicated that cultivar IPZ 24727 classified as most resistant cultivar and Barke and Quench as the most susceptible. Statistical analysis showed a significant correlation between disease symptom development under field conditions and amount of fungal DNA at GS 73-75 with a correlation coefficient of $r_{s}=0.851$ (Fig. 39). 


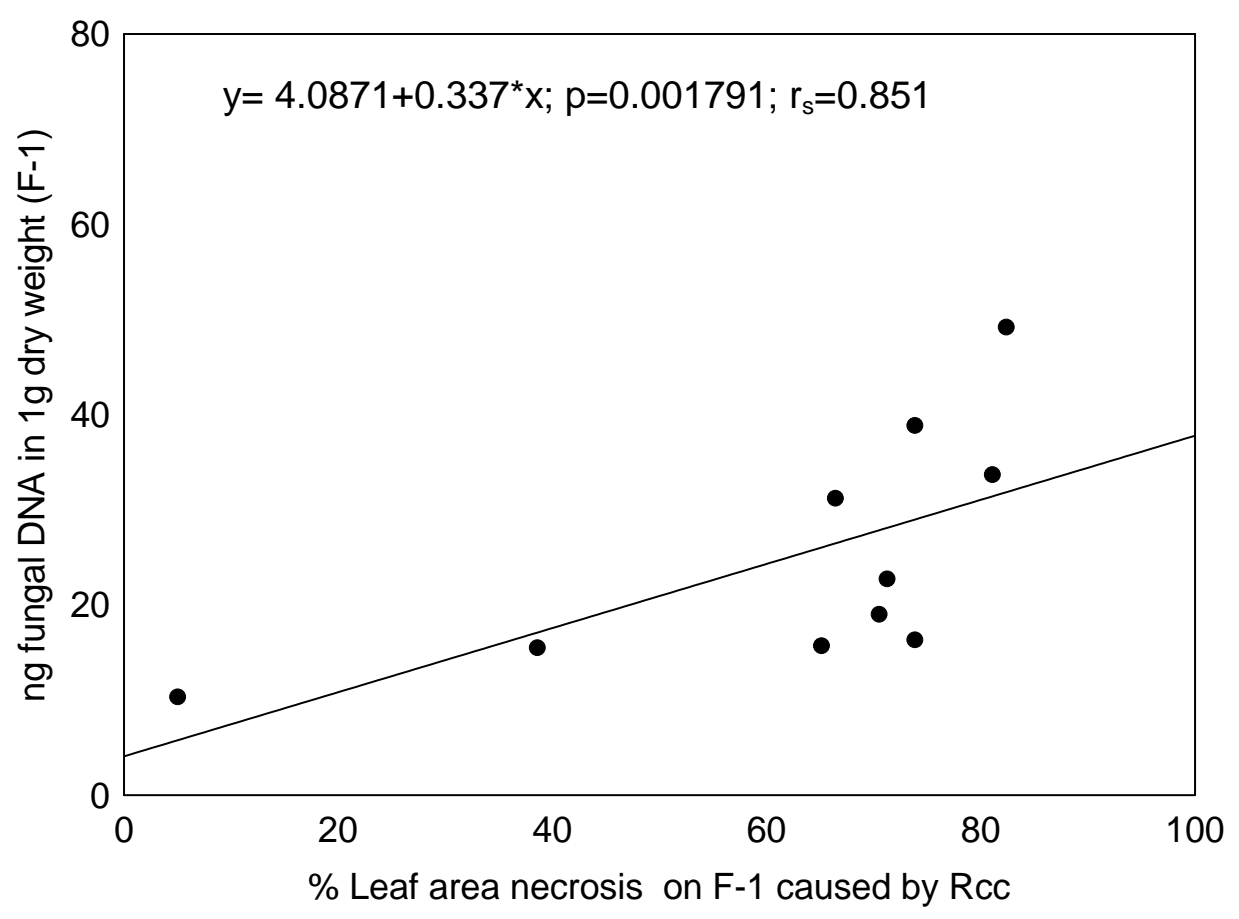

Figure 39. Correlation between percentage of disease symptoms on F-1 leaves in 10 different spring barley cultivars under field conditions in 2010 at GS 73-75 with ng fungal DNA in $1 \mathrm{~g}$ dry-weight of F-1 leaves at GS 73-75. $\mathrm{r}_{\mathrm{s}}$ : Spearman's rank correlation coefficient, p: $p$-value $\leq 0.05$.

\subsubsection{Quantification of fungal toxin during symptom development}

In the present study, different solvents were tested to extract rubellin $D$ from infected leaves. Finally, acetone: methanol: water was chosen as the best extraction solvent which isolated most of the rubellin D. Simultaneously fluorescence detection maintained advanced sensitivity as compared to previously published methods studies enabled picogram quantification of rubellin D. Different excitation (450-570 $\mathrm{nm})$ - emission (450-700 nm) wavelength combinations were checked to find the optimum conditions for rubellin $\mathrm{D}$ detection. The strongest fluorescent signals were obtained with the $500 \mathrm{~nm}$ excitation and $547 \mathrm{~nm}$ emission wavelength combinations (Fig. 40). This wavelength was furthermore used to determine rubellin inside the infected leaves. 


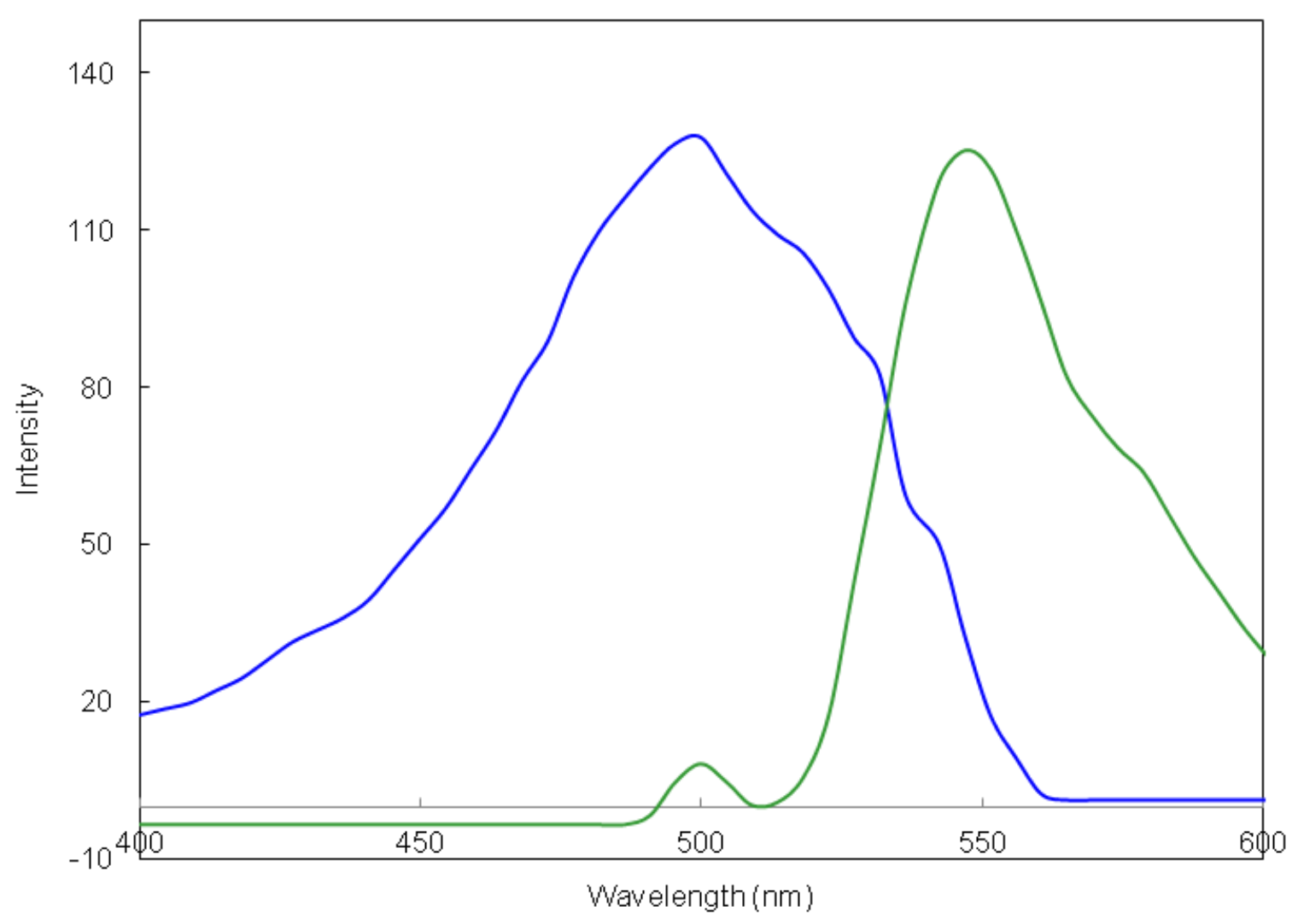

Figure 40. Fluorescent excitation (blue line) and emission (green line) spectra of rubellin $D$. The best sensitivity of rubellin $D$ detection was achieved with the $500 \mathrm{~nm}$ excitation and $547 \mathrm{~nm}$ emission wavelengths.

The HPLC florescence analysis showed that the standard rubellin $D$ had a retention time of $7.66 \mathrm{~min}$. Furthermore, similar peaks were observed from infected barley leaves extractions (Fig. 41). No peaks were observed in the healthy barley leaves extractions which were used as a negative control. As a result the limit of detection was calculated to $0.25 \mathrm{ng} / \mathrm{g}$. 


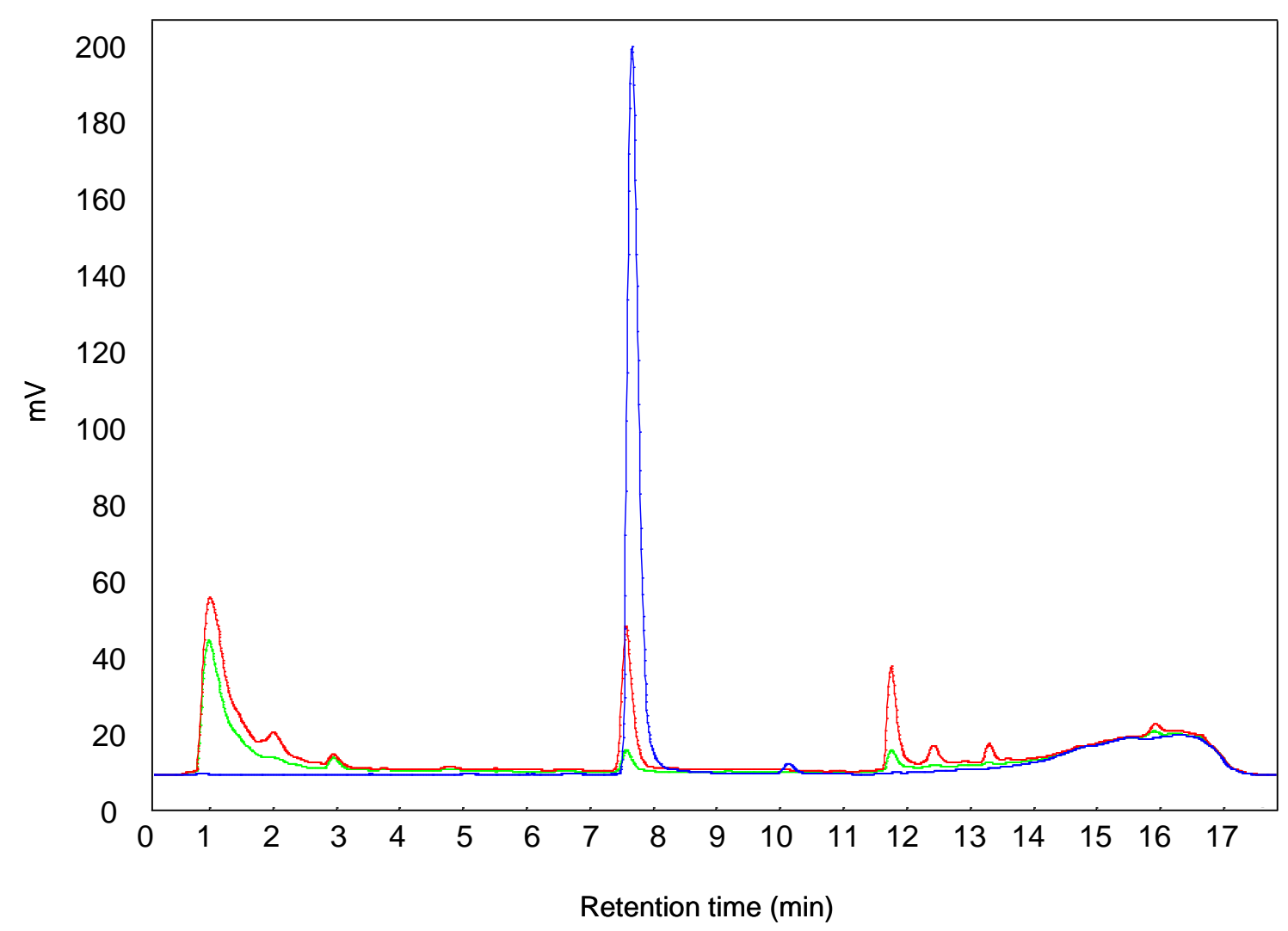

Figure 41. Chromatogram of the $1 \mathrm{ppm}$ pure standard rubellin $\mathrm{D}$ (blue line) with two naturally Rcc infected samples from the field (red and green line) in the wavelength of $500 \mathrm{~nm}$ excitation and $547 \mathrm{~nm}$ emission.

A spike test was carried out to check the matrix effects and influence of plant materials on toxin detection. By adding different concentrations of rubellin $D$ to a specific amount of non infected, dried and ground barley leaves $(500 \mathrm{mg})$, with a correlation coefficient of $R^{2}=0.996$, a high degree of sensitivity of toxin extraction and toxin measurement by HPLC-FD was achieved. The highest peak area was already calculated for $1000 \mathrm{ppb}$ to be 221.3 and continued to 0.5 for $10 \mathrm{ppb}$ (Fig. 42). 


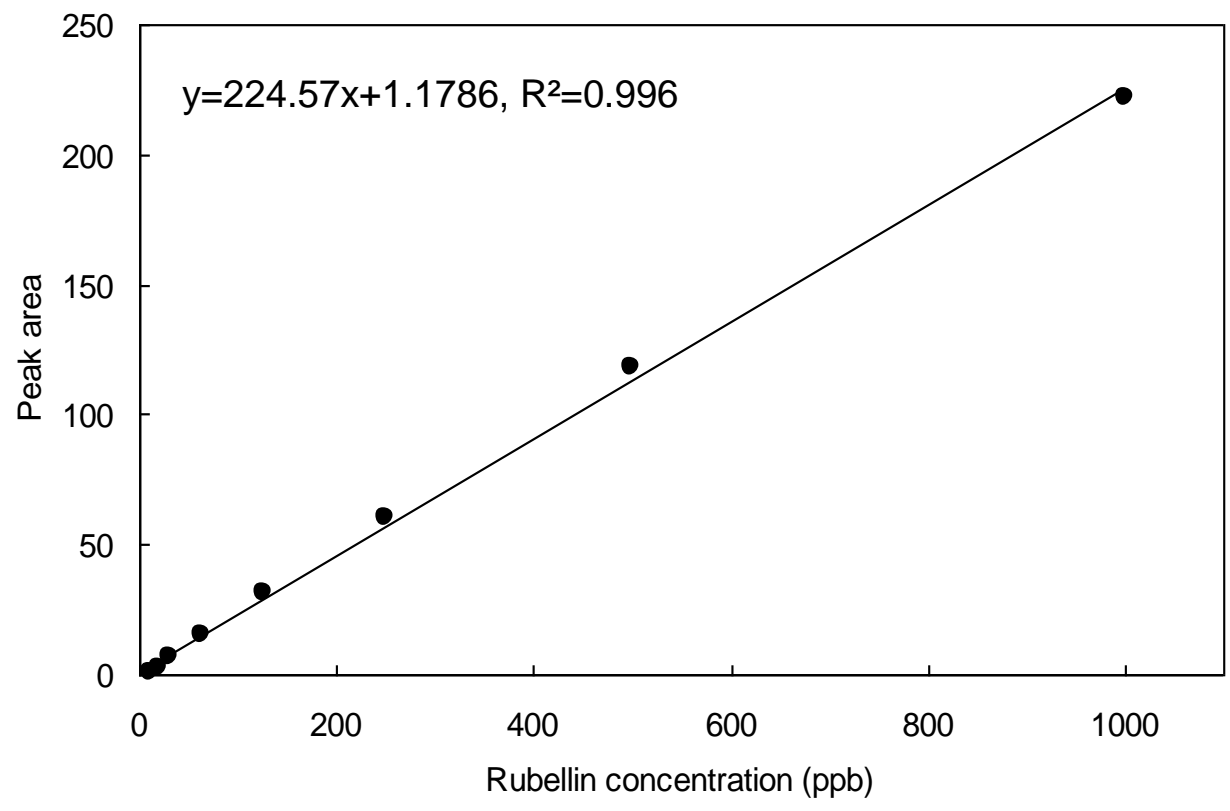

Figure 42. Spike calibration curve of different rubellin D concentrations (1-1000 ppb) in non infected barley leaves matrix.

In 2010, development of fungal toxin inside the plant was evaluated in 120 naturally infected barley samples from ten different barley cultivars, starting at GS 61-65 and continued until GS 73-75. According to the optimized method, fungal toxin was detected as early as GS 61-65 in F-1 leaves before symptoms were visible. At this growth stage, rubellin $D$ concentrations in most cultivars were calculated roughly to be between $180 \mathrm{ng} / \mathrm{g}$ for IPZ24727 to $202 \mathrm{ng} / \mathrm{g}$ for Lisanne (Fig. 43). 


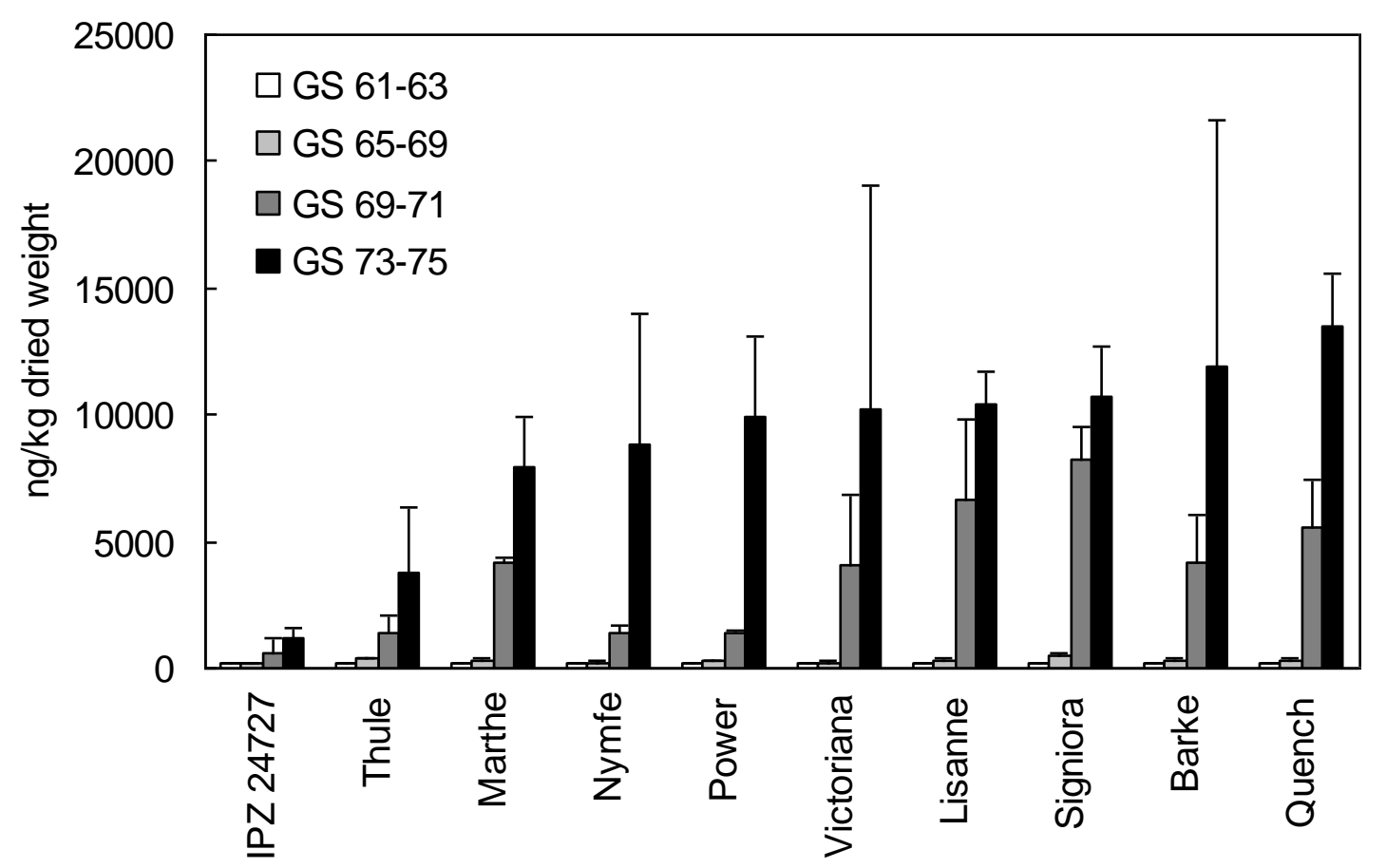

Spring barley genotype

Figure 43. Development of rubellin D detected by HPLC-FD in different spring barley genotypes at different growth stages under field conditions. Sampling time point: $25^{\text {th }}$ June (GS 61-65); $2^{\text {nd }}$ July (GS 65-69); $9^{\text {th }}$ July (GS 71-73) and $16^{\text {th }}$ July (GS 73-75). Columns and whiskers represent the mean and standard deviations of fifty samples ( $F-1)$ of three repetitions each; the field experiment was conducted in 2010; Lenglern, Lower Saxony, Germany.

At growth stage 65-69, the amounts of rubellin D increased gently in all cultivars to the maximum amount of $485 \mathrm{ng} / \mathrm{g}$ dry weights for cultivar Signiora. At the following growth stage, rubellin concentrations increased from $639 \mathrm{ng} / \mathrm{g}$ in cultivar IPZ 24727 (most resistant cultivar) and $6600 \mathrm{ng} / \mathrm{g}$ in cultivar Lisanne (moderately susceptible) to $8185 \mathrm{ng} / \mathrm{g}$ in cultivar Signiora (susceptible). At growth stage 73-75, rubellin D concentrations rose dramatically. Amounts of rubellin $D$ were $1160 \mathrm{ng} / \mathrm{g}$ for IPZ 24727, $10385 \mathrm{ng} / \mathrm{g}$ for Lisanne, $11929 \mathrm{ng} / \mathrm{g}$ for Barke and $13535 \mathrm{ng} / \mathrm{g}$ for Quench. At this growth stage plants were strongly infected and the fungus had already formed conidiophores and conidia on the abaxial part of the leaves. These results were comparable to the results of symptom assessment under field conditions. The strongest correlation $\left(r_{s}=0.966\right)$ in the present study was observed between the amount of fungal toxin with disease symptom development under field conditions (Fig. 44). 


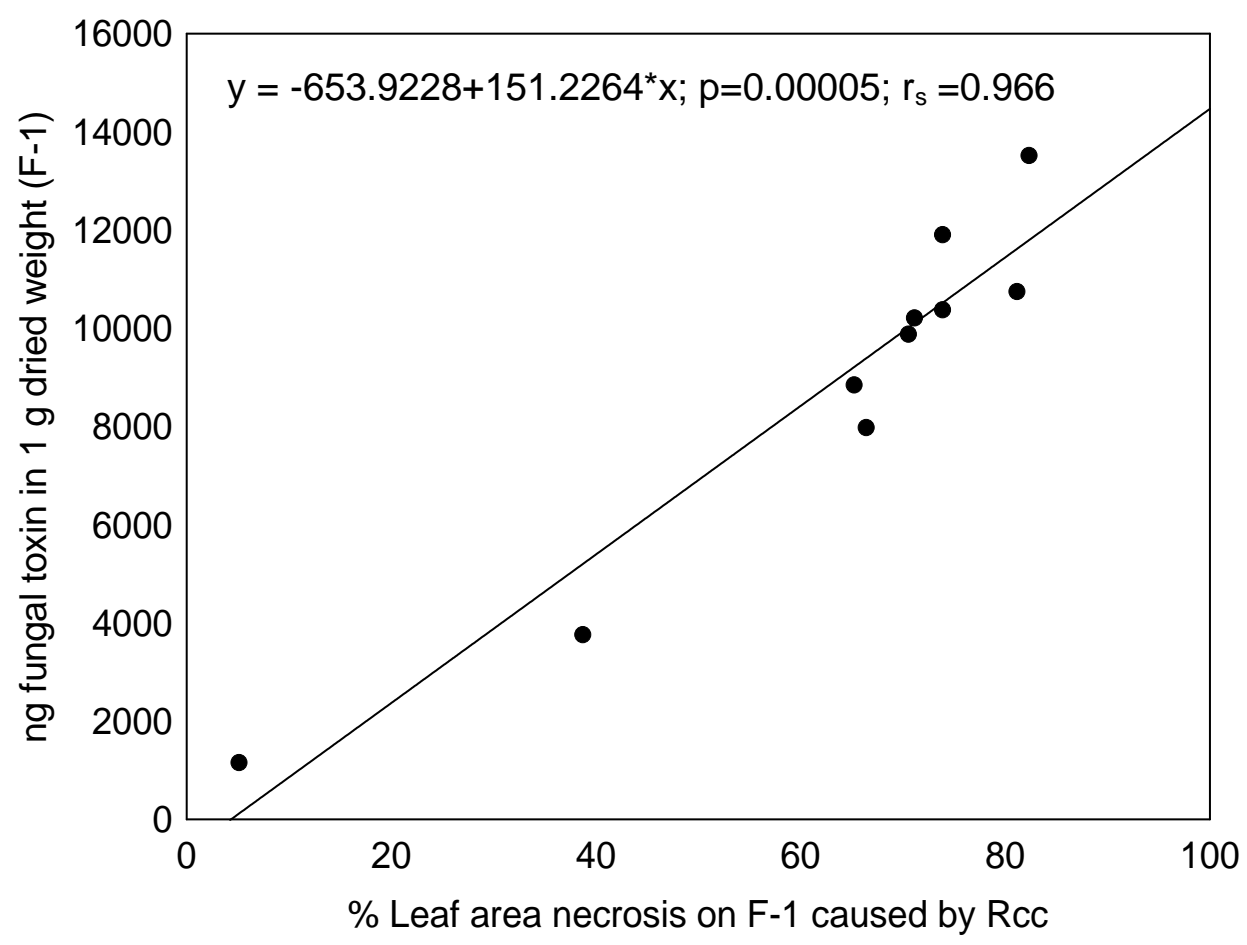

Figure 44. Correlation between development of disease symptoms in 10 different spring barley cultivars under field conditions in 2010 at GS 73-75 with ng fungal toxin (rubellin D) in $1 \mathrm{~g}$ leaf $(\mathrm{F}-1)$ dry weight. $\mathrm{r}_{\mathrm{s}}$ : Spearman's rank correlation coefficient, $\mathrm{p}$ : $\mathrm{p}$-value $\leq 0.05$

Furthermore, the statistical analysis showed a highly significant correlation $\left(r_{s}=0.84242\right)$ between the amount of rubellin $D$ with the amount of fungal DNA at GS 73-75 (Fig. 45). Toxin analysis also indicated that cultivar IPZ 24727 is classified as the most resistant cultivar and Barke and Quench as the most susceptible of the tested genotypes. 


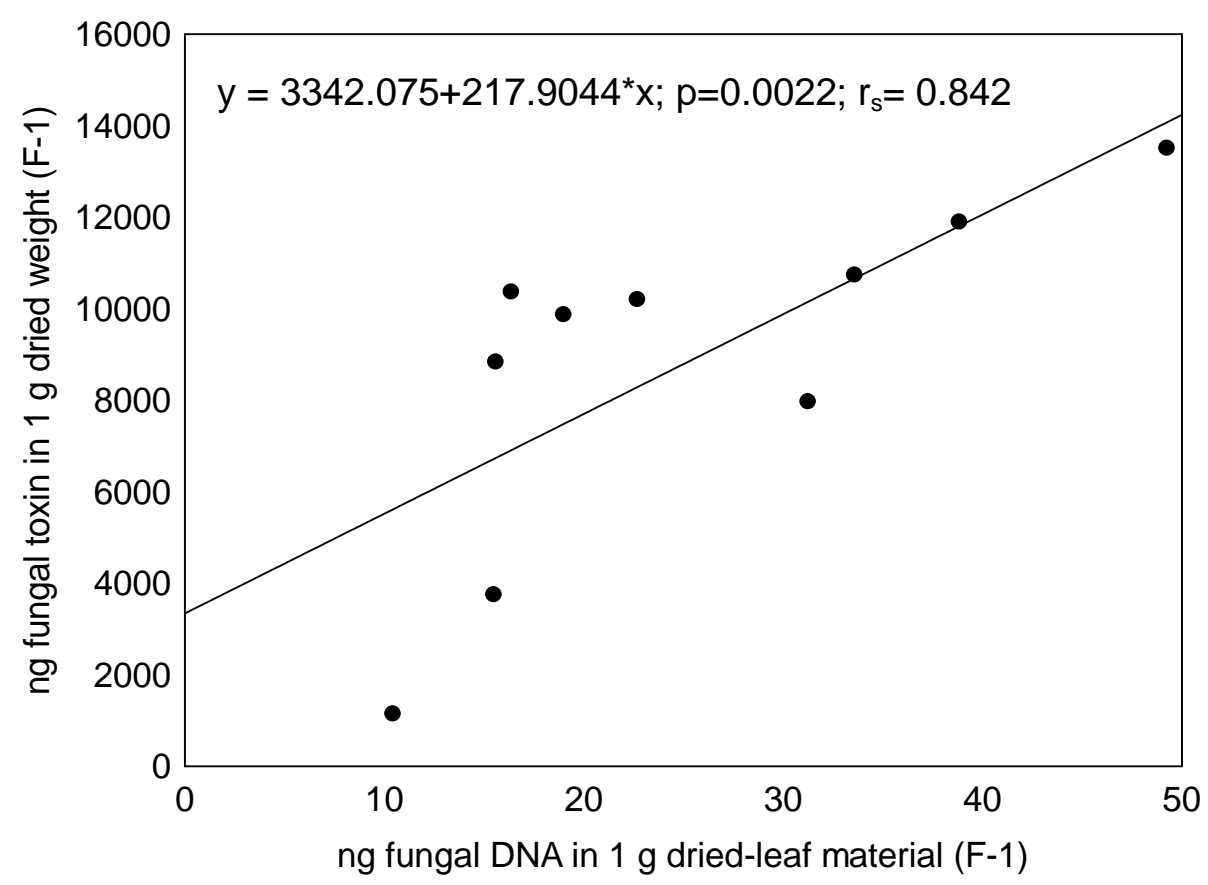

Figure 45. Correlation between ng fungal DNA and $\mathrm{ng}$ fungal toxin (rubellin D) in $1 \mathrm{~g}$ dry weight materials ( $F-1$ leaf) under field conditions at GS 73-75 in 2010. $r_{s}$ : Spearman's rank correlation coefficient, $p$ : $p$-value $\leq 0.05$

Finally, the correlation of disease severity with the amount of Rcc DNA and the toxin levels in three different cultivars (IPZ 24727 as the most resistant cultivar, Thule as a moderate susceptible and Barke as the most susceptible cultivar) was studied at different growth stages (61-65, 65-69, 71-73 and 73-75) (Fig 46). Results indicated that in the presence of fungal inoculum, the development of Rcc DNA and the toxin levels inside the plants and thus the amount of disease symptoms are strongly dependent on host genotype. 


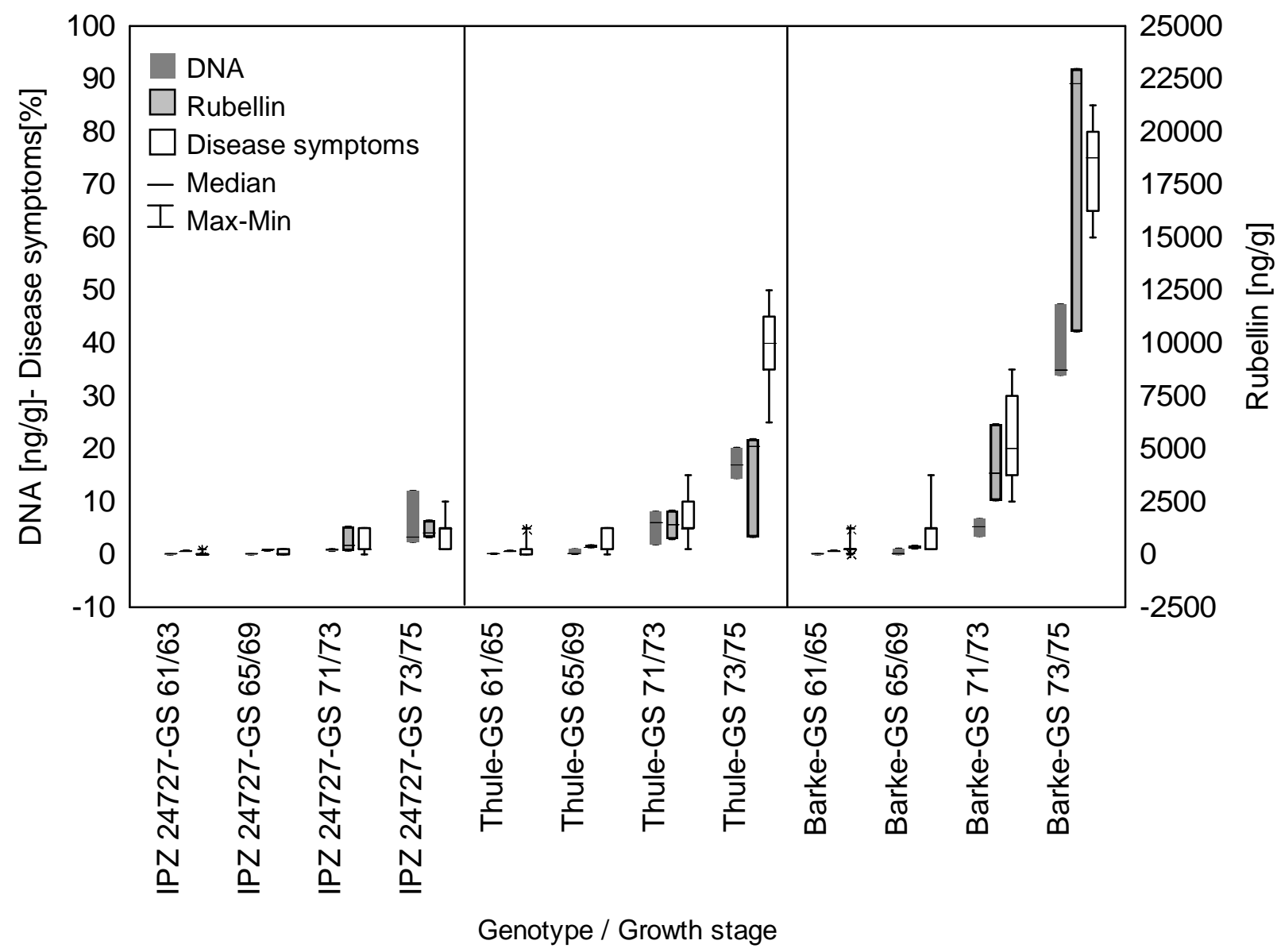

Figure 46. Correlation of RLS disease severity with amount of Rcc DNA and toxin (rubellin D) levels in three different cultivars (IPZ 24727 as the most resistant cultivar, Thule as a moderate susceptible and Barke as the most susceptible cultivar) at four different growth stages. Data show Box-Whisker-Plots with median values. Borders of boxes in disease symptoms represent $25 \%$ and $75 \%$ quartiles, thus boxes contain $50 \%$ of observed values and whiskers contain minimum and maximum values. For the DNA and toxin levels $(n=3)$, the borders of boxes represent the maximum and minimum amounts. 


\section{Discussion}

Ramularia leaf spot disease was identified already 100 years ago, but relatively recently it became as an important barley disease.

Since the detection of Rcc for the first time in barley fields in the south of Germany (Sachs et al., 1998), the pathogen has spread to all barley growing areas in the whole country. RLS subsequently has established as an endemic disease with consequences for barley production in Germany. Under field conditions, we observed that RLS first appears on winter barley and starts spreading towards spring barley fields in the following growing season. The first symptoms appear on older leaves when the plants are at the beginning of the flowering stage. Under favourable weather conditions, symptoms reach the awns in a few days. Leaf sheaths, flag leaves and awns are sometimes heavily infected. At this stage, new generation of conidia are visible at the abaxial surface of the leaves and spread to the other cereals, grasses, maize and volunteer barley as intermediate host (Sachs, 2006).

\subsection{Cultivation of Rcc}

In the present study, spore production depended strongly to Rcc isolates, nutrient medium, temperature and days after transferring to the new medium. On the one hand, sporulation intensity differed significantly among different Rcc isolates. On the other hand, sporulation increased from three days to 12 days, then decreased until it reached the lowest amount after 18 days post inoculation. Strong differences were also observed after second transfer into new V8A media after taking from $-80^{\circ} \mathrm{C}$. Salamati \& Reitan (2006) demonstrated that one Rcc isolate differs strongly in its capacity to produce conidia on different agar media. In this study, modified V8A medium increased production of conidia, achieving concentrations appropriate for inoculation of plants and further experiments. Previous studies indicated that Rcc conidia could germinate over a wide temperature range from $4^{\circ} \mathrm{C}$ to $32^{\circ} \mathrm{C}$, with an observed optimum at $20^{\circ} \mathrm{C}$ (Balz, 2009; Wallner \& von Tiedemann, 2008). At a favourable temperature in presence of a thin layer of water, Rcc conidia germinated in less than one hour. Relative humidity played a crucial role in Rcc spores germination during plant inoculation. Lower relative humidity (less than 75\%) significantly reduced spores germination. 


\subsection{Ramularia leaf spot disease phenotyping}

The major fact about RLS disease is that the symptoms appear after plant flowering at the relatively late growth stages. Under field conditions, first symptoms (small brown spots) appear on lower leaves at GS 61-65. At this time point, symptoms can be similar to physiological leaf spots (PLS) which can be caused by different abiotic factors (Wu \& von Tiedemann, 2002). In contrast to RLS, PLS is just visible on the one side of the leaf, which is oriented to the sun light. At favourable weather conditions, once RLS symptoms become visible, they spread rapidly onto younger (upper) leaves, sheaths, ears and awns during further maturation of the plant. Symptoms are characterised by small necrotic spots surrounded by a yellow halo and limited by leaf veins. Initially, leaves become yellow and die within a few days.

\subsection{Rec spore dispersal by wind and precipitation}

Disease development caused by Rcc is related to the concentration of airborne inoculum, therefore monitoring of conidia may be helpful for disease assessment and disease forecasting. To study the dispersion of inoculum from different pathogens different types of spore traps have been used in the past (Ben-Yephet \& Bitton, 1985; Aylor, 1993; Kohl et al., 1994; Evenhuis et al., 1997; Stensvand et al., 1998; Hunter et al., 1999). In this study, semi-selective media were used for the detection of inoculum of Rcc by exposing Petri dishes to the wind. Rcc spores are small and similar to spores of some other fungal species; therefore it was difficult to identify Rcc spores morphologically on the spore traps based on air-suction and adhesive tape. On the other hand, Rcc has been reported a slow growing pathogen, thus it takes several days to identify Rcc colonies on the agar plates. Spore traps containing semi selective V8A medium including Acanto and streptomycin sulphate gave the best results which either inhibit or slow down the growth of the other fungi or bacteria. Results demonstrated that Rcc conidia were detectable during late autumn and winter months at a larger distance from fields and at higher elevation above the ground. We therefore assume that Rcc inoculum is widespread also in the cooler season and may spread over large distances via the atmosphere and in the rain water or snow. Initially, it has been shown that Rcc spores are present throughout the growing season. Although a low number of spores was trapped at the beginning of 
the growing season, two major peaks were detected which were correlated to disease outbreak in the spring barley field. Our study showed that Rcc conidia, in high numbers, could be dispersed to a distance of minimum 30 to $60 \mathrm{~m}$ from the sources of inoculum. It was observed that a strongly Rcc infected winter barley field was the main source of primary inoculum for the spring barley trials. The same result was reported by Frei et al. (2007), who observed that the pathogen present in winter barley may furthermore act as a primary inoculum for spring barley fields. Once Rcc conidia infected barley plants and disease was established throughout the field, a new generation of conidia could be dispersed to greater distances in less than two weeks. The same results have been demonstrated for some other pathogens with occurrence of long distance dispersal (Nagarajan \& Singh, 1990; Davis \& Fitt, 1990; Fountaine et al., 2010). Limpert (1987) also showed that Erysiphe graminis spores can be transported over a distance of $110 \mathrm{~km}$. Weather data during present experiments indicated that environmental conditions did not have a significant effect on spore deposition. These results are comparable with the results of Schützendübel et al. (2008) who reported that neither rainfall nor temperature were correlated to the peaks of spore release, since spores were trapped under conditions ranging from 10$20^{\circ} \mathrm{C}$.

In a parallel study, inoculum of Rcc was identified by PCR in precipitation (rain and snow) at large distances from barley fields and in higher elevations. Applying an optimised sensitive PCR based method allowed us to detect low amounts of inoculum in the colder season in different rain and snow samples. These results were similar to previous studies, which demonstrated the importance of rain in dispersal of pathogen inoculum (Fitt et al., 1989; Kushalappa \& Eskes, 1989; Geagea et al., 1999). Rain splash intensified spore removal from sporulating source, washed out airborne spores and deposited them onto other plants at larger distances. These results provided evidence that conidia of Rcc exist throughout the year in a low concentration and released in a mass from winter barley fields some days before symptoms appearance in spring barley fields. This fact may explain why the early protective foliar fungicide treatment can later decrease the amount of disease severity in spring barley fields. 


\subsection{Rcc systemic development inside the plant}

One leaf inoculation study was carried out to prove systemic fungal development inside the plant from lower parts to upper parts in a symptomless manner. For some reasons which are not clear yet, the pathogen produced any characteristic symptoms under controlled environmental conditions. Results of PCR show positive systemic development in $5 \%$ of total samples, in which Rcc reached higher leaves up to F-2 and F-1 leaves three weeks after inoculation.

In a parallel study, a PCR-based diagnostic assay was used to detect Rcc in spring barley seeds which were harvested from heavily infected barley fields and sown again under controlled environmental conditions. All emerging plant parts (tiller, F-2, $\mathrm{F}-1$, leaf sheath, flag leaf and new generation seeds) showed presence of Rcc DNA which indicates a systemic infection spreading from the seed to emerging plant in a symptomless manner. Similar results were observed by Havis et al. (2006), who found the presence of Rcc in grain samples harvested in 1999 and 2004 in Scotland. Walters et al. (2008) identified a high latency of Rcc in barley field regions confirming a life cycle through infected seeds and latent growth inside the plant before the outbreak of Rcc epidemic. These results support the hypothesis that Rcc can be classified as a seed borne pathogen. Frei et al. (2007) also described Rcc as a seed borne pathogen by PCRs testing of winter barley from Switzerland. Till date, the importance of these infected seeds in the disease cycle and disease epidemic in the field is not clear. This is in contrast to the sudden and relatively late outbreak of RLS symptoms in the field-grown barley which was related to a loss in the physiological vigour during senescence in the previous work (Schützendübel et al., 2008). It remains to be determined whether this outbreak of symptoms in the field-grown barley derives from symptomless internal infestation or from infection with conidia delivered from the environment, or both. In 2011, we detected Rcc by PCR in samples which were taken from a small university field trial at early growth stage (data not shown). Dry condition during this year leads to the less and late symptom appearance. One possible explanation is that the environmental conditions also affect the fungal growth and development inside the plants. The other explanation could be that in comparison with mass release of Rcc conidia under favourable conditions, the amount of pathogen present inside the plants may not be enough for pathogenesis. On the other hand, previous work on naturally infected seeds 
demonstrated that Rcc cannot survive for a long period in the seeds and also it depends strongly on seed storage conditions (data not shown). More work should be done to prove whether Rcc is a seedborne pathogen or not.

In this study, hot water treatment was used to kill the pathogen or inhibit its growth with minimum damage to the seed tissue and seed germination. Previous studies demonstrated the effect of different heating treatments of barley seeds against various pathogens (Russel \& Tyner, 1954; Batts, 1956; Doling, 1965; Couture \& Sutton, 1980; Jensen, 1888; Fourest et al., 1990). In the present study, treatment temperature and treatment duration were the most critical points. Increasing temperature from $48^{\circ} \mathrm{C}$ to $52^{\circ} \mathrm{C}$ reduced subsequent seed germination from $80.4 \%$ to $53.8 \%$. On the other hand, increasing treatment duration significantly decreased the seed germination in all treatments. To avoid reduction of barley seed germination, the temperature of $48^{\circ} \mathrm{C}$ for 5 minutes was applied in future experiment which has shown to be optimal against Rcc at the early plant growth stages. At later growth stages, the application of hot water treatment did not appear to eliminate the presence of Rcc on/in the seeds or impair the transfer of the pathogen into the developing plant.

In a parallel study, in order to evaluate the importance of latent seedborne infection against leaf infection with airborne conidia, we used seed dressings and consecutive applications of foliar fungicides during plant development to produce pathogen-free plants and seeds. Three different fungicides (EFA, Solitaer and Zardex G) were used as seed dressing to evaluate the efficacy of fungicide application on the pathogen elimination inside the seeds. The results of qPCR indicated that under controlled environmental conditions the fungicide Zardex G (cyproconazole and imazalil) can significantly decrease in planta growth of Rcc but cannot completely eliminate the fungus and Rcc spread into upper parts of the plant at later growth stages. Nyman et al. (2009) also showed that applying Raxil $R$ (tebuconazole and thiram) as a seed treatment on winter barley has not stopped the movement of the fungus inside the plant. Furthermore, we applied the foliar fungicide Proline (prothioconazole) at different growth stages to inhibit fungal development inside the plant. Results indicated that timing of fungicide application is crucial to prevent the development of Rcc inside the plant. Analysing samples derived from treated and untreated seeds ten days after applying foliar fungicide at growth stage 39-41 indicated that both seed 
dressing treatment and foliar application are necessary to control development of the pathogen inside the plants. Thus, neither seed dressing nor foliar application had any complete effect on fungal development inside the plants when they were used separately. Extracting DNA from the first generation seeds and evaluating them with qPCR demonstrated that application of foliar fungicide at late growth stages (GS 6569) has less effect on fungal development into first generation seeds in comparison with early growth stage (GS 39-41). These results are consistent with results from O'Reilly et al. (1988) who found that most fungicides work best when applied early in the infection cycle, prior to visual symptom expression. Results from this study also confirm the conclusions from previous experiments which showed that the azole fungicides were more effective against Rcc (Oxley et al., 2002; 2006; Balz et al., 2006). Jørgensen \& Christiansen (2006) showed that the fungicides Bell (boscalid and epoxiconazole), Opera (pyraclostrobin and epoxiconazole) and Proline (prothioconazole) achieved good control of RLS in the spring barley under field conditions. In contrast, Christiansen et al. (2009) demonstrated that strobilurin fungicides like Acanto have less effect on inhibition of Rcc. These results were comparable with the result from Oxley et al. (2008), which indicated that resistance to strobilurin fungicides has now developed in populations of Ramularia in both Scotland and Denmark.

In conclusion, this study indicates that neither hot water treatment nor seed dressing fungicide could completely eliminate the systemic development of Rcc within the plant. It suggests that seed surface sterilization alone is not enough to remove the pathogen, as Rcc can come from inside the seed. More studies and visualization experiments will be needed to determine the location of Rcc within the seed.

\subsection{Analysis of cuticular wax layer}

The cuticle, with its associated waxes, gives a different functional integration, between the plant and its environment. One of the most important functions of the cuticular wax layer is identified to be defence barrier against pathogens (Jenks et al., 1994; Mariani \& Wolters-Arts, 2000). Wallner (2008) has shown that Rcc can penetrate not only via natural plant openings like stomata but also via plant tissue directly through the outer surface. Previous studies on Colletotrichum 
gloeosporioides, Magnaporthe grisea, Blumeria graminis and Erysiphe pisi demonstrated the importance of plant epicuticular wax compositions in the inhibition of fungal structures and fungal development (Podila et al., 1993; Hegde \& Kolattukudy, 1997; Gniwotta et al., 2005; Zabka et al., 2008). These results support the hypothesis that changes in the amount of barley leaves wax layer at different growth stages may have an effect on Rcc development during infection. In the present study, we have measured the chemical composition of the cuticular wax layer during plant development at different growth stages. Among eight different chemical compounds with different carbon chain length (20,22, 24, 26 and 28), which were identified in the total wax load from leaves at different growth stages, primary alcohol C26 was the major component and its concentration was significantly higher than the other compounds (Fig. 23). Any significant differences have been observed in the amount of other chemical compounds in different leaves at different growth stages. These results were further supported by results from Richardson et al. (2005), who also found that the wax composition along the barley leaf development did not change post emergence. Kolattukudy (2001) demonstrated that the barley cuticle contains an insoluble polymer of mainly C16 and C18 hydroxy and epoxy fatty acids. Furthermore, Samuels et al. (2008) reported the presence of mainly C20-C60 alkanes, alcohols, and ketones in the barley wax layer.

Environmental scanning electron microscopy of barley leaf surface shows that the surface of barley leaves is covered with platelet epicuticular crystals. Images from ESEM indicated no differences in shape and pattern of wax layer deposition between abaxial and adaxial surface. On the other hand, ESEM indicated that the platelet shape crystals of the wax layer did not vary in leaves at different growth stages. They arose from both sides to the centre of the surface. In the early growth stages, the density of wax crystals was low and they did not cover the entire leaf surface. At later growth stages, however, they covered the whole leaf surface and it was more densely covered by wax platelet crystals. The same results were observed by Koch et al. (2004) and Richardson et al. (2005), which support the similarity of wax compositions and wax layer shape during leaf development. ESEM analysis of leaves surface showed deformation and abnormality of epidermal cells at later growth stages. This observation may support the hypothesis that abnormalities at later growth stages can better facilitate direct cuticle penetration. Further research is 
required to investigate the effect of cuticular layer on Rcc conidia germination and penetration.

Furthermore, the ESEM photos of the naturally infected leaves indicated that in some cases, cuticular wax layer was removed around mycelia. It supports the hypothesis that Rcc mycelia may diffuse special exudates with enzyme activity which removed a part of the outer surface of the leaf cuticle crystals around mycelia. This may help Rcc penetration during infection periods. In 1986, Dickman and Patil demonstrated that cutinase deficient mutants of Colletotrichum gloeosporioides fail to penetrate host tissue. Kunoh et al. (1990) reported that the conidial exudate of Erysiphe graminis contains enzyme activity capable of eroding a portion of the outer surface of the leaf cuticle. These results supported by results from Feng et al. (2009), which showed that Blumeria graminis secretes a hydrolytic lipase to facilitate its adhesion and pathogenesis on the host plant. Obviously more works should be done to confirm whether Rcc mycelia have enzyme activities or whether the removal of the cuticular layer was done mechanically.

\subsection{Molecular diagnosis of Rcc}

The main objective of the present study was to develop a specific and sensitive PCRbased detection method for the identification and detection of low-level, including symptomless Rcc infection from vegetative to reproductive stages of the host plants. For a sensitive experiment, the desired PCR primers must be highly specific as there may be a number of other fungal or bacterial saprophytes or pathogens present on the surface of the leaf which will be extracted as well as Ramularia. The PCR primer pair Rcc1-Rcc5b previously proved to be highly specific to Rcc as well as highly sensitive (Havis et al., 2006). Specificity and sensitivity tests were confirmed with different fungal DNA samples which had been collected from different countries, mainly Germany. Specificity tests further demonstrated that neither DNA of the other fungal isolates, nor plant DNA was detected by Rcc1-Rcc5b primers. This set of primers could specifically amplify Rcc DNA down to $0.1 \mathrm{pg}$. Rcc was successfully detected and identified in culture, in host plant tissues and in seeds as well as in rain and snow. These results indicated that optimised PCR also can help to detect Rcc on 
non host plants which can furthermore help to specify the main role of them in epidemiology of RLS disease.

The fact that plant DNA was not detected by using the Rcc specific primer set, suggests that this method might be used to measure DNA concentration of Rcc in the host tissues to assess cultivar resistance under field conditions before symptom appearance. In the present study, quantitative real time PCR was developed to detect and quantify the PCR product after each amplification cycle by fluorescence emission measurement. Furthermore, it was possible to quantify Rcc DNA in the host plant and describe the correlation of Rcc DNA concentration with disease symptoms and disease development. The qPCR method was also used in diagnostic estimation of DNA concentration in other fungal pathogens for host resistance or susceptibility and also for monitoring disease progress under field and controlled environmental conditions (Bates et al., 2001; Cullen et al., 2001; Fraaije et al., 2001; Qi \& Yang, 2002; Brouwer et al., 2003; Luo et al., 2007; Fountaine et al., 2010).

In the present study, the specificity of qPCR helped to identify and specifically measure Rcc DNA in the presence of other barley pathogens which might occur simultaneously on the plant. Barley crops are seldom infected by a single pathogen. They are infected with mixtures of Blumeria graminis f. sp. hordei, Rhynchosporium secalis, and Pyrenophora teres which made difficulties in visual assessments of Rcc. For acceptable classification of resistance levels, it is important to detect and quantify pathogen colonization at a stage in which plant resistance mechanisms are still present and active. A method such as qPCR that is able to detect the pathogen inside the plant in the early growth stages can therefore achieve clear differentiations.

Strong correlation coefficient $\left(R^{2}=0.994\right)$ and PCR efficiency $(0.99)$ were observed between the initial DNA quantity and the $\mathrm{C}_{\mathrm{T}}$ value (Fig. 6). These results demonstrate that we could specifically quantify Rcc DNA among total DNA isolated from infected leaves. For investigation of Rcc development in the field in the year 2010, F-1 leaves of ten different barley cultivars with different susceptibility or resistance to Rcc were investigated by qPCR. On the one hand, Rcc DNA was detected in all barley genotypes. This suggests that none of the spring barley cultivars were completely resistant to Rcc. On the other hand, results indicated that the PCR was able to detect the presence of the pathogen before symptoms appearance at early growth stages. 
Results showed that the amount of Rcc inside the plant at GS 61-65 was five times higher in the susceptible cultivar (Barke) than in the resistant cultivar (IPZ 24727). At GS 73-75, the amount of fungal DNA in the most susceptible cultivar (Quench) was almost five times higher than in the most resistant cultivar (IPZ 24727). This was likely the result of less pathogen growth and multiplication occurring in resistant plants. At GS 73-75, the amount of Rcc DNA and disease symptoms also were significantly correlated $\left(p=0.00179, r_{s}=0.851\right)$, suggesting that quantitative real-time PCR can be used for the selection of resistant plants between different barley genotypes that are considered to be equally resistant based on disease scoring.

\subsection{Toxin analysis}

Previous studies have shown that several plant pathogenic fungi and bacteria produce phytotoxins, which trigger disease symptoms development on the infected plants (Yoder, 1980; Levings \& Siedow, 1992; Schäfer, 1994; Jackson \& Taylor, 1996; Bender et al., 1999; Daub \& Ehrenschaft 2000; Rep, 2005).

Heiser et al. (2003) demonstrated that Rcc produces a photodynamically active phytotoxin called rubellin. It was reported by Sutton \& Waller (1988) that the hyphae are able to stain nutrient media, implying the probability of toxin production. Salamati \& Reitan (2006) observed that different growth media produced different colouration from the same isolate. Heiser et al. (2003) remarked a variety of colours from cultures on Czapek-Thom-Medium concluding that culture conditions would affect the release of different substances belonging to a group of anthraquinone derivatives, mainly consisting of rubellin $\mathrm{B}$ and $\mathrm{D}$. Further studies demonstrated that rubellins are a group of compounds which were identified as rubellin $A, B, C, D$ and $E$ as phytotoxic compounds from Rcc (Miethbauer et al., 2003, 2006; Heiser et al., 2003, 2004). Rubellin B is the primary product biosynthesized and is most abundant in the infected tissue. Rubellin B, however, is not soluble in planta and will be converted into the more soluble rubellin D. Heiser et al. (2004) have proved the lack of hostspecificity of rubellin by inducing the same symptoms on barley and tobacco leaves. Miethbauer et al. (2003) have identified that pure rubellin D, which was extracted from Rcc in liquid culture, causes the same necrotic symptoms on barley leaves. This evidence demonstrated that rubellin $D$ is a pathogenicity factor, killing plant tissue 
which the fungus can then colonize and sporulate. Rubellins first have been distinguished in the medical plant Angelica sylvestris with a necrotic spot disease caused by Mycosphaerella rubella (Arnone et al., 1986, 1988). These results support the hypothesis that, if Rcc has a teleomorph, it would presumably be a species of Mycosphaerella.

Further experiments have shown that rubellin $D$ in a photodynamic reaction induces the formation of reactive oxygen species (super oxide, hydrogen peroxide or hydroxyl radicals) which induce the peroxidation of membrane fatty acids and the oxidation of pigment finally resulting in chlorotic and necrotic symptoms (Heiser et al., 2004).

Previous analytical methods for the identification and isolation of rubellin in pure culture or infected barley leaves have based on HPLC with UV detector (Heiser et al., 2003, 2004; Miethbauer, 2003, 2006).

In this study, we clearly demonstrated for the first time that rubellin $D$ fluoresces under UV radiation and can be detected by HPLC with fluorescence detector, which is among the most sensitive of HPLC detectors. Depending on the compound, fluorescent detector can be 10-1000 times more sensitive than UV detectors. The method which developed in this study, can detect rubellin at low ppb levels with excellent resolution and peak efficiency. After testing several excitation-emission wavelength combinations, the best fluorescent result was achieved with the $500 \mathrm{~nm}$ excitation and $547 \mathrm{~nm}$ emission wavelengths. We also used acetone-methanol-water as the extraction solvent, which lead to a good extraction of rubellin $D$ from the infected barley leaves. A strong correlation coefficient $\left(R^{2}=0.996\right)$ was observed between the different rubellin $\mathrm{D}$ concentrations and the peak area in the standard curve. These results indicate that we can specifically quantify rubellin $D$ among the total leaf extraction from infected leaves. In the present study, the analysis of 120 Rcc infected leaf ( $F-1)$ samples obtained from ten different spring barley genotypes at a naturally infected field in Lenglern/Germany 2010, revealed the presence of rubellin $D$ in all samples at the early growth stages before symptom appearance. These results may help us to evaluate cultivar resistance under field conditions before symptom appearance.

First HPLC-FD results show that the amount of rubellin $D$ inside the plant at GS 61-65 was 1.2 times less in the resistant cultivar (IPZ 24727) than in the susceptible cultivar (Barke). At GS 73-75, the amount of rubellin D in the most 
susceptible cultivar (Quench) was almost 11 times higher than the most resistant cultivar (IPZ 24727). At GS 73-75 the strongest significant correlation has observed between the amount of rubellin $D$ and the disease symptoms $(p=0.00005$, $r_{s}=0.96657$ ). Significant correlations were also found between the amount of Rcc DNA and fungal toxin $\left(p=0.0022, r_{s}=0.8424\right)$, suggesting that toxin analysis can be used for evaluating cultivar resistance against Rcc among different barley genotypes.

\subsection{Evaluation of resistance screening methods for RLS}

Field trials: Till date, different methods have been used for different barley diseases resistance screening under field conditions (Ali et al., 1976; Brown, 1985; Jørgensen \& Smedegaard-Peterson, 1995; Bai \& Shaner, 2004; Skadsen \& Hohn, 2004). In the present study, a percentage of necrotic leaf area on different leaves was used to evaluate resistance and compare the reaction of different spring barley genotypes against Rcc. The main problem in breeding barley cultivars for Rcc resistance is the screening. Rcc field screening has some limitations; it is slow, time-consuming and depends strongly on the presence of the proper environmental conditions such as humidity, temperature, sun light and simultaneous presence of other fungal and bacterial pathogens. Besides, a field screening can usually be carried out only once a year. Even though the selected field location was expected to be optimal for Rcc development and disease screening in this study, dry conditions in 2010 resulted in a limited Rcc development during growing season. In most spring barley genotypes, the percentage of disease symptoms was lower in 2010 in comparison with 2009. These results were comparable with the results of Oxley et al. (2008), who concluded the high importance of environmental factors on disease development during field monitoring for evaluation of the efficacy of fungicides treatment at different places. Djurle (2009) also reported that yield losses can become considerable if the environmental conditions for RLS development are favourable. She has observed that with low disease symptom in barley field which suffering from drought stress, the yield increase in the field trial in comparison with the place with favourable weather conditions. 
The Rcc spots are often confused with the physiological leaf spots (PLS) wich caused by the abiotic factors. Accordingly, Frei et al. (2007) demonstrated that a maximum of one third of the leaf surface which is covered by necrotic spots was colonized with Rcc, while the remaining two thirds were attributed to PLS. McRobert et al. (2009) demonstrated that RLS presents as part of complex of symptoms on the barley leaves involving Rcc, Rhynchosporium and physiological leaf spots. According to these results, we applied Acanto fungicide to control a different range of foliar barley diseases such as powdery mildew, barley net and leaf blotch. Previous studies have demonstrated that strobilurin based fungicides have no effect on Rcc or the disease development (Jørgensen \& Christiansen 2006; Oxley et al., 2006; Christiansen et al., 2009). Therefore by applying Acanto, field experiments were under optimal conditions for barley screening against Rcc.

On the other hand, the time point of the resistance screening for Rcc is critical, as too early or too late evaluations may lead to different assessment of resistance. Appearance of the RLS symptoms under field conditions occurred relatively late in the plant development when the plants reached GS 61-65. The first symptoms became visible on the lower leaves and almost no symptoms have been observed on the younger leaves such as F-1 or flag leaves. In our experimental spring barley fields in 2009 and 2010, the percentage of necrotic leaf area caused by Rcc was less than $10 \%$ in most genotypes at the early plant growth stages (61-65). The most reliable data were collected when most of the plants were at growth stage $73-75$, at which RLS is characterized by abundant small brown spots usually with a yellow halo. Later on, microscopic observation of the abaxial surface of the leaves and observation of the typical fungal structures (conidiophores and conidia) confirmed the presence of Rcc on infected leaves. In addition to traditional observation and morphological characterisation, molecular detection by PCR and using specific primers for Rcc confirmed the occurrence of RLS in the field.

Under field conditions, 40 different spring barley genotypes were evaluated for field resistance against Rcc in the year 2009 and 2010. Although the field trials in two consecutive years lead to different disease scoring results, a significant correlation $\left(r_{s}=0.419, p=0.041\right)$ was observed between field experiments in two different years at growth stage 73-75. No genotype was observed to be completely immune or resistant to RLS disease under field conditions. This conclusion was further 
supported by the results from the field experiments by Pinnschmidt \& Sindberg (2006), which demonstrated that there seems to be moderate resistance to Rcc in some spring and winter barley genotypes, but most of the genotypes are susceptible. Among the spring barley cultivars which evaluated in this study, cultivar IPZ 24727 was reported previously as the most resistant cultivar (Bistrich et al., 2006), Barke, Quench, Hatifa, and Braemer as the most susceptible cultivars under field conditions (Bistrich et al., 2006; Pinnschmidt \& Sindberg, 2006). Besides, cultivars Isabella, Mimer, Power, and Scandium were reported to have moderate resistance against Rcc in Denmark (Pinnschmidt \& Sindberg, 2009). These results are comparable with the results of the present study and show its reproducibility and the reliability under field conditions. In this study, cultivar Quench showed a moderate resistance to Rcc in 2009 but a strong susceptibility in 2010. The result was confirmed by breeders in other field trials (personal communication with project partners). It can be explained by breaking of the plant defence system against Rcc or breaking of plant antioxidative and detoxification systems in this cultivar due to high temperature and low humidity in 2010. It was reported that high temperature stress increases the rapid production and accumulation of reactive oxygen species inside the plants (Sairam et al., 2000; Mittler 2002; Almeselmani et al., 2006). Goyal and Asthir (2009) showed that high temperature significantly increased the activities of reactive oxygen species in wheat plants. Srivalli et al. (2003) showed that water stress induces oxidative stress through generation of ROS, which can cause damage to the cell membrane by lipid peroxidation. Obviously more work should be done to accept all these theories and explain why just the cultivar Quench showed a different reaction in two different years. In this study, cultivars which possess the mlo gene showed the highest susceptibility reaction to Rcc. This result agrees with the result of Oxley et al. (2006) and Pinnschmidt \& Sindberg (2006). Makepeace et al. (2008) showed that presence of mlo 5 increases the susceptibility of the cultivar to Ramularia, particularly where the plant is stressed by light. In contrast, the field studies by Makepeace et al. (2006) showed that mlo resistance alone was not the cause of the increase in Ramularia. However the importance of the mlo gene on increasing or decreasing the susceptibility of barley cultivars to Ramularia needs more detailed study. On the other hand, barley cultivars, which have no mlo gene, are susceptible to the powdery mildew. Under field conditions, powdery mildew occurs at the younger 
growth stages and if one cultivar is infected with powdery mildew, although in the presence of Rcc inoculum, it is almost impossible to evaluate Rcc symptoms at the later growth stages. Accordingly, cultivars which possess mlo gene are resistant to powdery mildew and can show RLS symptoms at later growth stages, in the presence of Rcc inoculum and favourable weather conditions. Weather conditions also play a major role in the interaction between two pathogens and pathogens and the plant, respectively.

Greenhouse experiments: One of the main objectives of the present study was to develop reliable Rcc screening methods under controlled conditions. The critical point of growing different barley cultivars was to keep them in suitable conditions and avoid any physiological leaf spots due to the various environmental stresses or growth factors until the plants develop to GS 55-59 (Mehdy, 1994; Wu \& von Tiedemann, 2002, 2004). However, greenhouse screening has also some limitations. It needs proper conditions for plant development and only a limited number of barley genotypes can be screened at one time point due to the space limitations.

The success of greenhouse screening depends strongly on plant age, inoculum quality and quantity, inoculation technique, and pre- and post inoculation environmental conditions. In the present study, plant age at the time of inoculation had a strong influence on RLS development. At the early growth stages, up to GS 41-45, no visible symptoms have been observed in all barley genotypes.

Previous study showed that different temperatures had a different effect on spore production by different Rcc isolates, spore germination and disease development. Balz (2009) demonstrated that Rcc isolates germinate over a wide temperature range from $4^{\circ} \mathrm{C}$ to $32^{\circ} \mathrm{C}$, while the optimal temperature is approximately $20^{\circ} \mathrm{C}$, which was used in all experiments in the present study. Although it was reported that light intensity was the important factor for disease development (Heiser et al., 2003), high relative humidity after inoculation played the major role in disease development under controlled conditions in this study. This can be explained that leaf wetness is necessary for spore germination, penetration, and disease development. Shaw (1991) reported that interrupting $100 \%$ relative humidity by dry periods of $50 \%$ relative humidity, significantly reduced wheat infection by Mycosphaerella graminicola. Similar results were observed in Rhynchosporium secalis, which needs 
leaf wetness duration for at least 10 to 12 hours for infection (Salamati \& Magnus, 1997). Van den Berg and Rossnagel (1990) have also shown that Pyrenophora teres spores need free water on the leaf surface for at least 6 hours for the infection.

It was observed that the duration of leaf wetness in the spring is well correlated with the severity of RLS symptoms under field conditions which occur after flowering. Balz (2009) showed the importance of the leaf surface wetness in disease development in an experiment in which some plants were left outside to get covered with dew, whilst others were taken inside during the night. Frei et al. (2007) reported that in some regions of Switzerland an explosive increase of RLS was observed due to high humidity and dewy climate during plant flowering stage.

Previous works demonstrated that Rcc spores germinated well in the presence of a thin layer of water. A long period of dryness after inoculation evaporated the water of the spore suspension and reduced spore germination. Additionally, the germinating spores were more sensitive to dryness. The germinated spores, which were exposed to dryness, were not able to grow further and died (data was not shown). The results of the greenhouse experiments were comparable with the screening results from the field which concluded by significant correlations between greenhouse and field data. In particular, a stronger correlation was observed between greenhouse experiments with the field trial in 2009 when there was a greater Rcc epidemic due to higher humidity and more precipitation. Among different barley genotypes, which were evaluated for resistance to Rcc under controlled conditions, IPZ 24727 was the most resistant cultivar, while Barke and Hatifa were the most susceptible genotypes. Furthermore, cultivar Gaute, Varberg and Nymfe showed moderate resistance to Rcc.

These results indicate that RLS screening can be effectively and reliably carried out in the greenhouse by providing proper conditions. Furthermore, resistance evaluation in the greenhouse can be conducted during the whole year. Additionally, greenhouse screening could be appropriate when field screening is inefficient because of unfavourable environmental conditions and/or the simultaneous presence of other barley pathogens.

In a parallel study in the greenhouse, we tried to develop an inoculation technique to enable screening for resistance to Rcc in different barley genotypes at the younger growth stages. Under controlled conditions, in which we could produce symptoms on 
barley leaves at older growth stages, we were not successful to inoculate young plants. We identified that seedling assays have no correlation with adult disease monitoring to Rcc. Similar negative correlation were shown for other cereal and crops pathogens, therefore seedling assays for quantitative resistance were not used in some of the assays on grown adult crops (Nelson \& Marshall, 1990; Walther, 1990; Wicki et al., 1999; Shah et al., 2000; Mebrate \& Cooke, 2001). These results demonstrate that different resistance genes can operate at the seedling and adult growth stage (Milus \& Line, 1986; Badawy et al., 1996; Ballinger \& Salisbury, 1996). Initially, we have proved the development of the pathogen inside the plants at early growth stages in a symptomless manner. We could only conclude that the plant defence system may overcome the pathogenicity factors of Rcc at early growth stages. This conclusion is further supported by results from Makepeace (2006), who showed that varieties most resistant to Rcc under controlled conditions following seedling inoculation were most susceptible as adult plants under field conditions. These data suggest that there are different genes for resistance to Rcc at the seedling and adult plant stages or that some resistance genes are only expressed under specific field conditions. Heiser \& Liebermann (2006) have shown that the Rcc toxin (rubellin) induces the establishment of reactive oxygen species (superoxide radical anion, hydrogen peroxide and the hydroxyl radical), which are strong oxidants and promote the oxidative disruption of the plant membranes and pigments when the antioxidative capacity of the plant cell is overextended. It was also shown that the susceptibility of barley to Rcc is mainly governed by the ontogenetic senescence status of the leaves, indicated by a breakdown of the antioxidative systems (Schützendübel, et al., 2008). In previous studies, different chemical and physical treatments have been used to induce oxidative stress in different plants, resulting in an increase of ROS (Amory et al., 1992; Prasad et al., 1994; Schützendübel \& Polle, 2002). In the present study we tried to increase oxidative stress by different stressors to unbalance the ROS production and plant defence systems in barley seedlings during inoculation.

Paraquat: Previous studies have shown that Paraquat or methyl viologen (which is known as a herbicide) conducts its phytotoxic efficiency by catalyzing the electrons transfer from Photosystem I to molecular oxygen which is generating ROS (Harvey \& 
Fraser, 1980; Lehoczki et al., 1992; Cummins et al., 1999; Mascher et al., 2004). Mascher et al. (2005) observed the higher glutathione concentration in barley shoots, which were exposed to Paraquat. Moskova et al. (2009) reported that applying $2.5 \mathrm{mM}$ Paraquat on the leaves of young pea plants resulted in an increase in the hydrogen peroxide content.

Ethephon: Ethephon, which is known as a plant growth regulator, is the most widely used among the plant hormones. During plant metabolisms it converted into ethylene, an effective regulator of plant development and maturity. It was demonstrated that applying Ethephon in Arabidopsis thaliana activated the plant antioxidative systems as a defence response (Penninckx et al., 1996). Pageau et al. (2006) reported the increase of ROS concentration in tobacco leaves after Ethephon application. These results are furthermore supported by Jung et al. (2009), which have shown a significant increase in ROS production in Arabidopsis thaliana after roots treatment by Ethephon.

High-temperature: Treatment with high temperature is one of the physical stressors associated with ROS accumulation. Kraus \& Fletcher (1994) reported changes in the antioxidants in wheat seedlings during high-temperature treatment. It was also shown that exposing tobacco seedling to $40^{\circ} \mathrm{C}$ significantly increased the concentration of $\mathrm{H}_{2} \mathrm{O}_{2}$ (Foyer et al., 1997). Increased production of ROS was also demonstrated by Dat et al. (1998) after 30 minutes heat treating of mustard seedlings.

Low temperature: Chilling is one of the stressor treatments which were used in this study to induce ROS production. Patterson \& Myers (1973) reported the production of $\mathrm{H}_{2} \mathrm{O}_{2}$ in a photosynthetic system using Anacytis nidulans by chilling treatment. The same results have been observed in vitro by using isolated spinach chloroplasts (Robinson \& Gibbs, 1982). Further studies demonstrated an increase in the $\mathrm{H}_{2} \mathrm{O}_{2}$ concentration in winter wheat leaves which were treated with low temperature in a dark icebox at $4^{\circ} \mathrm{C}$ (Okuda et al., 1991). These results further supported by results from O'Kane et al. (1996) and Foyer et al. (1997), which have shown cold treatment of Arabidopsis thaliana tissue to $4^{\circ} \mathrm{C}$ resulted of oxidative stress as demonstrated by increased levels of ROS. Santis et al. (1999) determined that growing maize seedlings at low temperature induces oxidative stress which increases production of ROS such as superoxide and $\mathrm{H}_{2} \mathrm{O}_{2}$. 
UV-light: UV radiation was reported to be a causal agent of ROS formation. Murphy \& Huerta (1990) indicated that suspension-cultured of rose cells which were illuminated with UV, showed production of $\mathrm{H}_{2} \mathrm{O}_{2}$. Foyer et al. (1994) demonstrated that the lightdependent generation of ROS can be produced by UV irradiation. These results further are supported by results from Santos et al. (1999) which have shown that UVB caused oxidative stress in different plants (maize, potato, sorghum and wheat) by generating active oxygen species.

In the present study, any significant differences were observed in Rcc symptoms appearance between the stressor treated plants and the control plants. The treatment with physical stressors $\left(4^{\circ} \mathrm{C}\right.$ and $\left.40^{\circ} \mathrm{C}\right)$ for 24 hours resulted in the limited necrosis spots on older leaves in few plants which were comparable to Rcc symptoms. These studies showed encouraging results, however, they were not sufficient to consistently establish reliable methods for resistance assessment against Rcc in different barley genotypes. Obviously more work should be done to evaluate Rcc resistance screening in barley plants at early growth stages.

Leaf segment assay: Leaf segment experiment was reported several times previously as an accurate and convincing method to evaluate resistance against different fungal pathogens in different host plants (Osman-ghani, 1982; Locke, 1984; Foolad et al., 2000; Arraiano et al., 2001; Browne et al., 2006; Jackson et al., 2008). This kind of experiment overcomes a lot of limitations of the field experiment. It is also reliable and fast to evaluate different resistance reaction to Rcc. Like whole plant inoculation under controlled conditions, the age of leaf segments at the time of inoculation was the critical point in this assay. The number of necrotic spots caused by Rcc were significantly $(p \leq 0.5)$ affected by the age of leaves. Leaf segments that were at early growth stages (up to 41-45) had significantly lower number of necrotic spots than leaves which were at older growth stages like 55-59. In this assay, the critical aspect was keeping the leaflets green during disease assessment. Applying benzimidazole in the incubation medium was reported as an effective agent for retarding chlorosis of leaf segments (Benedikz et al., 1981; Diamond et al., 1999; Asnaghi et al., 2001; Arraiano et al., 2001; Jackson et al., 2008). Using 0.75\% water agar containing $40 \mathrm{ppm}$ benzimidazole has the best result to prevent degradation of chlorophyll. 
Previous studies demonstrated that inoculum concentration plays a significant role in disease development. It has shown that a concentration of $1 \times 10^{5} \mathrm{spores} / \mathrm{ml}$ resulted in the highest levels of leaf necrosis (data not shown). Therefore, a concentration of $1 \times 10^{5}$ spores $/ \mathrm{ml}$ was used for all inoculation methods during evaluating different barley genotypes against Rcc using leaf segments and whole plant inoculation in the greenhouse.

In the present study, the result of leaf segment assay was comparable to the results of whole plant inoculation under controlled conditions and field experiments, which is reflected by significant correlations between all experiments. This method also was able to identify IPZ 24727 as the most resistant cultivar and Hatifa as the most susceptible one. There was sometimes little agreement between the results of two inoculation methods in cultivars with moderate to high susceptibility to Rcc (e. g. cultivar Quench). One possible explanation is the size of necrotic spots on leaf segments. Although cultivar Quench had a high average of necrotic spots (91.70), they should be relatively small that in the whole plant inoculation they covered just $46.45 \%$ of leaf surface. All these experiments and results indicate that by achieving the optimal conditions for Rcc development under controlled environmental condition, the In vitro methods can be adopted for the preliminary screening of different barley genotypes. This is considered more convenient and less time consuming in comparison with field screening. 


\section{Summary}

The deuteromycete, Ramularia collo-cygni (Rcc) has gained increasing importance as the causal agent of a novel leaf spot disease, Ramularia leaf spot (RLS), on barley. The disease occurs conspicuously late in the growing season. When the crop has passed the flowering stage, the disease severity in the field increases dramatically causing complete browning and leaf death within 12 days. Studies on Ramularia collo-cygni are fairly recent and classical and molecular knowledge on the disease epidemiology and control are continuously improved. Recently, molecular bioanalytical tools based on PCR have been developed and are now available for the detection of Rcc in plant tissues. This study aimed to improve knowledge on the epidemiology, pathogenicity, sources of inoculum and spread of Rcc, and to develop reliable phenotyping assays for resistance evaluation in different barley genotypes under field and greenhouse conditions.

Initially, a SYBR Green-based quantitative polymerase chain reaction (qPCR) assay for quantification of fungal DNA in plant material was developed. Rcc was successfully detected and identified down to $0.1 \mathrm{pg}$ in culture, in host plant tissues and in seeds as well as in rain and snow.

Qualitative PCR analyses revealed the transmission of the fungus from seeds into emerging plants and confirmed the spread of the fungus in adult plants in a symptom-less manner. Under greenhouse conditions, the symptomless stage of RLS persisted throughout the first generation of plants emerging from infested seeds until maturity and grain formation. Hot water treatment of seeds did not eliminate Rcc or impair the transfer of the pathogen into the developing plant.

Further studies on effects of seed dressings and consecutive applications of foliar fungicides during plant development were conducted in order to produce pathogenfree plants. The efficacy of the seed dressing fungicide Zardex $G$ (cyproconazole and imazalil) and the systemic foliar fungicide Proline (prothioconazole) on fungal systemic spread was assessed during different growth stages by means of real time PCR. Results show that both fungicides were not effective in controlling fungal development inside the plants when used separately. However, using Zardex G 
before sowing the seeds and applying Proline at early growth stages (39-41) had the strongest inhibitory effect on fungal development.

In a parallel study, the mobility and spread of Rcc inoculum through the air and over large distances was investigated using spore traps placed either close to a barley field or in a place at long distance from any fields. Rcc conidia were detectable during late autumn and winter months at larger distance from fields and in higher elevation above ground. This suggests that Rcc inoculum is widespread also in the cooler season and may spread over large distances via the atmosphere and in rain water or snow.

In the screening assay, different spring barley genotypes were evaluated for resistance to RLS. Evaluations were conducted in replicated experiments in a growth chamber (with leaf segments) and under greenhouse and field conditions (with whole plants) at mature growth stages (73-75). Genotypes displayed significant differences in their response to Rcc infection in the field, greenhouse, and the growth chamber experiments. Upon naturally infection in the field, the cultivar IPZ 24727 was significantly more resistant to Rcc compared to the other cultivars. A significant correlation has been shown between greenhouse experiment (whole plant inoculation) and field experiment $2009\left(\mathrm{p}=0.005, r_{s}=0.483\right)$ and field experiment 2010 $\left(p=0.03, r_{s}=0.384\right)$. A significant correlation was found between leaf segment assay and severity of leaf symptoms in the greenhouse experiments $\left(p=0.0002, r_{s}=0.592\right)$ and leaf segment assay between field experiment $2009\left(\mathrm{p}=0.0005, r_{s}=0.576\right)$ and field experiment $2010\left(p=0.002, r_{s}=0.513\right)$. A significant correlation has been also observed between field experiments in two different years $\left(p=0.04, r_{s}=0.419\right)$.

By using qPCR, DNA of Rcc was detected in all barley genotypes. This suggests that none of the spring barley cultivars was completely resistant to Rcc. The results indicate that the PCR was able to detect the presence of the pathogen before appearance of the symptoms at early growth stages. Quantitative real time PCR analyses demonstrated a strong correlation $\left(p=0.00179, r_{s}=0.851\right)$ between the visual disease symptoms and fungal DNA concentration in leaf $F-1$, suggesting that quantitative real-time PCR can be used for the selection of resistant barley.

Furthermore, a novel detection method for the Rcc phytotoxin, rubellin, was developed by using HPLC with fluorescence detector. With this method, the 
presence of the toxin was detected before appearance of the symptoms at early growth stages. Levels of fungal toxins in infected leaf tissue correlated strongly $\left(p=0.00005, r_{s}=0.966\right)$ with the visual disease symptoms.

These results demonstrate the potential for screening barley cultivars for Rcc resistance under controlled conditions. 


\section{Zusammenfassung}

Ramularia collo cygni (Rcc), der Erreger der Sprenkelkrankheit an Gerste, gewinnt zunehmend an Bedeutung. Das pilzliche Pathogen wird den Deuteromyceten zugeordnet. Typisch für die Krankheit ist ein auffallend spätes Auftreten von Symptomen in der Vegetationsperiode. Nach Abschluss der Blüte nimmt die Befallsstärke stark zu, was sich in einer Verbräunung und Absterben der Blätter innerhalb von 12 Tagen zeigt.

Klassische Untersuchungsmethoden der Rcc-Gerste-Interaktion werden kontinuierlich durch molekulare Untersuchungen zur Befallsdynamik unterstützt. So stehen seit kurzem PCR-basierte Verfahren zum Nachweis von Rcc in Pflanzengewebe zur Verfügung.

Ziel dieses Projektes waren Untersuchungen zur Epidemiologie und Pathogenität von Rcc, weiterhin wurde die Herkunft des Inokulums und die Verbreitung des Pathogens untersucht. Ein weiterer Schwerpunkt war die Entwicklung von robusten Phänotypisierungs-Assays zur Bewertung der Resistenz unterschiedlicher GerstenGenotypen sowohl unter Gewächshaus- als auch unter Feldbedingungen.

Zunächst wurde eine auf SYBR-Green basierende quantitative Real-Time PCR (qPCR)-Methode zum Nachweis von pilzlicher DNA in Pflanzengewebe entwickelt. Die Nachweisgrenze der pilzlichen DNA lag hier bei 0,1 pg in Flüssigkultur, sowie in Pflanzengewebe und in Samenmaterial; auch in Regenwasser und Schnee konnte diese DNA-Konzentration noch nachgewiesen werden.

Mittels qualitativer PCR konnte eine Übertragung des Pathogens von Samen auf Keimlinge gezeigt werden. Die Untersuchungen bestätigten auch, dass die weitere Ausbreitung des Pathogens in älteren Pflanzen ohne Ausbildung von Symptomen erfolgte. Unter Gewächshausbedingungen traten in infizierten Pflanzen erste Symptome erst zur Abreife und Kornentwicklung auf. Eine Desinfektion der Samen mit heißem Wasser führte nicht zur Abtötung von Rcc und somit zur Verbreitung des Pathogens in der Pflanze.

In weiteren Untersuchungen wurde die Wirkung von Saatgutbehandlung und Blattfungiziden zu unterschiedlichen Entwicklungsstadien der infizierten Pflanze getestet. Die Beizmittel Zardex G (Cyproconazol und Imazalil) und das systemische 
Blattfungizid Proline (Prothioconazole) wurden zu unterschiedlichen Wachstumsphasen der Pflanze appliziert und die Verbreitung von Rcc mittels RealTime PCR analysiert. Dabei konnte gezeigt werden, dass die Fungizide bei separater Anwendung keine Wirkung hatten, eine Kombination der beiden Pflanzenschutzmittel jedoch Effekte zeigte. So konnte nach Beizung mit Zardex G und anschließender Anwendung von Proline im Wachstumsstadium 39-41 ein starker inhibitorischer Effekt auf das pilzliche Wachstum demonstriert werden.

In einer weiteren Studie wurde die Verbreitung und Mobilität von Rcc Inokulum über die Luft mittels Sporenfallen untersucht, die entweder in der Nähe eines Gerstenfeldes oder weiter enfernt aufgestellt wurden. Im späten Herbst und in den Wintermonaten wurden Sporen von Rcc in größerer Entfernung von Gerstenfeldern und in höheren Lagen nachgewiesen. Rcc Inokulum ist demnach weit verbreitet und kann auch über größere Distanzen durch die Luft, im Regenwasser oder Schnee transportiert werden. Interessanterweise ist Inokulum auch auch in kühleren Jahreszeiten nachweisbar.

Zur Identifizierung resistenter Genotypen erfolgten Phänotypisierungen von Blattsegmenten in der Klimakammer und parallel dazu wurden Screenings unter Feldbedingungen im Reifestadium 73-75 durchgeführt. Es konnten signifikant unterschiedliche Anfälligkeiten gegenüber Rcc sowohl im Feld, als auch unter kontrollierten Bedingungen im Gewächshaus und der Klimakammer gezeigt werden. So konnten einige Genotypen identifiziert werden, die besonders gute Resistenzen aufwiesen wie z. B. die Sorte IPZ 24727.

Eine signifikante Korrelation konnte zwischen den Gewächshausdaten (Inokulation ganzer Pflanzen) und den Felddaten 2009 ( $\left.p=0,005, r_{s}=0,483\right)$ und 2010 ( $p=0,03$, $\left.r_{s}=0,384\right)$ nachgewiesen werden. Ein Vergleich der Daten des Blattsegment-Assays und der ermittelten Befallsstärke im Gewächshausversuch zeigte eine signifikante Korrelation $\left(p=0,0002, r_{s}=0,592\right)$. Darüber hinaus korrelierten die Werte des Assays mit den Felddaten aus dem Jahr 2009 ( $\left.p=0,0005, r_{s}=0,576\right)$ und $2010(p=0,002$, $\left.r_{s}=0,513\right)$. Eine signifikante Korrelation wurde auch zwischen den Daten der Feldversuche der beiden untersuchten Jahren gezeigt $\left(p=0,04, r_{s}=0,419\right)$.

Mittels qPCR wurde Rcc in allen getesteten Genotypen nachgewiesen, d.h., dass keiner der Genotypen komplett resistent war. Die Ergebnisse zeigen, dass ein Nachweis des Pathogens in frühen Wachstumsstadien bereits vor der 
Symptomausbildung mittels PCR möglich ist. QPCR Analysen zeigten eine starke Korrelation $\left(p=0,00179, r_{s}=0,851\right)$ zwischen den visuellen Boniturdaten und der pilzlichen DNA-Konzentration im F-1Blatt. Eine Anwendung der qPCR zur Selektion resistenter Gerste Genotypen ist daher möglich. Weiterhin wurde mittels HPLC eine neue Detektionsmethode für das Rcc Phototoxin Rubellin entwickelt. Mit dieser sensitiven Methode konnten Konzentrationen des Toxins bereits vor der Symptomausbildung in frühen Wachstumsstadien der Pflanze nachgewiesen werden. Die gemessenen Toxinwerte in infiziertem Blattgewebe korrelierten stark mit den Werten der Sichtbonitur ( $\left.p=0,00005, r_{s}=0,966657\right)$. Diese Methode ist daher zur Identifizierung von resistenten Gerste-Genotypen unter kontrollierten Bedingungen geeignet. 


\section{References}

Ali SM, Mayfield AH, Clare BG, 1976. Pathogenicity of 203 isolates of Rhynchosporium secalis on 21 barley cultivars. Plant Pathology 9,135-43.

Almeselmani M, Deshmukh PS, Sairam RK, Kushwaha SR, Singh TP, 2006. Protective role of antioxidant enzymes under high temperature stress. Plant Science 171, 382-8.

Amory AM, Ford L, Pammenter NW, Cresswell CF, 1992. The use of 3-amino-1,2,4 triazole to investigate the short-term effects of oxygen toxicity on carbon assimilation by Pisum sativum seedlings. Plant, Cell and Environment 15, 655-63.

Arnone A, Nasini G, Camarda L, Assante G, 1986. Secondary mould metabolites. Part 15. Structure elucidation of rubellins $A$ and $B$, two novel anthraquinone metabolites from Mycosphaerella rubella. Journal of the Chemical SocietyPerkin Transactions I, 255-60.

Arnone A, Assante G, Caronna T, di Modugno V, Nasini G, 1988. Comparative evaluation of photodynamic efficiency of some natural quinonoid fungal toxins. Phytochemistry 27, 1669-74.

Arraiano LS, Brading PA, Brown JKM, 2001. A detached seedling leaf technique to study resistance to Mycosphaerella graminicola (anamorph Septoria tritici) in wheat. Plant Pathology 50, 339-46.

Asnaghi C, D'Hont A, Glaszmann JC, Rott P, 2001. Resistance of sugarcane cultivar R 570 to Puccinia melanocephala isolates from different geographic locations. Plant Disease 85, 282-6.

Aylor AE, 1993. Relative collection efficiency of Rotorod and Burkard spore samplers for airborne Venturia inaequalis ascospores. Phytopathology 83, 1116-19.

Badawy H, Hoppe H, Koch E, 1991. Differential reactions between the genus Brassica and aggressive single spore isolates of Leptosphaeria maculans. Journal of Phytopathology 131, 109-19.

Bai GH, Shaner G, 2004. Management and resistance in wheat and barley to Fusarium head blight. Annual Review of Phytopathology 4, 135-61. 
Ballinger D, Salisbury P, 1996. Seedling and adult plant evaluation of race variability in Leptosphaeria maculans on Brassica species in Australia. Australian Journal of Experimental Agriculture 36, 485-8.

Balz T, Prigge G, Krieg U, Sattler U, von Tiedemann A, 2006. Strategies of chemical control of Ramularia collo-cygni. In Proceedings of the First European Ramularia Workshop, Göttingen, Germany, 121-2.

Balz T, 2009. Ramularia collo-cygni an Gerste - Biologie, Verbreitung, ökonomische Bedeutung und Bekämpfungsmöglichkeiten. Dissertation, University of Göttingen, Division of Plant Pathology and Crop Protection, Department of Crop Sciences.

Bartels G, Broschewitz B, Frahm J, Grabe V, von Kröcher C, Mielke H, Saur R, Schmidt C, Steck U, 2000. EPPO-Richtlinie PP 1/26(3) Blattkrankheiten an Getreide. Biologische Bundesanstalt für Land- und Forstwirtschaft. (http://www.bba.bund.de).

Bates JA, Taylor EJA, Kenyon DM, Thomas JE, 2001. The application of real-time PCR to the identification, detection and quantification of Pyrenophora species in barley seed. Molecular Plant Pathology 2, 49-57.

Batts CCV, 1956. The control of loose smut in wheat and barley. Annals of applied biology 44, 437-452.

Bender CL, Alarcon-Chaidez F, Gross DC, 1999. Pseudomonas syringae phytotoxins: mode of action, regulation, and biosynthesis by peptide and polyketide synthetases. Microbiology and Molecular Biology Reviews 63, 266-92.

Benedikz PW, Mappledoram CJ, Scott PR, 1981. A laboratory technique for screening cereals for resistance to Septoria nodorum using detached seedling leaves. Transactions of the British Mycological Society 77, 667-9.

Ben-Yephet Y, Bitton S, 1985. Use of a selective medium to study the dispersal of ascospores of Sclerotinia sclerotiorum. Phytoparasitica 13, 33-40.

van den Berg CGJ, Rossnagel BG, 1990. Effects of temperature and leaf wetness period on conidium germination and infection of barley by Pyrenophora teres. Canadian Journal of Plant Pathology 12, 263-6.

Bistrich H, Breun J, Emmert G, Fleck A, Jaiser H, Kempe H, Lemmens M, 2006. Screening for leaf spot resistance - results and impact on practical breeding. In 
Proceedings of the First European Ramularia Workshop, Göttingen, Germany, 83.

Brandfass C, Karlovsky P, 2008. Upscaled CTAB-based DNA extraction and realtime PCR assays for Fusarium culmorum and F. graminearum DNA in plant material with reduced sampling error. International Journal of Molecular Sciences 9, 2306-21.

Brown JS, 1985. Pathogenic variation among isolates of Rhynchosporium secalis from cultivated barley growing in Victoria, Australia. Euphytica 34,129-33.

Brouwer M, Lievens B, Van Hemelrijck W, Van den Ackerveken G, Cammue BPA, Thomma BPHJ, 2003. Quantification of disease progression of several microbial pathogens on Arabidopsis thaliana using real-time fluorescence PCR. FEMS Microbiology Letters 228, 241-248.

Browne RA, Mascher F, Golebiowska GI, Jofgaard SJ, 2006. Components of Partial Disease Resistance in Wheat Detected in a Detached Leaf Assay Inoculated with Microdochium majus using First, Second and Third Expanding Seedling Leaves. Phytopathology 154, 204-8.

Burke JI, Hackett R, O'Sullivan E, 2001. The barley leaf spot problem - causes and control. Irish Agriculture and Food Development,Teagasc Crops Research Centre, Oak Park.

http://www.teagasc.ie/publications/2001/tillageconference/paper03.htm

Cavara F, 1893. Über einige parasitische Pilze auf dem Getreide. Zeitschrift für Pflanzenkrankheiten 3, 16-26.

Christiansen A, Jørgensen LN, von Tiedemann A, Balz T, Libermann B, Mietbauer S, 2009. Aspects of Applied Biology 92, 33-9.

Couture L, Sutton JC, 1980. Effect of dry heat treatments on survival of seed borne Bipolaris sorokiniana and germination of barley seeds. Canadian Plant Disease Survey 60, 59-61.

Cromey MG, Harvey IC, Sheridan JE, Grbavac N, 2004. Occurrence, importance, and control of Ramularia collo-cygni in New Zealand. In: Meeting the challenges of barley blights, eds. Yahyaoui, Brader, Wallwork and Steffenson, p. 337-42.

Crous PW, Aptroot JCH, Braun U, Wingfield M, 2000. The genus Mycosphaerella and its anamorphs. Studies in Mycology 45, 107-21. 
Cullen DW, Lees AK, Toth IK, Duncan JM, 2001. Conventional PCR and real-time quantitative PCR detection of Helminthosporium solani in soil and potato tubers. European Journal of Plant Pathology 107, 387-98.

Cummins I, Cole DJ, Edwards R, 1999. A role for glutathione transferases functioning as glutathione peroxidases in resistance to multiple herbicides in blade-grass. Plant Journal 18, 285-92.

Dat JF, Foyer CH, Scott IM, 1998. Changes in salicylic acid and antioxidants during induced thermo tolerance in mustard seedlings. Plant Physiology 118, 1455-61.

Daub ME, Ehrenschaft M, 2000. The photoactive cercospora toxin cercosporin: contributions to plant disease and fundamental biology. Annual Review of Phytopathology 38, 461-90.

Davis H, Fitt BDL, 1990. Symptomless infection of Rhynchosporium secalis on leaves of winter barley. Mycological Research 94, 557-60.

Diamond $\mathrm{H}$, Cooke BM, 1999. Towards the development of a novel in vitro strategy for early screening of Fusarium ear blight resistance in adult winter wheat plants. European Journal of Plant Pathology 105, 363-72.

Dickman MB, Patil SS, 1986. Cutinase deficient mutants of Colletotrichum gloeosporioides are non-pathogenic to papaya fruit. Physiology and Molecular Plant Pathology, 28, 235-42.

Djurle A, 2009. Ramularia leaf spot in Sweden; a trifle or a treat?. Aspects of Applied Biology 92, 23-5.

Doling DA, 1965. Single-bath hot-water treatment for the control of loose smut (Ustilago nuda) in cereals. Annals of Applied Biology 55, 295-301.

Evenhuis A, Verdam B, Zadoks JC, 1997. Splash dispersal of conidia of Mycocentrospora acerina in the field. Plant Pathology 46, 459-69.

Feng J, Wang F, Liu G, Greenshields D, Shen W, Kaminskyj S, Hughes GR, Peng Y, Selvaraj G, Zou J, 2009. Analysis of a Blumeria graminis-secreted lipase reveals the importance of host epicuticular wax components for fungal adhesion and development. Molecular Plant-Microbe Interactions 22, 1601-10.

Fitt BDL, McCartney HA, Walklate PJ, 1989. The role of rain in dispersal of pathogen inoculum. Annual Review of Phytopathology 27, 241-70. 
Foolad MR, Ntahimpera N, Christ BJ, Lin GY, 2000. Comparison of field, greenhouse, and detached-leaflet evaluations of tomato germplasm for early blight resistance. Plant Disease 84, 967-72.

Fountaine JM, Shaw MW, Ward E, Fraaije BA, 2010. The role of seeds and airborne inoculum in the initiation of leaf blotch (Rhynchosporium secalis) epidemics in winter barley. Plant Pathology 59, 330-7.

Fourest E, Rehms LD, Sands DC, Bjarko M, 1990. Eradication of Xanthomonas campestris pv. translucens from barley seed with dry heat treatments. Plant disease 74, 816-8.

Foyer CH, Lelandais M, Kunert KJ, 1994. Photooxydative stress. Physiologia Plantarum 92, 696-717.

Foyer CH, Lopez-Delgado H, Dat JF, Scott IM, 1997. Hydrogen peroxide- and glutathione-associated mechanisms of acclamatory stress tolerance and signalling. Physiologia Plantarum 100, 241-54.

Fraaije BA, Lovell DJ, Coelho JM, Baldwin S, Hollomon DW, 2001. PCR-based assays to assess wheat varietal resistance to blotch (Septoria tritici and Stagonospora nodorum) and rust (Puccinia striiformis and Puccinia recondita) diseases. European Journal of Plant Pathology 107, 905-17.

Frei P, Gindro K, Richter H, Schürch S, 2007. Direct-PCR detection and epidemiology of Ramularia collo-cygni associated with barley necrotic leaf spots. Journal of Phytopathology 155, 281-8.

Geagea L, Huber L, Sache I, 1999. Dry-dispersal and rain-splash of brown (Puccinia recondita f. sp. tritici) and yellow ( $P$. striiformis) rust spores from infected wheat leaves exposed to simulated raindrops. Plant Pathology 48, 472-82.

Gniwotta F, Vogg G, Gartmann V, Carver TLW, Riederer M, Jetter R, 2005. What do microbes encounter at the plant surface? Chemical composition of pea leaf cuticular waxes. Plant Physiology 139, 519-30.

Goyal M, Asthir B, 2009. Polyamine catabolism influences antioxidative defence mechanism in shoots and roots of five wheat genotypes under high temperature stress. Plant Growth Regulation 60, 13-25. 
Greif $\mathrm{P}, 2004$. Importance of Ramularia collo-cygni for barley growers and breeders. In: Meeting the challenges of barley blights, eds. Yahyaoui, Brader, Wallwork and Steffenson, p. 331-6.

Harvey BMR, Fraser TW, 1980. Paraquat tolerant and susceptible perennial ryegrasses: effects of paraquat treatment on carbon dioxide uptake and ultra structure of photosynthetic cells. Plant Cell Environment 3, 107-17.

Harvey IC, 2002. Epidemiology and control of leaf and awn spot of barley caused by Ramularia collo-cygni. New Zealand Plant Protection 331-5.

Havis ND, Piper SR, Oxley SJP, Langrell SR, 2004. Development of a PCR based identification and detection assay for Ramularia collo-cygni direct from barley leaf tissue. In Proceeding of the 2nd International Workshop on Barley Leaf Blights. ICARDA Aleppo, Syria, 343-0.

Havis ND, Oxley SP, Piper SR, Langrell SR, 2006. Rapid nested PCR-based detection of Ramularia collo-cygni direct from barley. FEMS Microbiology Letters 256, 217-23.

Hegde Y, Kolattukudy PE, 1997. Cuticular waxes relieve self inhibition of germination and appressorium formation by the conidia of Magnaporthe grisea. Physiological and Molecular Plant Pathology 51, 75-84.

Heiser I, Sachs E, Liebermann B, 2003. Photodynamic oxygen activation by rubellin D, a phytotoxin produced by Ramularia collo-cygni (Sutton et al., Waller). Physiological and Molecular Plant Pathology 62, 29-36.

Heiser I, Heß M, Schmidtke KU, Vogler U, Miethbauer S, Liebermann B, 2004. Fatty acid peroxidation by rubellin $\mathrm{B}, \mathrm{C}$ and $\mathrm{D}$, phytotoxins produced by Ramularia collo-cygni (Sutton et Waller). Physiological and Molecular Plant Pathology 64, 135-43.

Heiser I, Liebermann B, 2006. Phytotoxins from Ramularia collo-cygni: Mode of action and contribution to pathogenicity. In Proceedings of the First European Ramularia Workshop, Göttingen, Germany, 57-62.

Hunter T, Coker RR, Royle DL, 1999. The teleomorph stage, Mycosphaerella graminicola, in epidemics of Septoria tritici blotch on winter wheat in UK. Plant Pathology 48, 51-7. 
Huss H, Mayerhofer H, WetschnigW, 1987. Ophiocladium hordei CAV. (Fungi imperfecti), ein für Österreich neuer parasitischer Pilz der Gerste. Der Pflanzenarzt 40, 167-9.

Huss H, 2004. The Biology of Ramularia collo-cygni. In Proceeding of the 2nd International Workshop on Barley Leaf Blights. ICARDA Aleppo, Syria, 54.

Huss H, 2008. Die Sprenkelkrankheit nun auch auf Mais! Der Pflanzenarzt (Heft 1112), 6-7.

Huss $H, 2011$. Untersuchungen zur biologischen Kontrolle der Sprenkelkrankheit (Ramularia - Blattfleckenkrankheit) der Gerste. Abschlussbericht Ramu, Projekt Nr. 2328, Lehr- und Forschungszentrum der Landwirtschaft Raumberg-Gumpenstein, Österreich, $34 \mathrm{pp.}$

Jackson AO, Taylor CB, 1996. Plant-microbe interactions: life and death at the interface. Plant Cell 8,1651-68.

Jackson EW, Obert DE, Chong J, Avant JB, Bonman JM, 2008. Detached-leaf method for propagating Puccinia coronata and assessing crown rust resistance in oat. Plant Disease 92, 1400-6.

Jenks MA, Joly RJ, Peters PJ, Rich PJ, Axtell JD, Ashworth EA, 1994. Chemically induced cuticle mutation affecting epidermal conductance to water vapor and disease susceptibility in Sorghum bicolor (L.) Moench. Plant Physiology 105, 1239-45.

Jensen JL, 1888. The propagation and prevention of smut in oats and barley. Journal of the Royal Agricultural Society of England 24, 397-415.

Jørgensen HJL, Smedegaard-Peterson V, 1995. Pathogenic variation of Rhynchosporium secalis in Denmark and sources of resistance in barley. Plant Disease 79, 297-301.

Jørgensen LN, Christiansen A, 2006. Control of Ramularia in winter barley and spring barley using different fungicides - Experience from Denmark. In Proceedings of the First European Ramularia Workshop, Göttingen, Germany, 113-9.

Jung JY, Shin R, Schachtman DP, 2009. Ethylene mediates response and tolerance to potassium deprivation in Arabidopsis. Plant Cell 21, 607-21. 
Koch K, Neinhuis C, Ensikat H, Barthlott W, 2004. Self assembly of epicuticular waxes on living plant surfaces imaged by atomic force microscopy (AFM). The Journal of Experimental Botany 55, 711-8.

Kohl R, Blanco J, Kollar A, 1994. Detection of infection and evaluation of the parameters for the epidemiology of the apple scab disease. Journal of Plant Disease 101, 378-85.

Kolattukudy PE, 2001. Polyesters in higher plants. In Advances in biochemical engineering biotechnology 71, 1-19.

Kraus TE, Fletcher RA, 1994. Paclobutrazol protects wheat seedlings from heat and paraquat injury: is detoxification of active oxygen involved? Plant Cell Physiology 35, 45-52.

Kunoh H, Nicholson RL, Yoshioka H, Yamaoka N, Kobayashi I, 1990. Preparation of the infection court by Erysiphe graminis: degradation of the host cuticle. Physiological and Molecular Plant Pathology 36, 397-407.

Kushalappa AC, Eskes AB, 1989. Advances in coffee rust research. Annual Review of Phytopathology 27, 503-31.

Lehoczki E, Laskay G, Gaal I, 1992. Mode of action of paraquat in leaves of paraquat-resistant Conyza nandensis (L.). Plant Cell Environ 15, 531-9.

Leistrumaite A, Liatukas Z, 2006. Resistance of spring barley cultivars to the new disease Ramularia leaf spot, caused by Ramularia collo-cygni. Agronomy Research 4, 251-5.

Levings CS, Siedow JN, 1992. Molecular basis of disease susceptibility in the Texas cytoplasm of maize. Plant Molecular Biology 19, 135-47.

Limpert E, 1987. Barley mildew in Europe: evidence of wind-dispersal of the pathogen and its implications for improved use of host resistance and of fungicides for mildew control, p. 31-33. In M. S. Wolfe and E. Limpert (ed.), Intergrated control of cereal mildews: monitoring the pathogen. Martinus Nijhof Publishers, Dortrecht, The Netherlands.

Locke SB, 1984. A method for measuring resistance to defoliation diseases in tomato and other Lycopersicon species. Phytopathology 38, 937-42.

Luo X, Xiao J, Lin H, Li B, Lu Y, Yang B, Wang Z, 2007. Transcriptional activation by stimulating protein 1 and post-transcriptional repression by musclespecific 
microRNAs of IKs-encoding genes and potential implications in regional heterogeneity of their expressions. Journal of Cell Physiology 212, 358-67.

Mariani C, Wolters-Arts M, 2000. Complex waxes. Plant Cell 12, 1795-8.

Makepeace JC, Oxley SJP, Havis ND, Hackett R, Burke JI, Brown JKM, 2006. Associations between fungal and abiotic leaf spotting and the presence of $\mathrm{mlo}$ alleles in barley. Plant Pathology 56, 934-42.

Makepeace JC, Havis ND, Burke JI, Oxley SJP, Brown JKM, 2008. A method of inoculating barley seedlings with Ramularia collo-cygni. Plant Pathology 57, 991-9.

Mascher R, Nagy E, Lippmann B, Hornlein S, Fischer S, Scheiding W, Neagoe A, Bergmann $H$, 2004. Improvement of stress tolerance in barley (Hordeum vulgare L.) by 2-aminoethanol: effects on superoxide dismutase activity and chloroplast ultrastructure. Plant Science 168, 691-8.

Masher R, Fisher S, Scheiding W, Neagoe A, Bergmann H, 2005. Exogenous 2-aminoethanol can diminish paraquat induced oxidative stress in barley (Hordeum vulgare L.). Plant Growth Regular 45, 103-12.

McRoberts N, Oxley SJP, Havis N, 2009. Ramularia epidemic dynamics in untreated trial plots: interactions with variety and other pathogens. Aspects of Applied Biology 92, 17-22.

Mebrate SA, Cooke BM, 2001. Response of wheat cultivars to infection by Stagonospora nodorum isolates mixture on detached and intact seedling leaves. Euphytica 122, 263-8.

Mehdy MC, 1994. Active oxygen species in plant defence against pathogens. Plant Physiology 105, 467-72.

Miethbauer S, Heiser I, Liebermann B, 2003. The phytopathogenic fungus Ramularia collo- cygni produces biologically active rubellins on infected barley leaves. Journal of Phytopathology 151, 665-8.

Miethbauer S, Haase S, Schmidtke K, Günther W, Heiser I, Liebermann B, 2006. Biosynthesis of photodynamically active rubellins and structure elucidation of new anthraquinone derivatives produced by Ramularia collo-cygni. Phytochemistry 67, 1206-13.

Milus E, Line R, 1986. Number of genes controlling high temperature, adult-plant resistance to stripe rust in wheat. Phytopathology 76, 93-6. 
Minarikova V, Marik P, Stemberkova L, 2002. Occurrence of a New Fungal Pathogen on Barley, Ramularia collo-cygni, in the Czech Republic. In Proceeding of the 2nd International Workshop on Barley Leaf Blights. ICARDA Aleppo, Syria, 65-7.

Mittler R, 2002. Oxidative stress, antioxidants, and stress tolerance. Trends Plant Science 7, 405-10.

Moskova D, Todorova V, Alexieva S, Ivanov I, Sergiev N, 2009. Effect of exogenous hydrogen peroxide on enzymatic and nonenzymatic antioxidants in leaves of young pea plants treated with paraquat. Plant growth Regular 57, 193-202.

Murphy TM, Huerta AJ, 1990. Hydrogen peroxide formation in cultured rose cells in response to UV-C radiation. Physiologia Plantarum 78, 247-53.

Nagarajan S, Singh DV, 1990. Long-distance dispersion of rust pathogens. Annual Review of Phytopathology 28, 139-53.

Nelson LR, Marshall D, 1990. Breeding wheat for resistance to Septoria nodorum and Septoria tritici. Advances in Agronomy 44, 257-77.

Nyman M, Havis ND, Oxley SJP, 2009. Importance of seed-borne infection of Ramularia collo-cygni. Aspects of Applied Biology 92,91-96.

O'Kane D, Gill V, Boyd P, Burdon R, 1996. Chilling, oxidative stress and antioxidant responses in Arabidopsis thaliana callus. Planta 198, 371-7.

O'Reilly P, Bannon E, Doyle A, 1988. Timing of fungicide applications in relation to the development of Septoria nodorum in winter wheat. Proceedings of the British Crop Protection Conference-Pests and Diseases. Farnham, UK: BCPC, 929-34.

Okuda T, MatsudaY, Yamanaka A, Sagisaka S, 1991. Abrupt increase in the level of hydrogen peroxide in leaves of winter wheat is caused by cold treatment. Plant Physiology 97, 1265-7.

Osman-ghani N, 1982. The uses and limitations of detached leaf culture for the assessment of reaction type in yellow rust of barley. Cereal Rusts Bull 10, 16-21.

Oxley SJP, Havis ND, Sutherland KG, Nuttall M, 2002. Development of a rationale to identify the causal agent of necrotic lesions in spring barley and to identify control mechanisms. HGCA Project Report No. 282. HGCA Publications, London, UK. 
Oxley SJP, Havis ND, 2004. Development of Ramularia collo-cygni on spring barley and its impact on yield. Paper presented to Crop Protection in Northern Britain.

Oxley SJP, Havis ND, Hackett R, 2006. Impact of fungicides and varietals resistance on Ramularia collo-cygni in spring barley. In Proceedings of the First European Ramularia Workshop, Göttingen, Germany, 103.

Oxley SJP, Havis ND, Brown JKM, Makepeac JC, Fountaine J, 2008. Impact and interactions of Ramularia collo-cygni and oxidative stress in barley. HGCA Project Report 431, 1-100.

Pageau K, Reisdorf-Cren M, Morot-Gaudry JF, Masclaux- Daubresse C, 2006. The two senescence-related markers, GS1 (cytosolic glutamine synthetase) and $G D H$ (glutamate dehydrogenase), involved in nitrogen mobilization, are differentially regulated during pathogen attack and by stress hormones and reactive oxygen species in Nicotiana tabacum L. leaves. Journal of Experimental Botany 57, 547-57.

Patterson COP, Myers J, 1973. Photosynthetic production of hydrogen peroxide by Anacystis nidulans. Plant Physiology 51, 104-9.

Penninckx IAMA, Eggermont K, Terras FRG, Thomma BPHJ, De Samblanx GWD, Samblanx A, Buchala JP, Metraux JM, Broekaert WF, 1996. Pathogeninduced systemic activation of a plant defense gene in Arabidopsis follows a salicylic acid-independent pathway involving components of the ethylene and jasmonic acid responses. Plant Cell 12, 2309-23.

Pinnschmidt HO, Hovmøller MS, 2003. Ramularia, a new disease of barley - a review of present knowledge. DJF rapport $n r .89,313-21$.

Pinnschmidt HO, Sindberg SA, 2006. Expression of resistance of barley varieties to Ramularia leaf spot and the status of the disease in Denmark. In Proceedings of the First European Ramularia Workshop, Göttingen, Germany, 85.

Pinnschmidt HO, Sindberg SA, 2009. Assessing Ramularia leaf spot resistance of spring barley cultivars in the presence of other disease. Aspects of Applied Biology 92, 71-80.

Podila GK, Rogers LM, Kolattukudy PE, 1993. Chemical signals from avocado surface wax triggers germination and appressorium formation in Colletotrichum gloeosporioides. Plant Physiology 103, 267-72 
Prasad TK, Anderson MD, Martin BA, Stewart CR, 1994. Evidence for chillinginduced oxidative stress in maize seedlings and a regulatory role for hydrogen peroxide. The Plant Cell 6, 65-74.

Qi M, Yang Y, 2002. Quantification of Magnaporthe grisea during infection of rice plants using real-time polymerase chain reaction and northern blot/phosphoimaging analyses. Phytopathology 92, 870-6.

Rep M, 2005. Small proteins of plant-pathogenic fungi secreted during host colonization. FEMS Microbiology Letters 253, 19-27.

Reitan L, Salamati S, 2006. Field screening in Norway for resistance to Ramularia collo-cygni in old and new barley material. In Proceedings of the First European Ramularia Workshop, Göttingen, Germany, 73.

Richardson A, Franke R, Kerstiens G, Jarvis M, Schreiber L, Fricke W, 2005. Cuticular wax deposition in growing barley (Hordeum vulgare) leaves commences in relation to the point of emergence of epidermal cells from the sheaths of older leaves. Planta 222, 472-83.

Robinson JM, Gibbs M, 1982. Hydrogen peroxide synthesis in isolated spinach chloroplast lamellae. Plant Physiology 70, 1249-54.

Russel RC, Tyner LE, 1954. The influence of temperature on the time required to control loose smut of barley by means of Spergon or water-soak treatments. CanadianJournal of Agricultural Science 34, 533-8.

Sachs E, Greil P, Amelung D and Huss H, 1998. Ramularia collo cygni a rediscovered barley pathogen in Europe. Mitt BBA 357, 96-7.

Sachs E, 2002. Monitoring zur Verbreitung der Ramularia-Blattfleckenkrankheit an Wintergerste in Deutschland im Jahre 2000. Nachrichtenblatt Deutscher Pflanzenschutzdienst 54, 31-5.

Sachs E, 2004. A 'New' Leaf Spot Disease of Barley Caused by Ramularia collo-cygni: Description, Diagnosis and Comparison with Other Leaf Spots. In Proceeding of the 2nd International Workshop on Barley Leaf Blights. ICARDA Aleppo, Syria, 365-369.

Sachs E, 2006. The history of research into Ramularia leaf spot on barley. Nachrichtenblatt Deutscher Pflanzenschutzdienst 58, 186-9. 
Sairam RK, Srivastava GC, Sexena DC, 2000. Increased antioxidant activity under elevated temperature: a mechanism of heat stress tolerance in wheat genotypes. Biology of Plant 43, 245-51.

Salamati S, Magnus HA, 1997. Leaf blotch severity on spring barley infected by isolates of Rhynchosporium secalis under different temperature and humidity regimes. Plant Pathology 46, 939-45.

Salamati S, Reitan L, 2006. Ramularia collo-cygni on spring barley, an overview of its biology and epidemiology. In Proceedings of the First European Ramularia Workshop, Göttingen, Germany, 13-9.

Sambrook J, Fritch EF, Maniatis T, 1989. Molecular Cloning: A Laboratory Manual Cold Spring Harbor Laboratory Press, Cold Spring Harbor, NY, ed. 2.

Samuels L, Kunst L, Jetter R, 2008. Sealing plant surfaces: Cuticular wax formation by epidermal cells. Annual Review of Plant Biology 59, 683- 707.

Santis AD, Landi P, Genchi G, 1999. Changes of mitochondrial properties in maize seedlings associated with selection for germination at low temperature: fatty acid composition, cytochrome c oxidase, and adenine nucleotide translocase activities. Plant Physiology 119, 743-54.

Santos I, Almeida J, Salema R, 1999. The influence of UV-B radiation on the superoxide dismutase of maize potato sorghum and wheat leaves. Canadian Journal of Botany 77, 70-6.

Scandalios JG, 1993. Oxygen stress and superoxide dismutases. Plant Physiology $101,7-12$.

Schaefer W, 1994. Molecular mechanisms of fungal pathogenicity to plant. Annual Review of Phytopathology 32, 461-77.

Schützendübel A, Polle A, 2002. Plant responses to abiotic stress: heavy metal induced oxidative stress and protection by mycorrhization. Journal of Experimental Botany 53, 1351-65.

Schützendübel $A$, Stadler M, Wallner D, von Tiedemann A, 2008. A hypothesis on physiological alterations during plant ontogenesis governing susceptibility of winter barley to Ramularia leaf spot. Plant Pathology 57, 518-26.

Shah DA, Bergstrom GC, Sorrells ME, 2000. Differential seed infection of wheat cultivars by Stagonospora nodorum. Plant Disease 84, 749-52. 
Shaw W, 1991. Interacting effects of interrupted humid periods and light on infection of wheat leaves by Mycosphaerella graminicola (Septoria tritici). Plant Pathology 40, 595-607.

Sheridan JE, 1996. Cereal diseases 1995-1996. Mycology and Plant Pathology Report 33, 47.

Skadsen RW, Hohn TM, 2004. Use of Fusarium graminearum transformed with gfp to follow infection patterns in barley and Arabidopsis. Physiology of Molecular Plant Pathology 64, 45-53.

Srivalli B, Sharma G, Khanna-Chopra R, 2003. Antioxidative defense system in an upland rice cultivar subjected to increasing intensity of water stress followed by recovery. Physiology of Plant 119, 503-12.

Stensvand A, Amundsen T, Semb L, Gadoury DM, Seem RC, 1998. Discharge and dissemination of ascospores by Venturia inaequalis during dew. Plant Disease 82, 761-4.

Sutton B, Waller J, 1988. Taxonomy of Ophiocladium hordei causing leaf lesions on Triticale and other Gramineae. Transaction of the British Mycology Society 90, $55-61$.

Tottman DR, Broad H, 1987. The decimal code for the growth stages of cereals. Annals of Applied Biology 110, 441-54.

Wallner D, von Tiedemann A, 2008. Mikroskopische und molekulargenetische Untersuchungen der frühen Pathogenese von Ramularia collo-cygni an Gerste (Hordeum vulgare) in Abhängigkeit von Ontogenesestadium. Master study at University of Göttingen, Division of Plant Pathology and Crop Protection, Department of Crop Sciences.

Walther $\mathrm{H}, 1990$. An improved assessment procedure for breeding for resistance to Septoria. Plant Breeding 105, 53-61.

Walters DR, Havis ND, Oxley SJP, 2008. Ramularia collo-cygni the biology of an emerging pathogen. FEMS Microbiology Letters 279, 1-7.

Wicki W, Messmer M, Winzeler M, Stamp P, Schmid JE, 1999. In vitro screening for resistance against Septoria nodorum blotch in wheat. Theoretical and Applied Genetics 99, 1273-80. 
Wu YX, von Tiedemann A, 2002. Evidence for oxidative stress involved in physiological leaf spot formation in winter and spring barley. Journal of Phytopathology 92, 145-55.

Wu YX, von Tiedemann A, 2004. Light-dependent oxidative stress determines physiological leaf spot formation in barley. Phytopathology 94, 584-92.

Yoder OC, 1980. Toxins in pathogenesis. Annual Review of Phytopathology 18,103-29.

Zabka V, Stang M, Bringmann G, Vogg G, Riederer M, Hildebrandt U, 2008. Host surface properties affect prepenetration processes in the barley powdery mildew fungus. New Phytology 177, 251-63. 


\section{Appendix}

In the present study, twenty-four barely DH-lines (IPZ 24727 * Barke) were screened under environmental controlled conditions for percentage of necrotic leaf area caused by Rcc according to the rating scale of Bartels et al. (2000).

The analyses of variance for different lines in both experiments (whole plant inoculation and leaf segment assay) are presented in table A1.

Table A1. Susceptibility of different spring barley cultivars to Ramularia leaf spot disease in whole plant inoculation and leaf segment assay under controlled conditions. Data are means of 20 replicates for whole plant inoculation and 10 replicates for leaf segment assay with standard deviations (in brackets)

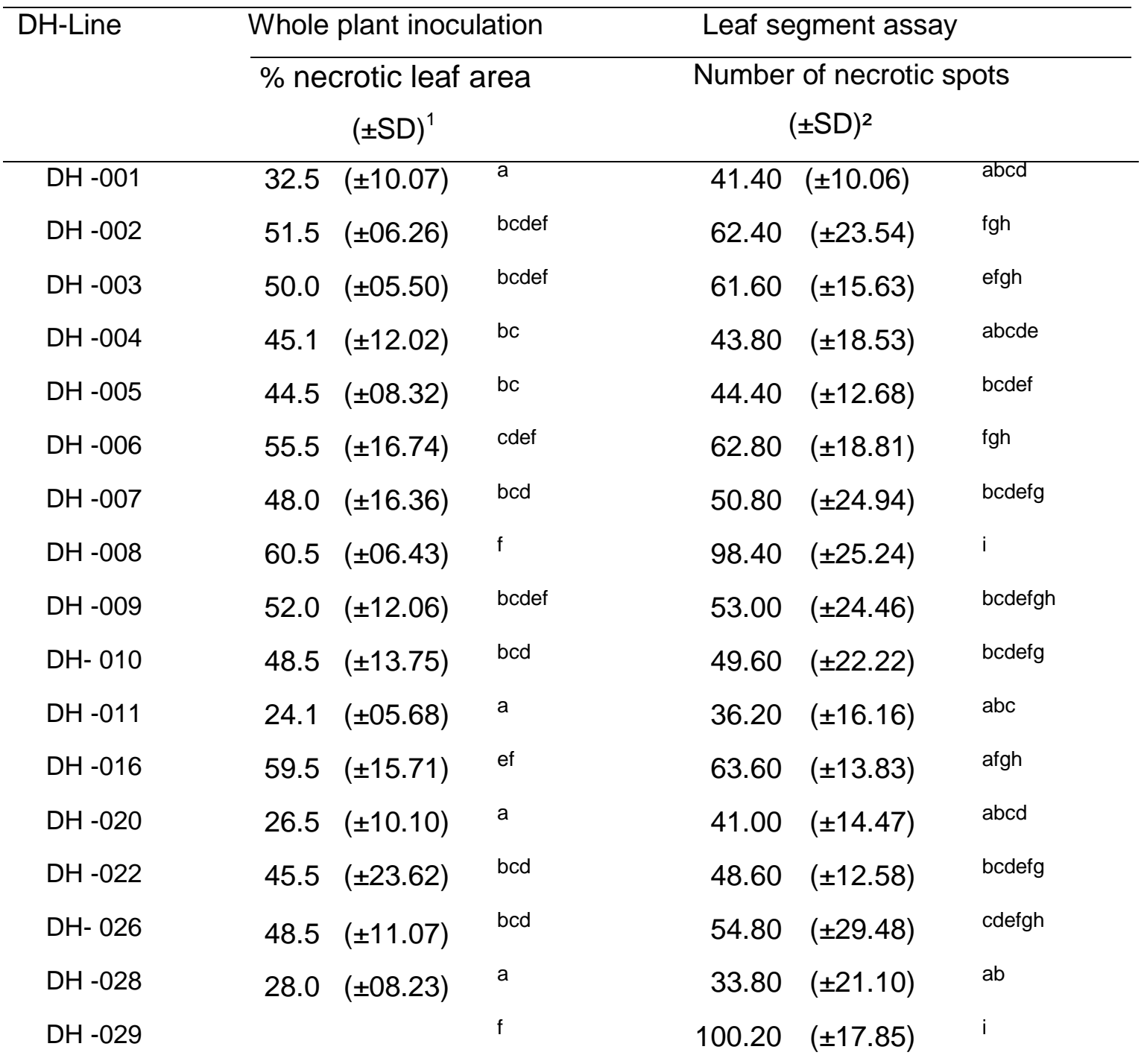

$60.5( \pm 14.23)$ 
Continuing from previous page (Table A1)

\begin{tabular}{llllrll}
\hline DH -035 & 47.0 & $( \pm 10.85)$ & bcd & 46.60 & $( \pm 26.78)$ & bcdefg \\
DH -040 & 57.5 & $( \pm 15.68)$ & def & 64.60 & $( \pm 13.16)$ & gh \\
DH -050 & 49.5 & $( \pm 08.96)$ & bcde & 50.80 & $( \pm 16.15)$ & bcdefg \\
DH- 056 & 93.0 & $( \pm 06.32)$ & $\mathrm{g}$ & 84.80 & $( \pm 14.86)$ & $\mathrm{h}$ \\
DH -057 & 53.1 & $( \pm 11.38)$ & bcdef & 59.40 & $( \pm 15.08)$ & defgh \\
DH -058 & 26.0 & $( \pm 05.16)$ & $\mathrm{g}$ & 102.40 & $( \pm 22.96)$ & $\mathrm{i}$ \\
DH -062 & 4.90 & $( \pm 02.86)$ & $\mathrm{a}$ & 22.40 & $( \pm 15.94)$ & $\mathrm{a}$ \\
\hline
\end{tabular}

${ }^{1}$ Percentage of necrotic leaf area due to Rcc on leaf F-1 at $18 \mathrm{dpi}$

${ }^{2}$ Number of necrotic spots on leaf segments due to Rcc on leaf segment from F-1 at 14 dpi Values with different letter within the same column indicate significant differences $(p \leq 0.05)$ between the genotypes; calculated by the LSD-Fisher test 
Table A1. A decimal code for the growth stages of barley (Tottman \& Broad 1987)

\begin{tabular}{|c|c|c|c|}
\hline \multicolumn{2}{|c|}{ Seedling growth } & \multicolumn{2}{|c|}{ Ear emergence } \\
\hline GS10 & First leaf through coleoptile & GS51 & First spikelet of ear just visible \\
\hline GS11 & First leaf unfolded & GS55 & Half of ear emerged \\
\hline GS13 & 3 leaves unfolded & GS59 & Ear completely emerged \\
\hline GS15 & 5 leaves unfolded & & \\
\hline \multirow[t]{2}{*}{ GS19 } & 9 or more leaves unfolded & \multicolumn{2}{|c|}{ Flowering } \\
\hline & & GS61 & Start of flowering \\
\hline \multicolumn{2}{|c|}{ Tillering } & GS65 & Flowering half-way \\
\hline GS20 & Main shoot only & GS69 & Flowering complete \\
\hline GS21 & Main shoot and 1 tiller & & \\
\hline GS23 & Main shoot and 3 tillers & \multicolumn{2}{|c|}{ Milk development } \\
\hline GS25 & Main shoot and 5 tillers & GS71 & Grain watery ripe \\
\hline \multirow[t]{2}{*}{ GS29 } & Main shoot and 9 or more tillers & GS73 & Early milk \\
\hline & & GS75 & Medium milk \\
\hline \multicolumn{2}{|c|}{ Stem elongation } & GS77 & Late milk \\
\hline GS30 & Ear at $1 \mathrm{~cm}$ (pseudo stem erect) & & \\
\hline GS31 & First node detectable & \multicolumn{2}{|c|}{ Dough development } \\
\hline GS33 & 3rd node detectable & GS83 & Early dough \\
\hline GS35 & 5th node detectable & GS85 & Soft dough \\
\hline GS37 & Flag leaf just visible & GS87 & Hard dough \\
\hline \multirow[t]{2}{*}{ GS39 } & Flag leaf blade all visible & & \\
\hline & & \multicolumn{2}{|c|}{ Ripening } \\
\hline \multicolumn{2}{|c|}{ Booting } & GS91 & Grain hard (difficult to divide) \\
\hline GS41 & Flag leaf sheath extending & GS92 & Grain hard (not dented by nail) \\
\hline GS43 & Flag leaf sheath just visibly swollen & & \\
\hline GS45 & Flag leaf sheath swollen & & \\
\hline GS49 & First awns visible & & \\
\hline
\end{tabular}




\section{Acknowledgements}

I owe my gratitude to all those people who have made this dissertation possible.

First and foremost, I would like to express my sincere gratitude to my supervisor, Prof. Dr. Andreas von Tiedemann, who supported and inspired me throughout my $\mathrm{PhD}$ studies with his patience, knowledge, experience and new ideas whilst allowing me the room to work in my own way. Without him this thesis would not have been completed.

I sincerely thank Prof. Dr. Petr Karlovsky for his advice, guidance and support throughout the years and for co-reviewing of my thesis.

I wish to acknowledge Prof. Dr. Heiko Becker for being a part of my defence committee.

I am really grateful to Dr. Birger Koopmann for the many valuable discussions, his advices, supports and encouragement during all the times of my Ph.D.

I furthermore kindly thank Dr. Brigitte Ruge-Wehling, the project coordinator, for organising Ramularia meetings and all the matters involved with it. Many thanks go to Dr. Markus Hess and Dr. Josef Holzapfel by participating in this project with kind collaboration.

I like to express my thanks to Dr. Philip Kössler for helping me with HPLC measurements and relevant discussions.

I would like to acknowledge Dr. Kirsten Techmer for helping me to take photos with environmental scanning electron microscope.

I am grateful to Jessen Dirk for his kind help in analyses of cuticular wax layer.

I would like to thank Dr. Anke Sirrenberg, Dr. Susanne Weigand, Magdalena Siebold and Shirin Zamani-Nour for their kind advices during reviewing of my work. 
I would like to take this opportunity to say thank you to Ms. Martina Bode for all her kindness and helps which always made my days a little brighter, and problems seem a whole lot smaller.

I would like to pass my special thanks to Dagmar Tacke, Evelin Vorbeck and Jutta Schaper for their kindness, friendship and support and also their guidance with various technical issues.

Many thanks go in particular to Tobias Wulf, Jessica Knüfer, Mark Winter, Magdalena Siebold and Christian Comberg not only for fruitful scientific discussions and creating such a nice work atmosphere, but also for giving me your friendship as deep and as rich as a friendship can be. Your presents somehow were perpetually refreshed, helpful and memorable.

I am grateful to Eugen Hodyl and Hubertus Reintke for their help and support with greenhouse and field experiments.

I would like to extend my thanks to all colleagues in General Plant Pathology and Molecular Phytopathology Groups for such a great atmosphere. It was (is) a great honour to be all the time with you.

I would also like to convey thanks to the Federal Ministry of Food, Agriculture and Consumer Protection in Germany for financial support.

Finally, words fail me to express my strongest appreciation to my parents and my sisters for their love, incredible patience, support and encouragement. I am proud of you. 


\section{Eidesstattliche Erklärung}

Hiermit erkläre ich, die vorliegende Arbeit selbstständig und ohne unerlaubte Hilfe angefertigt zu haben.

Göttingen, im November 2011 